Prepared for the Bonneville Power Administration

under Contract DE-AC05-76RL01830

\title{
Ecology of Juvenile Salmon in Shallow Tidal Freshwater Habitats in the Vicinity of the Sandy River Delta, Lower Columbia River, 2008
}

\section{ANNUAL REPORT}

$\begin{array}{ll}\text { NK Sather } & \text { EM Dawley } \\ \text { GE Johnson } & \text { SA Zimmerman } \\ \text { AJ Storch } & \text { AB Borde } \\ \text { DJ Teel } & \text { C Mallette } \\ \text { JR Skalski } & \text { R Farr } \\ \text { TA Jones } & \end{array}$

May 2009 


\title{
DISCLAIMER
}

This report was prepared as an account of work sponsored by an agency of the United States Government. Neither the United States Government nor any agency thereof, nor Battelle Memorial Institute, nor any of their employees, makes any warranty, express or implied, or assumes any legal liability or responsibility for the accuracy, completeness, or usefulness of any information, apparatus, product, or process disclosed, or represents that its use would not infringe privately owned rights. Reference herein to any specific commercial product, process, or service by trade name, trademark, manufacturer, or otherwise does not necessarily constitute or imply its endorsement, recommendation, or favoring by the United States Government or any agency thereof, or Battelle Memorial Institute. The views and opinions of authors expressed herein do not necessarily state or reflect those of the United States Government or any agency thereof.

\author{
PACIFIC NORTHWEST NATIONAL LABORATORY \\ operated by \\ BATTELLE \\ for the \\ UNITED STATES DEPARTMENT OF ENERGY \\ under Contract DE-AC05-76RL01830
}

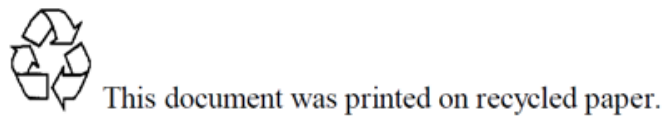

(9/2003) 


\title{
Ecology of Juvenile Salmon in Shallow Tidal Freshwater Habitats in the Vicinity of the Sandy River Delta, Lower Columbia River, 2008
} ANNUAL REPORT

\author{
NK Sather ${ }^{1} \quad$ EM Dawley $^{5}$ \\ GE Johnson ${ }^{1}$ SA Zimmerman ${ }^{1}$ \\ AJ Storch $^{2} \quad$ AB Borde ${ }^{1}$ \\ DJ Teel $^{3} \quad$ C Mallette $^{2}$ \\ JR Skalski $^{4} \quad$ R Farr $^{2}$ \\ TA Jones ${ }^{2}$
}

May 2009

Prepared for Bonneville Power Administration

under an agreement with the U.S. Department of Energy

Contract DE-AC05-76RL01830

Pacific Northwest National Laboratory

Richland, Washington 99352

\footnotetext{
${ }^{1}$ Pacific Northwest National Laboratory

${ }^{2}$ Oregon Department of Fish and Wildlife

${ }^{3}$ National Marine Fisheries Service

${ }^{4}$ University of Washington

${ }^{5}$ Fisheries consultant.
} 



\section{Executive Summary}

The tidal freshwater monitoring (TFM) project reported herein is part of the research, monitoring, and evaluation effort developed by the Action Agencies (Bonneville Power Administration, the U.S. Army Corps of Engineers [USACE], and the U.S. Bureau of Reclamation) in response to obligations arising from the Endangered Species Act (ESA) as a result of operation of the Federal Columbia River Power System. The project is being performed under the auspices of the Northwest Power and Conservation Council's Columbia Basin Fish and Wildlife Program (Project No. 2005-001-00). The research is a collaborative effort among the Pacific Northwest National Laboratory, the Oregon Department of Fish and Wildlife, the National Marine Fisheries Service, and the University of Washington.

\section{Goal and Objectives}

The overarching goal of the TFM project is to bridge the gap in knowledge between tidal freshwater habitats and the early life history attributes of migrating salmon. The research questions include: In what types of habitats within the tidal freshwater area of the Columbia River are juvenile salmon found, when are they present, and under what environmental conditions? What is the ecological contribution of shallow $(0-5 \mathrm{~m})$ tidal freshwater habitats to the recovery of ESA-listed salmon in the Columbia River basin?

Field data collection for the TFM project commenced in June 2007 and since then has continued monthly at six to nine sites in the vicinity of the Sandy River delta (river kilometer 192-208). While this report includes summary data spanning the 19-month period of study from June 2007 through December 2008, it highlights sampling conducted during calendar year 2008. Detailed data for calendar year 2007 were reported previously. The 2008 research objectives were as follows:

1. Characterize the vegetation composition and percent cover, conventional water quality, water surface elevation, substrate composition, bathymetry, and beach slope at the study sites within the vicinity of the Sandy River delta.

2. Characterize the fish community and juvenile salmon migration, including species composition, length-frequency distribution, density $\left(\# / \mathrm{m}^{2}\right)$, and temporal and spatial distributions in the vicinity of the Sandy River delta in the lower Columbia River and estuary (LCRE).

3. Determine the stock of origin for juvenile Chinook salmon (Oncorhynchus tshawytscha) captured at sampling sites through genetic identification.

4. Characterize the diets of juvenile Chinook and coho (O. kisutch) salmon captured within the study area.

5. Estimate run timing, residence times, and migration pathways for acoustic-tagged fish in the study area.

6. Conduct a baseline evaluation of the potential restoration to reconnect the old Sandy River channel with the delta.

7. Apply fish density data to initiate a design for a juvenile salmon monitoring program for beach habitats within the tidal freshwater segment of the LCRE (river kilometer 56-234). 


\section{Study Sites}

The 2008 study involved monthly sampling at six sites (A, B, C, D, E, and N; Figure ES.1). During fall 2008, in response to a recommendation from the Independent Scientific Review Panel to expand the spatial extent of sampling, we added three sampling sites (F, H, and I; Figure ES.1) for a total of nine sites. Sites were selected to provide a diversity of tidal freshwater habitats (e.g., main stem island, river confluence delta, shallow side channel), as well as allow evaluation of the effectiveness of the potential restoration of the historic Sandy River channel.

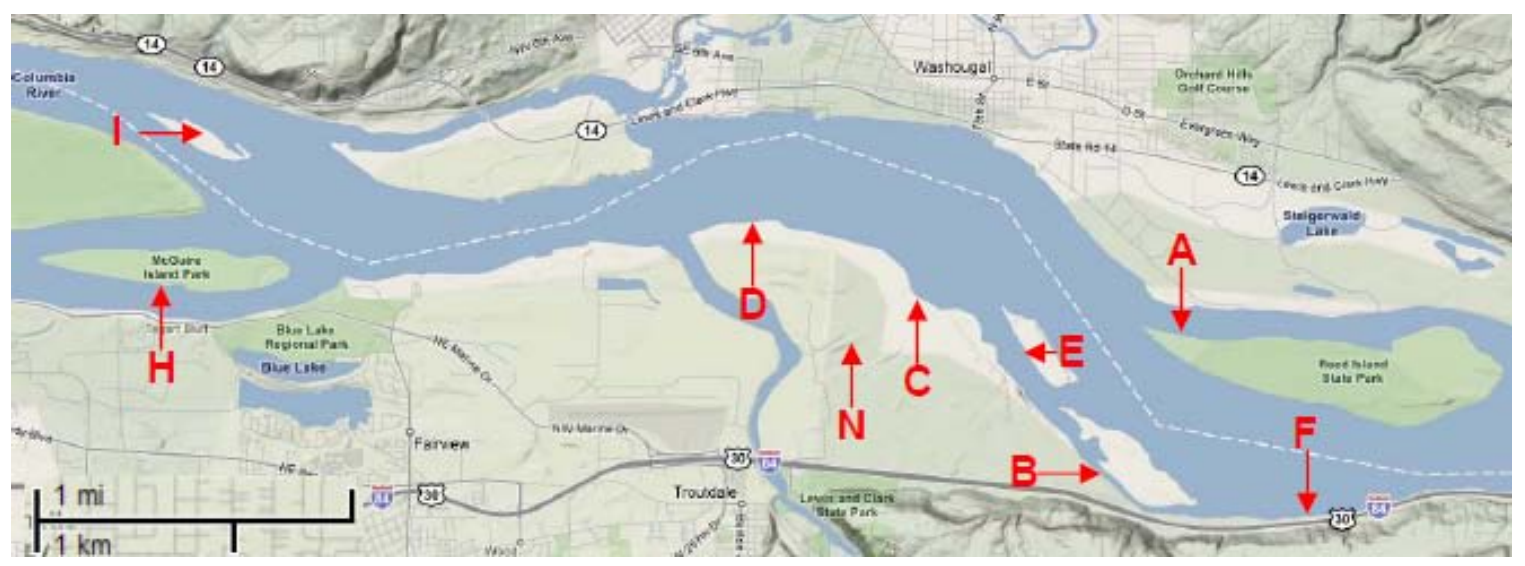

Figure ES.1. Tidal Freshwater Monitoring Sampling Sites 2007-2008 in the vicinity of the Sandy River Delta on the Lower Columbia River (rkm 192-208). Base sites established during 2007 include Sites A, B, C, D, E, and N. Three new sites were added to the study during 2008: Sites F, H, and I. Flow is from right to left.

\section{Methods}

The general approach of the TFM project is to integrate fish and ancillary data with habitat data at each site. During 2007 and 2008, these data were supplemented with acoustic telemetry data from our study area for juvenile salmon tagged as part of other studies. The methods for the TFM project address status and trends monitoring of juvenile salmon density and genetic stock identification, critical uncertainties research on juvenile salmon use of tidal freshwater habitats during winter, and action effectiveness research on the potential reconnection restoration of the historic Sandy River channel.

Habitat characteristics, including topography/bathymetry, substrate, and vegetation, were evaluated once at each site during the 2007/2008 study period. Water surface elevation and temperature data were collected continuously at several sites (A, B, C, and N) using permanent data loggers. To characterize vegetation, we documented site-specific plant community composition and percent cover to produce sitespecific maps that portrayed major vegetative features at the sites.

Fish were collected with beach seines. During June 2007 through April 2008, a seine constructed of 5-mm knotless mesh and measuring $30.5 \mathrm{~m}$ long and $3 \mathrm{~m}$ deep was used. We concluded that this net, while providing useful data, could be improved upon in terms of length, shape, and bridle arrangement. Therefore, we specified a new seine, which was delivered for sampling during May 2008 and beyond. The new seine is $46 \mathrm{~m}$ long and $3 \mathrm{~m}$ deep at the center with wings that taper to $1.5 \mathrm{~m}$. Whenever possible, we deployed the seine by boat. Two replicate, non-overlapping hauls were set at each site, with 
the hauls temporally segregated by at least 30 minutes. Fish captured were identified by species, counted, and their lengths were measured. Juvenile Chinook salmon were fin-clipped for genetics analysis and Chinook, coho, and chum salmon were lavaged for diet analysis. Fin clip samples were processed for stock identification using genetic mixture analysis. For the diet samples, we enumerated and identified all prey items to the lowest classification possible using standard taxonomic keys. Ancillary data collected at each site during the monthly sampling trip included water temperature, dissolved oxygen, water velocity, global positioning system location, distance between the water's edge and a bench mark, and a photograph.

As part of the USACE's acoustic telemetry studies, juvenile spring and fall Chinook salmon and steelhead were tagged with acoustic transmitters (weight $0.63 \mathrm{~g}$ in air) and released in the Snake River at Lower Granite Dam and at five locations in the Columbia River from Arlington (rkm 390) to Skamania (rkm 222), inclusive. To detect these fish as they migrated through the TFM study area during 2008, four autonomous acoustic receivers were deployed in deep areas to maximize signal detectability: Reed Island, near Site A; Flag Island downstream of Site B; the gap between Flag and Gary islands; and Gary Island near Site E (Figure ES.1). All nodes sampled $24 \mathrm{~h} / \mathrm{d}$ during their deployment (May through July 2008).

Statistical analyses were applied to evaluate the seasonal community structure of fish within the study area. We analyzed salmon density at paired sites as part of a preliminary baseline evaluation for the Sandy River rechannelization restoration. In addition, regression analysis examined the relationship between environmental variables and salmon density. An analysis-of-distance approach incorporated components of fish community structure and environmental variables at monthly time scales. Betweenand within-site variance components were examined for eventual development of a monitoring framework for juvenile salmon within shallow, tidal freshwater habitats of the Columbia River.

\section{Results}

\section{$\underline{\text { Habitat Characteristics }}$}

The shallow water habitats sampled for the TFM study are primarily comprised of substrates ranging from sandy to silty. Sites dominated by the mid-range fractions (e.g., $>70 \%$ fine to medium sands) included B, F, and $\mathrm{H}$. Only three sites (C, D, and H) included coarse sediment fractions that exceeded $15 \%$ of the overall grain size composition.

The topography of the TFM sites ranges from gradually sloping, low-relief transitions out of uplands to steeply graded beach slopes. Sites C, D, and F include expansive flats that extend from steep upland areas to the river channel. The micro-topographies at Sites C and D are unique from other sites in that small hummocks are scattered throughout expansive flats.

Water surface elevation was generally lowest from September through November. Water elevation increased through the winter months and into the spring freshet, after which it declined. The seasonal pattern of water-level fluctuation was most similar among Sites A, B, and C. Water elevation at Site N was least like the other sites in that the amplitude of change resembled a step pattern.

Water temperature was highest during August 2007 at all sites where continuous data loggers were deployed (Sites A, B, C, and N). Temperature decreased through the winter months after which 
temperatures increased through the spring and summer. Water temperature was highest from August through September and exceeded $20^{\circ} \mathrm{C}$ most frequently at Sites A and B. Temperatures exceeded $20^{\circ} \mathrm{C}$ at Sites $\mathrm{C}$ and $\mathrm{N}$ during similar time periods; however, elevated water temperatures occurred less frequently at these sites compared with Sites A and B.

Plant community types were grouped into several broad classes ranging from submerged aquatic vegetation at the lower elevations to stable riparian communities at the higher elevations in the study area. We encountered 62 species of plants at the eight sites investigated in 2007 and 2008. (Site I will be surveyed in 2009.) The most commonly encountered plant was Salix spp., which was noted at all eight sites surveyed. The frequency of occurrence of Creeping spikerush (Eleocharis palustris), horsetail (Equisetum spp.), rice cutgrass (Leersia oryzoides), marsh seedbox (Ludwigia palustris), water milfoil (Myriophyllum spp.), and reed canary grass (Phalaris arundinacea) was secondary to Salix spp. Reed canary grass, an invasive wetland species, was present at most sites, although its relative cover was less than $5 \%$ at all sites except Sites A and N (10\% to 15\%).

\section{$\underline{\text { Fish Characteristics }}$}

During the June 2007 through December 2008 sampling period, we performed 237 beach seine hauls and collected over 100,000 fish. The catch was comprised of 29 species. The diversity of taxa was greatest during summer and winter months. Threespine stickleback (Gasterosteus aculeatus), peamouth chub (Mylocheilus caurinus), banded killifish (Fundulus diaphanous), and juvenile Chinook salmon (Oncorhynchus tshawytscha) were captured at all nine sites. Non-native fishes comprised approximately 46\% of the taxa sampled during 2007-2008 and were predominant in shallow off-channel sites near Chatham and Gary islands (Sites B and E), and within the historic Sandy River delta (Sites C and N). Compared with the abundance of native and non-native groups, the overall abundance of juvenile salmon was much lower.

Abundance of juvenile salmon peaked during winter 2007 and spring 2008. Salmon density was greatest at Site E followed by Sites A, D, and B in decreasing order. Unmarked Chinook salmon were the most abundant salmon and were encountered at all sites except Site F, and during all months except January and February 2007. While the densities of marked Chinook and coho salmon were low compared to unmarked Chinook salmon, both were distributed at similar sites. The presence of marked Chinook salmon was limited to April through October. Unmarked coho salmon occurred during all months except late summer to early fall (August-October). The presence of chum salmon (O. keta) was brief; these species were only encountered during the April and May sampling dates.

The size of Chinook salmon increased through the spring and summer months. The largest fish (approximately 100- to 104-mm fork length) encountered at the TFM sites occurred during November and December of both years. At some sites ( $\mathrm{D}$ and $\mathrm{H}$ ), the sizes of marked and unmarked Chinook salmon were similar, while at other sites (Sites A-C) marked Chinook salmon were larger compared to their unmarked counterparts.

Genetic stock identification was conducted on fin-clip samples from 426 juvenile Chinook salmon: 277 unmarked and 149 marked fish. Most unmarked juvenile Chinook salmon were from the Upper Columbia River summer/fall stock group (52\%), which includes fish spawning below Bonneville Dam and areas well upstream. Substantial proportions were also estimated for the West Cascade Tributary (16\%) and Spring Creek (15\%) fall run stock groups. Smaller percentages were estimated for fall run 
populations in the Snake (8\%) and Deschutes (3\%) rivers and for spring Chinook salmon from the Willamette River (6\%) and West Cascade Tributary $(<1 \%)$ stock groups. Most marked fish were from the Spring Creek group fall stock (75\%). Seventeen percent of the marked fish sampled were from the Upper Columbia River summer/fall stock, originating from spawning populations upstream and downstream of Bonneville Dam. Small percentages were estimated for fall Chinook salmon from the Snake River (4\%) and West Cascade Tributary (3\%) groups. Spring run fish from the Snake River were absent from both the marked and unmarked samples.

Diets of juvenile Chinook salmon were generally dominated by aquatic Diptera (mostly Chironomidae and Ceratopogonidae), regardless of sampling month or site of capture. Mysids and amphipods were encountered sporadically, although at times composing appreciable proportions of the diet. The diets of juvenile coho salmon also were generally dominated by aquatic dipterans. Nondipteran aquatic insects comprised large proportions of coho salmon diets at times, particularly during April 2008 at Site A, where these taxa accounted for approximately 50\% of prey items encountered.

A total of 981 juvenile salmonids, approximately $7 \%$ of the total number of tagged fish, were detected by at least one of the four acoustic receivers in side channels of the Columbia River within the TFM study area. Of this total, the majority were yearling spring Chinook salmon (500) and subyearling fall Chinook salmon (415) with the remaining fish being steelhead (66). Of the 981 detected fish, 93\% had been released in the Columbia River; the remaining 7\% had been released in the Snake River at Lower Granite Dam. The majority of fish detections occurred at the Reed Island node (Site A). The Flag Island node (near Site B) yielded the fewest detections. Residence time was longer for subyearling fall Chinook salmon (1-10 h) than for yearlings ( $0.5-2 \mathrm{~h})$. Steelhead had the shortest residence times $(<0.5 \mathrm{~h})$ of the three species of tagged fish in the study area. Migration pathway data showed that the majority of the acoustic-tagged fish in the study area used the main river channel exclusively (93\%; 13,063 of 14,044 fish). Conversely, $7 \%$ of the acoustic-tagged fish migrating from upriver release sites were present in side-channel habitats in the study area, as mentioned above. Of these, an appreciable number of fish passed behind Reed Island in proximity to Site A. The migration pathway through the islands near the Sandy River delta was typically downstream, as indicated by sequential movements from the gap node to the Gary Island node (Site E). Few acoustic-tagged fish appeared to use the potential migration pathway along the Oregon shore behind Chatham Island.

A preliminary analysis of the relationship between juvenile salmon density and habitat characteristics did not reveal any environmental covariates or sets of covariates that adequately explained differences in salmon density between sites. However, a preliminary analysis of fish community composition categorized as native fishes, non-native fishes, and salmonids, indicated that fish community composition towards greater native and salmonid proportions was related to higher dissolved oxygen concentration. In addition, river stage was inversely related to salmonid and native species composition. During 2009, further analysis will be conducted on a spatially and temporally broader data set than was available for 2007/2008.

Statistical analysis indicated that the within-site variability among replicate beach seine hauls was twice as large as the between-site variability (coefficient of variation 1.514 vs. 0.731 , respectively). Within-site standard deviation between samples was 150\% larger than the mean salmonid density. Effective monitoring may necessitate greater within-site sampling effort, other more consistent techniques, or greater efforts aimed at sampling over larger spatial scales as opposed to an intensive sitescale focus. 


\section{Conclusions and Recommendations}

The results from the June 2007 through December 2008 study period lead to the following conclusions about the habitats and ecology of juvenile salmon in tidal freshwater of the LCRE as sampled monthly with beach seines and other equipment at nine sites in the vicinity of the Sandy River delta (rkm 192-208):

1. Habitat characteristics at the nine monthly sampling sites were diverse. Substrate spans from sandy to silty. Topography ranges from gradually sloping, low-relief areas to steeply graded beaches. Some sites had a moderate or high percent cover of emergent vegetation dominated by E. palustris, while Salix spp. are wide spread.

2. Juvenile Chinook and/or coho salmon were present at all types of tidal freshwater habitats sampled and were present during all months of the year. The fish community we sampled in shallow tidal freshwater was dominated by four species - threespine stickleback, peamouth chub, Northern pikeminnow, and banded killifish.

3. Unmarked juvenile Chinook salmon were primarily from the upper Columbia River summer/fall stock group, which includes individuals from the upper Columbia River, mid Columbia River, Columbia Gorge, and sources below Bonneville Dam. The West Cascade Tributary, Spring Creek, Snake River, and Deschutes River fall run stock groups were also present in the study area. Marked juvenile Chinook salmon were mostly from the Spring Creek group with some from the Snake River and West Cascade Tributary groups.

4. Regardless of sampling month or site of capture, the diets of juvenile Chinook salmon are generally dominated by aquatic insects (Diptera, mostly Chironomidae and Ceratopogonidae).

5. It is feasible to use acoustic telemetry to detect juvenile salmon tagged with the smallest available acoustic transmitters ( $0.45 \mathrm{~g}$ in air) in relatively deep $(>3 \mathrm{~m})$ side-channel habitats of the LCRE. Although most of the tagged fish ( $>95 \mathrm{~mm}$ FL) migrate downstream in the main river channel, about $10 \%$ of the tagged fish use side-channel routes in tidal freshwater.

6. The TFM project's baseline data on fish densities will be applicable to the evaluation of the potential rechannelization of the Sandy River delta and design of a juvenile salmon monitoring program for beach habitats within tidal freshwater segment of the LCRE (rkm 56-234).

Future TFM research will evaluate our cumulative datasets in the context of providing an understanding of the relationship between the ecological role of shallow tidal freshwater habitats and juvenile salmon life histories. Recommended objectives for the Year 3 study (May 2009 through April 2010) are as follows:

1. Describe migration characteristics of juvenile salmon in tidal freshwater in the context of their habitats and fish communities by completing the following activities:

a. Characterize the fish community and juvenile salmon migration, including species composition, length-frequency distribution, average weights, density $\left(\# / \mathrm{m}^{2}\right)$, and temporal and spatial distributions in the vicinity of the Sandy River delta and other tidal freshwater habitats within the lower Columbia River, and apply the density data to contribute to the 
design of a juvenile salmon monitoring program for the entire tidal freshwater segment (rkm 56-234).

b. Determine the genetic stock of origin for juvenile Chinook salmon captured at beach seine sampling sites.

c. Characterize vegetation composition and percent cover, conventional water quality, water surface elevation, substrate composition, bathymetry, and beach slope at sites within tidal freshwater.

d. Assess statistical relationships between salmon abundance and habitat characteristics, including ancillary variables such as temperature and river stage.

2. Assess the ecological importance of tidal freshwater habitats to juvenile salmon in the vicinity of the Sandy River delta by completing the following activities:

a. Assess juvenile salmon diet, including the composition and weight of stomach contents.

b. Ascertain the species composition and abundance of available prey from terrestrial, planktonic, and benthic sources.

c. Model the bioenergetics of juvenile salmon in shallow tidal freshwater to evaluate differences in growth among species, seasons, and habitat types.

d. Assess the condition of juvenile salmon using Fulton's Condition Factor.

e. Perform a pilot acoustic telemetry study to estimate residence times through mark-recapture of juvenile Chinook salmon during winter 2009/2010.

During the period June 2007 through December 2008, the TFM project made substantial progress addressing the questions: In what types of habitats within the tidal freshwater area of the Columbia River are juvenile salmon found, when are they present, and under what environmental conditions? What is the ecological contribution of shallow (0-5 m) tidal freshwater habitats to the recovery of ESA-listed salmon in the Columbia basin? A comprehensive report answering these questions will be released after research scheduled for January 2009 to April 2010 has been completed. 



\section{Preface}

The tidal freshwater monitoring (TFM) project documented in this report is part of the research, monitoring, and evaluation effort developed by the Action Agencies (Bonneville Power Administration [BPA], U.S. Army Corps of Engineers [USACE], U.S. Bureau of Reclamation) in response to obligations arising from the Endangered Species Act as a result of operation of the Federal Columbia River Power System . The project is being performed under the auspices of the Northwest Power and Conservation Council's Columbia Basin Fish and Wildlife Program.

The Pacific Northwest National Laboratory (PNNL) is leading the multiyear study under contract with BPA (Project No. 2005-001-00; Contract No. 0026934). The study is a collaborative effort among PNNL, the Oregon Department of Fish and Wildlife (ODFW), the National Marine Fisheries Service (NMFS), and the University of Washington (UW).

This is the second annual report for the TFM project. Electronic versions of both reports may be found at www.efw.bpa.gov. The data reported herein are archived with Nichole Sather at the Marine Sciences Laboratory in Sequim, Washington. For additional information, please contact Nichole at 360681-3688.

A suggested citation for the report is: Sather, NK, GE Johnson, AJ Storch, DJ Teel, JR Skalski, TA Jones, EM Dawley, SA Zimmerman, AB Borde, C Mallette, and R Farr. 2009. Ecology of Juvenile Salmon in Shallow Tidal Freshwater Habitats in the Vicinity of the Sandy River Delta, Lower Columbia River, 2008. PNNL-18450, final report submitted to the Bonneville Power Administration by Pacific Northwest National Laboratory, Oregon Department of Fish and Wildlife, National Marine Fisheries Service, and University of Washington. 



\section{Acknowledgments}

We are grateful to the contributions made by various individuals throughout the 19-month project period (June 2007-December 2008). Tracey Yerxa (BPA) was the contracting officer's technical representative for the project. Jan Slater (PNNL) provided contract management. Blaine Ebberts (USACE) coordinated the project acoustic receiving nodes the USACE loaned to the project. The U.S. Forest Service allowed property access to sampling sites within the vicinity of Sundial Island. Ron Kauffmann provided geographical information system support. Dave Nichols provided boat transportation during the habitat monitoring portion of the project. David Kuligowski (NMFS) collected the Chinook salmon genetic data used in the study. Susan Ennor and Mandi Oukrop (PNNL) edited and formatted the report. John Hedgepeth and Jim Strampe (Tenera Environmental) provided expertise to display bathymetric data. We are indebted to Kathryn Sobocinski for her contributions to the project during 2007-2008, and her technical review of this report. And, we especially want to acknowledge the dedication and hard work put forth in the field by Colin Chapman, Martyne Reesman, Shaffryn Schade, Justin Zweifel of the ODFW and Chris Anderson, Mike Anderson, Julia Ledbetter, and John Vavrinec of PNNL. 



\section{Acronyms and Abbreviations}

\begin{tabular}{|c|c|}
\hline BACI & before-after control-impact \\
\hline BiOp & Biological Opinion \\
\hline BPA & Bonneville Power Administration \\
\hline $\mathrm{C}$ & Centigrade or Celsius \\
\hline CSMEP & Collaborative Systemwide Monitoring and Evaluation Project \\
\hline $\mathrm{CV}$ & coefficient of variation \\
\hline CWT & coded-wire tag \\
\hline d & day(s) \\
\hline DART & Data Access in Real Time \\
\hline DNA & deoxyribonucleic acid \\
\hline DO & dissolved oxygen \\
\hline ESA & Endangered Species Act \\
\hline FAC & facultative \\
\hline FACU & facultative upland \\
\hline FACW & facultative wetland \\
\hline FCRPS & Federal Columbia River Power System \\
\hline FL & fork length \\
\hline g & $\operatorname{gram}(\mathrm{s})$ \\
\hline GIS & geographical information system \\
\hline GPS & global positioning system \\
\hline h & hour(s) \\
\hline ISAB & Independent Scientific Advisory Board \\
\hline ISRP & Independent Scientific Review Panel \\
\hline JSATS & Juvenile Salmon Acoustic Telemetry System \\
\hline kcfs & thousand cubic feet per second \\
\hline $\mathrm{kHz}$ & kilohertz \\
\hline $\mathrm{L}$ & liter(s) \\
\hline LCRE & lower Columbia River and estuary \\
\hline LCREP & Lower Columbia River Estuary Partnership \\
\hline LCFRB & Lower Columbia Fish Recovery Board \\
\hline $\mathrm{m}$ & meter(s) \\
\hline $\mathrm{mg} / \mathrm{L}$ & milligram(s) per liter \\
\hline $\min$ & minutes \\
\hline $\mathrm{ml}$ & milliliter(s) \\
\hline & millimeter(s) \\
\hline MS-222 & Tricaine Methanesulphonate \\
\hline
\end{tabular}




$\begin{array}{ll}\text { NAD } & \text { North America Datum } \\ \text { NAVD } & \text { North America Vertical Datum } \\ \text { NI } & \text { no indicator } \\ \text { NMFS } & \text { National Marine Fisheries Service } \\ \text { NOAA } & \text { National Oceanic and Atmospheric Administration } \\ \text { ODFW } & \text { Oregon Department of Fish and Wildlife } \\ \text { OBL } & \text { obligate } \\ \text { OPUS } & \text { Online Positioning User Service } \\ \text { oz } & \text { ounce(s) } \\ \text { PNNL } & \text { Pacific Northwest National Laboratory } \\ \text { ppt } & \text { parts per thousand } \\ \text { psi } & \text { pound(s) per square inch } \\ \text { PVC } & \text { polyvinyl chloride } \\ \text { rkm } & \text { river kilometer(s) } \\ \text { RM } & \text { river mile(s) } \\ \text { RTK } & \text { Trimble real time kinematic } \\ \text { SAV } & \text { submerged aquatic vegetation } \\ \text { TFM } & \text { tidal freshwater monitoring } \\ \text { TGO } & \text { Trimble Geomatics Office } \\ \mu \text { Um } & \text { micron(s) } \\ \text { obligate upland } & \text { U.S. Army Corps of Engineers, Portland District } \\ \text { USACE } & \text { U.S. Bureau of Reclamation } \\ \text { USBR } & \text { U.S. Geological Survey } \\ \text { USGS } & \end{array}$




\section{Contents}

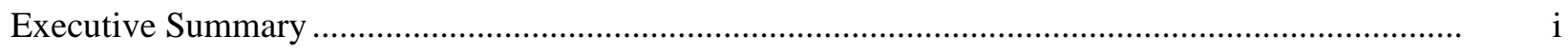

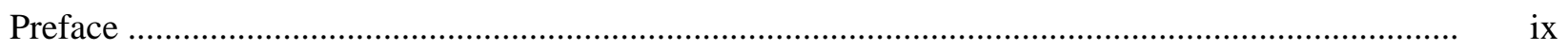

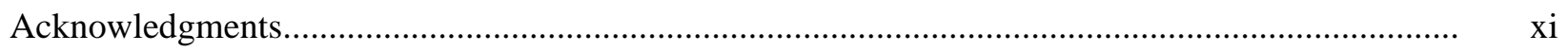

Acronyms and Abbreviations ................................................................................................. xiii

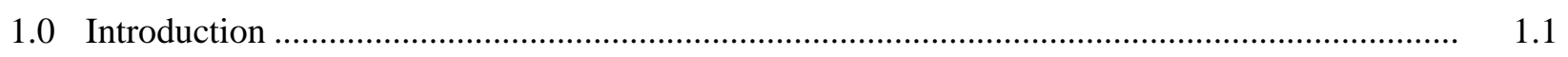

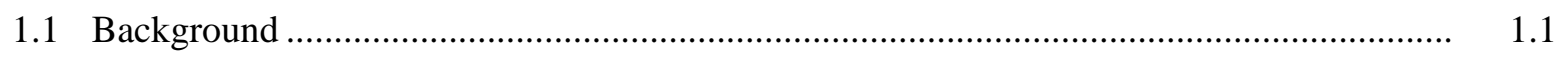

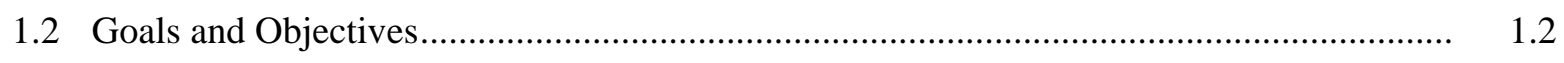

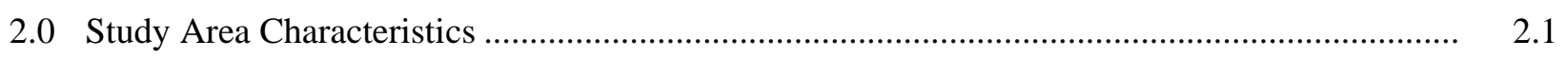

2.1 River Discharge and Water Temperature ........................................................................ 2.2

2.2 Emigration Characteristics .......................................................................................... 2.3

2.2.1 Species Composition and Run Timing ............................................................ 2.3

2.2.2 Hatchery Fish Releases ................................................................................. 2.4

2.2.3 Sources of Upper Columbia Summer/Fall Run Chinook Salmon .......................... 2.7

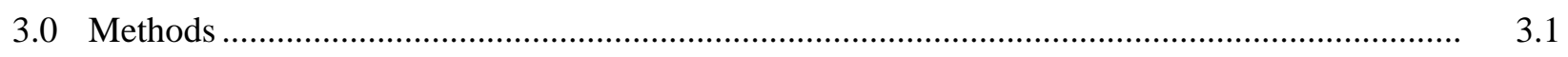

3.1 Sampling Locations and Schedule ............................................................................ 3.1

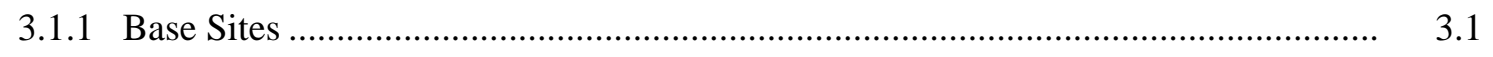

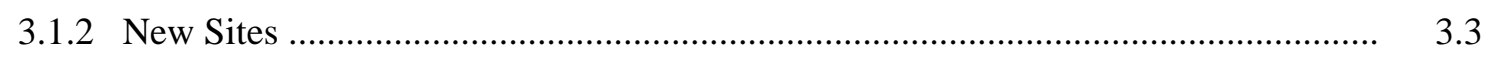

3.1.3 Sampling Schedule ....................................................................................... 3.3

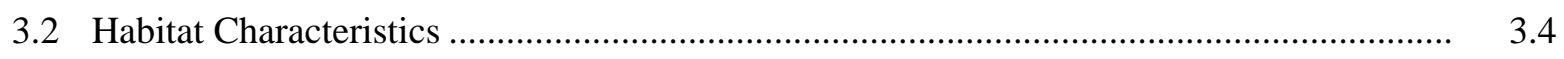

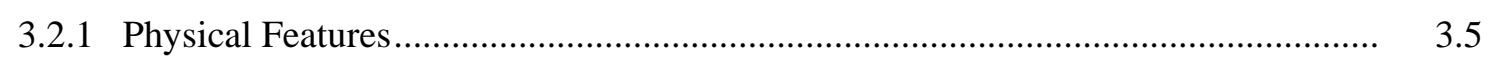

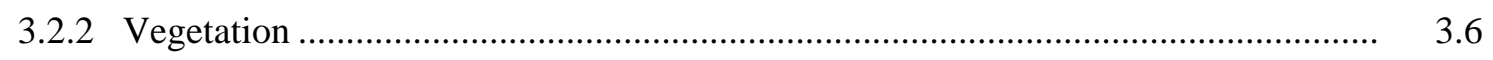

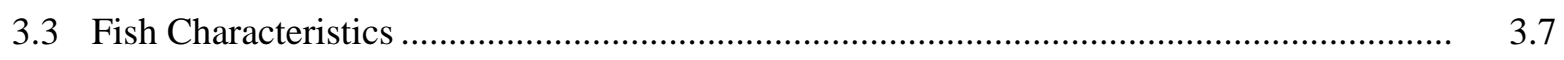

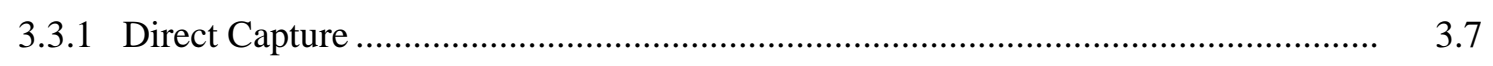

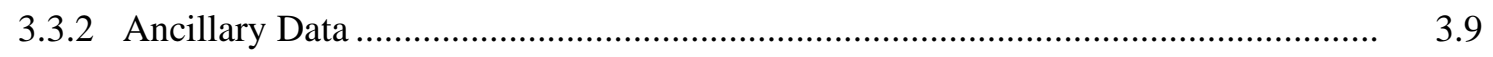

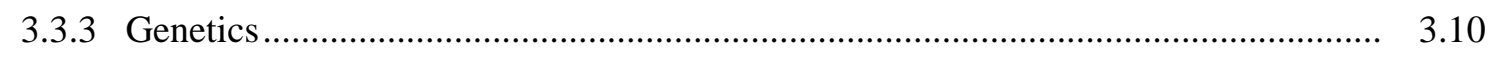

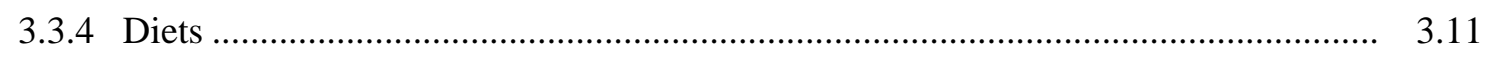

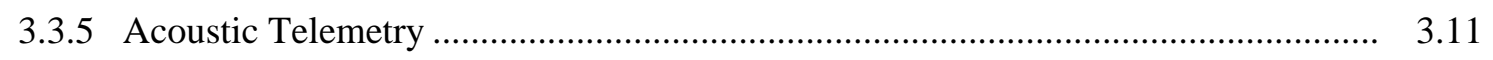

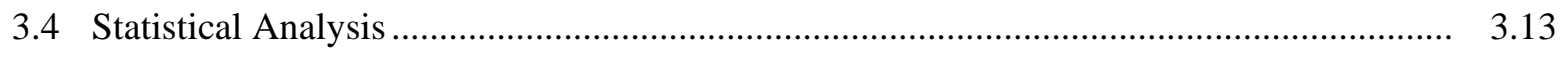

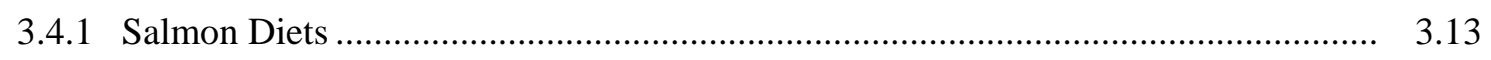

3.4.2 Temporal Trends in Salmon Density ................................................................. 3.13

3.4.3 Juvenile Salmon and Environmental Variables..................................................... 3.14

3.4.4 Fish Community Analysis ............................................................................. 3.14

3.4.5 Monitoring Program Design......................................................................... 3.15 


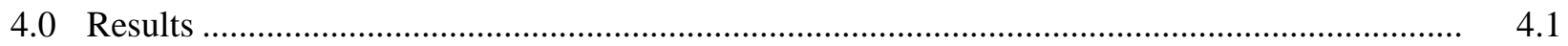

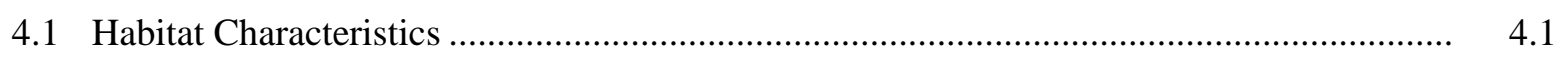

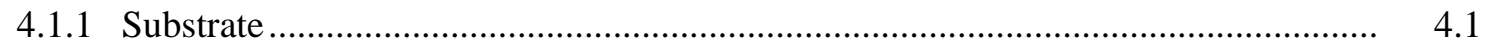

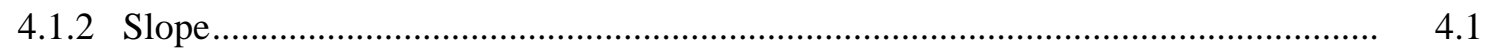

4.1.3 Water Surface Elevation................................................................................ 4.5

4.1.1 Water Temperature .......................................................................................... 4.6

4.1.2 Plant Communities .............................................................................. 4.6

4.2 Fish Characteristics ................................................................................................. 4.16

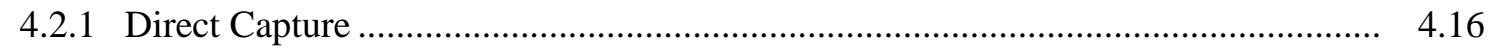

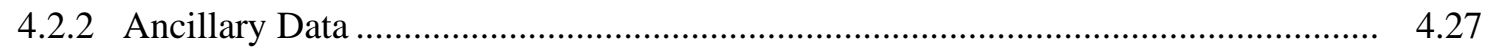

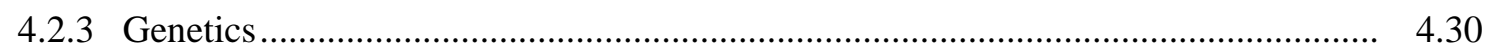

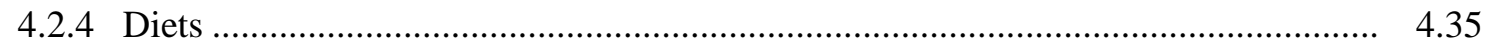

4.2.5 Acoustic Telemetry …................................................................................ 4.42

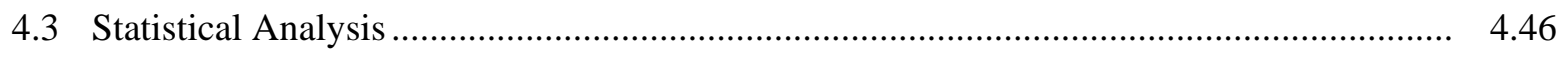

4.3.1 Baseline BACI Analysis.................................................................................. 4.46

4.3.2 Juvenile Salmon and Environmental Variables.................................................. 4.47

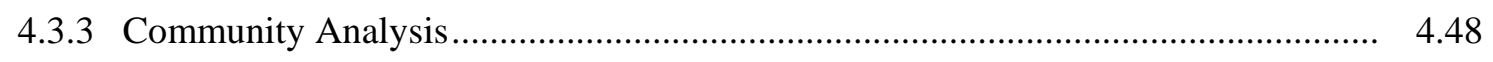

4.3.4 Monitoring Program Design............................................................................. 4.50

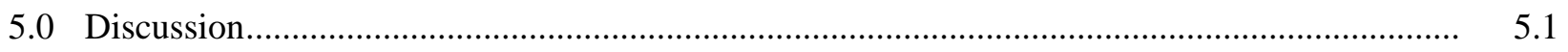

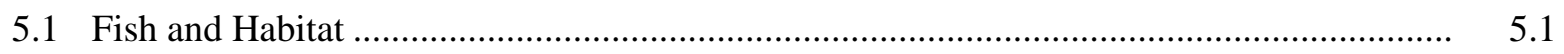

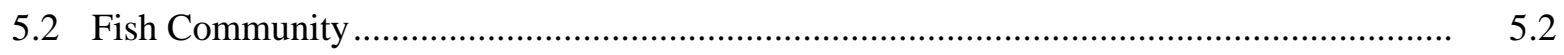

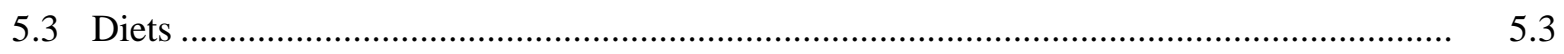

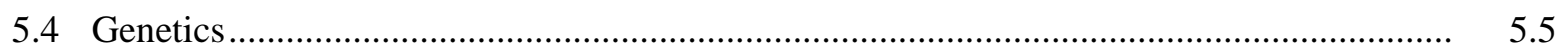

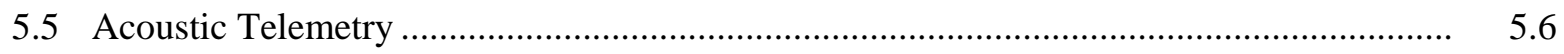

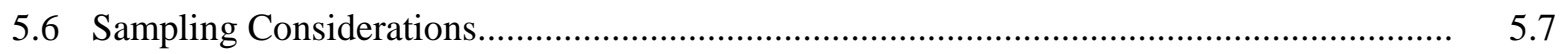

5.7 Rechannelization Restoration............................................................................... 5.8

6.0 Conclusions and Recommendations .................................................................................

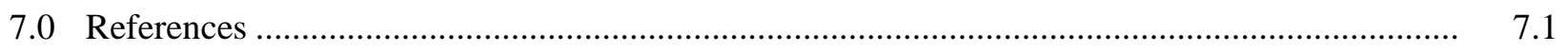

Appendix A - Relationships to Other Programs and Projects ..................................................... A. A

Appendix B - Contour Maps of Beach Seine Sites .......................................................................... B.1

Appendix C - Statistical Synopsis ....................................................................................... C.1

Appendix D - Photo Points............................................................................................. D. D. 1

Appendix E - Estimated of Spawner Abundances in the Upper Columbia River .............................. E. E.1

Appendix F - Ives Island Fall Chinook Salmon .................................................................... F.1 


\section{Figures}

1.1 Map of the Lower Columbia River and Estuary ................................................................ 1.2

2.1 The LCRE Showing the Eight Hydrogeomorphic Reaches ..................................................... 2.1

2.2 Outflow Measured at Bonneville Dam, 2007 and 2008 ...................................................... 2.2

2.3 Scroll Case River Temperature Measured at Bonneville Dam, 2007 and 2008........................ 2.3

2.4 Bonneville Dam Smolt Monitoring Index.............................................................................. 2.4

3.1 Tidal Freshwater Monitoring Sampling Sites 2007-2008 …................................................. 3.2

3.2 Seine Deployment Techniques Applied During the TFM Study …......................................... 3.8

3.3 Locations of the Four TFM Acoustic Telemetry Receiver Nodes ............................................ 3.12

4.1 Average Percent Composition of Grain Size Analytes from the TFM Beach Seine Sites .......... $\quad 4.2$

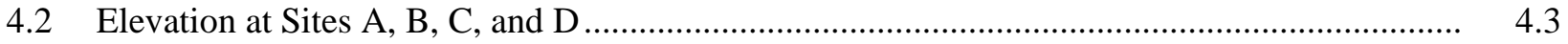

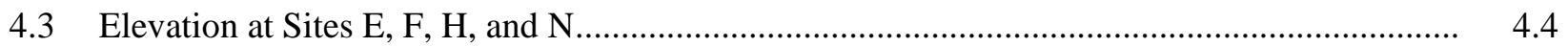

4.4 Water Elevation Derived from Hobo Data Loggers at Sites A, B, C, and N ........................... 4.5

4.5 Water Temperature Derived from Hobo Data Loggers at Sites A, B, C, and N ....................... 4.7

4.6 Relative Percent Cover of Vegetation from Transect Surveys at Each of the TFM Beach

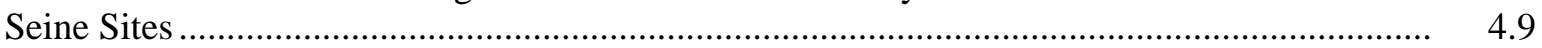

4.7 Vegetation Map for Site F Adjacent to Highway 84.......................................................... 4.14

4.8 Vegetation Map for Site F Adjacent to Highway 84 .............................................................. 4.15

4.9 Combined Total Catch for All Sites and Sample Dates Spanning the 2008 Sampling Effort .... 4.20

4.10 Combined Total Catch for All Sites and Sample Dates Spanning the 2007 Sampling Effort .... 4.20

4.11 Temporal Distribution of Fish Assemblages Encountered During the TFM Study ................... 4.21

4.12 Temporal Distribution of the Mean Density of the Six Most Abundant Fish for the 2007-

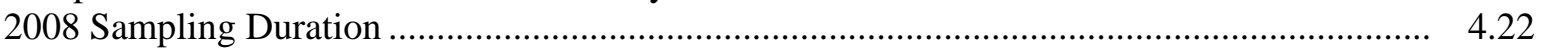

4.13 Length Frequency Distribution of the Six Most Dominant Species Encountered During 2007 and 2008 .

4.14 Temporal Distribution of the Mean Density of Salmonids Encountered During the Duration of 2007-2008 Sampling

4.15 Mean Fork Length for Unmarked and Marked Chinook at the TFM Sampling Sites from June 2007 Through December 2008

4.16 Water Temperature Measured During Beach Seining Efforts

4.17 Dissolved Oxygen Measured During Beach Seining Efforts ................................................... 4.27

4.18 Maximum Depth During Beach Seine Set at Each Site ....................................................... 4.28

4.19 GPS Locations of Beach Seine Hauls at the Base Sites During Year Two Sampling Efforts .... 4.29

4.20 GPS Locations of Beach Seine Hauls at the Three New Sites Sampled During 2008............... 4.30

4.21 Sums of Fractional Genetic Assignments of Individual Unmarked Chinook Salmon by Collection Date.

4.22 Sums of Fractional Genetic Assignments of Individual Marked Chinook Salmon by Collection Date. 
4.23 Sums of Fractional Genetic Assignments of Individual Unmarked Chinook Salmon by Sampling Site

4.24 Sums of Fractional Genetic Assignments of Individual Marked Chinook Salmon by Sampling Site

4.25 Spatial Comparison of Fork Lengths for Chinook Salmon from Which Gut Contents Were Sampled During 2008 .

4.26 Temporal Comparison of Fork Lengths for Chinook Salmon from Which Gut Contents Were Sampled During 2008

4.27 Spatial and Temporal Comparison of Fork Lengths for Coho Salmon from Which Gut Contents Were Sampled During 2008

4.28 Distribution of Major Prey Categories Found in the Gut Contents of Chinook Salmon During 2008

4.29 Distribution of Major Prey Categories Found in the Gut Contents of Coho Salmon During 2008.

4.30 Run Timing Based on Mean Detection Time of Unique JSATS-Tagged Fish for All Locations Combined

4.31 Residence Time as Determined by Mean Duration Between First and Last Valid Detections at a Given Sample Site

4.32 Principal Components for December 2007 and 2008

4.33 Principal Components for April 2008 and July 2008. 


\section{Tables}

2.1 Releases of Marked and Unmarked Subyearling Chinook Salmon in the Columbia River Basin Above the Study Site in 2008..................................................................................... 2.5

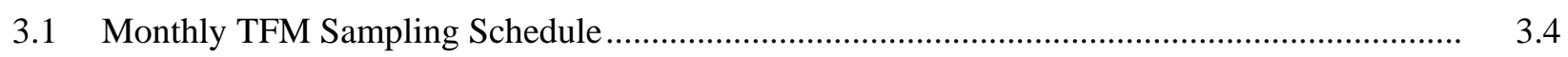

3.2 Genetic Stock Groups and Baseline Populations ............................................................... 3.10

4.1 Species Found to Occur at the TFM Sites .............................................................................. 4.10

4.2 Percent Cover of Community Types Within the Emergent Zone ............................................ 4.13

4.3 Percent Similarity of Vegetative Species at the TFM Sampling Sites .................................... 4.16

4.4 Temporal Trends in Species Composition .......................................................................... 4.17

4.5 Spatial Trends in Species Composition................................................................................. 4.18

4.6 Estimated Percentage Genetic Stock Group Composition and 95\% Confidence Intervals of 277 Unmarked Juvenile Chinook Salmon Sampled in the Study Area from March 18 Through September 172008

4.7 Estimated Percentage Genetic Stock Group Composition and 95\% Confidence Intervals of 149 Marked Juvenile Chinook Salmon Sampled in the Study Area from March 18 Through September 17, 2008.

4.8 Estimated Origin of Individual Chinook Salmon Assigned to the Snake River Fall and Mid and Upper Columbia Spring Stock Groups.

4.9 Distributions of Non-Empty and Empty Stomachs Encountered During Analyses for Gut Content Samples Collected During March Through December 2008.......

4.10 List of Taxa Encountered in the Gut Contents of Chinook and Coho Salmon Sampled in 2008.

4.11 Numbers of Unique Acoustic-Tagged Fish Detected at the TFM Nodes by Species and Release Location

4.12 Numbers of Acoustic-Tagged Fish Detected by Sample Location and Species .....

4.13 Migration Pathways for Yearling Spring Chinook Salmon and Steelhead and Subyearling Fall Chinook Salmon.

4.14 Results of Tukey's Test of Additivity.

4.15 Univariate Juvenile Salmon and Environmental Variables.

4.16 Environmental Covariates Analyzed with Salmon Density for Time Periods in Which Density was Highest.

4.17 Summary of the Mean Salmonid Density per Survey Period Along with the Within-Site Measurement Error and Spatial Variance on a Monthly Basis 



\subsection{Introduction}

Research, monitoring, and evaluation (RME) are being conducted by the Action Agencies (Bonneville Power Administration [BPA], U.S. Army Corps of Engineers [USACE], and U.S. Bureau of Reclamation [USBR]) in response to obligations arising from the Endangered Species Act (ESA) as a result of operation of the Federal Columbia River Power System (FCRPS) — the 31 federally owned dams and associated transmission system in the Columbia River basin. As a part of this federal RME effort, the tidal freshwater monitoring (TFM) project is conducted under the auspices of the Northwest Power and Conservation Council's Columbia Basin Fish and Wildlife Program. The TFM project was initiated in 2007 to address the early life history of juvenile salmon within tidal freshwater habitats of the lower Columbia River and estuary. The project involves the collaborative research efforts of the Oregon Department of Fish and Wildlife, the National Marine Fisheries Service, the University of Washington, and the Pacific Northwest National Laboratory ${ }^{1}$. Collection of field data commenced in June 2007. Since then, monthly sampling has continued in the vicinity of the Sandy River delta (river kilometer [rkm] 192208). While this report includes summary data spanning the 19-month period of study from June 2007 through December 2008, it emphasizes sampling conducted during calendar year 2008.

\subsection{Background}

Shallow water habitats in the tidal freshwater portion of the lower Columbia River and estuary (LCRE) (Figure 1.1) are thought to be important to multiple life history strategies adapted by juvenile salmon (Fresh et al. 2005). However, empirical evidence supporting this notion is sparse and current monitoring efforts are fragmented (Johnson et al. 2008). The lack of sufficient information regarding the ecology of juvenile salmon in tidal freshwater habitats has been regionally recognized by management resource agencies (LCREP and LCFRB 2004; USACE et al. 2005). The Independent Scientific Review Panel (ISRP) and the Independent Scientific Advisory Board (ISAB) have also advocated RME in the tidal freshwater area of the Columbia River (ISRP 2004; Bisson et al. 2000). Furthermore, the federal listing status of several salmonid stocks within the Columbia River basin and the resulting Biological Opinion (BiOp) has identified the need to augment data to fill gaps with a comprehensive understanding of salmon ecology within the tidal freshwater portions of the LCRE (NOAA 2008). In fact, Reasonable and Prudent Alternative 61.3 specifically states, "Investigate the importance of early life history of salmon populations in tidal freshwater of the lower Columbia River."

The early life history patterns exhibited by migrating salmon have been investigated within estuaries spanning the eastern Pacific region. From this collective body of research we have gained an understanding of the general life history patterns exhibited by juvenile salmon, including migrational timing, size at migration, residence time, and habitat associations (Carl and Healey 1984; Sandercock 1991; Bottom et al. 2005a; Miller and Sadro 2003). While commonalities among early life history attributes have been observed within and among species as well as among watersheds, juvenile salmon exhibit a considerable amount of variation among these early life history characteristics (Beamer et al 2005; Bottom et al 2005a; Carl and Healey 1984).

\footnotetext{
${ }^{1}$ Pacific Northwest National Laboratory is operated by Battelle for the U.S. Department of Energy under Contract DE-AC05-76RL01830.
} 


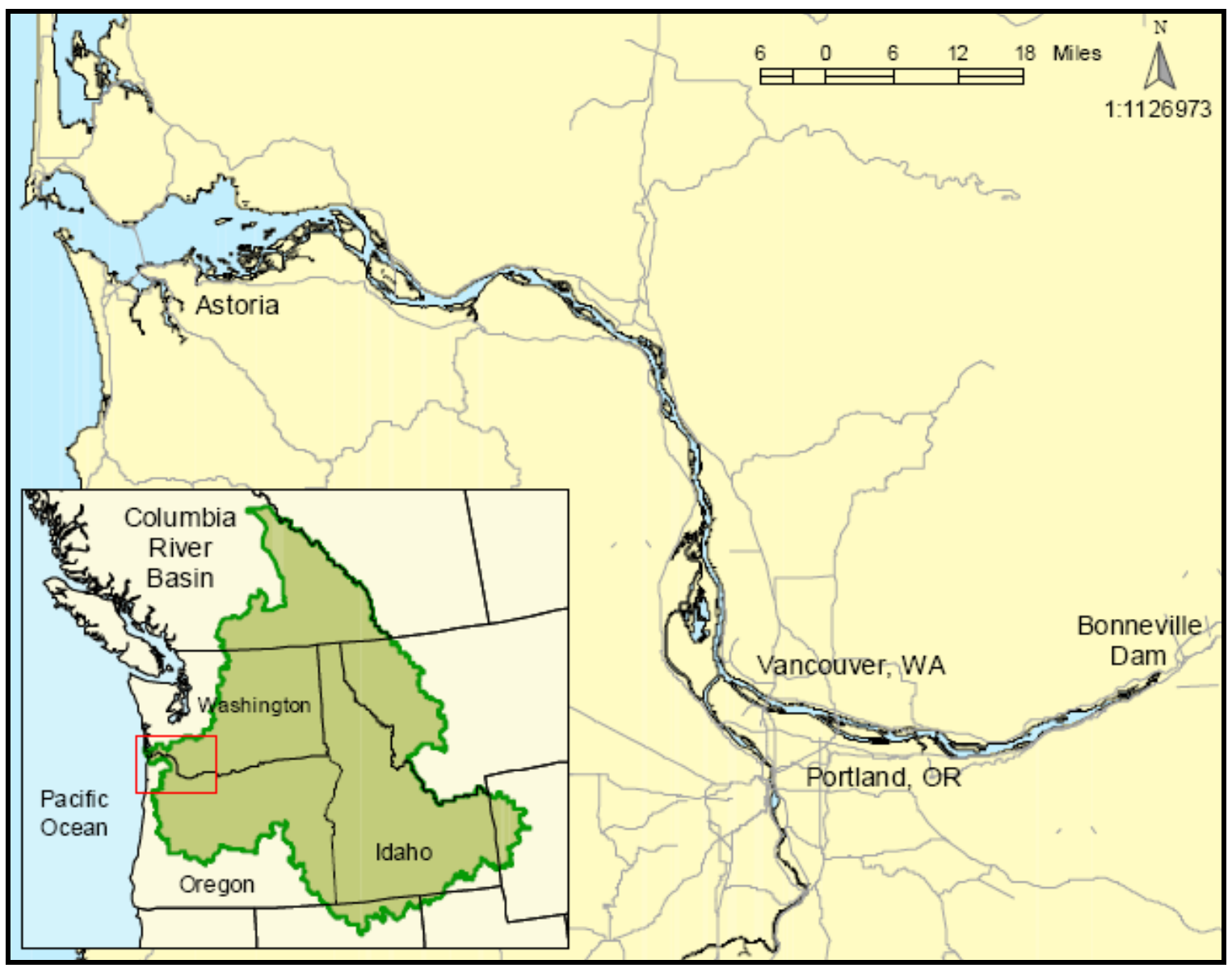

Figure 1.1. Map of the Lower Columbia River and Estuary (Bonneville Dam rkm 234 to the mouth rkm 0). The tidal freshwater region extends from rkm 56-234.

In the LCRE, the substantial loss of shallow water habitats (Thomas 1983) through diking, filling, dredging, and development has been linked to the decline of salmon (Bottom et al. 2005b). Fresh et al. (2005) suggested that the restoration of shallow water habitat could enhance performance (e.g., foraging success and growth), and thus, increase the survival of juvenile salmon. Knowledge pertaining to the use of habitats within upstream reaches of the LCRE by juvenile salmon has started to emerge. The TFM project is focused on supplying fundamental data on this topic both to enhance general understanding of how juvenile salmon use LCRE tidal freshwater habitat and to improve prioritization of restoration efforts. The study is designed to directly contribute to reducing uncertainty about the ecology of juvenile salmon within tidal freshwater habitats.

\subsection{Goals and Objectives}

The overarching goal of the TFM project is to bridge the gap in knowledge between tidal freshwater habitats and the early life history attributes of migrating salmon. The relevant questions are:

- In what types of habitats within the tidal freshwater area of the LCRE are yearling and subyearling salmon found, when are they present, and under what environmental conditions? 
- What is the ecological contribution of shallow $(0-5 \mathrm{~m})$ tidal freshwater habitats to the recovery of ESA-listed salmon in the Columbia River basin?

The 2008 research objectives were to do the following:

1. Characterize the vegetation composition and percent cover, conventional water quality, water surface elevation, substrate composition, bathymetry, and beach slope at the study sites within the vicinity of the Sandy River delta.

2. Characterize the fish community and juvenile salmon migration, including species composition, length-frequency distribution, density $\left(\# / \mathrm{m}^{2}\right)$, and temporal and spatial distributions in the vicinity of the Sandy River delta in the LCRE.

3. Determine the stock of origin for juvenile Chinook salmon (Oncorhynchus tshawytscha) captured at sampling sites through genetic identification.

4. Characterize the diets of juvenile Chinook and coho (O. kisutch) salmon captured within the study area.

5. Estimate run timing, residence times, and migration pathways for acoustic-tagged fish in the study area.

6. Conduct a baseline evaluation of the potential restoration to reconnect the old Sandy River channel with the delta.

7. Apply fish density data to initiate a design for a juvenile salmon monitoring program for beach habitats within the tidal freshwater segment of the lower Columbia River and estuary (rkm 56234). 



\subsection{Study Area Characteristics}

Tidal freshwater within the LCRE extends from around Tenasillahe Island to Bonneville Dam (rkm 56-234). Tidal extent is a function of the geomorphology, such as channel geometry and bathymetry, and hydrodynamic influences within the LCRE, including hydrosystem operations, river discharge, and tidal elevation (Kukulka and Jay 2003). The LCRE has been segregated into eight hydrogeomorphic reaches (Figure 2.1), six of which fall within the tidal freshwater portion of the estuary. The TFM study initially has focused research efforts on a segment of the LCRE within the hydrogeomorphic Reach G, near the vicinity of the Sandy River delta (rkm 192-208) (Figure 2.1). This area includes a variety of habitats (e.g., shallows, main channel islands, river confluence) that may be important to the ecology of juvenile salmon within tidal freshwater portions of the estuary. Furthermore, our study focused on this area because of the opportunity to investigate effects on the ecosystem from the proposed rechannelization restoration within the Sandy River delta ${ }^{1}$. See Appendix A for a comprehensive list of ongoing research in the LCRE that is relevant to the TFM project and the study area in the vicinity of the Sandy River delta, and vice versa. The material that follows on study area characteristics includes river discharge and water temperature, juvenile salmon species composition and run timing as indexed at Bonneville Dam by the Smolt Monitoring Program, and releases of juvenile salmon from hatcheries near the study area.

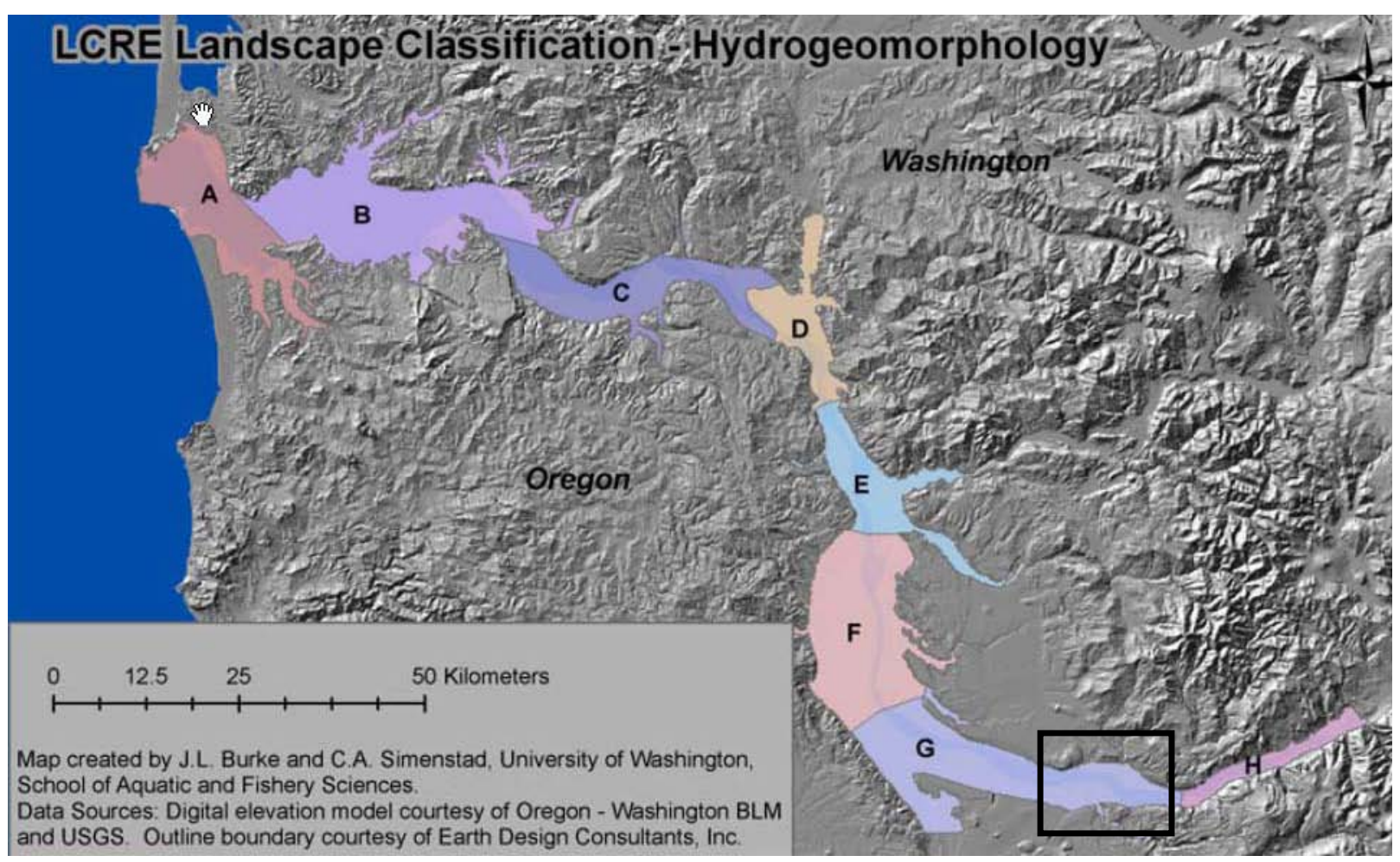

Figure 2.1. The LCRE Showing the Eight Hydrogeomorphic Reaches (LCREP 2004a). The tidally influenced freshwater portions of the estuary include reaches $\mathrm{C}-\mathrm{H}$. The TFM sites are within the upper portions of Reach $G$ within the square outlined on the map (image courtesy of Jen Burke, University of Washington).

\footnotetext{
${ }^{1}$ An effort is underway to design, permit, and fund a restoration project that would remove the blockage of the historic Sandy River channel to restore this habitat for the benefit of juvenile salmon.
} 


\subsection{River Discharge and Water Temperature}

The hydrograph, as measured at Bonneville Dam, indicates dissimilar patterns of peak discharge events for 2007 and 2008 (Figure 2.2). During 2007, discharge peaked between April and June. Maximum outflow at the dam exceeded $300 \mathrm{kcfs}$ on only one date during 2007. During 2008, outflow exceeded the 10-year average and persisted for a longer time period compared to 2007. In fact, Bonneville outflow exceeded 300 kcfs during 49 days from May through July 2008. High discharge events actually prevented sampling at several sites during the June 2008 sampling trip. While differences among peak discharge events were apparent between 2007 and 2008, low-flow conditions were similar between years in terms of timing and discharge amplitude. Discharge was lowest throughout September and October during both years (75-100 kcfs).

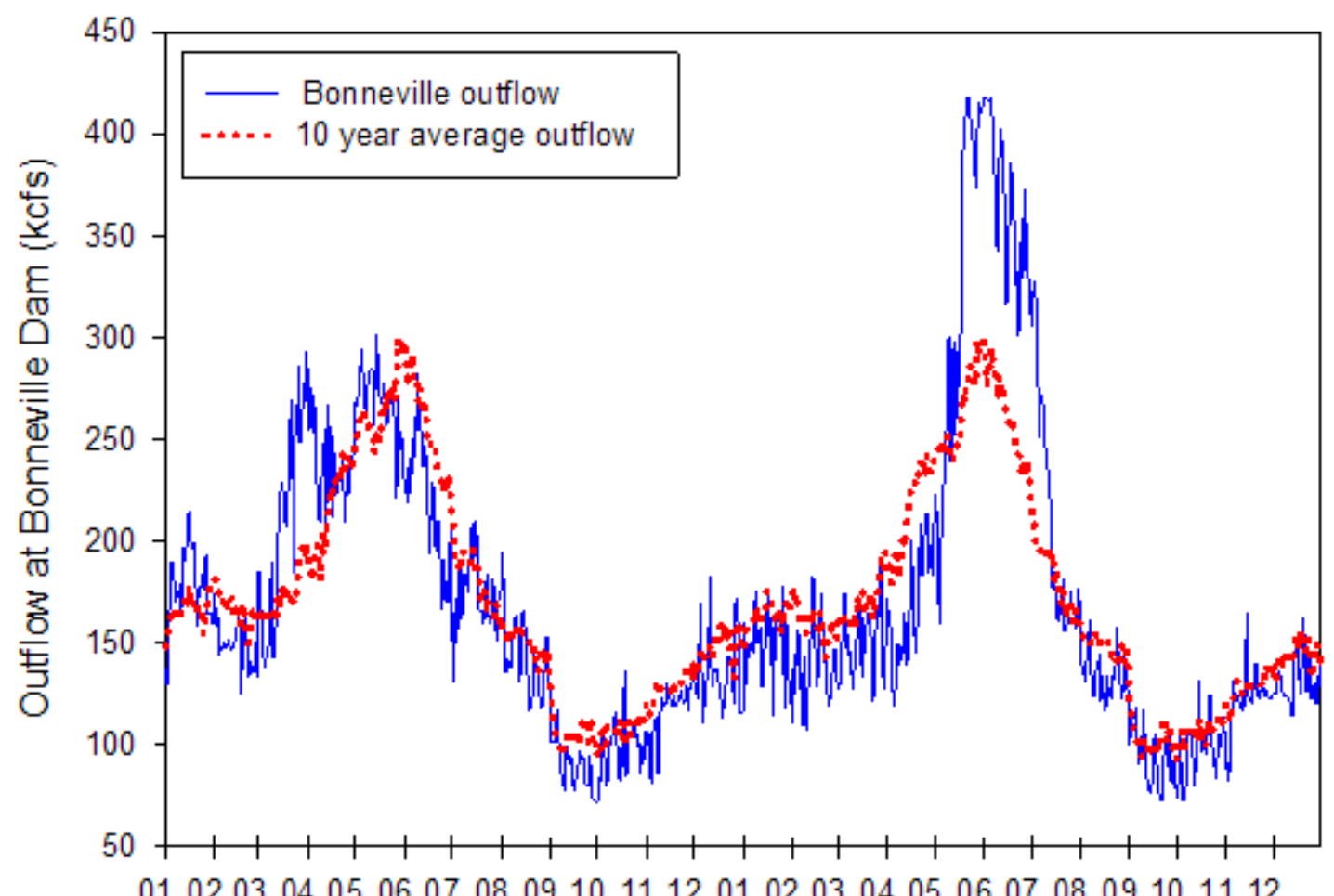

Month (Jan 2007 - Dec 2008)

Figure 2.2. Outflow Measured at Bonneville Dam, 2007 and 2008 (Data from Columbia River DART 2009a)

While site-specific water quality data were collected throughout the TFM sampling events, the scroll case temperature measured at Bonneville Dam provides a baseline for riverine conditions and reveals temporal patterns. On an annual cycle, water temperature exhibits seasonal patterns, whereby temperature peaks occur between July and September, after which temperature decreases throughout the fall and winter months (Figure 2.3). 


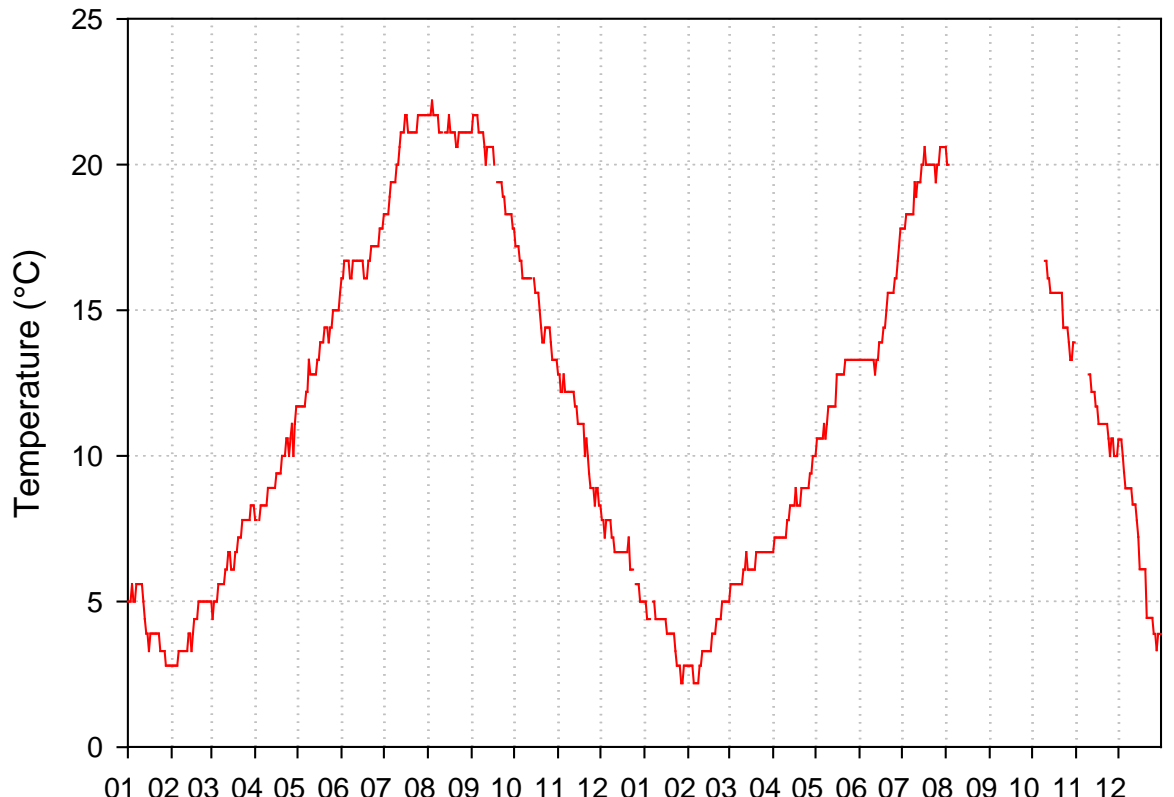

Month (Jan 2007-Dec 2008)

Figure 2.3. Scroll Case River Temperature Measured at Bonneville Dam, 2007 and 2008. Missing data correspond to the discontinuous line (data from Columbia River DART 2009a).

\subsection{Emigration Characteristics}

Juvenile salmon emigration can be characterized by species composition, run timing, and releases of fish from hatcheries within the Columbia River watershed.

\subsubsection{Species Composition and Run Timing}

The smolt index for passage at Bonneville Dam offers a means by which to evaluate the abundance and run timing of migrating juvenile salmon. Chinook salmon are classified as either subyearling or yearling migrants through a combination of metrics aimed at distinguishing fish size and morphological characteristics (DART 2009b). While some differences between the estimated abundance of salmon in 2007 and 2008 exist, the run timing of migrating salmonids was similar between years (Figure 2.4). Peak migration of subyearling Chinook salmon was detected during four distinct time intervals (March, April, May, and July) at the Bonneville fish passage facility during 2007 and 2008. The remaining salmon species did not elicit a temporally diverse migrational pattern; peaks generally occurred during late spring months (Figure 2.4). The peaks for subyearling Chinook salmon in March, April, and May are caused by releases of large numbers of hatchery fish. 


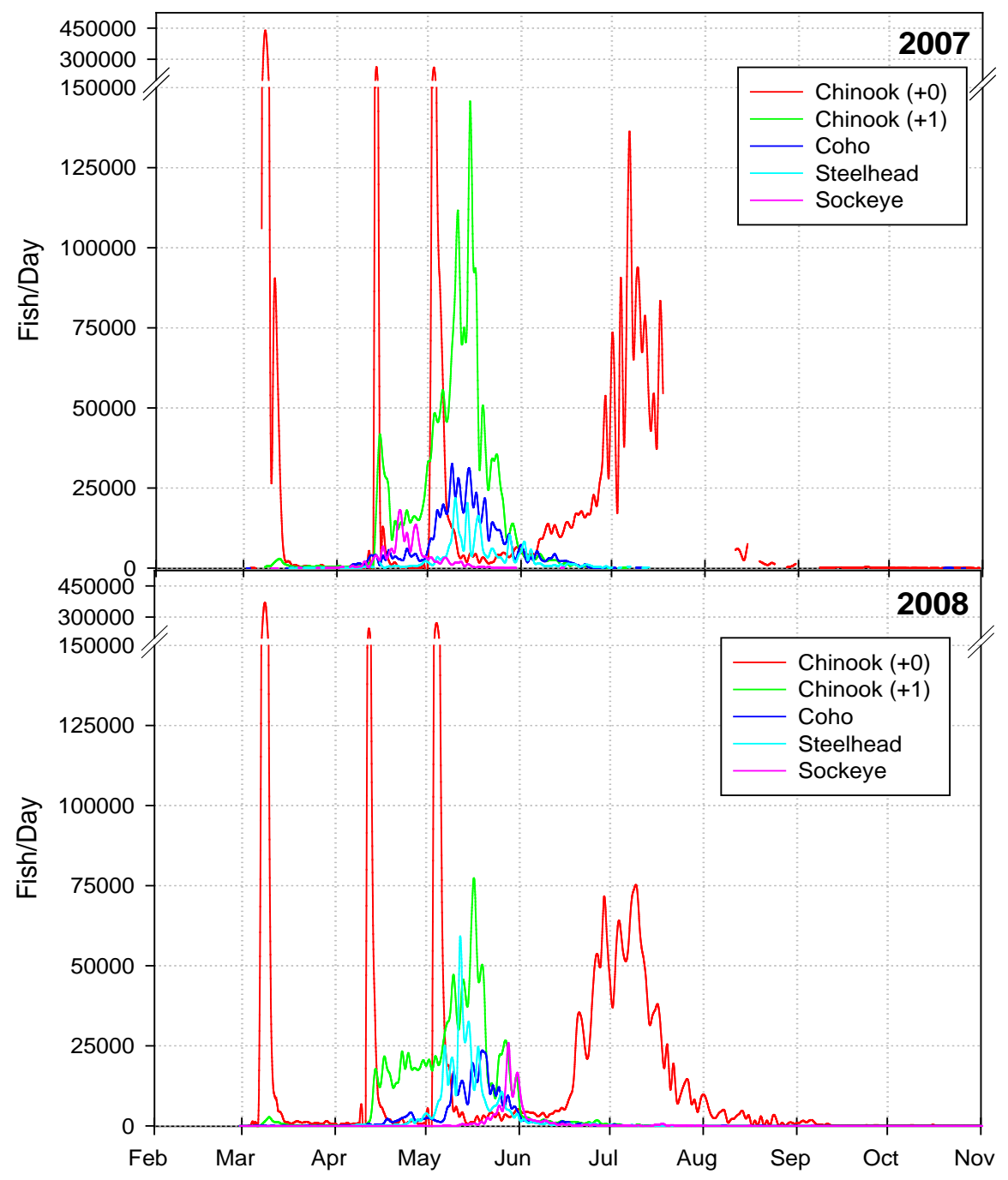

Figure 2.4. Bonneville Dam Smolt Monitoring Index. Summary counts combine all rear types (e.g., hatchery, wild, and unknown) within a given species (data from DART 2009a).

\subsubsection{Hatchery Fish Releases}

Current management practices do not include marking (with adipose clip and/or coded wire tags) $100 \%$ of the hatchery fish released in the Columbia River basin (Table 2.1). Therefore, the smolt monitoring index at Bonneville Dam does not distinguish naturally produced salmon from hatcheryreared salmon. The data depicted in Figure 2.4 represent the combined abundance and run timing of hatchery and naturally produced salmonids at Bonneville Dam. The hatchery Chinook salmon released upstream of our study area represent five distinct stock groups (Table 2.1). Release schedules for hatchery fish occurred between the spring and early summer months during 2008. The hatchery release locations nearest to our study area occurred in the Washougal and Sandy rivers. Additional information on the Upper Columbia Summer and Fall stock is provided in the next section. 
Table 2.1. Releases of Marked (adipose clipped, coded-wire tagged) and Unmarked Subyearling Chinook Salmon in the Columbia River Basin Above the Study Site in 2008. Except where noted, data are from the Regional Mark Processing Center (http://www.rmpc.org/), accessed March 13 2009. Data are preliminary and may be incomplete. Stocks are grouped based on descriptions provided by the National Oceanic and Atmospheric Administration (NOAA) Fisheries' Salmon and Steelhead Stock Assessment Group (unpublished report available at http://www.nwr.noaa.gov/Publications/Hatchery-Rpts.cfm). Releases of subyearling interior Columbia River Basin spring Chinook salmon are not included.

\begin{tabular}{|c|c|c|c|c|c|c|}
\hline Release Region & Stock Group & Hatchery & Release River & Date & $\begin{array}{c}\text { Marked } \\
\text { (thousands) }\end{array}$ & $\begin{array}{l}\text { Unmarked } \\
\text { (thousands) }\end{array}$ \\
\hline \multirow{3}{*}{ Snake River } & Snake River Fall & Oxbow & Snake & $6 / 6$ & 192.5 & 0 \\
\hline & Snake River Fall & Lyons Ferry & Snake & $5 / 28-6 / 2$ & 400.6 & 30.6 \\
\hline & Snake River Fall & Irrigon & Grande Ronde & $5 / 29$ & 190.4 & 112.9 \\
\hline Upper Columbia & $\begin{array}{l}\text { Upper Columbia River } \\
\text { Summer }\end{array}$ & Wells Complex & Upper CR & $6 / 16-6 / 20$ & 791.3 & 443.8 \\
\hline \multirow{5}{*}{ Mid Columbia } & Upper Columbia River Fall & Priest Rapids & Priest Rapids & $5 / 27-6 / 20$ & 203.4 & 4344.9 \\
\hline & Upper Columbia River Fall & Ringold Springs & Ringold & $6 / 11-7 / 5$ & 3075.2 & 22.3 \\
\hline & Upper Columbia River Fall & Prosser $^{(a)}$ & Yakima & $4 / 22$ & 199.8 & 98.6 \\
\hline & Upper Columbia River Fall & Marion Drain ${ }^{(\mathrm{b})}$ & Yakima & $4 / 18$ & 12.0 & 0 \\
\hline & Upper Columbia River Fall & Umatilla & Umatilla & $5 / 27-5 / 30$ & 342.7 & 0 \\
\hline \multirow{3}{*}{ Columbia Gorge } & Upper Columbia River Fall & Klickitat ${ }^{(\mathrm{b})}$ & Klickitat & $6 / 20-7 / 4$ & 1595.0 & 1957.0 \\
\hline & Upper Columbia River Fall & Little White Salmon $^{(\mathrm{c})}$ & L.W. Salmon & $6 / 16-7 / 3$ & 2001.8 & 0 \\
\hline & Spring Creek Group Fall & Spring Creek ${ }^{(\mathrm{a})}$ & Spring Creek & $3 / 5-5 / 2$ & 14899.3 & 0 \\
\hline \multirow{3}{*}{ Below Bonneville Dam } & Upper Columbia River Fall & Bonneville ${ }^{(\mathrm{d})}$ & Tanner Creek & $6 / 30-7 / 31$ & 3637.7 & 0 \\
\hline & Spring Creek Group Fall & Washougal & Washougal & $7 / 1-7 / 6$ & 4051.7 & 118.1 \\
\hline & West Cascade Fall & Sandy & Sandy & $7 / 1$ & 60.1 & 0.4 \\
\hline $\begin{array}{l}\text { (a) Data from Stephen Pas } \\
\text { (b) Data from Fish Passage } \\
\text { (c) Data from Speros Doul } \\
\text { (d) Data from Brett Requa }\end{array}$ & $\begin{array}{l}\text { U.S. Fish and Wildlife Service (L } \\
\text { tter (http://www.fpc.org/) access } \\
\text { USFWS, Little White Salmon Ha } \\
\text { egon Department of Fish and Wi }\end{array}$ & $\begin{array}{l}\text { SFWS), Vancouver, Wash } \\
\text { d May } 8 \text { 2009. } \\
\text { chery, Cook, Washington. } \\
\text { llife (ODFW), Bonneville }\end{array}$ & $\begin{array}{l}\text { on. } \\
\text { chery, Cascade Lo }\end{array}$ & Oregon. & & \\
\hline
\end{tabular}





\subsubsection{Sources of Upper Columbia Summer/Fall Run Chinook Salmon}

Genetic estimates of stock proportions in mixed-stock populations are based on genetic differences among populations of fish whereby the contributions of genetically similar populations are summed into stock groups (Milner et al. 1985, Seeb et al. 2007). In the present study we estimated the proportions of 10 Columbia River basin stock groups in our samples of Chinook salmon juveniles (see Section 3.3.4 Diets). These stock groupings, based on genetic lineages also correspond with life-history and geographic patterns (Waples et al. 2004). It is therefore often possible to make inferences about the life-history type (e.g., season of adult return) or region of origin of a group of fish based on membership in a genetic group. However, stock management activities have sometimes made such inferences difficult. For example, as a result of stock transfers and translocations, Chinook salmon in the Upper Columbia Summer/Fall stock are now produced in the upper Columbia River as well in locations that are considerably distant from the stock's historical spawning habitats. Genetic data alone therefore, do not necessarily indicate that fish from this stock group originated in the natal areas.

The native populations of summer and fall run (time of adult return) Chinook salmon in the Columbia River above the confluence with the Snake River comprise the Upper Columbia River Summer and Fall Run Evolutionarily Significant Unit (ESU) (Myers et al. 1998). This is one of eight ESUs of Chinook salmon that have been identified within the Columbia River basin based on a synthesis of genetic, lifehistory, biogeographic, geologic, and environmental information (Myers et al. 1998). The boundaries of the ESU are the Grand Coulee Dam upstream and down-river at the crest of the Cascade Range. Most of the current natural production of fish in the Upper Columbia River Summer and Fall Run ESU are summer run populations in the Wenatchee, Methow, Okanagon, and Similkameen rivers and fall run populations in the Yakima River and in the mainstem Columbia River in the Hanford Reach area (Waknitz et al. 1995, Myers et al. 1998). Estimates of spawner abundances in these rivers are provided in Table 2.2. Large hatchery programs associated with these populations also release summer and fall run fish in the Upper and Mid Columbia River (Table 2.1).

The history of stock transfers of Upper Columbia River Summer and Fall Chinook salmon to other ESUs is extensive (Myers et al. 1998). Beginning in 1971, upper Columbia River fall run smolts (termed "Upriver Bright Fall” because of the silvery appearance of returning adults) have been released into numerous streams and mainstem areas within the boundaries of the Lower Columbia River ESU (Myers et al. 2006). Lower river releases of Upriver Bright Fall run smolts in 2008, included releases from Little White Salmon National Fish Hatchery and Klickitat Hatchery in the Columbia Gorge region and from Bonneville Fish Hatchery below Bonneville Dam (Table 2.1). The progeny of Upriver Bright Fall hatchery programs are also thought to be the source for a number of natural spawning populations of fall run Chinook salmon that now exist in Columbia Gorge tributaries and in mainstem areas just below Bonneville Dam (Marshall et al. 1995, Myers et al. 2006). The largest of these lower river natural spawning populations of Upriver Bright Fall fish are in the area of Ives and Pierce islands below Bonneville Dam (Van der Naald et al. 2001). An earlier study has shown that the late spawning Chinook salmon in these areas are genetically more similar to upriver summer and fall run fish than to fall run fish native to the lower Columbia ESU (Marshall 1998). Genetic estimates of upper Columbia River summer/fall juveniles sampled in our TFM study therefore include the potential contributions of introduced (lower Columbia River) in addition to native (upper Columbia River) Chinook salmon. 
Table 2.2. Spawning Escapement Estimates for Summer and Fall Chinook Salmon in the Mid and Upper Columbia River in 2007. Estimates for summer Chinook salmon are from Peven et al. 2008 and for fall Chinook salmon are from Hoffarth 2008.

\begin{tabular}{cccc}
\hline Region & Stock Group & River & Spawners \\
\hline Upper Columbia & Upper Columbia & Okanogan & 2,862 \\
& River Summer & Similkameen & 1,555 \\
& & Methow & 1,364 \\
& & Wenatchee & 4,590 \\
Mid Columbia & Upper Columbia & Hanford Reach & 47,095 \\
& River Fall & Yakima & 1,268 \\
\hline
\end{tabular}




\subsection{Methods}

This section includes sampling locations and schedule, methods to evaluate habitat characteristics, e.g., vegetation, bathymetry, water surface elevation, and fish characteristics, e.g., species composition, density, genetic stock identification, juvenile salmon diet composition, and residence time and migratory pathways of acoustic-tagged fish, and statistical analysis methods.

The general approach of the TFM project is to integrate fish and ancillary data with data on habitat characteristics at each site. During 2007 and 2008, these data were supplemented with acoustic telemetry data from our study area for juvenile salmon tagged as part of other studies. The methods for the TFM project address status and trends monitoring of juvenile salmon density and genetic stock identification, critical uncertainties research on juvenile salmon use of tidal freshwater habitats during winter, and action effectiveness research on the potential reconnection restoration of the historic Sandy River channel.

\subsection{Sampling Locations and Schedule}

The 2008 study involved monthly sampling at six sites (A, B, C, D, E, and N; Figure 3.1). And, starting in September and October 2008, in response to a recommendation from the ISRP to expand the spatial extent of sampling, we added monthly sampling sites (F, G, and I; Figure 3.1) for a total of nine sites. Sites were selected to provide a diversity of tidal freshwater habitats (e.g., main stem island, river confluence delta, shallow side channel), as well as allow evaluation of the effectiveness of the potential restoration of the historic Sandy River channel.

\subsubsection{Base Sites}

At the beginning of the field work in April 2007, we conducted a reconnaissance survey to evaluate potential sampling sites in the vicinity of the Sandy River delta. Criteria for site selection included capabilities for boat access, net deployment, and retrieval. We also evaluated site-specific physical characteristics and features to identify representative habitat types (e.g., island, off-channel, main stem) within our study area. We selected an initial set of sites (e.g., A, B, C, and D) during this inaugural field trip (Figure 3.1). Because we were interested in quantitatively evaluating the effects of ecosystem restoration within shallow tidal freshwater habitats, Site $\mathrm{N}$ was added to allow for pre-restoration monitoring related to the proposed restoration activities aimed at reconnecting the Sandy River to its historical delta. The TFM study initiated sampling of these five sites during June 2007. After the development of a before-after control-impact (BACI) design (Sobocinski et al. 2008; Appendix B), Site E was added to the study and initially sampled during the September 2007 event. A thorough description of the characteristics and habitat features encountered at each of the base sites can be reviewed in the report by Sobocinski et al. (2008). Brief descriptions of the sites (Figure 3.1) follow.

- Site A: Located on the north side of Reed Island State Park, this sampling location is broadly characterized by a fringing wetland with a gradually sloping beach face. Site A is an off-channel island sampling site (i.e., it is not directly connected to the mainstem).

- Site B: On the southwest side of Chatham Island, this off-channel site maintains a steeply sloping beach face adjacent to a fairly deep channel. While the thalweg of the channel adjacent to Site B is 
fairly deep, the inlet and outlet to this channel maintain a higher elevation, making boat access to this site problematic during low-flow conditions.

- Site C: At the historic mouth of the Sandy River, this site maintains connection to a small channel from the remnant delta. The topography of this site is higher in elevation compared to the other sampling locations and is the only site that completely dewaters during periods of low flow (e.g., September and October).

- Site D: Located adjacent and upstream from the current mouth of the Sandy River, this site is directly connected to the mainstem of the Columbia River. The extensive sand flats at this site are likely related to the sedimentation and hydraulic interactions at the river confluence.

- Site E: On the west side of Gary Island, this off-channel site is similar to Site B in that it is adjacent to a channel that maintains deep water $(>1.5 \mathrm{~m}$ ) during periods of low flow.

- Site N: Unlike any of the previously described sites, Site N is located within the remnant Sandy River delta. Site $\mathrm{N}$ is within the upper extent of the remnant channel that drains to Site $\mathrm{C}$ (the former mouth of the Sandy River).

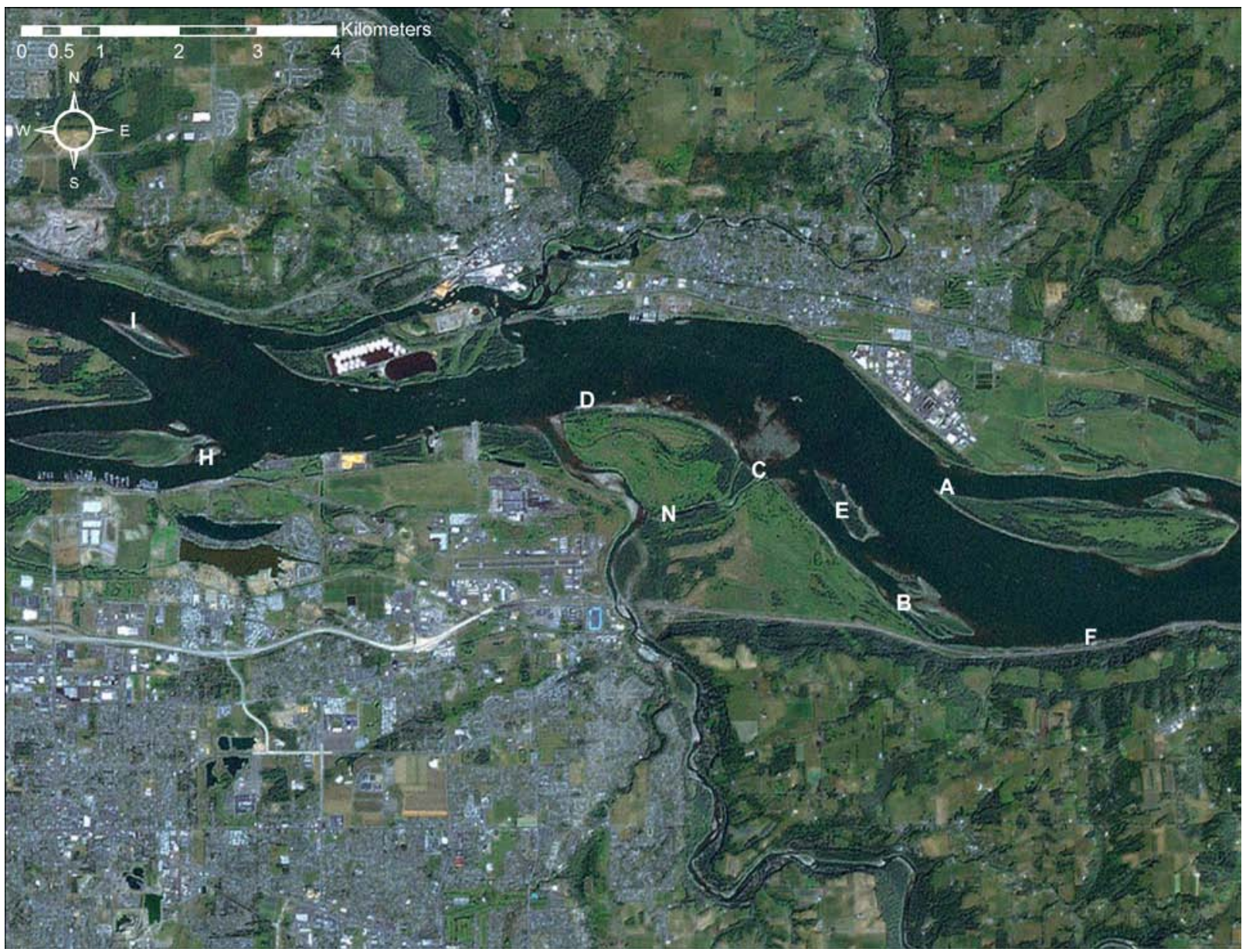

Figure 3.1. Tidal Freshwater Monitoring Sampling Sites 2007-2008. Base sites established during 2007 include Sites A, B, C, D, E, and N. Three new sites were added to the study during 2008: Sites F, H, and I. 


\subsubsection{New Sites}

During year two of the TFM project (2008), we supplemented our study to incorporate a recommendation by the ISRP to expand the work study to broaden sample coverage (ISRP 2006). As a result, when resources became available in 2008, three new sites were added to the existing base sites. In choosing new sites, our goal was to select additional sites that offered diverse habitat types while expanding the initial study area in the vicinity of the Sandy River delta. Beginning in September 2008, we implemented sampling at Sites F, G, and H (Figure 3.1). After several failed seining attempts at the newly chosen site on Lady Island (Site G), it was dropped due to a significant amount of underwater debris along the shoreline. To replace this site, a new site on Ackerman Island, Site I, was added during October 2008. The new sites (also labeled in Figure 3.1) are described as follows:

- Site $\mathbf{F}$ is located along the Oregon shore of the mainstem Columbia River, upstream of the Sandy River delta. The site is bound at both upstream and downstream ends by pile dikes and coarse woody debris. Overall, the site is relatively shallow $(<1.5 \mathrm{~m})$ and dominated by sandy substrate with little submerged aquatic vegetation. The beach face is moderately vegetated above the high-water mark.

- Site $\mathbf{H}$ is an off-channel site located along the southeastern shore of McGuire Island, downstream of the mouth of the Sandy River. The site is dominated by sandy substrate with minimal submerged aquatic vegetation. At the high-water mark, trees and emergent vegetation are abundant; however, below this point, steep sloping beaches support little ground cover.

- Site I is located at the approximate mid-point of the north shore of Ackerman Island, and is downstream of the mouth of the Sandy River. Ackerman Island is a main channel island dominated by sandy substrate. Site I is generally shallow $(<1.0 \mathrm{~m})$, with little or no submerged aquatic vegetation and sparse emergent vegetation. A relatively dense overstory exists above the high-water mark.

In addition to adding three new sites within the vicinity of the Sandy River delta, we modified our study design to increase the spatial extent of our sampling effort within the tidal freshwater portion of the LCRE. This effort was also aimed at addressing the evaluation provided by the ISRP with regard to expanding our sampling breadth. Briefly, we implemented a sampling scheme, dubbed "fish blitz," whereby we adapted a stratified random sampling approach to investigate the link between salmon distribution and habitat characteristics within Reach E of the LCRE (Figure 3.1). We conducted fish blitz sampling during January and February 2009 to investigate overwintering life history groups of juvenile

salmon. The results from this effort will be summarized in a forthcoming report scheduled for completion by April 2010.

\subsubsection{Sampling Schedule}

Since June 2007, fish sampling for the TFM study has occurred over a two- or three-day period each month. The daily sampling order for each of the sites was selected randomly except for Site N. To avoid unnecessary logistical constraints, Site N, which is accessed by walking, was sampled prior to or after the boat sites on a given day. Throughout our sampling efforts, low-flow events often presented logistical constraints for gaining access to sites, and on few occasions, prevented the occurrence of sampling. Conversely, high flows sometimes also prevented sampling. The sampling dates and sites are listed in Table 3.1. 
Table 3.1. Monthly TFM Sampling Schedule by Site

\begin{tabular}{|c|c|c|c|c|c|c|c|c|c|}
\hline & \multicolumn{9}{|c|}{ Site } \\
\hline & A & $\mathrm{B}$ & $\mathrm{C}$ & $\mathrm{D}$ & $\mathrm{E}$ & $\mathrm{F}$ & $\mathrm{H}$ & I & $\mathrm{N}$ \\
\hline June 5-6 and 26-27, 2007 & -- & $\sqrt{ }$ & $\sqrt{ }$ & $\sqrt{ }$ & -- & -- & -- & -- & $\sqrt{ }$ \\
\hline July 11, 19, 2007 & -- & $\sqrt{ }$ & $\sqrt{ }$ & $\sqrt{ }$ & -- & -- & -- & -- & $\sqrt{ }$ \\
\hline August 14-15, 2007 & $\sqrt{ }$ & $\sqrt{ }$ & $\sqrt{ }$ & $\sqrt{ }$ & -- & -- & -- & -- & $\sqrt{ }$ \\
\hline September 11-12, 2007 & $\sqrt{ }$ & $\sqrt{ }$ & $\sqrt{ }$ & $\sqrt{ }$ & $\sqrt{ }$ & -- & -- & -- & $\sqrt{ }$ \\
\hline October 16-17 2007 & $\sqrt{ }$ & $\sqrt{ }$ & o & $\sqrt{ }$ & $\sqrt{ }$ & -- & -- & -- & $\sqrt{ }$ \\
\hline November 19-20, 2007 & $\sqrt{ }$ & $\sqrt{ }$ & $\sqrt{ }$ & $\sqrt{ }$ & $\sqrt{ }$ & -- & -- & -- & $\sqrt{ }$ \\
\hline December 18-19, 2007 & $\sqrt{ }$ & $\sqrt{ }$ & $\sqrt{ }$ & $\sqrt{ }$ & $\sqrt{ }$ & -- & -- & -- & $\sqrt{ }$ \\
\hline January 30-31, 2008 & $\sqrt{ }$ & $\sqrt{ }$ & $\sqrt{ }$ & $\sqrt{ }$ & $\sqrt{ }$ & -- & -- & -- & $\sqrt{ }$ \\
\hline February 11, 2008 & $\sqrt{ }$ & $\sqrt{ }$ & $\sqrt{ }$ & $\sqrt{ }$ & $\sqrt{ }$ & -- & -- & -- & $\sqrt{ }$ \\
\hline March 18-19, 2008 & $\sqrt{ }$ & $\sqrt{ }$ & $\sqrt{ }$ & $\sqrt{ }$ & $\sqrt{ }$ & -- & -- & -- & $\sqrt{ }$ \\
\hline April 17-18, 2008 & $\sqrt{ }$ & $\sqrt{ }$ & $\sqrt{ }$ & $\sqrt{ }$ & $\sqrt{ }$ & -- & -- & -- & $\sqrt{ }$ \\
\hline May 14-15 2008 & $\sqrt{ }$ & $\sqrt{ }$ & $\sqrt{ }$ & $\sqrt{ }$ & $\sqrt{ }$ & -- & -- & -- & $\sqrt{ }$ \\
\hline June 16-17 2008 & $\sqrt{ }$ & $\sqrt{ }$ & $\sqrt{ }$ & $\sqrt{ }$ & $\cdot$ & -- & -- & -- & - \\
\hline July 15-16 2008 & $\sqrt{ }$ & $\sqrt{ }$ & $\sqrt{ }$ & $\sqrt{ }$ & $\sqrt{ }$ & -- & -- & -- & $\sqrt{ }$ \\
\hline August 13-14, 2008 & $\sqrt{ }$ & $\sqrt{ }$ & $\sqrt{ }$ & $\sqrt{ }$ & $\sqrt{ }$ & -- & -- & -- & $\sqrt{ }$ \\
\hline September 15-17, 2008 & $\sqrt{ }$ & $\sqrt{ }$ & o & $\sqrt{ }$ & $\sqrt{ }$ & $\sqrt{ }$ & $\sqrt{ }$ & -- & $\sqrt{ }$ \\
\hline October 20-22, 2008 & $\sqrt{ }$ & $\sqrt{ }$ & o & $\sqrt{ }$ & $\sqrt{ }$ & $\sqrt{ }$ & $\sqrt{ }$ & $\sqrt{ }$ & $\sqrt{ }$ \\
\hline November 18-21, 2008 & $\sqrt{ }$ & $\sqrt{ }$ & $\sqrt{ }$ & $\sqrt{ }$ & $\sqrt{ }$ & $\sqrt{ }$ & $\sqrt{ }$ & $\sqrt{ }$ & $\sqrt{ }$ \\
\hline December 8-11, 2008 & $\sqrt{ }$ & $\sqrt{ }$ & $\sqrt{ }$ & $\sqrt{ }$ & $\sqrt{ }$ & $\sqrt{ }$ & $\sqrt{ }$ & $\sqrt{ }$ & $\sqrt{ }$ \\
\hline $\begin{array}{l}\sqrt{ } \text { sampled } \\
\text {-- not sampled: site not in } \\
\text { o not sampled: no water a } \\
\text { - not sampled: too much }\end{array}$ & & & & & & & & & \\
\hline
\end{tabular}

\subsection{Habitat Characteristics}

In-depth habitat characteristics such as vegetation and elevation were evaluated once for each of the sites. The base sites were evaluated during 2007 and described by Sobocinski et al. (2008). The newly added sites are described herein and are summarized in conjunction with the six base sites. Habitat characteristics for Site I, on Ackerman Island, are not included in this report because the site was added to the study after the completion of the 2008 habitat surveys. Habitat information pertaining to Site I will be included in the 2009 annual report. 


\subsubsection{Physical Features}

The TFM monitoring sites were evaluated to describe habitat characteristics that included key physical features such as substrate and land elevation. Water surface elevation and temperature data were collected at four sites (A, B, C, and N) using continuous data loggers. Vegetation was described through quantitative and qualitative methods.

\subsubsection{Substrate}

To characterize substrate, we collected sediment samples at low-water conditions during the September 2007 sampling trip. At each site, we collected grab samples ( 200 ml) at three locations near the water's edge (upstream, middle, and downstream of the beach seine sampling locations). Samples were refrigerated prior to analysis. Columbia Analytical Services performed grain size analysis according to the Puget Sound Estuary Program protocol (Puget Sound Water Quality Authority 1986). Quality assurance measures were followed by the laboratory. Reported values include the average of the three samples per site, with percent composition for each of eight size classes.

\subsubsection{Land Elevation}

Because water elevation is linked to seasonal discharge and the beach slope at a given site, land elevation data were collected at each site using a Trimble real time kinematic (RTK) global positioning system (GPS; Trimble Navigation Limited, Sunnyvale, California) with survey-grade accuracy. Data were collected using a static approach, whereby the receiver remained stationary at a single location for 5-10 seconds. The spatial extent of data collection resembled a grid pattern along the beach face (i.e., upstream to downstream). The horizontal distance between transects spanned $20 \mathrm{~m}$ and data collection along a given transect occurred at intervals of 2-5 m. At each site, the grid pattern comprised a minimum of six transects. All surveying was referenced to the North America Vertical Datum 88 (NAVD 88); horizontal position was referenced to North America Datum 83 (NAD 83). Data collected from the base receiver were processed using the automated Online Positioning User Service (OPUS) provided by the National Geodetic Survey. To ensure proper spatial reference, OPUS provides a rootmean-square value, an estimate of error, for each set of static data collected by the base receiver.

We used Trimble Geomatics Office (TGO 2005) to process the data, importing, reviewing, and annotating each survey. The survey was then recomputed within TGO and exported in a geographic information system (GIS) shapefile format. Surveys were visually checked within TGO and ArcGIS software for validity. Due to the spatial distance between the sites, each site was processed separately. Processing all of the sites together could create artifacts in the surfaces generated from the data. The elevation data from the grid at each site were processed through ArcGIS using either kriging or triangulated irregular networks to produce a surface (ESRI 2008, 2009). The contour tool in ArcGIS was used on these surfaces to create a map of the site with contour spacing of $0.25 \mathrm{~m}$ (see Appendix B). 


\subsubsection{Water Surface Elevation}

To gain a better understanding of water surface elevation within our study area, we installed Onset Hobo water level loggers (Model U20-001-01; Onset Computer Corporation, Pocasset, MA) during August 2007. This initial installation included Sites A-D and N. The sensors were cable-tied inside polyvinyl chloride pipe that was affixed to either a t-post or a cinder block near our beach seining locations. The elevation of each sensor was surveyed using the RTK GPS.

The five data loggers were retrieved from the field during August 2008. Data were downloaded from the sensors using Hoboware Pro software (version 2.6.0; Onset Computer Corporation). Because these sensors record absolute pressure (psi) as a proxy for water level, the data were corrected for changes in atmospheric condition. We used the weather station nearest to our sampling sites located at the PortlandTroutdale airport (NOAA 2009). Depth sensor measurements were corrected by subtracting the sensor reading from the barometric pressure. After conversion from kilopascals to meters, the water elevation was calculated as the sum of the elevation of the depth sensor and the corrected sensor reading.

During the retrieval of the data loggers, new data loggers were installed at the Sites A-C and N. The t-post at Site D was found lying on the ground with the sensor still attached to it. Because we were not able to discern when this occurred, the data from Site D is unusable for the period of August 2007August 2008. The t-post was moved to a new location at Site D in September 2008. New sensors were installed at the remaining Sites_E, F, and H-during September 2008. Data collected from the hobo sensors during the 2008-2009 period will be summarized in our 2009 annual report.

\subsubsection{Vegetation}

In characterizing vegetation, we considered site-specific plant communities, including the associated percent cover, and we compared communities across sampling sites. Site-specific maps were created to portray major vegetative features at the sites.

\subsubsection{Plant Communities}

The vegetative characteristics at each of the sites were evaluated using two approaches. The first method systematically assesses the percent cover of vegetative species identified at three transects at each of the sites. The length of the transects was contingent upon the size of the beach slope, which ran from the water's edge to the high-water mark. The second approach involved using a Trimble GeoXT handheld GPS unit (Trimble Navigation Limited, Sunnyvale, California) to delineate major vegetative features. The mapping approach characterized a combination of emergent and riparian vegetation at the sites. Data collected on the GPS unit were transferred to ArcGIS to create maps of the sites. Additional details regarding the methods used for characterizing vegetation are explained by Sobocinski et al. (2008). 


\subsubsection{Relative Percent Cover}

To evaluate site-specific vegetation characteristics, we used data collected from the transects to determine the relative percent cover for each species. Relative percent cover for the $i^{\text {th }}$ plant species was calculated using the following equation:

$$
\text { Relative Percent Cover } \mathrm{i}_{\mathrm{i}}=\left(\frac{\sum_{j=1}^{n_{j}} x_{i j}}{\sum_{i=1}^{n_{i}} \sum_{j=1}^{n_{j}} x_{i j}}\right) * 100
$$

where, $x_{i j}=$ percent cover for the $i^{\text {th }}$ plant species in the $j^{\text {th }}$ plot

$n_{i}=$ number of plant species

$n_{j}=$ number of plots.

\subsubsection{Similarity Index}

While the relative percent cover calculation allows for the examination of vegetation characteristics at a particular site, the similarity index compares the plant communities between sites. We used the Czekanowski Index (Thom et al. 2002):

$$
\text { Percent Similarity }=\left(\frac{2 a}{2 a+b+c}\right) * 100
$$

where, $a=$ the number of species common between two sites

$b=$ the number of species exclusive to the first site

$c=$ the number of species exclusive to the second site.

\subsection{Fish Characteristics}

Fish characteristics were based on direct capture of fish, as well as the collection of ancillary data, the identification of genetic stock and diets, and the use of acoustic telemetry.

\subsubsection{Direct Capture}

The direct capture of fish involved beach seining. We modified our fishing technique during 2008. Between June 2007 and April 2008, we used a bagless beach seine (called the "KS-9 net”) to sample fish communities along the beach face at our established sites. After thorough deliberation and a systematic beach seine comparison exercise (see Appendix E in Sobocinski et al. 2008), the team decided to acquire a larger net (called the "TFM net") and use a new setting technique starting in May 2008. Regardless of the net or set technique, each time the net was set we calculated the area swept, which allowed us to standardize catches by calculating fish density $\left(\# / \mathrm{m}^{2}\right)$. 


\subsubsection{Net Descriptions}

The KS-9 net was constructed of 5-mm knotless mesh and measured $30.5 \mathrm{~m}$ long and $3 \mathrm{~m}$ deep. It was set by either boat or foot, depending on water elevation, at all sites from June 2007 through April 2008. The set technique applied to the KS-9 net involved anchoring one end on shore and deploying the remainder of the net into the water in a semi-circular pattern (Figure 3.2). Once both ends of the net were on shore, the lead lines were evenly pulled toward shore, keeping the fish in the center of the net. However, the team ultimately thought the KS-9 net was not sufficient to adequately sample the sites. We concluded that this net, while providing useful data, could be improved upon in terms of length, shape, and bridle arrangement. We specified a new net for May 2008 and beyond.

The custom TFM net was designed specifically to sample within shallow water habitats encountered in our study area. The TFM net is $46 \mathrm{~m}$ long and $3 \mathrm{~m}$ deep at the center with wings that taper to $1.5 \mathrm{~m}$. The wings are constructed of 13-mm stretch black knotless netting. This seine is fit with a bag constructed of 3.2-mm knotless mesh netting dyed green, and measures $2.4 \mathrm{~m}$ wide by $1.5 \mathrm{~m}$ deep. The seine is fit with 17-oz buoyancy EVA floats on 46-mm centers and a solid core lead line with a poly sleeve sewed to the base. A 15-m-long haul line was affixed to a bridle at the tapered ends of each wing. One end of the haul line was held to the shore while the boat moved toward the deep end of the channel. Once the end of the line was reached, the boat turned 90 degrees and began deploying the net (Figure 3.2). After the full length of the net had been set, the haul lines were used to bring the wings to shore. Haul lines facilitated more consistent sets for the TFM net compared to the KS-9 net. We ceased using the KS-9 net for all sites in 2008, except for Site N where we continued to use the KS-9 net due to the small, confined sampling area at this site.

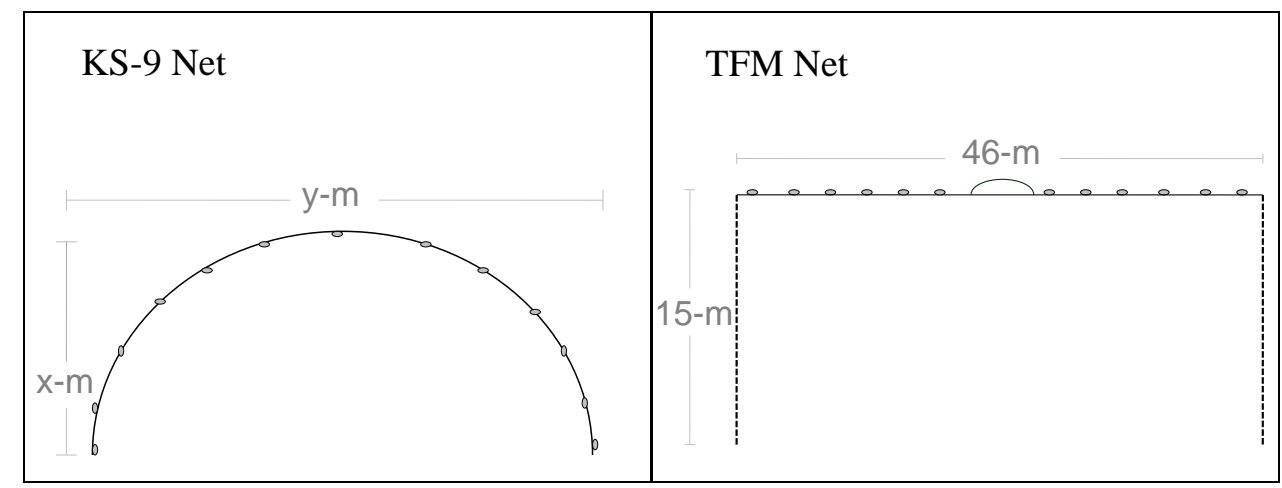

Figure 3.2. Seine Deployment Techniques Applied During the TFM Study. Illustrations are not to scale. The length (y) and width (x) of the KS-9 net were recorded for each set, because it is difficult to achieve consistent dimensions for the area swept. The length and width were also recorded when the TFM net was deployed.

\subsubsection{Net Sampling}

Whenever possible, we deployed the beach seine by boat. However, when water elevation prevented motorized boat access, the net was moved and set by foot. Two replicate, non-overlapping hauls were set at each site with the two hauls at least 30 minutes apart. After each haul, we removed fish from the net and placed them in holding buckets filled with river water at ambient temperature. All salmon were separated from the catch into buckets for immediate processing. Aerators were used to maintain adequate levels of dissolved oxygen in the holding water. 
When catches were large, we implemented a subsampling procedure to rapidly process the catch without imposing undue stress on the fishes. After removing all salmon from the beach seine, the remaining catch was homogenized and 1-2 aliquots were removed using a standard aquarium net. The subsampled catch was placed in holding buckets for further processing, and the volume of the remaining catch was quantified by enumerating the scoops required to remove all fish from the bag. While this approach does not permit precise quantification of taxa, it does provide a means for documenting thousands of fish over a short time period. After the data had been electronically entered, the subsampled catch was calculated as the product of the actual number of fish enumerated within each taxon and the number of scoops required to process the catch.

Catches were processed by enumerating all taxa and measuring to the nearest millimeter up to 20 individuals within each size class for a given species. Fish were identified to the lowest taxonomic level possible. In addition to enumeration and length measurements, salmon were further processed for information regarding genetic stock identification (see Section 3.3.3) and diet composition (see Section 3.3.4). We also used a coded-wire tag (CWT) wand and a passive integrated transponder (PIT) tag reader to detect tagged fish to help distinguish hatchery origin salmon in the field. All salmon subjected to gastric lavage or tissue collection were anesthetized using a 10\% Tricaine Methanesulphonate (MS-222) solution. After processing, anesthetized individuals were held in a recovery bucket filled with river water at ambient temperature. During recovery, dissolved oxygen was maintained in the bucket using aerators. We released fish processed from the first haul downstream of the sampling area to minimize potential contamination of the second sample; fish from the second haul were released at the site of capture. All observed mortalities were documented.

Data transfers from field to electronic datasheets were subjected to independent quality assurance/quality control review. Using the area swept for each beach seine haul we calculated fish density as the number of individuals per square meter. Details pertaining to statistical analyses are explained in Section 3.4.

\subsubsection{Ancillary Data}

Site-specific water quality and haul locations also were documented in conjunction with monthly fish sampling. We evaluated the condition of water quality at each site during our monthly sampling efforts. Using a handheld YSI-85 or YSI-556 device (Yellow Springs Instruments, Yellow Springs, Ohio) we measured temperature $\left({ }^{\circ} \mathrm{C}\right)$, salinity $(\mathrm{ppt})$, and dissolved oxygen $(\mathrm{mg} / \mathrm{L})$. The analyst measuring water quality properties waded into the water and suspended the probes approximately $0.3 \mathrm{~m}$ below the water surface. An internal test verification was regularly performed on water quality instruments. We also obtained velocity readings at each site using a Flo-Mate electromagnetic flow meter (Marsh-McBirney Inc., Frederick, Maryland). Finally, we used a surveyed benchmark (see Section 3.2.1.2 for RTK procedures) to measure the distance between this fixed location and the water's edge. This measurement documented seasonal shifts in water level.

Using a Trimble GeoXT handheld GPS unit (Trimble Navigation Limited, Sunnyvale, California), we recorded the coordinates for each beach seine haul. To maintain a record of our actual sampling locations and visually depict our haul locations at a particular site throughout the study period, we used TGO to post-process the GPS data that were later exported into ArcGIS (ESRI 2004) software for mapping. 


\subsubsection{Genetics}

Fin clips on subsamples of Chinook salmon were preserved in ethanol for genetic mixture analysis. We used standard methods of genetic stock identification and individual assignment (reviewed by Manel et al. 2005). Chinook salmon were genotyped using the methods described by Teel et al. (2009). Data were collected for 13 microsatellite loci that have recently been standardized among several west coast genetics laboratories (Seeb et al. 2007). Genetic mixture analysis and the relative probability of stock origin of each sample were estimated using the genetic stock identification computer program ONCOR (Kalinowski et al. 2007). Population baseline data were from the multilaboratory standardized Chinook salmon genetic database described by Seeb et al. (2007). Mixture proportions and assignment probabilities for individual baseline populations were summed to 10 Columbia River basin stock groups (Table 3.2). The baseline includes populations from all known major genetic lineages in the Columbia River basin. However, it is not comprehensive and efforts are currently underway to include data for additional hatchery and natural spawning populations (Seeb et al. 2007). Confidence intervals of the mixture proportions were estimated using ONCOR by re-sampling mixture and baseline data 100 times.

Table 3.2 Genetic Stock Groups and Baseline Populations. Genetic data are from Seeb et al. (2007) except where noted.

\begin{tabular}{|c|c|}
\hline Genetic Stock Group & Baseline Populations \\
\hline $\begin{array}{l}\text { West Cascade Tributary } \\
\text { Fall }\end{array}$ & Cowlitz Hatchery, Lewis River, Sandy River \\
\hline $\begin{array}{l}\text { West Cascade Tributary } \\
\text { Spring }\end{array}$ & $\begin{array}{l}\text { Cowlitz Hatchery, Kalama Hatchery, } \\
\text { Lewis Hatchery }\end{array}$ \\
\hline $\begin{array}{l}\text { Willamette River } \\
\text { Spring }\end{array}$ & $\begin{array}{l}\text { Mckenzie Hatchery and River, }{ }^{(a)} \text { North Santiam Hatchery and River }{ }^{(\mathrm{a}),} \text { North } \\
\text { Fork Clackamas River }^{(\mathrm{a})}\end{array}$ \\
\hline $\begin{array}{l}\text { Spring Creek Group Tule } \\
\text { Fall }\end{array}$ & $\begin{array}{l}\text { Spring Creek Hatchery, Big Creek Hatchery, } \\
\text { Elochoman River, }^{(a)} \text { Willamette River } \\
{ }^{(a)}\end{array}$ \\
\hline $\begin{array}{l}\text { Deschutes River } \\
\text { Fall }\end{array}$ & Lower Deschutes River, Upper Deschutes River ${ }^{(\mathrm{b})}$ \\
\hline $\begin{array}{l}\text { Upper Columbia River } \\
\text { Summer/Fall }\end{array}$ & Hanford Reach, Methow River, Wells Hatchery, Wenatchee River ${ }^{(\mathrm{c})}$ \\
\hline $\begin{array}{l}\text { Mid and Upper Columbia River } \\
\text { Spring }\end{array}$ & $\begin{array}{l}\text { Carson Hatchery, John Day River, Upper Yakima River, Warm Springs } \\
\text { Hatchery, Wenatchee Hatchery }^{(\mathrm{c})} \text { and River }\end{array}$ \\
\hline $\begin{array}{l}\text { Snake River } \\
\text { Fall }\end{array}$ & Lyons Ferry Hatchery \\
\hline $\begin{array}{l}\text { Snake River } \\
\text { Spring }\end{array}$ & $\begin{array}{l}\text { Imnaha River, Minam River, Rapid River Hatchery, Secech River, Tucannon } \\
\text { Hatchery and River, }{ }^{(\mathrm{c})} \text { Newsome Creek, }{ }^{(\mathrm{d})} \text { West Fork Yankee Creek } \\
{ }^{(\mathrm{d})}\end{array}$ \\
\hline Rogue River & Cole Rivers Hatchery, Applegate River \\
\hline
\end{tabular}

(a) Northwest Fisheries Science Center, unpublished data

(b) Columbia River Inter-Tribal Fish Commission, unpublished data

(c) Washington Department of Fish and Wildlife, unpublished data

(d) Narum et al. (2007) 


\subsubsection{Diets}

We used gastric lavage to remove stomach contents from juvenile salmon species that were larger than 50-mm fork length (FL). Gastric lavage has been reported to be $99 \%$ effective at removing prey organisms, with no impacts on survival, from the stomachs of coho salmon (Meehan and Miller 1978). At each site each sampling trip, the contents from the digestive tracts of up to 20 each of Chinook, coho, and chum salmon (Oncorhynchus keta) were flushed into individual polyethylene sample bottles using filtered river water at ambient temperature. After lavage, samples were preserved in a $10 \%$ ethanol solution to slow degradation. Within 24 hours, samples were preserved in a $70 \%$ ethanol solution for later analysis.

In the laboratory, stomach contents were removed from sample bottles using a pipette or by straining through a $500-\mu m$ sieve. Samples were then placed in a shallow glass dish containing a $70 \%$ ethanol solution and examined under a dissecting microscope. We identified all prey items to the lowest classification possible using standard taxonomic keys (e.g., Merritt and Cummins 1996). Partially degraded organisms were identified based on paired or individual characteristic structures. Prey items of the same taxon were counted and placed in small polyethylene centrifuge vials. To archive samples, vials were filled with $70 \%$ ethanol and labeled appropriately. Unidentifiable prey appendages and insect exuviae were then returned to the original sample bottle and stored in $70 \%$ ethanol. To ensure the quality of diet data, a second analyst independently quantified 1 of every 25 samples enumerated by the primary analyst. If the difference between the two evaluations exceeded $15 \%$ for any taxon, the analysts convened to discuss and refine classification techniques, thereby limiting error in the enumeration of subsequent samples.

\subsubsection{Acoustic Telemetry}

Acoustic telemetry was used to detect tagged and released fish at selected sampling sites for sampling periods for which the field data were subsequently downloaded and analyzed. A basic acoustic telemetry system consists of a tag (the transmitter), a hydrophone (the receiving transducer or node), a signal processor, and processing and analysis software. Such a system can be used to detect the presence of a tagged animal in an area of interest. The micro-acoustic tags used in this study transmitted $417 \mathrm{kHz}$ of sound once every 5 seconds for about 60 days. The equipment we used was developed as part of the USACE acoustic telemetry program (McComas et al. 2008).

As part of other projects (e.g., USACE post-FCRPS and Bonneville spillway survival studies), juvenile spring Chinook and fall Chinook salmon and steelhead were tagged and released upstream of the study area. Individual fish were surgically implanted with acoustic tags weighing no more than $0.63 \mathrm{~g}$ in air (0.39 g in water; $5.5 \mathrm{~mm}$ wide x $4.8 \mathrm{~mm}$ thick x $19 \mathrm{~mm}$ long) using a procedure similar to that described by Adams et al. (1998). In addition, each fish received a PIT tag. All fish tagged were of hatchery origin. Acoustic-tagged fish were released in the Snake River at Lower Granite Dam and in the Columbia River at Arlington, the John Day Dam tailwater, The Dalles Dam tailwater, Bonneville second powerhouse corner collector, Bonneville Dam tailwater, and Skamania. 


\subsubsection{Sampling Sites}

Four autonomous receivers (called nodes) were deployed in relatively deep areas in the study area to maximize signal detectability: 1) Reed Island, near Site A; 2) Flag Island downstream of Site B; 3) the gap between Flag and Gary islands; and 4) Gary Island near Site E (Figure 3.3). All acoustic telemetry nodes were attached to moorings and retrieved using an acoustic release device. The TFM nodes were incorporated into the arrays for the USACE survival studies. We also used data from hydrophones deployed upstream (upper end of Reed Island) and downstream (Lady Island) of our study sites in the mainstream of the Columbia to determine migration pathways (Figure 3.3).

Nodes were deployed on April 26, 2008, and retrieved on July 25, 2008. All nodes sampled 24 h/d during their deployment, except during servicing (i.e., replacing the batteries and data media). Data were backed up on a laptop computer and external hard drive; acoustic data were downloaded from the nodes once during each month of the April-July telemetry field season.

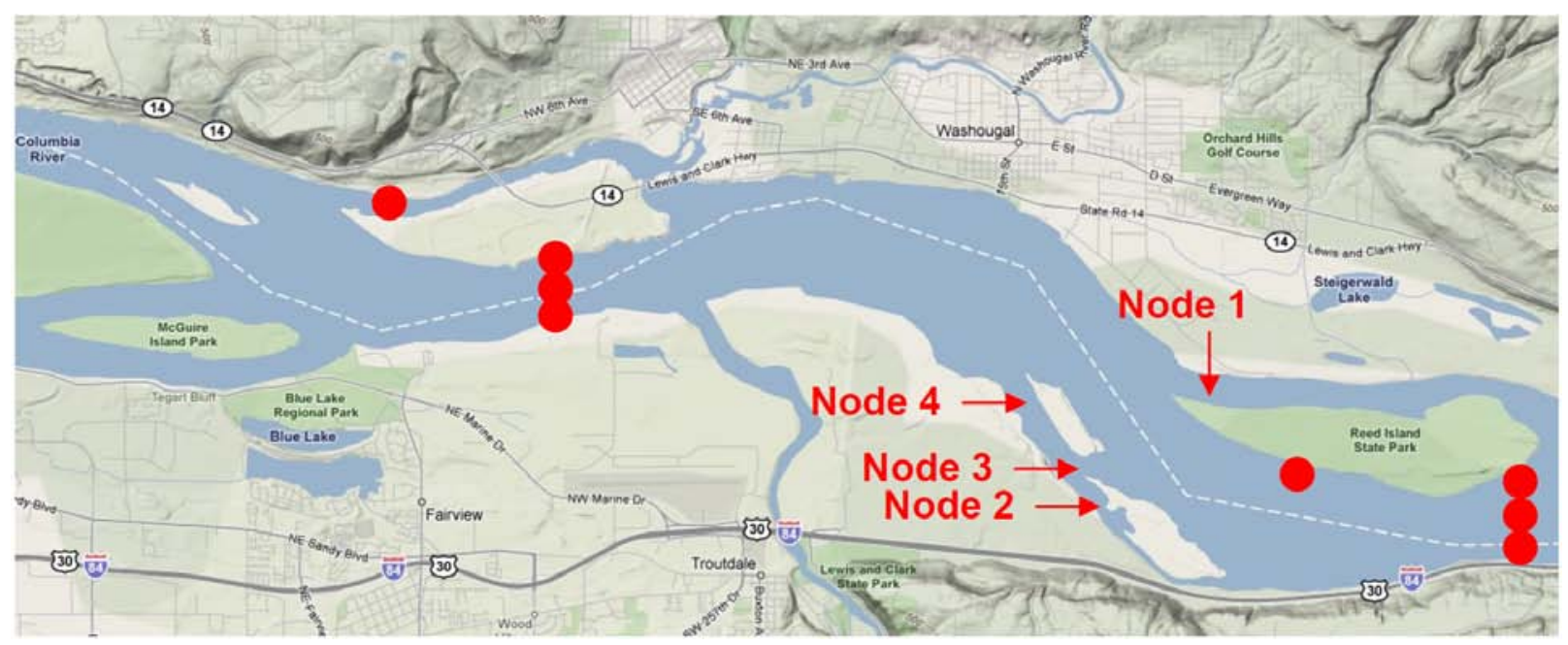

Figure 3.3. Locations of the Four TFM Acoustic Telemetry Receiver Nodes. Node 1 was near Site A off Reed Island; node 2 was behind Flag Island; node 3 was in the gap between Gary and Flag islands; and node 4 was near Site E off Gary Island. The red dots denote the locations of hydrophone arrays for other studies.

\subsubsection{Data Analysis}

A detection event was defined by at least four valid acoustic signal receptions within a 60 -second window. We matched detected fish with release codes and developed time-of-detection histories. The primary results from the analysis of the acoustic data were species of tagged fish, time of first detection, time of last detection, location(s) (i.e., nodes where detections occurred), and total number of valid detections. These data were analyzed in conjunction with data from acoustic telemetry nodes for the USACE survival studies placed across the Columbia River at Reed and Lady islands just upstream and downstream, respectively, from the Sandy River delta study area (Figure 3.3).

Besides providing data about migration characteristics of acoustic-tagged fish in the study area, we assessed the feasibility of using acoustic telemetry technology for action effectiveness research in the LCRE. Detections of tagged fish through time were used to determine the temporal distribution of tagged 
fish at the study sites. We investigated whether detections of tagged salmon at each of the hydrophones could be used to determine the residence time and migration pathways of tagged fish as represented by the detections among the sampling sites.

Analyses were performed for each species of acoustic-tagged fish: yearling spring Chinook salmon, yearling steelhead and subyearling fall Chinook salmon. The primary database of acoustic tag detections was provided by G. Ploskey (PNNL). The data analysis methods for each objective were as follows:

- Detections - Sort primary database by array and node, then tally the frequency of occurrence on the four TFM study nodes by species and release location.

- Run Timing - For each day of the sampling period, total the number of detections of unique acoustic-tagged fish for all species combined.

- $\quad$ Residence Time - Compute descriptive statistics for the time of duration between first and last detection of individual fish for each TFM node separately.

- Migration Pathways - Tally the numbers of acoustic-tagged fish using particular pathways through the study area (Figure 3.3), including a) detections in the main channel only versus side channels (Reed and delta islands); b) behind Reed Island versus along the main channel side of Reed Island (node 1); and c) detection combinations for fish detected in the delta islands (nodes 2, 3, and 4).

\subsection{Statistical Analysis}

The statistical analyses applied to the data were aimed at quantitatively evaluating the seasonal community structure of fish within the study area. Analysis included salmon diet data and a baseline BACI to evaluate salmon density at paired sites. Regression analysis was used to examine the relationship between environmental variables and salmon density. An analysis-of-distance approach incorporated components of fish community structure and environmental variables at monthly time scales. The combined results of these analyses will be applied toward developing a monitoring framework within the tidal freshwater portion of the Columbia River. The entire statistical synopsis developed for the TFM project can be reviewed in Appendix C.

\subsubsection{Salmon Diets}

Due to small sample sizes and because the diet data were not distributed normally (Shapiro-Wilk, $\mathrm{p}<0.0001$ ), fork lengths of fish with non-empty guts were rank transformed prior to statistical analysis. Where possible, parametric analysis of variance (ANOVA) was applied to evaluate differences among months and sampling locations. Mean separations of ranked data were then conducted after correcting for multiple comparisons with a Bonferroni adjustment. All statistical analyses were conducted using SAS/STAT analysis software (SAS Institute 2005). Tests were considered significant at $\alpha=0.05$.

\subsubsection{Temporal Trends in Salmon Density}

The increase in both long-term monitoring and BACI assessment designs depends, in part, on how well replicate sites are correlated over time. If monitoring sites within a region are responding to common climate and environmental changes, fish density patterns over time should be similar at replicate sites. This process of parallel profiles over time will occur only if the data are analyzed on the proper 
scale. The two most common schemes are the additive (i.e., arithmetic) and log scales. In ecology, most populations respond on a log scale because environmental effects tend to be multiplicative in nature. For example, populations are likely to increase or decrease a common percentage regardless of abundance rather than add or subtract the same number of individuals. To evaluate the temporal trends in salmon density we examined pairs of sites based on similar habitat features. We performed an analysis using Tukey's Test of Additivity to test the null hypothesis that the differences in salmon density between paired sites is additive. Salmon density was plotted in both the arithmetic and logarithmic scale. The sites were grouped according to habitat type, and the salmon density was plotted for the grouped sites as a function of time. Salmon density (D) was calculated for all hauls in a given month as:

$$
\mathrm{D}=\mathrm{C} / \mathrm{A}
$$

where $C$ is the total number of salmon for all hauls of the month, and $A$ is the total area swept by the beach seine.

The groupings were as follows:

- Sites A and E: off-channel habitat with fine substrata

- Sites B and H: off-channel habitat with sandy substrata and steep beach slope

- Sites C and N: impact sites associated with the Sandy River Delta

- Sites D, F, and I: sites adjacent to the river mainstem dominated by sandy substrata.

\subsubsection{Juvenile Salmon and Environmental Variables}

Regression analysis was used to assess the relationships between salmon densities and environmental variables at the fixed sites. Variables included water property metrics (temperature, dissolved oxygen, water depth, flow velocity), riverine condition (outflow, gage height), and site-specific characteristics (mean beach slope, dominant grain size). The variable grain size parameter was categorical, so a one-way ANOVA was used instead of regression to test the null hypothesis of equal density across sites for the given time period. The purpose of this analysis is to identify environmental factors that may be used in stratifying sites in a regional monitoring program. It is important to note that the analysis described herein does not include the vegetative metrics assessed at our sites. A comprehensive analysis of the relationship between salmon densities and habitat associations will be conducted during the 2009-2010 reporting period.

\subsubsection{Fish Community Analysis}

A principal component analysis was performed on the proportions of salmon, native species, and nonnative species during time periods that coincided with relatively high fish counts. Because our catches were dominated by native non-salmon taxa as well as exotic species, we wanted to investigate the associations between fish community and habitat metrics. Analysis of distance (ANODIS) was performed on covariate data. For those data with significant p-values, a vector was superimposed on a plot of the first two principle components indicating the direction of increased fish density as a function of the covariate. 


\subsubsection{Monitoring Program Design}

Variance component estimation (methods outlined by Sobocinski et al. 2008) was used to examine the variation in salmon density at different spatial scales, sites, and study areas. Data were pooled to include all salmon (e.g., multiple stocks, species, and marked and unmarked groups) and were evaluated on a month time scale. Combining data in such a manner permits more accurate estimates of the variance components for the determination of appropriate sample sizes in future study designs. 



\subsection{Results}

The results of the TFM study described in the following sections include habitat characteristics, fish characteristics, and associated statistical analyses.

\subsection{Habitat Characteristics}

Substrate, slope, water elevation and temperature, plant communities, and relative percent cover of vegetation were evaluated across and within sampling sites in the study area.

\subsubsection{Substrate}

The shallow water habitats sampled for the TFM study are primarily comprised of substrates ranging from sandy to silty (Figure 4.1). Sites dominated by the mid-range fractions (e.g., $>70 \%$ fine to medium sands) included B, F, and $\mathrm{H}$. Only three sites (C, D, and H) included coarse sediment fractions that exceeded $15 \%$ of the overall grain size composition. Compared to other sites, the overall composition of sediment at Sites C and D was distributed across multiple grain sizes (Figure 4.1). The grain size composition at these sites is likely linked to their proximity to deltaic river confluence (either historic or current) habitats. Grain size composition at Sites A and E was greater than $70 \%$ for the very fine to clay fractions. These off-channel sites both maintain a gradually sloping beach face characterized by wetland vegetation that grows to the water's edge and is often submerged during high flows. Site $\mathrm{N}$ is also similar to Sites A and E with regard to the majority of substrate composition consisting of fine sediments. The pond-like nature of Site N likely inhibits sediment mixing.

\subsubsection{Slope}

The topography of the TFM sites ranges from gradually sloping, low-relief transitions from the uplands to steeply graded beach slopes. Sites C, D, and F include expansive flats that extend from steep upland areas to the river channel (Figures 4.2 and 4.3). These sites are the most difficult to access during periods of low flow. The micro-topographies at Sites C and D are unique from other sites in that small hummocks are scattered throughout the expansive flats. These hummocks may be residual formations resulting from sediment deposition within the Sandy River delta. During periods of low flow, these hummocks trap water, which creates features similar to wetland pannes; however, the persistence of these panne features are transient because the water elevation in the vicinity of the TFM sites regularly fluctuates as a result of dam operations, and to a lesser extent, tidal amplitude.

Sites B, H, and to some extent A, likely offer greater opportunity for fish use during periods of low flow because the waterbodies adjacent to the steeply sloping beach faces maintain more water compared to the sites with expansive shallows. Despite the low relief of Site N, this site was the least impacted by periods of low flow. The bowl shaped bathymetry of this site maintains water throughout the year (Figure 4.3). 

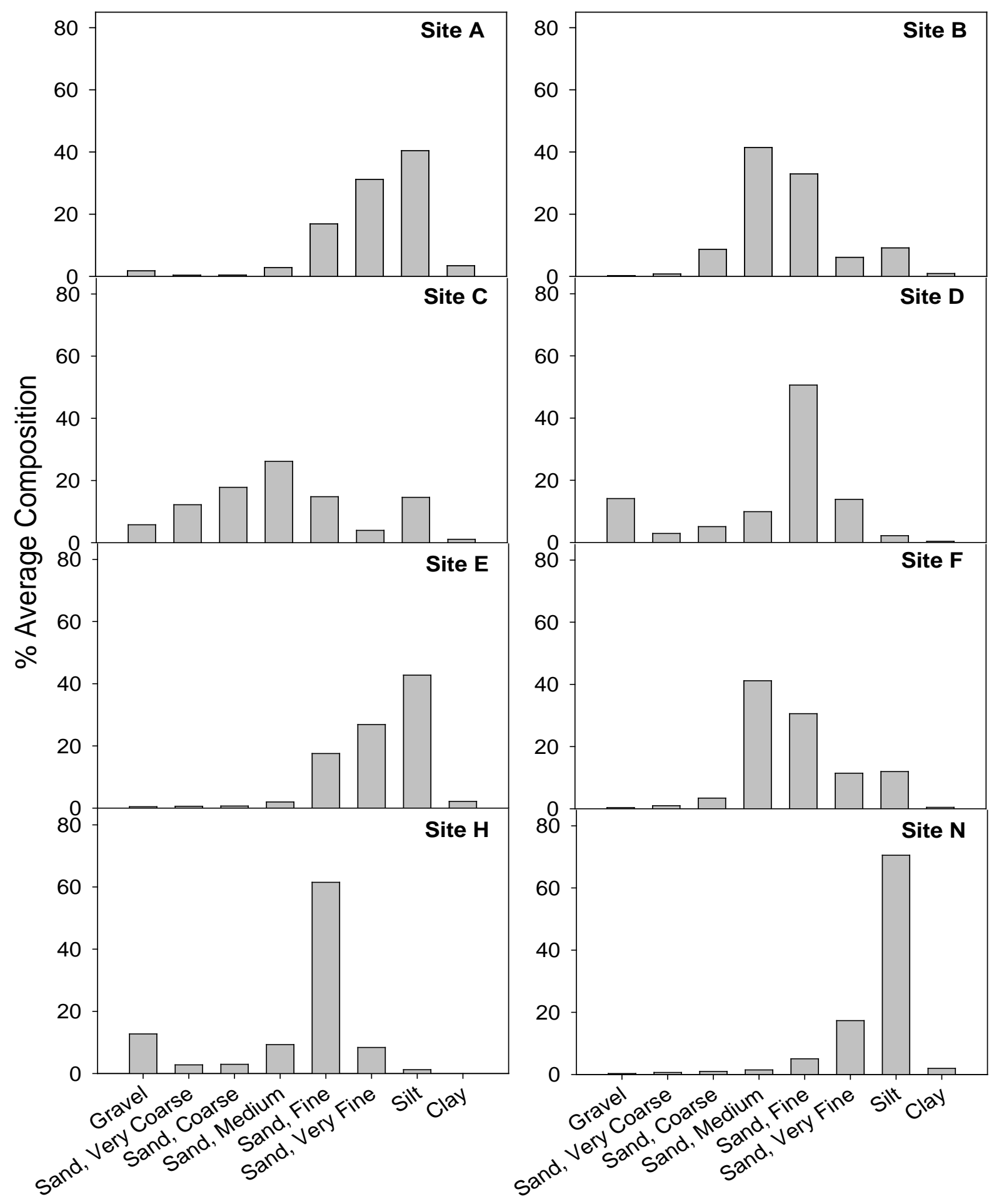

Figure 4.1. Average Percent Composition of Grain Size Analytes from the TFM Beach Seine Sites. Sites A-E and N were analyzed in 2007. Sediments from Sites F and H were collected and analyzed in 2008. 

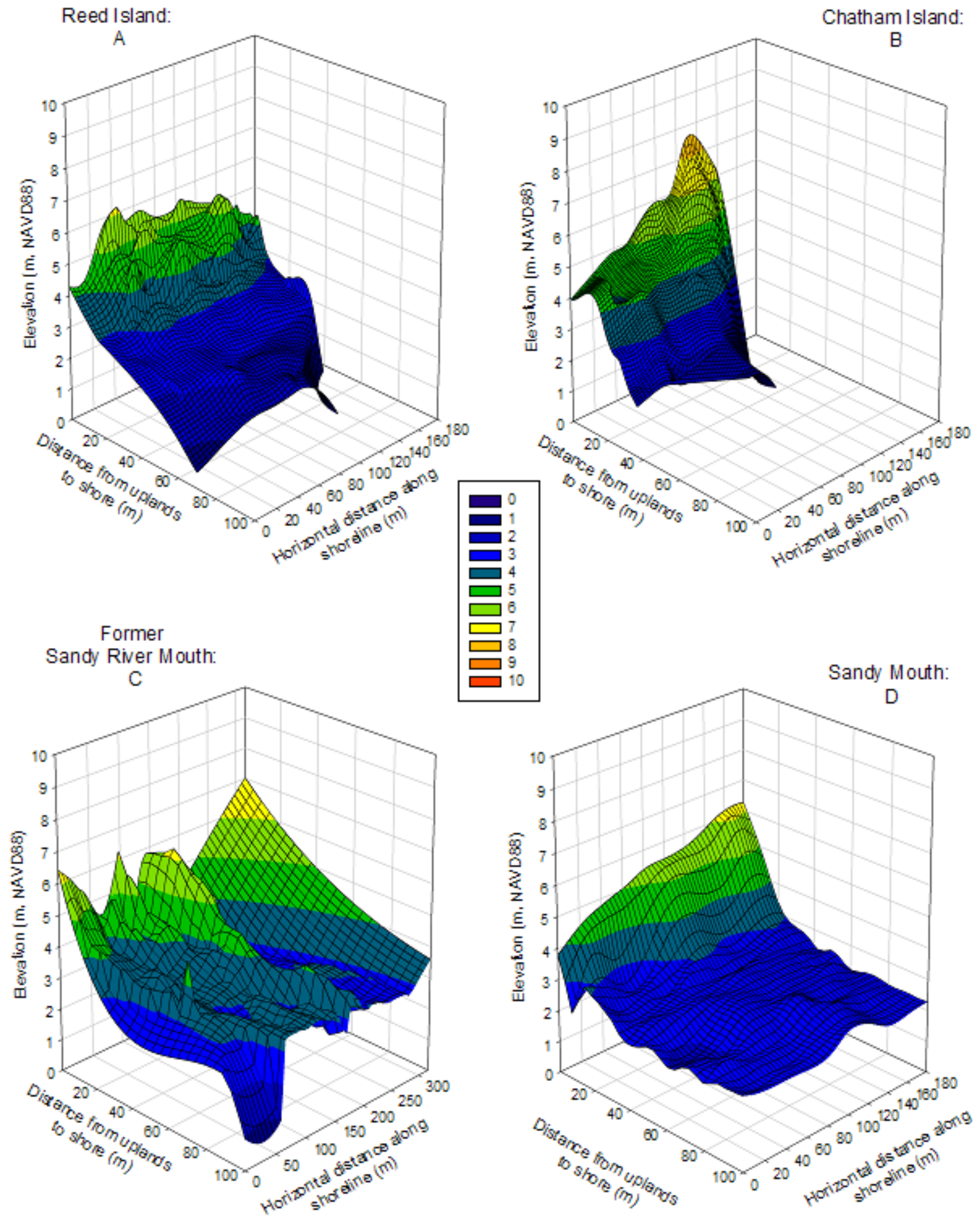

Figure 4.2. Elevation (m, NAVD88) at Sites A, B, C, and D. Because data were recorded using a handheld RTK, the distance from the uplands to the shore was limited by water depth. Therefore, low-relief sites include more expansive spatial coverage of elevation compared to steeply sloped beaches. The values on color key (1-10) correspond to meters. 


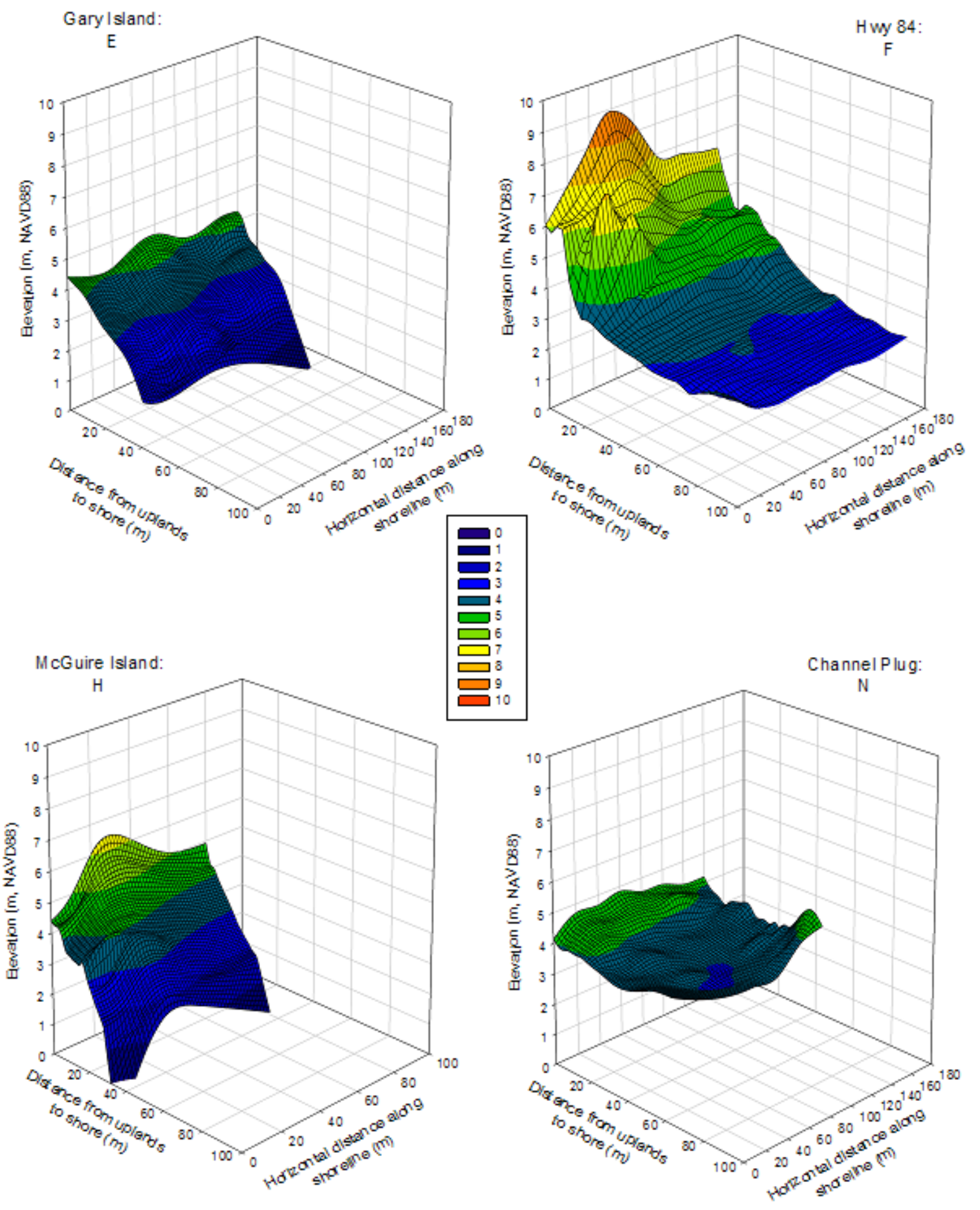

Figure 4.3. Elevation (m, NAVD88) at Sites E, F, H, and N. Because data were recorded using a handheld RTK, the distance from the uplands to the shore was limited by water depth. Therefore, low-relief sites include more expansive spatial coverage of elevation compared to steeply sloped beaches. 


\subsubsection{Water Surface Elevation}

The seasonal pattern of water-level fluctuation was most similar between Sites A, B, and C. The water elevation at these sites was generally lowest from September through November. Water elevation increased through the winter months until the spring freshet and began to decline in June. While Sites A, $\mathrm{B}$, and $\mathrm{C}$ maintained similar patterns of water elevation over large temporal scales, a closer examination during periods of low flow reveals differences in water elevation over shorter time periods (Figure 4.4). The amplitude of fluctuating water elevation is greater at Site A compared to Sites B and C from September through November.
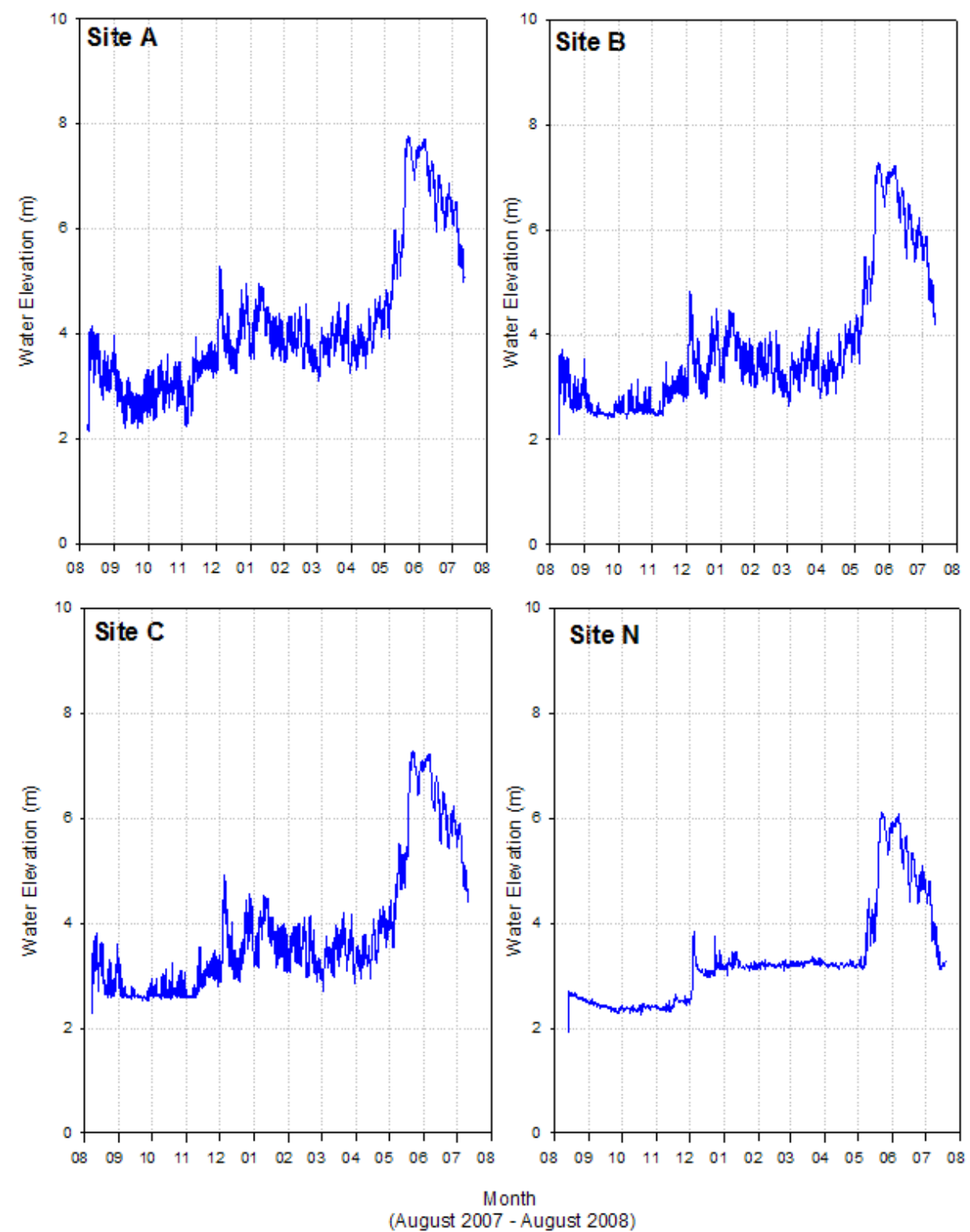

Figure 4.4. Water Elevation (m) Derived from Hobo Data Loggers at Sites A, B, C, and N. The loggers were programmed to record temperature once per 30 minutes. Data collection occurred from August 2007 through August 2008. 
Water surface elevation at Site $\mathrm{N}$ was least like the other sites in that the amplitude of change resembled a step pattern, which is explained by periods of intermittent hydraulic connectivity (Figure 4.4). The upstream end of Site $\mathrm{N}$ is blocked with earthen fill and does not maintain connectivity with the Sandy River. However, during periods of high flow, excess water from the Sandy River flows over the floodplain and enters into Site $\mathrm{N}$ via a former channel within the historic delta. Connectivity between Site $\mathrm{N}$ and the Columbia River is maintained at the channel outlet. Thus, water elevation at Site $\mathrm{N}$ is likely influenced by the hydrology from the mainstem of both the Columbia and Sandy Rivers.

\subsubsection{Water Temperature}

The seasonal temperature patterns recorded from the permanent data loggers installed at Sites A, B, $\mathrm{C}$, and $\mathrm{N}$ indicate similar trends at each of the sites. Temperature was highest during the initial deployment during August 2007 and decreased through the winter months to February when water temperatures began to increase through the spring and summer (Figure 4.5). This seasonal pattern is similar to that measured at the Bonneville scroll case (Figure 2.3).

Water temperature exceeded $20^{\circ} \mathrm{C}$ most frequently at Sites A and B from August through September. During this time period, Site A demonstrated greater variability in water temperature compared to the other sites. Temperatures exceeded $20^{\circ} \mathrm{C}$ at Sites $\mathrm{C}$ and $\mathrm{N}$ during similar time periods; however, elevated water temperatures occurred less frequently compared with Sites A and B. An explanation for lower water temperatures at Sites $\mathrm{C}$ and $\mathrm{N}$ is likely linked to hydraulic connectivity between these two sites and the Sandy River. While there is not a continuous overland flow between the Sandy River and Site N, cool stable temperatures (Figure 4.5) are likely maintained via groundwater seepage or hyporheic flow. The sensor at Site C was situated in the channel thalweg that drains from Site N. Water temperatures at Site C were lower than at Sites A and B during periods of low flow; however, the higher fluctuation at Site C (most notable from August through November; Figure 4.5) may stem from the mixing of cool water draining from the channel associated with Site $\mathrm{N}$ and warmer shallow waters (from the Columbia River) within the historic Sandy River delta.

\subsubsection{Plant Communities}

Plant community types can be grouped into several broad classes ranging from submerged aquatic vegetation at the lower elevations to stable riparian communities at the higher elevations in the study area. We encountered 62 species of plants throughout the eight sites investigated in 2007 and 2008. Site I will be characterized during 2009. The most commonly encountered vegetation included willow (Salix spp.), which was noted at all eight sites surveyed. The frequency of occurrence of creeping spikerush (Eleocharis palustris), horsetail (Equisetum spp.), rice cutgrass (Leersia oryzoides), marsh seedbox (Ludwigia palustris), water milfoil (Myriophyllum spp.), and reed canary grass (Phalaris arundinacea) occurred secondary to willow, because these plants were found at six of the eight sites (Table 4.1). While reed canary grass, an invasive wetland species, was present at most sites, the relative cover was less than 5\% at all sites except Sites A and N, where the relative cover accounted for $10 \%$ to 15\% (Figure 4.6). 

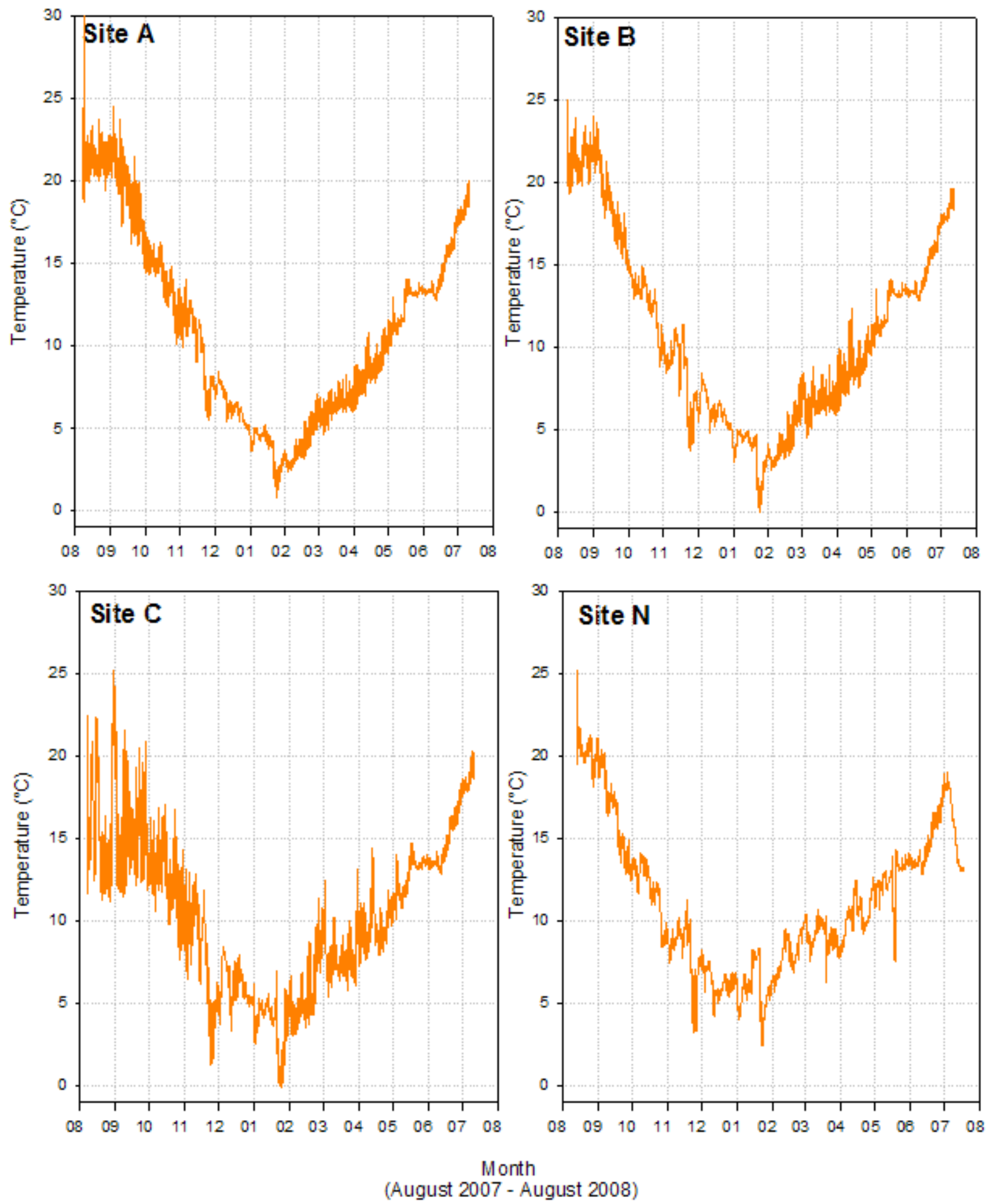

Figure 4.5. Water Temperature Derived from Hobo Data Loggers at Sites A, B, C, and N. The loggers were programmed to record temperature once per 30 minutes. Data collection occurred from August 2007 through August 2008. 
With the exception of Site N, submerged aquatic vegetation (SAV) was not quantified as part of the vegetation assessments. However, observations regarding the presence and species composition of SAVs were noted. At Site N, SAV species present in the vegetation survey included Canadian waterweed (Elodea Canadensis ), curly-leaved pondweed (Potamogeton crispus), and coontail ( Ceratophyllum demersum). These species were observed at other sites, as was milfoil (Myriophyllum spp).

The emergent vegetation noted at the TFM beach seine sites included a mixture of species indicative of various wetland communities. Most of the sites with a moderate or high percent cover of emergent vegetation (A, B, C, and E) were dominated by creeping spikerush (Figure 4.6). This community is common throughout the overflow plain (Kunz 1994; Christy and Putera1993) and is also characterized by the presence of reed canary grass and slough sedge (Carex obnupta). Knotgrass (Paspalum distichum), a co-dominant species at Site B, is indicative of areas with seasonal inundation and summer drying (Kunz 1994). At Site $\mathrm{N}$, the emergent vegetation was dominated by swamp smartweed (Polygonum hydropiperoides) in the lower emergent zone and reed canary grass in the mid to high emergent zone. The percentage of obligate wetland species exceeded $43 \%$ of the total taxa evaluated at Sites A, B, C, E, and N (Figure 4.6).

Saplings were primarily black cottonwood (Populus balsamifera) and willow (Salix spp.); however, invasive indigo bush (Amorpha fruticosa) saplings were also present at Site A. The sapling communities were distinctive in that there was very little overlap between them, with willow saplings occurring at a slightly lower elevation ( 3.0 to $4.5 \mathrm{~m}$ ) than black cottonwood saplings (4.5 to $6.0 \mathrm{~m}$ ) (Sites D and F) (Figure 4.7 and 4.8, also see Sobocinski et al. 2008). Of note is that indigo bush often occurred at same elevation as mature willow and black cottonwood saplings, indicating the potential for this invasive species to out-compete the native vegetation in this elevation range (4.0 to $6.0 \mathrm{~m}$ ).

A well-established riparian community existed in the uplands adjacent to the beach face at each of the sites evaluated. The riparian community generally occurred at an elevation above $6.0 \mathrm{~m}$. Black cottonwood was present at all sites (except A) and was mixed with other understory species including willow species, Red-osier dogwood (Cornus stolonifera), and Oregon ash (Fraxinus latifolia). These findings are consistent with vegetative characterizations in the region made by Kunz (1994) and Christy and Putera (1993). At Site A, the riparian area was dominated by willow species and Oregon ash. At many sites, the invasive species Oregon ash and Himalayan blackberry (Rubus discolor) were present on the edge of the riparian zone and at times were a dense component of the understory. 

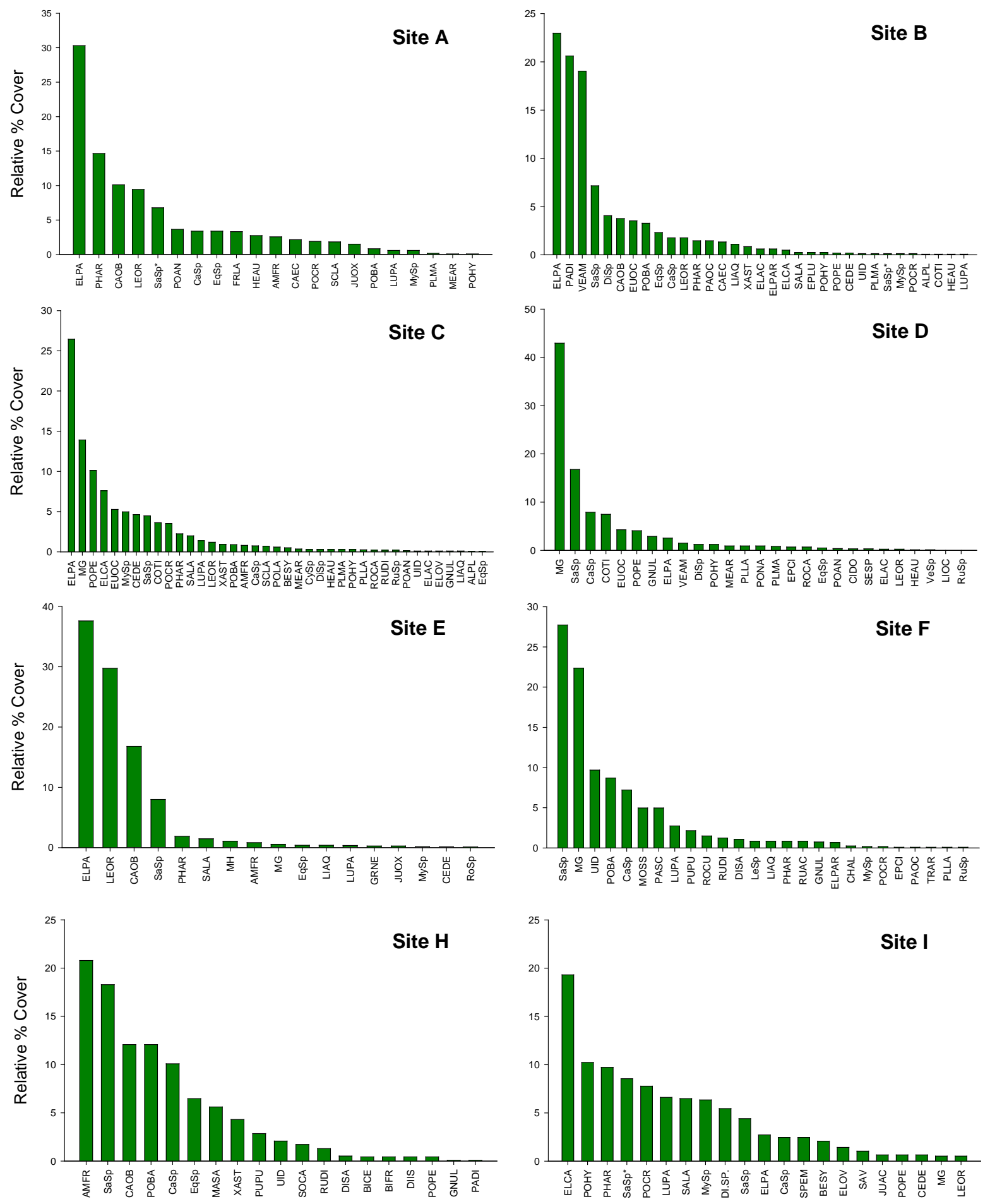

Figure 4.6. Relative Percent Cover of Vegetation from Transect Surveys at Each of the TFM Beach Seine Sites. Plant names are represented by four-letter codes that reflect the first two letters of the genus and species names (see Table 4.1 for code definitions). 
Table 4.1. Species Found to Occur at the TFM Sites. This species list was developed in conjunction with transect surveys that evaluated vegetation from the water's edge to the ordinary highwater mark.

\begin{tabular}{|c|c|c|c|c|c|}
\hline Code & Scientific Name & Common Name & Sites & $\begin{array}{l}\text { Wetland } \\
\text { Status }\end{array}$ & Native \\
\hline ALPL & Alisma plantago-aquatica & broadleaf water plantain & $\mathrm{B}, \mathrm{C}$ & OBL & yes \\
\hline AMFR & Amorpha fruticosa & indigo bush & A, C, E, H & FACW & no \\
\hline BESY & Beckmannia syzigachne & American sloughgrass & $\mathrm{C}, \mathrm{N}$ & OBL & yes \\
\hline BICE & Bidens cernua & nodding beggartick & $\mathrm{H}$ & FACW+ & yes \\
\hline BIFR & Bidens frondosa & devil's beggartick & $\mathrm{H}$ & FACW+ & yes \\
\hline $\mathrm{CaSp}$ & Carex spp. & sedge & $\mathrm{A}, \mathrm{B}, \mathrm{C}, \mathrm{D}, \mathrm{F}, \mathrm{H}, \mathrm{N}$ & -- & -- \\
\hline CAEC & Carex echinata & star sedge & A, B & NI & yes \\
\hline CAOB & Carex obnupta & slough sedge & A, B, E, H & OBL & yes \\
\hline CEDE & Ceratophyllum demersum & coontail & $\mathrm{B}, \mathrm{C}, \mathrm{E}, \mathrm{N}$ & OBL & yes \\
\hline CHAL & Chenopodium album & lamb's quarters, goosefoot & $\mathrm{F}$ & FAC & yes \\
\hline CIDO & Cicuta douglasii & western water hemlock & $\mathrm{D}$ & OBL & yes \\
\hline COTI & Coreopsis tinctoria & golden tickseed & B, C, D & FACU & yes \\
\hline CYST & Cyperus strigosus & strawcolored flatsedge & $\mathrm{C}$ & FACW & yes \\
\hline DISA & Digitaria sanguinalis & hairy crabgrass & $\mathrm{F}, \mathrm{H}$ & FACU & yes \\
\hline DIIS & Digitaria ischaemum & smooth crabgrass & $\mathrm{H}$ & FACU & no \\
\hline DiSp & Digitaria spp. & crabgrass & $\mathrm{B}, \mathrm{C}, \mathrm{D}, \mathrm{N}$ & FACU & -- \\
\hline ELAC & Eleocharis acicularis & needle spikerush & B, C, D & OBL & yes \\
\hline ELOV & Eleocharis ovata & ovate spikerush & $\mathrm{C}, \mathrm{N}$ & OBL & yes \\
\hline ELPA & Eleocharis palustris & creeping spikerush & A, B, C, D, E, N & OBL & yes \\
\hline ELPAR & Eleocharis parvula & small spikerush & $\mathrm{B}, \mathrm{F}$ & OBL & yes \\
\hline ELCA & Elodea canadensis & Canadian waterweed & $\mathrm{B}, \mathrm{C}, \mathrm{N}$ & OBL & yes \\
\hline EPCI & Epilobium ciliatum & willowherb & $\mathrm{D}, \mathrm{F}$ & FACW- & yes \\
\hline EPLU & Epilobium luteum & yellow willowherb & B & FACW & yes \\
\hline EQ.SP. & Equisetum spp. & horsetail & A, B, C, D, E, H & mixed & yes \\
\hline EUOC & Euthamia occidentalis & western goldentop & B, C, D & FACW* & yes \\
\hline FRLA & Fraxinus latifolia & Oregon ash & A & FACW & yes \\
\hline GNUL & Gnaphalium uliginosum & marsh cudweed & $\mathrm{C}, \mathrm{D}, \mathrm{F}, \mathrm{H}$ & FAC+ & no \\
\hline GRNE & Gratiola neglecta & clammy hedgehyssop & $\mathrm{E}$ & OBL & yes \\
\hline HEAU & Helenium autumnale & common sneezeweed & A, B, C, D & FACW & yes \\
\hline JUAC & Juncus acuminatus & tapertip rush & $\mathrm{N}$ & OBL & yes \\
\hline JUOX & Juncus oxymeris & pointed rush & $\mathrm{A}, \mathrm{E}$ & FACW+ & yes \\
\hline LEOR & Leersia oryzoides & rice cutgrass & A, B, C, D, E, N & OBL & yes \\
\hline
\end{tabular}


Table 4.1. (cont'd)

\begin{tabular}{|c|c|c|c|c|c|}
\hline Code & Scientific Name & Common Name & Sites & $\begin{array}{l}\text { Wetland } \\
\text { Status }\end{array}$ & Native \\
\hline LeSp & Leontodon spp. & hawkbit & $\mathrm{F}$ & -- & no \\
\hline LIAQ & Limosella aquatica & water mudwort & B, C, E, F & OBL & yes \\
\hline LIOC & Lilaeopsis occidentalis & western grasswort & $\mathrm{D}$ & OBL & yes \\
\hline LUPA & Ludwigia palustris & marsh seedbox & $A, B, C, E, F, N$ & OBL & yes \\
\hline MASA & Madia sativa & coast tarweed & $\mathrm{H}$ & UPL & yes \\
\hline MEAR & Mentha arvensis & wild mint & A, C, D & FACW- & yes \\
\hline MG & mixed grass & & $\mathrm{E}, \mathrm{F}$ & -- & -- \\
\hline MH & mixed herbs & & $\mathrm{E}, \mathrm{F}$ & -- & -- \\
\hline MYSP & Myriophyllum spp. & water milfoil & A, B, C, D, E, F & OBL & -- \\
\hline PADI & Paspalum distichum & knotgrass & B, $\mathrm{H}$ & FACW & yes \\
\hline PACA & Panicum capillare & witchgrass & $\mathrm{B}$ & FACU+ & yes \\
\hline PAOC & Panicum occidentale & western panicgrass & $\mathrm{F}$ & FACW & yes \\
\hline PASC & Panicum scribarianum & few flowered panicum & $\mathrm{F}$ & -- & -- \\
\hline DIOL & $\begin{array}{l}\text { Dichanthelium } \\
\text { oligosanthes }\end{array}$ & Scribner's rosette grass & $\mathrm{F}$ & FACU & yes \\
\hline PHAR & Phalaris arundinacea & reed canary grass & $A, B, C, E, F, N$ & FACW & yes \\
\hline TRAR & Trifolium arvense & rabbitfoot clover & $\mathrm{F}$ & UPL & no \\
\hline PLLA & Plantago lanceolata & narrowleaf plantain & C, D, F & FAC & no \\
\hline PLMA & Plantago major & common plantain & A, B, C, D & FACU+ & no \\
\hline POHY & $\begin{array}{l}\text { Polygonum } \\
\text { hydropiperoides }\end{array}$ & swamp smartweed & A, B, C, D, N & OBL & yes \\
\hline POLA & Polygonum lapathifolium & curly top knotweed & $\mathrm{C}$ & FACW & yes \\
\hline POPE & Polygonum persicaria & spotted lady's thumb & B, C, D, H, N & FACW & no \\
\hline POBA & Populus balsamifera & black cottonwood & A, B, C, F, H & FAC & yes \\
\hline POAN & $\begin{array}{l}\text { Potentilla anserina ssp. } \\
\text { pacifica }\end{array}$ & Pacific silverweed & A, C, D & OBL & yes \\
\hline POCR & Potamogeton crispus & curly leaf pondweed & A, B, C, F, N & OBL & no \\
\hline PONA & Potamogeton natans & floating-leaved pond weed & $\mathrm{D}$ & OBL & yes \\
\hline PUPU & Puccinellia pumila & dwarf alkaligrass & $\mathrm{F}, \mathrm{H}$ & FACW + & yes \\
\hline ROCA & Rorippa calycina & $\begin{array}{l}\text { Persistent-sepal yellow } \\
\text { cress }\end{array}$ & & & \\
\hline ROCU & Rorippa curvisiliqua & curvepod yellow cress & C, D, F & OBL & yes \\
\hline ROSP & Rorippa spp. & yellow cress or water cress & $\mathrm{E}$ & OBL & yes \\
\hline RUAC & Rumex acetosella & Sheep sorrel & $\mathrm{F}$ & FACU+ & no \\
\hline
\end{tabular}


Table 4.1. (cont’d)

\begin{tabular}{|c|c|c|c|c|c|}
\hline Code & Scientific Name & Common Name & Sites & $\begin{array}{l}\text { Wetland } \\
\text { Status }\end{array}$ & Native \\
\hline RUDI & Rubus discolor & Himalyan blackberry & $\mathrm{C}, \mathrm{F}, \mathrm{H}$ & FACU & no \\
\hline RUSP & Rumex spp. & dock & C, D, F & -- & -- \\
\hline SALA & Sagittaria latifolia & wapato & $\mathrm{B}, \mathrm{C}, \mathrm{E}, \mathrm{N}$ & OBL & yes \\
\hline SASP & Salix spp. & willow & $\begin{array}{c}\text { A, B, C, D, E, F, } \\
\text { H, N }\end{array}$ & -- & -- \\
\hline SCLA & Scirpus lacustris & tule & A, C & OBL & yes \\
\hline SESP & Sedum sp. & stonecrop & $\mathrm{D}$ & -- & -- \\
\hline SOCA & Solidago canadensis & Canada goldenrod & $\mathrm{H}$ & FACU & yes \\
\hline SPEM & Sparganium emersum & narrowleaf burreed & $\mathrm{N}$ & OBL & yes \\
\hline UID & unidentified & & $\mathrm{F}, \mathrm{H}$ & -- & -- \\
\hline VEAM & Veronica americana & American brooklime & B, D & OBL & yes \\
\hline VESP & Veronica sp. & speedwell & $\mathrm{D}$ & -- & -- \\
\hline XAST & Xanthium strumarium & rough cocklebur & B, C, H & FAC & yes \\
\hline \multicolumn{6}{|c|}{$\begin{array}{l}\text { FAC = facultative } \\
\text { FACU = facultative upland } \\
\text { FACW = facultative wetland } \\
\text { NI = no indicator } \\
\text { OBL = obligate } \\
\text { UPL = obligate upland } \\
--=\text { unknown }\end{array}$} \\
\hline
\end{tabular}

Plant community cover maps based on delineation of dominant vegetation communities in the field were analyzed for percent cover of emergent community types. Emergent areas were defined as the elevations between 3.0 and $4.5 \mathrm{~m}$, where emergent vegetation would be expected to develop in this hydrogeomorphic reach. The delineation of open water areas and riparian areas was outside this range of elevation and was highly variable with arbitrary boundaries because of the extensive nature of these cover classes, i.e., extending far beyond the study area boundaries. Therefore, these classes were not included in the "emergent" community type percent cover assessment. Percent cover of the emergent community types is presented in Table 4.2. 
Table 4.2. Percent Cover of Community Types Within the Emergent Zone. Data were derived from GPS field mapping of major vegetative features at the TFM sites which occurred during 2007 and 2008.

\begin{tabular}{ccccc}
\hline Site & \% Emergent Bare & \% Emergent Vegetation & \% Emergent Shrubs & \% Emergent Saplings \\
\hline A & 9.00 & 77.0 & 0.00 & 14.0 \\
B & 8.00 & 42.0 & 0.00 & 50.0 \\
C & 5.00 & 24.0 & 0.00 & 71.0 \\
D & 11.0 & 0.00 & 1.00 & 88.0 \\
E & 13.0 & 67.0 & 0.00 & 20.0 \\
F & 52.0 & 7.00 & 0.00 & 41.0 \\
H & 69.0 & 2.00 & 0.00 & 29.0 \\
N & 0.00 & 45.0 & 0.00 & 55.0 \\
\hline
\end{tabular}

Data from the GPS mapping approach indicated varying degrees of emergent vegetation coverage relative to the amount of bare ground, shrubs, and saplings. Three sites (D, F, and H) had very little emergent vegetation. At these sites, either the amount of bare area was high (Site H; 69\% bare ground), or the amount of area covered by saplings was high (Site D; 88\% saplings), or bare areas and sapling cover were both relatively high (Site F; $52 \%$ bare ground and $41 \%$ saplings). Moderate coverage of emergent vegetation was noted at Sites B, C, and N, where a substantive amount of saplings accounted for the majority of vegetation coverage. Sites $\mathrm{A}$ and $\mathrm{E}$ had the largest proportion of emergent vegetation compared with the other six sites. Sites A and E were characterized as maintaining areas of fringing emergent vegetation along gently sloping beaches adjacent to off-channel island channels.

The percent similarity index of emergent vegetation indicates Sites $\mathrm{C}$ and B were most similar with regard to number of vegetative taxa shared by the two sites ( $71 \%$ similar). The similarity index exceeded $50 \%$ most frequently for Sites A and C. Vegetation composition at Sites F and H shared the least degree of similarity with other sites (similarity ranged from $24 \%$ to $40 \%$ ) (Table 4.3 ). 


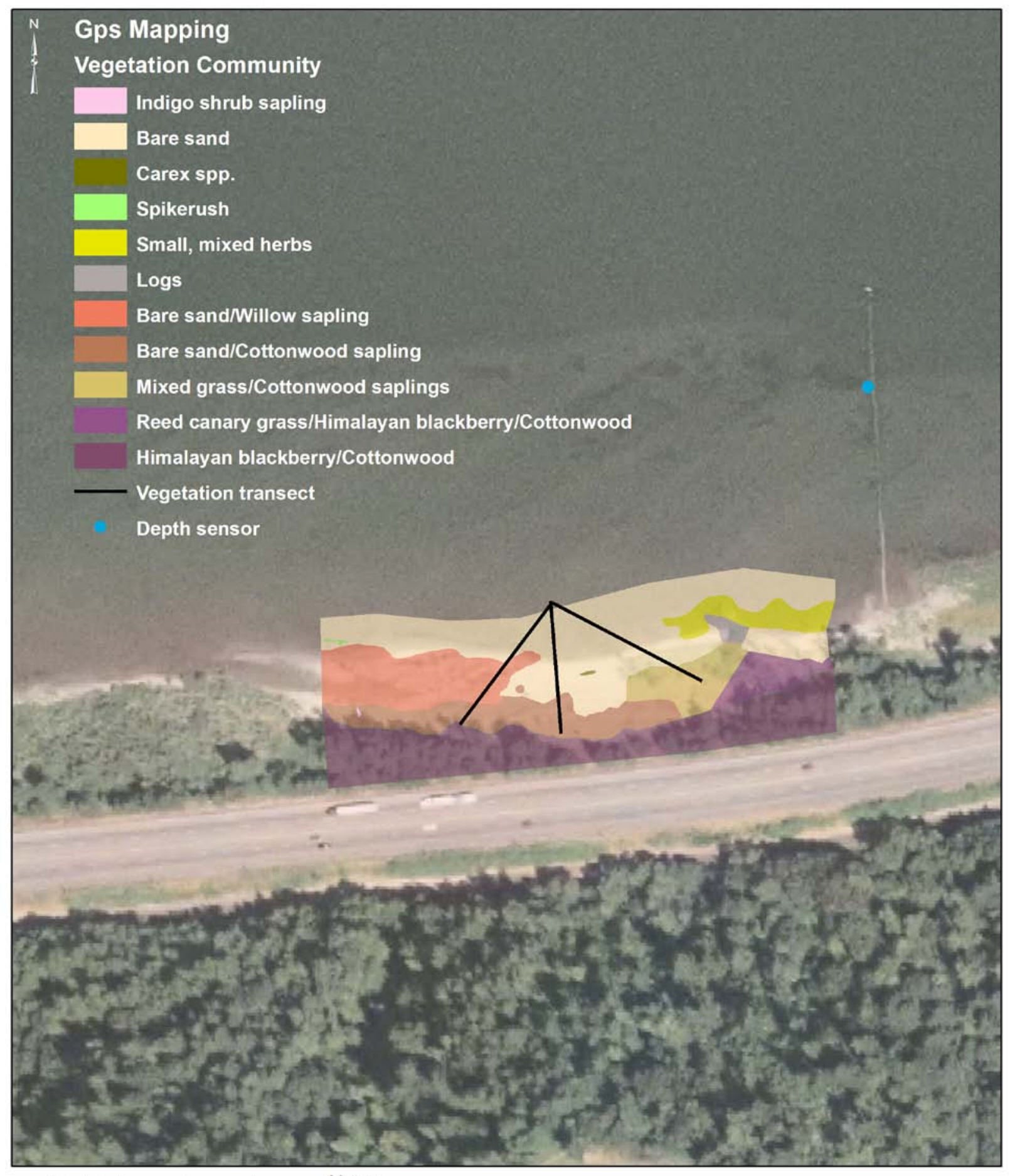

\begin{tabular}{llllll}
\hline & & & & & \\
0 & 15 & 30 & 60 & 90 & 120
\end{tabular}

Figure 4.7. Vegetation Map for Site F Adjacent to Highway 84. Solid black lines indicate the location of the vegetation transects used for estimating percent cover. 


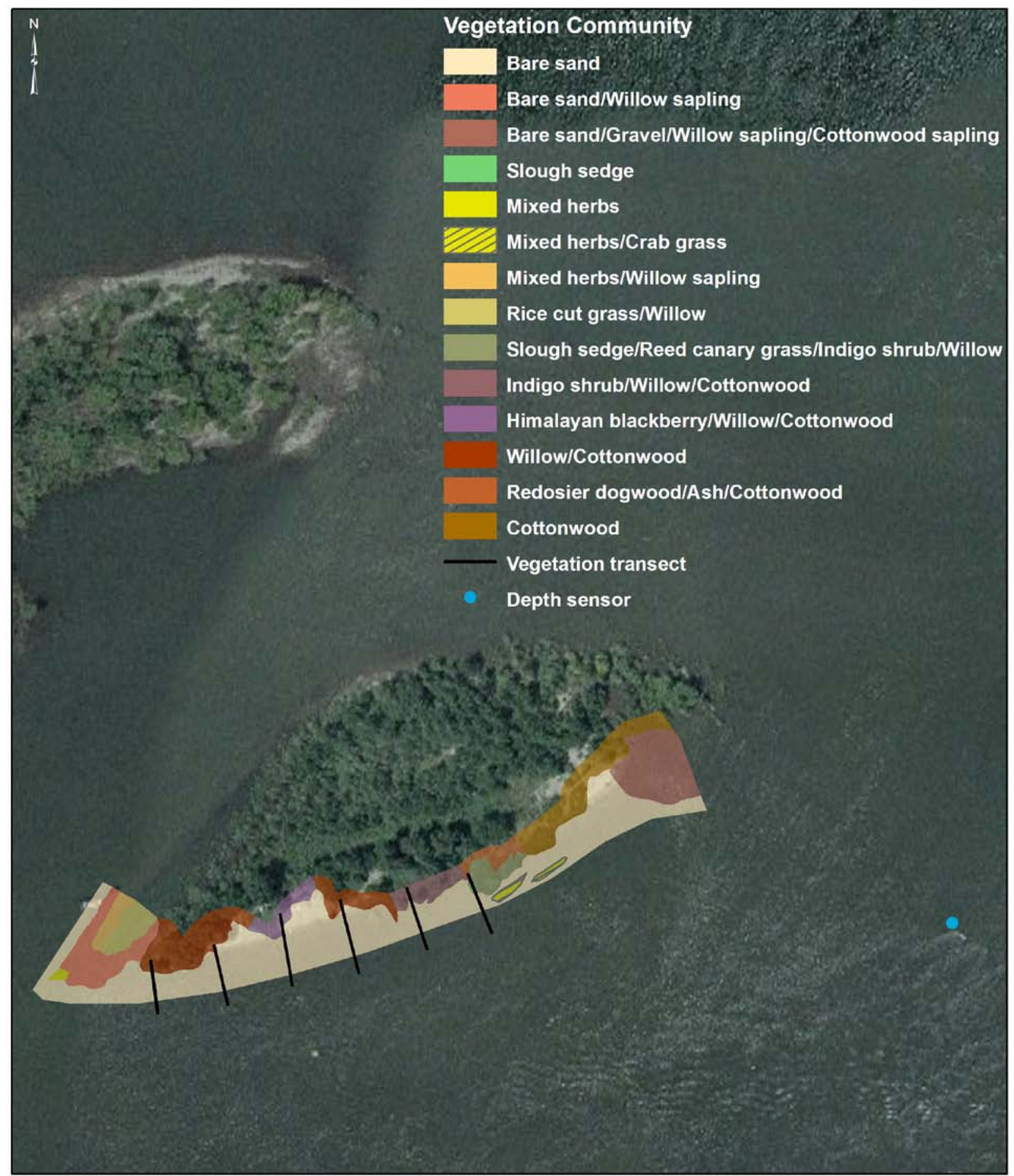

\begin{tabular}{llllll}
\hline & 15 & 30 & 60 & 90 & 120
\end{tabular}

Figure 4.8. Vegetation Map for Site H McGuire Island. Solid black lines indicate the location of the vegetation transects used for estimating percent cover. 
Table 4.3. Percent Similarity of Vegetative Species at the TFM Sampling Sites

\begin{tabular}{lllllllll}
\hline & A & B & C & D & E & F & H & N \\
\hline A & & & & & & & \\
B & 58 & & & & & & \\
C & 59 & 71 & & & & & \\
D & 43 & 49 & 60 & & & & \\
E & 56 & 48 & 42 & 20 & & & \\
F & 32 & 33 & 40 & 24 & 26 & & \\
H & 31 & 33 & 33 & 23 & 24 & 34 & \\
N & 46 & 57 & 58 & 32 & 48 & 29 & 17 \\
\hline
\end{tabular}

\subsection{Fish Characteristics}

The following sections describe the results of fish characterization efforts related to direct capture, ancillary data, genetics, diets, and acoustic telemetry.

\subsubsection{Direct Capture}

During the June 2007 through December 2008 sampling period, we performed 237 beach seine hauls and encountered over 100,000 fish. The catch was comprised of 29 species. The total catch was greater during 2008; however, the 2008 effort persisted for 12 months (Figure 4.9), while the 2007 effort only included 7 months of sampling (Figure 4.10). The diversity of taxa was greatest during summer and winter months (Table 4.4). Threespine stickleback (Gasterosteus aculeatus), peamouth chub (Mylocheilus caurinus), banded killifish (Fundulus diaphanus), and Chinook salmon were captured at all nine sites (Table 4.4). Non-native fishes comprised approximately $46 \%$ of the taxa sampled during $2007-$ 2008 and were most predominant in shallow off-channel sites near Chatham and Gary islands (Sites B and E), and within the historic Sandy River delta (Sites C and N) (Table 4.5). The following section describes the structure of the fish community at the sampling sites, including the ubiquitous and salmon species encountered. 
Table 4.4. Temporal Trends in Species Composition. The $\sqrt{ }$ denotes species were collected during the corresponding sampling period. A blank means the species was not collected.

\begin{tabular}{|c|c|c|c|c|c|c|c|c|c|c|c|c|c|c|c|c|c|c|c|c|c|c|c|c|c|}
\hline \multirow[b]{2}{*}{ Taxon } & \multirow[b]{2}{*}{ Common Name } & \multicolumn{2}{|c|}{ January } & \multicolumn{2}{|c|}{ February } & \multicolumn{2}{|c|}{ March } & \multicolumn{2}{|c|}{ April } & \multicolumn{2}{|c|}{ May } & \multicolumn{2}{|c|}{ June } & \multicolumn{2}{|c|}{ July } & \multicolumn{2}{|c|}{ August } & \multicolumn{2}{|c|}{ September } & \multicolumn{2}{|c|}{ October } & \multicolumn{2}{|c|}{ November } & \multicolumn{2}{|c|}{ December } \\
\hline & & 2007 & 2008 & 2007 & 2008 & 2007 & 2008 & 2007 & 2008 & 2007 & 2008 & $2007^{(a)}$ & 2008 & 2007 & 2008 & 2007 & 2008 & 2007 & 2008 & 2007 & 2008 & 2007 & 2008 & 2007 & 2008 \\
\hline Acipenser transmontanus & white sturgeon & 0 & & 0 & & 0 & & 0 & & 0 & & $\checkmark$ & & & & & & & & & & & & & \\
\hline Acrocheilus alutaceus & chiselmouth & o & & o & & 0 & & 0 & & 0 & & $\sqrt{ }$ & $\checkmark$ & & & & & & & & & & & & \\
\hline Actinopterygii & unidentified larvae & 0 & & 0 & & 0 & & 0 & V & 0 & & & & & V & & v & & & & & & & & \\
\hline Alosa sapidissima & American shad ${ }^{(b)}$ & o & & 0 & & 0 & & o & & o & & & & & & $\sqrt{ }$ & $\sqrt{ }$ & $\sqrt{ }$ & $\sqrt{ }$ & $\sqrt{ }$ & $\sqrt{ }$ & $\sqrt{ }$ & $\sqrt{ }$ & & \\
\hline Ameiurus nebulosus & brown bullhead ${ }^{(\mathrm{b})}$ & 0 & & 0 & & 0 & & 0 & & 0 & & & & & $\sqrt{ }$ & & & $\checkmark$ & & & $\sqrt{ }$ & $\sqrt{ }$ & & & \\
\hline Carassius auratus & goldfish $^{(\mathfrak{b})}$ & 0 & $\sqrt{ }$ & 0 & & 0 & & 0 & & 0 & & & & & & & & & & & $\sqrt{ }$ & & $\checkmark$ & & $\checkmark$ \\
\hline Catostomus macrocheilus & largescale sucker & o & & 0 & & 0 & & o & & 0 & $\checkmark$ & v & $\checkmark$ & $\sqrt{ }$ & V & V & & $\checkmark$ & $\checkmark$ & & & & & & $\checkmark$ \\
\hline Catostomus spp. & unidentified sucker & o & $\sqrt{ }$ & 0 & $\sqrt{ }$ & 0 & $\checkmark$ & 0 & & 0 & & $\sqrt{ }$ & & & & $\sqrt{ }$ & V & & $\sqrt{ }$ & $\sqrt{ }$ & $\sqrt{ }$ & $\sqrt{ }$ & $\sqrt{ }$ & V & V \\
\hline Cottus asper & prickly sculpin & 0 & & 0 & & 0 & & 0 & & 0 & & $\checkmark$ & & & & & & 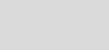 & $\checkmark$ & & $\sqrt{ }$ & & & & \\
\hline Cottus spp. & freshwater sculpin & o & & o & $\sqrt{ }$ & o & $\sqrt{ }$ & 0 & $\sqrt{ }$ & o & & $\sqrt{ }$ & & $\sqrt{ }$ & $\sqrt{ }$ & $\sqrt{ }$ & $\sqrt{ }$ & $\sqrt{ }$ & $\sqrt{ }$ & $\sqrt{ }$ & $\sqrt{ }$ & $\sqrt{ }$ & $\checkmark$ & $\sqrt{ }$ & $\sqrt{ }$ \\
\hline Cyprinidae & unidentified minnow & o & & 0 & & 0 & & 0 & & 0 & & & & & & & & & & & & $\checkmark$ & & & \\
\hline Cyprinus carpio & ${\text { common } \text { carp }^{(b)}}^{(b)}$ & o & & o & & 0 & & o & & o & & & 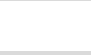 & $\sqrt{ }$ & $\sqrt{ }$ & $\sqrt{ }$ & $\sqrt{ }$ & $\sqrt{ }$ & $\sqrt{ }$ & & & & $\checkmark$ & & $\sqrt{ }$ \\
\hline Fundulus diaphanus & banded killifish $^{(b)}$ & 0 & $\sqrt{ }$ & 0 & $\sqrt{ }$ & 0 & $\checkmark$ & 0 & $\sqrt{ }$ & 0 & $\sqrt{ }$ & $\sqrt{ }$ & $\sqrt{ }$ & $\sqrt{ }$ & $\sqrt{ }$ & $\sqrt{ }$ & $\sqrt{ }$ & $\checkmark$ & $\sqrt{ }$ & $\sqrt{ }$ & $\checkmark$ & $\checkmark$ & $\checkmark$ & $\sqrt{ }$ & $\sqrt{ }$ \\
\hline Gasterosteus aculeatus & threespine stickleback & o & $\sqrt{ }$ & 0 & $\sqrt{ }$ & 0 & $\sqrt{ }$ & 0 & $\sqrt{ }$ & o & $\sqrt{ }$ & $\sqrt{ }$ & $\sqrt{ }$ & $\sqrt{ }$ & $\sqrt{ }$ & $\sqrt{ }$ & $\sqrt{ }$ & $\sqrt{ }$ & $\sqrt{ }$ & $\sqrt{ }$ & $\sqrt{ }$ & $\sqrt{ }$ & $\checkmark$ & $\sqrt{ }$ & $\checkmark$ \\
\hline Ictaluridae & unidentified catfish $^{(b)}$ & 0 & & 0 & & 0 & & 0 & & 0 & & & & & & & & & & & & & $\checkmark$ & & $\checkmark$ \\
\hline Lepomis cyanellus & green sunfish $^{(b)}$ & o & & o & & o & & o & & 0 & & & & $\sqrt{ }$ & & & & & & & & & & & \\
\hline Lepomis gibbosus & pumpkinseed $^{(b)}$ & 0 & $\sqrt{ }$ & 0 & $\sqrt{ }$ & 0 & $\sqrt{ }$ & 0 & $\sqrt{ }$ & 0 & $\sqrt{ }$ & $\sqrt{ }$ & 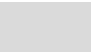 & $\sqrt{ }$ & $\sqrt{ }$ & $\sqrt{ }$ & $\sqrt{ }$ & $\sqrt{ }$ & $\sqrt{ }$ & $\sqrt{ }$ & $\sqrt{ }$ & $\checkmark$ & $\sqrt{ }$ & $\sqrt{ }$ & $\sqrt{ }$ \\
\hline Lepomis macrochirus & bluegill $^{(b)}$ & 0 & $\sqrt{ }$ & 0 & $\sqrt{ }$ & 0 & & 0 & $\sqrt{ }$ & 0 & v & $\sqrt{ }$ & $\sqrt{ }$ & $\sqrt{ }$ & $\sqrt{ }$ & $\sqrt{ }$ & $\sqrt{ }$ & $\sqrt{ }$ & $\sqrt{ }$ & $\sqrt{ }$ & $\sqrt{ }$ & $\sqrt{ }$ & 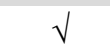 & $\sqrt{ }$ & $\checkmark$ \\
\hline Lepomis spp. & unidentified sunfish ${ }^{(b)}$ & 0 & & 0 & & 0 & & 0 & & 0 & & & & & & & & & & & $\sqrt{ }$ & & $\checkmark$ & & $\checkmark$ \\
\hline Micropterus dolomieu & smallmouth bass ${ }^{(b)}$ & o & & o & $\sqrt{ }$ & 0 & & o & & o & $\sqrt{ }$ & $\sqrt{ }$ & $\checkmark$ & $\sqrt{ }$ & $\sqrt{ }$ & $\checkmark$ & $\sqrt{ }$ & $\sqrt{ }$ & $\sqrt{ }$ & & $\sqrt{ }$ & $\sqrt{ }$ & $\sqrt{ }$ & $\sqrt{ }$ & $\sqrt{ }$ \\
\hline Micropterus salmoides & largemouth bass ${ }^{(\mathrm{b})}$ & 0 & $\sqrt{ }$ & 0 & & 0 & & 0 & $\sqrt{ }$ & 0 & & $\sqrt{ }$ & & $\sqrt{ }$ & $\sqrt{ }$ & $\sqrt{ }$ & $\sqrt{ }$ & $\sqrt{ }$ & $\sqrt{ }$ & $\sqrt{ }$ & $\sqrt{ }$ & $\sqrt{ }$ & $\sqrt{ }$ & $\sqrt{ }$ & $\sqrt{ }$ \\
\hline Micropterus spp. & unidentified bass $^{(b)}$ & o & & 0 & & 0 & & 0 & & o & & & & $\sqrt{ }$ & $\sqrt{ }$ & & & & & & & & & & \\
\hline Mylocheilus caurinus & peamouth chub & 0 & $\sqrt{ }$ & 0 & $\sqrt{ }$ & 0 & $\sqrt{ }$ & o & $\sqrt{ }$ & 0 & $\sqrt{ }$ & $\sqrt{ }$ & $\sqrt{ }$ & $\sqrt{ }$ & $\sqrt{ }$ & $\sqrt{ }$ & $\sqrt{ }$ & $\sqrt{ }$ & $\sqrt{ }$ & $\sqrt{ }$ & $\sqrt{ }$ & $\sqrt{ }$ & $\sqrt{ }$ & $\sqrt{ }$ & $\sqrt{ }$ \\
\hline Oncorhynchus keta & chum salmon & o & & o & & 0 & & 0 & $\sqrt{ }$ & o & & & & & & & & & & & & & & & \\
\hline Oncorhynchus kisutch & coho salmon & 0 & v & 0 & $\checkmark$ & 0 & $\checkmark$ & 0 & $\sqrt{ }$ & 0 & $\checkmark$ & $\sqrt{ }$ & $\checkmark$ & & V & & & & & & & $\checkmark$ & $\checkmark$ & $\checkmark$ & $\sqrt{ }$ \\
\hline Oncorhynchus mykiss & steelhead trout & o & & o & & o & & o & & o & $\sqrt{ }$ & & & & & & & & & & & & & & \\
\hline Oncorhynchus spp. & unidentified trout & 0 & & 0 & & 0 & & 0 & & 0 & & & & & $\sqrt{ }$ & & & & & & & & & & \\
\hline Oncorhynchus tshawytscha & Chinook salmon & o & & o & & 0 & $\sqrt{ }$ & o & $\sqrt{ }$ & 0 & $\sqrt{ }$ & $\sqrt{ }$ & $\checkmark$ & $\sqrt{ }$ & $\sqrt{ }$ & $\sqrt{ }$ & $\sqrt{ }$ & & $\sqrt{ }$ & & $\sqrt{ }$ & $\sqrt{ }$ & $\checkmark$ & $\sqrt{ }$ & $\sqrt{ }$ \\
\hline Perca flavescens & yellow perch $^{(\mathrm{b})}$ & o & & 0 & $\checkmark$ & 0 & & 0 & & 0 & & & & & $\sqrt{ }$ & & $\sqrt{ }$ & & $\sqrt{ }$ & & $\sqrt{ }$ & $\checkmark$ & $\sqrt{ }$ & $\sqrt{ }$ & v \\
\hline Percidae & unidentified perch ${ }^{(b)}$ & 0 & & o & & o & & o & & $\mathrm{o}$ & & & & & & & & & & & & & v & & \\
\hline Percopsis transmontana & sandroller & 0 & & 0 & & 0 & & 0 & & 0 & & & & & & & & & & & $\sqrt{ }$ & & & & $\sqrt{ }$ \\
\hline Platichthys stellatus & starry flounder & o & & o & $\sqrt{ }$ & o & $\sqrt{ }$ & o & $\sqrt{ }$ & o & & $\sqrt{ }$ & & & $\sqrt{ }$ & & $\sqrt{ }$ & & $\sqrt{ }$ & & $\sqrt{ }$ & & $\sqrt{ }$ & $\sqrt{ }$ & $\sqrt{ }$ \\
\hline Pomoxis spp. & crappie $^{(b)}$ & 0 & $\checkmark$ & 0 & $\mathrm{v}$ & 0 & & 0 & $\sqrt{ }$ & 0 & $\checkmark$ & & & $\sqrt{ }$ & 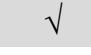 & $\checkmark$ & & $\checkmark$ & $\sqrt{ }$ & V & V & 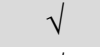 & & & \\
\hline Prosopium williamsoni & mountain whitefish & 0 & & 0 & & 0 & & 0 & $\sqrt{ }$ & 0 & $\sqrt{ }$ & $\sqrt{ }$ & $\checkmark$ & & & & & & & & & $\sqrt{ }$ & & & \\
\hline Ptychocheilus oregonensis & Northern pikeminnow & o & $\checkmark$ & 0 & $\sqrt{ }$ & 0 & 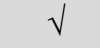 & 0 & $\sqrt{ }$ & 0 & $\checkmark$ & $\sqrt{ }$ & $\checkmark$ & $\sqrt{ }$ & V & v & $\checkmark$ & $\checkmark$ & $\checkmark$ & V & V & $\sqrt{ }$ & $\checkmark$ & $\sqrt{ }$ & $\checkmark$ \\
\hline Rhinichthys spp. & dace & o & $\sqrt{ }$ & 0 & & 0 & & 0 & & o & & $\sqrt{ }$ & & & & & & & & & & $\sqrt{ }$ & $\sqrt{ }$ & $\sqrt{ }$ & $\sqrt{ }$ \\
\hline Rhinogobius brunneus & Amur goby ${ }^{(\mathfrak{)})}$ & 0 & & 0 & & 0 & & 0 & & 0 & & $\sqrt{ }$ & & & v & & $\checkmark$ & & & V & & & & & \\
\hline Richardsonius balteatus & redside shiner & 0 & & 0 & $\sqrt{ }$ & 0 & & 0 & & 0 & $\sqrt{ }$ & $\sqrt{ }$ & $\sqrt{ }$ & & $\sqrt{ }$ & & $\sqrt{ }$ & & $\sqrt{ }$ & & & & & & \\
\hline $\begin{array}{l}\mathrm{o}=\text { No sampling conductec } \\
\text { (a) Includes two separate } \mathrm{s} \\
\text { (b) Non-native taxa }\end{array}$ & 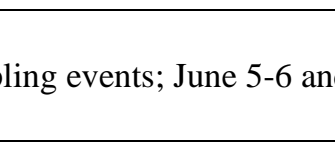 & & & & & & & & & & & & & & & & & & & & & & & & \\
\hline
\end{tabular}


Table 4.5. Spatial Trends in Species Composition. The $\sqrt{ }$ denotes species were collected during the corresponding sampling period.

\begin{tabular}{|c|c|c|c|c|c|c|c|c|c|c|c|c|c|c|c|c|c|c|c|}
\hline \multirow[b]{2}{*}{ Taxon } & \multirow[b]{2}{*}{ Common Name } & \multicolumn{2}{|c|}{ Site A } & \multicolumn{2}{|c|}{ Site B } & \multicolumn{2}{|c|}{ Site C } & \multicolumn{2}{|c|}{ Site D } & \multicolumn{2}{|c|}{ Site E } & \multicolumn{2}{|c|}{ Site F } & \multicolumn{2}{|c|}{ Site H } & \multicolumn{2}{|c|}{ Site I } & \multicolumn{2}{|c|}{ Site N } \\
\hline & & ‘07 & ‘08 & ‘07 & ‘08 & ‘07 & ‘08 & ‘07 & ‘08 & ‘07 & ‘08 & ‘07 & ‘08 & ‘07 & ‘08 & ‘07 & ‘08 & ‘ 07 & ‘08 \\
\hline Acipenser transmontanus & white sturgeon & & & & & & & $\sqrt{ }$ & & & & 0 & & 0 & & 0 & & & \\
\hline Acrocheilus alutaceus & chiselmouth & & & & & & & $\sqrt{ }$ & $\sqrt{ }$ & & & o & & o & & o & & $\sqrt{ }$ & \\
\hline Actinopterygii & unidentified larvae & & $\sqrt{ }$ & & $\sqrt{ }$ & & $\sqrt{ }$ & & & & $\sqrt{ }$ & o & & 0 & & 0 & & & $\sqrt{ }$ \\
\hline Alosa sapidissima & American shad ${ }^{(a)}$ & $\sqrt{ }$ & $\sqrt{ }$ & $\sqrt{ }$ & $\sqrt{ }$ & & & $\sqrt{ }$ & $\sqrt{ }$ & $\sqrt{ }$ & $\sqrt{ }$ & o & $\sqrt{ }$ & o & $\sqrt{ }$ & o & $\sqrt{ }$ & & \\
\hline Ameiurus nebulosus & brown bullhead $^{(a)}$ & & $\sqrt{ }$ & $\sqrt{ }$ & & $\sqrt{ }$ & & & & & $\sqrt{ }$ & 0 & & 0 & & 0 & & $\sqrt{ }$ & $\sqrt{ }$ \\
\hline Carassius auratus & goldfish $^{(a)}$ & & & & $\sqrt{ }$ & & & & & & & o & & o & $\sqrt{ }$ & o & & & $\sqrt{ }$ \\
\hline Catostomus macrocheilus & largescale sucker & $\sqrt{ }$ & $\sqrt{ }$ & $\sqrt{ }$ & $\sqrt{ }$ & $\sqrt{ }$ & $\sqrt{ }$ & $\sqrt{ }$ & $\sqrt{ }$ & & $\sqrt{ }$ & o & & o & & 0 & & $\sqrt{ }$ & $\sqrt{ }$ \\
\hline Catostomus spp. & unidentified sucker & & $\sqrt{ }$ & $\sqrt{ }$ & $\sqrt{ }$ & $\sqrt{ }$ & $\sqrt{ }$ & $\sqrt{ }$ & $\sqrt{ }$ & & $\sqrt{ }$ & o & $\sqrt{ }$ & 0 & $\sqrt{ }$ & o & & $\sqrt{ }$ & $\sqrt{ }$ \\
\hline Cottus asper & prickly sculpin & & & & $\sqrt{ }$ & & & $\sqrt{ }$ & & & & 0 & & 0 & & 0 & & & \\
\hline Cottus spp. & freshwater sculpin & $\sqrt{ }$ & $\sqrt{ }$ & $\sqrt{ }$ & $\sqrt{ }$ & $\sqrt{ }$ & $\sqrt{ }$ & & $\sqrt{ }$ & $\sqrt{ }$ & $\sqrt{ }$ & o & $\sqrt{ }$ & 0 & $\sqrt{ }$ & 0 & & $\sqrt{ }$ & $\sqrt{ }$ \\
\hline Cyprinidae & unidentified minnow & & & & & $\sqrt{ }$ & & $\sqrt{ }$ & & & & o & & o & & 0 & & & \\
\hline Cyprinus carpio & common carp $^{(\mathrm{a})}$ & & $\sqrt{ }$ & $\sqrt{ }$ & $\sqrt{ }$ & $\sqrt{ }$ & $\sqrt{ }$ & & & & $\sqrt{ }$ & o & & o & & o & & $\sqrt{ }$ & $\sqrt{ }$ \\
\hline Fundulus diaphanus & banded killifish $^{(a)}$ & $\sqrt{ }$ & $\sqrt{ }$ & $\sqrt{ }$ & $\sqrt{ }$ & $\sqrt{ }$ & $\sqrt{ }$ & $\sqrt{ }$ & $\sqrt{ }$ & $\sqrt{ }$ & $\sqrt{ }$ & 0 & $\sqrt{ }$ & 0 & $\sqrt{ }$ & 0 & $\sqrt{ }$ & $\sqrt{ }$ & $\sqrt{ }$ \\
\hline Gasterosteus aculeatus & threespine stickleback & $\sqrt{ }$ & $\sqrt{ }$ & $\sqrt{ }$ & $\sqrt{ }$ & $\sqrt{ }$ & $\sqrt{ }$ & $\sqrt{ }$ & $\sqrt{ }$ & $\sqrt{ }$ & $\sqrt{ }$ & o & $\sqrt{ }$ & o & $\sqrt{ }$ & 0 & $\sqrt{ }$ & $\sqrt{ }$ & $\sqrt{ }$ \\
\hline Ictaluridae & unidentified catfish $^{(a)}$ & & & & & & $\sqrt{ }$ & & & & & 0 & & 0 & & o & & & \\
\hline Lepomis cyanellus & green sunfish $^{(\mathrm{a})}$ & & & & & $\sqrt{ }$ & & & & & & o & & o & & o & & & \\
\hline Lepomis gibbosus & pumpkinseed $^{(\mathrm{a})}$ & & $\sqrt{ }$ & $\sqrt{ }$ & $\sqrt{ }$ & & $\sqrt{ }$ & & $\sqrt{ }$ & & $\sqrt{ }$ & 0 & & 0 & $\sqrt{ }$ & 0 & & $\sqrt{ }$ & $\sqrt{ }$ \\
\hline Lepomis macrochirus & bluegill $^{(\mathrm{a})}$ & $\sqrt{ }$ & $\sqrt{ }$ & $\sqrt{ }$ & $\sqrt{ }$ & $\sqrt{ }$ & $\sqrt{ }$ & $\sqrt{ }$ & & $\sqrt{ }$ & $\sqrt{ }$ & o & & o & $\sqrt{ }$ & 0 & & $\sqrt{ }$ & $\sqrt{ }$ \\
\hline Lepomis spp. & unidentified sunfish ${ }^{(a)}$ & & & & $\sqrt{ }$ & & $\sqrt{ }$ & & & & $\sqrt{ }$ & 0 & & o & & 0 & & & $\sqrt{ }$ \\
\hline Micropterus dolomieu & smallmouth bass $^{(\mathrm{a})}$ & $\sqrt{ }$ & $\sqrt{ }$ & $\sqrt{ }$ & $\sqrt{ }$ & $\sqrt{ }$ & $\sqrt{ }$ & $\sqrt{ }$ & $\sqrt{ }$ & $\sqrt{ }$ & $\sqrt{ }$ & o & $\sqrt{ }$ & 0 & $\sqrt{ }$ & o & & $\sqrt{ }$ & $\sqrt{ }$ \\
\hline Micropterus salmoides & largemouth bass ${ }^{(a)}$ & $\sqrt{ }$ & $\sqrt{ }$ & $\sqrt{ }$ & $\sqrt{ }$ & $\sqrt{ }$ & $\sqrt{ }$ & $\sqrt{ }$ & & $\sqrt{ }$ & $\sqrt{ }$ & 0 & & 0 & & 0 & & $\sqrt{ }$ & $\sqrt{ }$ \\
\hline
\end{tabular}


Table 4.5. (cont'd)

\begin{tabular}{|c|c|c|c|c|c|c|c|c|c|c|c|c|c|c|c|c|c|c|c|}
\hline \multirow[b]{2}{*}{ Taxon } & \multirow[b]{2}{*}{ Common Name } & \multicolumn{2}{|c|}{ Site A } & \multicolumn{2}{|c|}{ Site B } & \multicolumn{2}{|c|}{ Site C } & \multicolumn{2}{|c|}{ Site D } & \multicolumn{2}{|c|}{ Site E } & \multicolumn{2}{|c|}{ Site F } & \multicolumn{2}{|c|}{ Site $\mathrm{H}$} & \multicolumn{2}{|c|}{ Site I } & \multicolumn{2}{|c|}{ Site N } \\
\hline & & ‘ 07 & ‘ 08 & ‘ 07 & ‘08 & ‘07 & ‘08 & ‘07 & ‘08 & ‘07 & '08 & ‘07 & ‘ 08 & ‘07 & '08 & ‘07 & ‘08 & ‘07 & ‘08 \\
\hline Micropterus spp. & unidentified bass $^{(\mathrm{a})}$ & & $\sqrt{ }$ & & & $\sqrt{ }$ & & & & & & 0 & & 0 & & 0 & & & \\
\hline Mylocheilus caurinus & peamouth chub & $\sqrt{ }$ & $\sqrt{ }$ & $\sqrt{ }$ & $\sqrt{ }$ & $\sqrt{ }$ & $\sqrt{ }$ & $\sqrt{ }$ & $\sqrt{ }$ & $\sqrt{ }$ & $\sqrt{ }$ & o & $\sqrt{ }$ & o & $\sqrt{ }$ & o & $\sqrt{ }$ & $\sqrt{ }$ & $\sqrt{ }$ \\
\hline Oncorhynchus keta & chum salmon & & $\sqrt{ }$ & & $\sqrt{ }$ & & $\sqrt{ }$ & & & & $\sqrt{ }$ & 0 & & 0 & & o & & & \\
\hline Oncorhynchus kisutch & coho salmon & & $\sqrt{ }$ & $\sqrt{ }$ & $\sqrt{ }$ & $\sqrt{ }$ & $\sqrt{ }$ & & $\sqrt{ }$ & $\sqrt{ }$ & $\sqrt{ }$ & o & & o & $\sqrt{ }$ & o & & $\sqrt{ }$ & $\sqrt{ }$ \\
\hline Oncorhynchus mykiss & steelhead trout & & & & & & & & & & $\sqrt{ }$ & 0 & & 0 & & 0 & & & \\
\hline Oncorhynchus spp. & unidentified trout & & $\sqrt{ }$ & & & & & & & & & o & & o & & o & & & \\
\hline Oncorhynchus tshawytscha & Chinook salmon & $\sqrt{ }$ & $\sqrt{ }$ & $\sqrt{ }$ & $\sqrt{ }$ & $\sqrt{ }$ & $\sqrt{ }$ & $\sqrt{ }$ & $\sqrt{ }$ & $\sqrt{ }$ & $\sqrt{ }$ & 0 & $\sqrt{ }$ & o & $\sqrt{ }$ & 0 & $\sqrt{ }$ & $\sqrt{ }$ & $\sqrt{ }$ \\
\hline Perca flavescens & yellow perch ${ }^{(a)}$ & & $\sqrt{ }$ & $\sqrt{ }$ & $\sqrt{ }$ & $\sqrt{ }$ & & & & & $\sqrt{ }$ & 0 & & o & $\sqrt{ }$ & o & & & \\
\hline Percidae & unidentified perch ${ }^{(a)}$ & & & & & & & & & & & 0 & & 0 & $\sqrt{ }$ & 0 & & & \\
\hline Percopsis transmontana & sandroller & & & & $\sqrt{ }$ & & & & $\sqrt{ }$ & & & o & & o & & o & & & \\
\hline Platichthys stellatus & starry flounder & $\sqrt{ }$ & $\sqrt{ }$ & $\sqrt{ }$ & $\sqrt{ }$ & $\sqrt{ }$ & $\sqrt{ }$ & $\sqrt{ }$ & $\sqrt{ }$ & & $\sqrt{ }$ & 0 & $\sqrt{ }$ & o & $\sqrt{ }$ & 0 & $\sqrt{ }$ & & \\
\hline Pomoxis spp. & crappie $^{(a)}$ & & & $\sqrt{ }$ & $\sqrt{ }$ & & & & & & $\sqrt{ }$ & 0 & & o & & o & & $\sqrt{ }$ & $\sqrt{ }$ \\
\hline Prosopium williamsoni & mountain whitefish & $\sqrt{ }$ & & $\sqrt{ }$ & & & & $\sqrt{ }$ & $\sqrt{ }$ & & $\sqrt{ }$ & 0 & & 0 & & 0 & & & \\
\hline Ptychocheilus oregonensis & Northern pikeminnow & $\sqrt{ }$ & $\sqrt{ }$ & $\sqrt{ }$ & $\sqrt{ }$ & $\sqrt{ }$ & $\sqrt{ }$ & $\sqrt{ }$ & $\sqrt{ }$ & $\sqrt{ }$ & $\sqrt{ }$ & o & $\sqrt{ }$ & o & $\sqrt{ }$ & o & & $\sqrt{ }$ & $\sqrt{ }$ \\
\hline Rhinichthys spp. & dace & & & $\sqrt{ }$ & & $\sqrt{ }$ & $\sqrt{ }$ & & $\sqrt{ }$ & $\sqrt{ }$ & & 0 & & 0 & & 0 & & $\sqrt{ }$ & $\sqrt{ }$ \\
\hline Rhinogobius brunneus & Amur goby $^{(a)}$ & & & & & & & & & & & o & & o & & o & & $\sqrt{ }$ & $\sqrt{ }$ \\
\hline Richardsonius balteatus & redside shiner & & $\sqrt{ }$ & $\sqrt{ }$ & $\sqrt{ }$ & $\sqrt{ }$ & $\sqrt{ }$ & $\sqrt{ }$ & $\sqrt{ }$ & & $\sqrt{ }$ & o & & 0 & & 0 & & & $\sqrt{ }$ \\
\hline
\end{tabular}

$\mathrm{o}=$ No sampling conducted

(a) Non-native taxa 


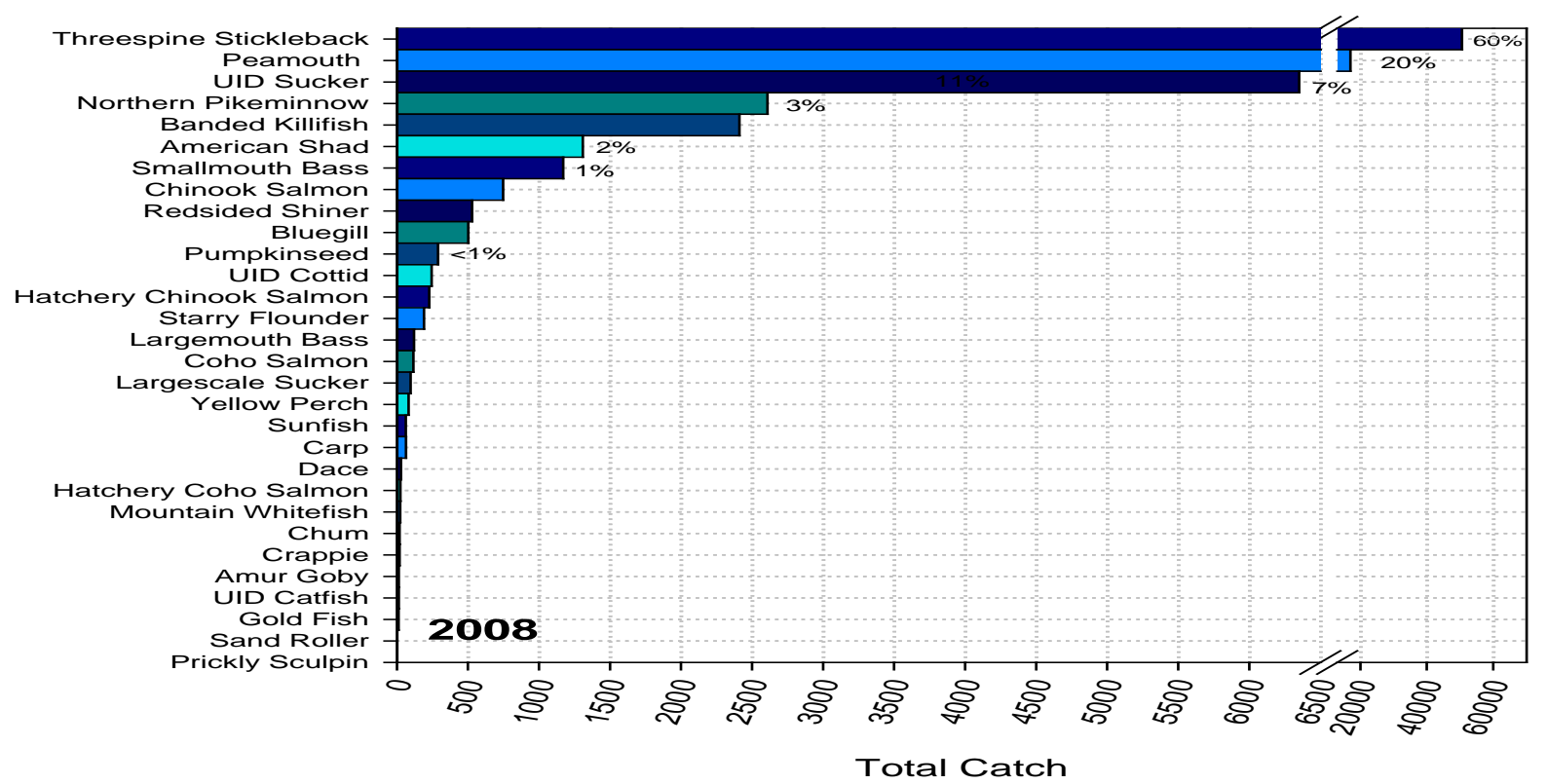

Figure 4.9. Combined Total Catch for All Sites and Sample Dates Spanning the 2008 Sampling Effort (January-December). Percentages were determined by the number of individuals of a species divided by the total number of fish encountered during 2008.

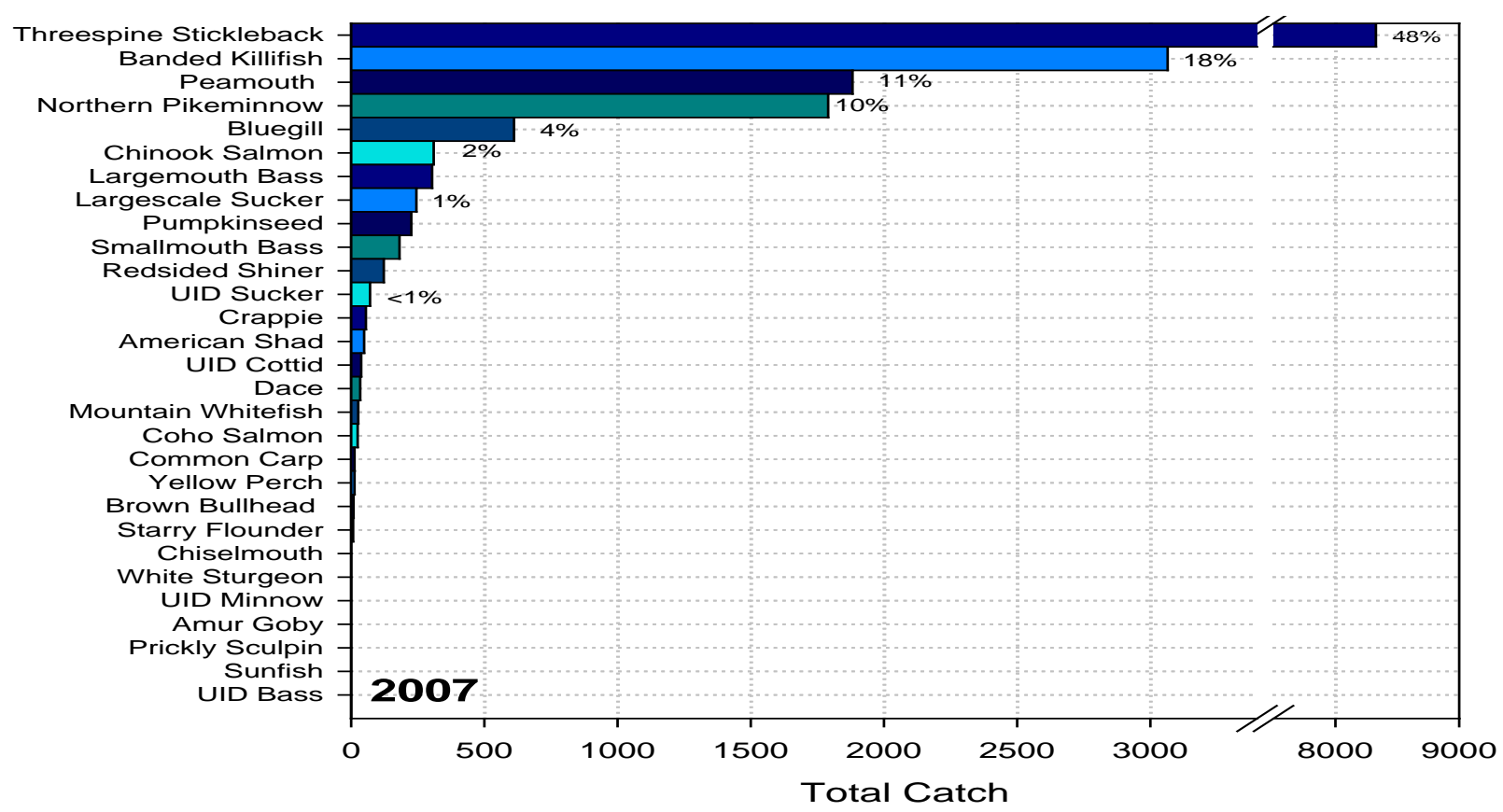

Figure 4.10. Combined Total Catch for All Sites and Sample Dates Spanning the 2007 Sampling Effort (June-December). Percentages were determined by the number of individuals of a species divided by the total number of fish encountered during 2008. 


\subsubsection{Fish Community}

The taxa encountered at our sampling sites can be divided into various assemblages; however, because a large number of non-native fishes were encountered during our study, we have summarized our catch by dividing the community composition into three categories: salmons, remaining native fishes, and non-native fishes (Figure 4.11). Native fishes were most predominant during late summer and early winter. In 2007, the abundance of non-native fishes increased during winter, but showed little increase for the remainder of the study period. Compared with native and non-native groups, the overall abundance of salmon was much less. Density of salmon was highest during December 2007 and spring 2008.

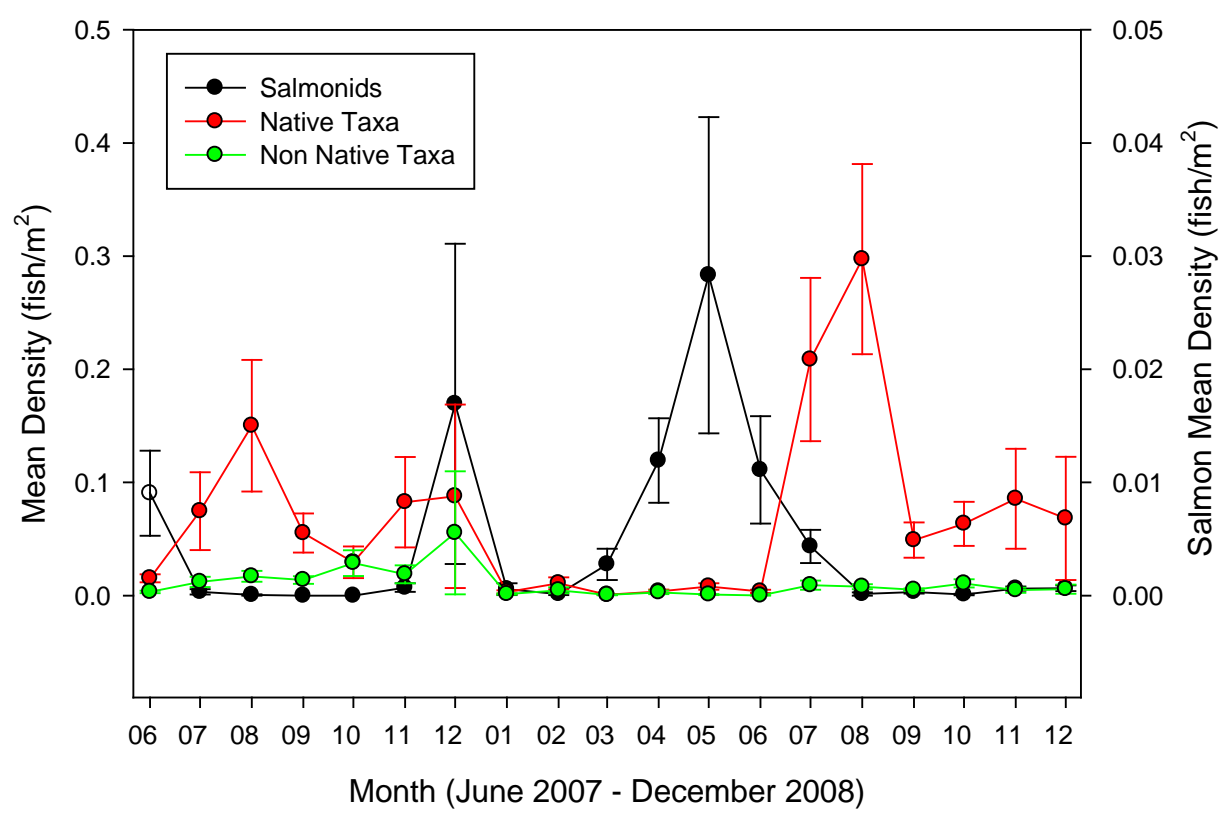

Figure 4.11. Temporal Distribution of Fish Assemblages. Fish density is calculated as the number of taxa within the area swept by the beach seine. Mean density corresponds to the average taxa within a given guild during a particular sample month. The left vertical axis is for native and non-native taxa and the right vertical axis is for juvenile salmon.

\subsubsection{Ubiquitous Species}

The most dominant species included four native species: threespine stickleback, peamouth chub, Northern pikeminnow (Ptychocheilus oregonensis), unidentified sucker (Catostomus sp.); and two nonnative species: banded killifish and bluegill (Lepomis macrochirus) (Figures 4.9 and 4.10). Four of these species - threespine stickleback, peamouth chub, Northern pikeminnow, and banded killifish—were encountered during every month of the study. The density for ubiquitous species was generally low at Sites F, H, and I. Density was disproportionately greatest at Site C followed by Site N (Figure 4.12). The two non-native species (e.g., banded killifish and bluegill) were most predominant at Sites $\mathrm{C}$ and N. The size of dominant taxa encountered at our sampling sites ranges from 10 to $250 \mathrm{~mm}$ (Figure 4.13). The size distribution of Northern pikeminnow, peamouth chub, and suckers encountered throughout our study sites is primarily representative of juvenile stages; however, some of the larger fish indicate sub-adult stages (Figure 4.13). 

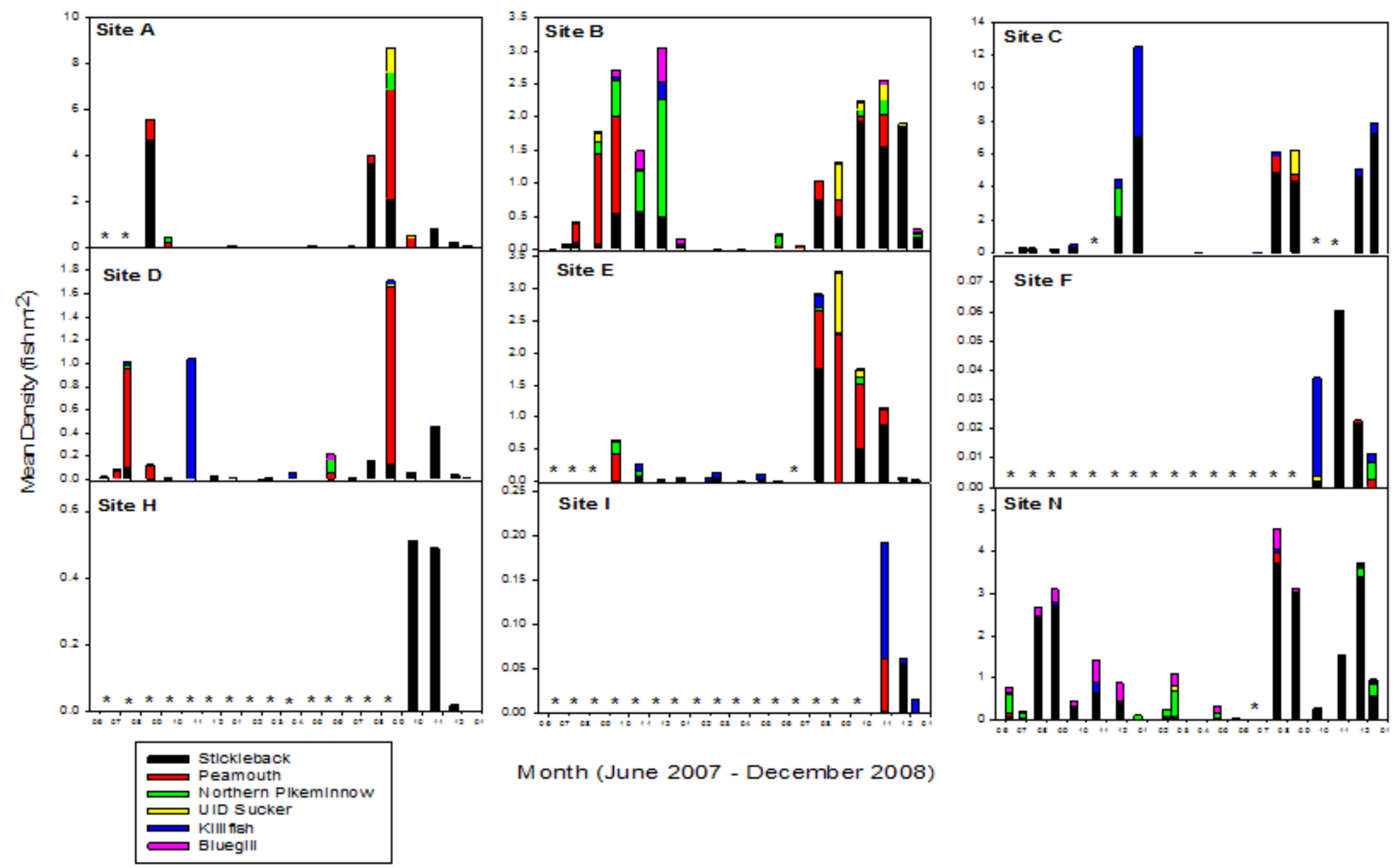

Figure 4.12. Temporal Distribution of the Mean Density (fish $/ \mathrm{m}^{2}$ ) of the Six Most Abundant Fish for the 2007-2008 Sampling Duration. The asterisk symbol $(*)$ indicates that sampling did not occur at a particular site on the corresponding date. 

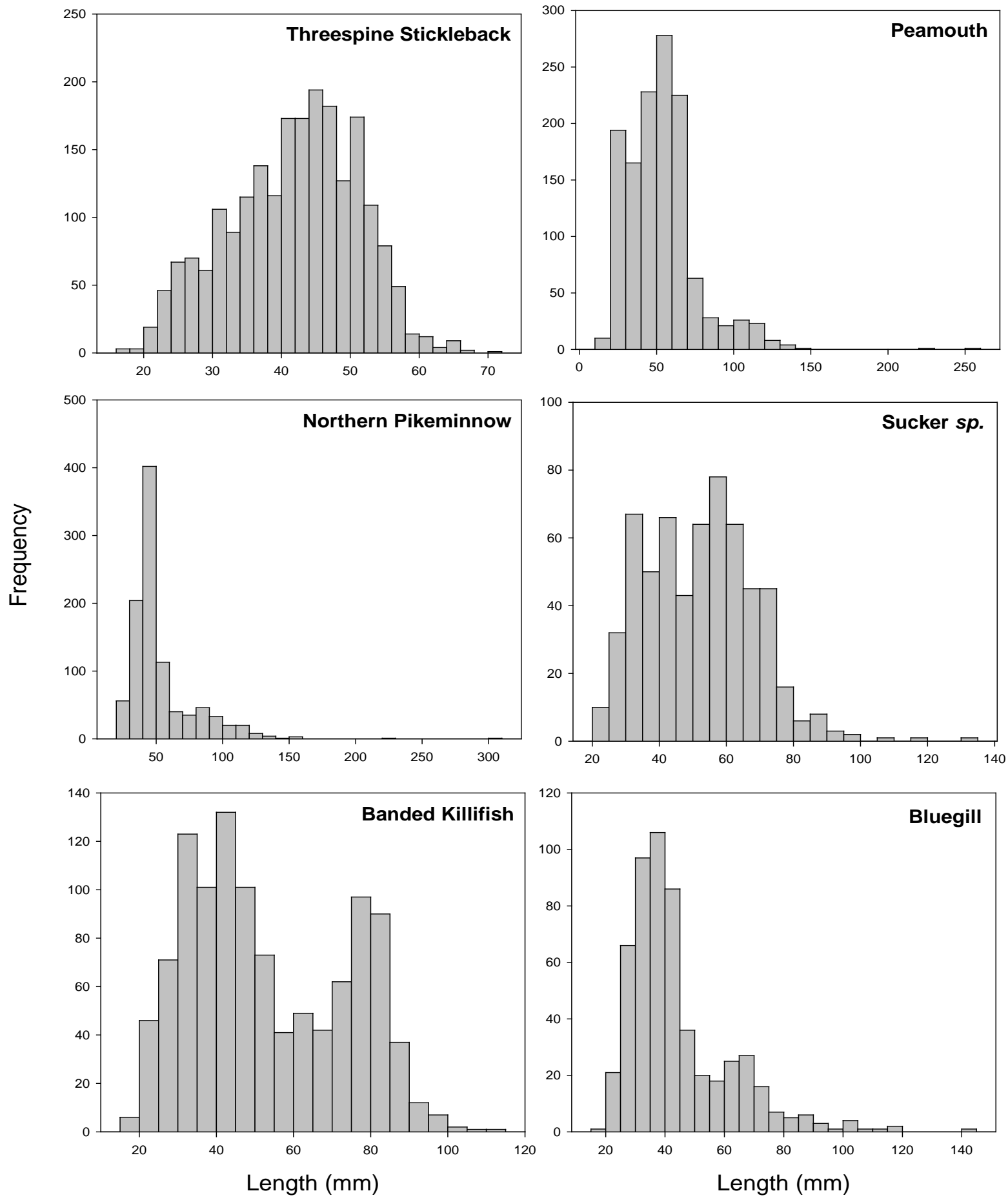

Figure 4.13. Length Frequency Distribution of the Six Most Dominant Species Encountered During 2007 and 2008. The size of threespine stickleback, banded killifish, and bluegill is represented as total length while fork length is used to summarize the peamouth and Northern pikeminnow. Scales differ between panels. 


\subsubsection{Salmon}

As with the ubiquitous species, densities of salmonids were comparatively low at Sites F, H, and I; however, sampling did not commence at these locations until fall 2008, so a seasonal comparison of these sites to the base sites is inappropriate. Salmonid density was greatest at Sites D, E, and N. Unmarked Chinook salmon were the most abundant salmonid within the study area and were encountered at all sites except for F (Figure 4.14). We encountered unmarked Chinook salmon in our study area during all months except for January and February. Fish densities were also low for other species (salmon and nonsalmon) during this time period. Unmarked coho salmon occurred during all months except late summer to early fall (August-October).

Marked Chinook salmon and coho salmon were secondary and tertiary in abundance rank throughout the study period. While the densities of marked Chinook and coho salmon were lower compared to unmarked Chinook salmon, these fish were distributed at similar sites (Figure 4.14). The presence of marked Chinook salmon was limited to April through October.

The presence of chum salmon was brief. This species was only encountered during the April and May sampling dates, and compared with other salmon encountered during the same time interval, the density of chum salmon was markedly low. Similar to chum salmon, steelhead trout (Oncorhynchus mykiss) were only encountered once during the spring migration period and the catch was limited to one unmarked fish and one marked hatchery steelhead.

Temporal trends in size class distribution of salmon was apparent, to some degree, when the presence of fish was consistent between sample periods at a particular site. For example, Sites A and B (Figure 4.15) best demonstrate the increasing size of migrating Chinook salmon. The first pulse of migrating subyearling Chinook salmon (approximately 40-mm FL) began appearing in our catches during March. The size of Chinook salmon increased throughout the spring and summer months. The largest fish (approximately 100- to 104-mm FL) encountered at the TFM sites occurred during November and December of both years. At some sites (D and H; Figure 4.15), the sizes of marked and unmarked Chinook salmon were similar, yet at some sites, marked Chinook salmon were larger compared to their unmarked counterparts (Sites A-C; Figure 4.15). 

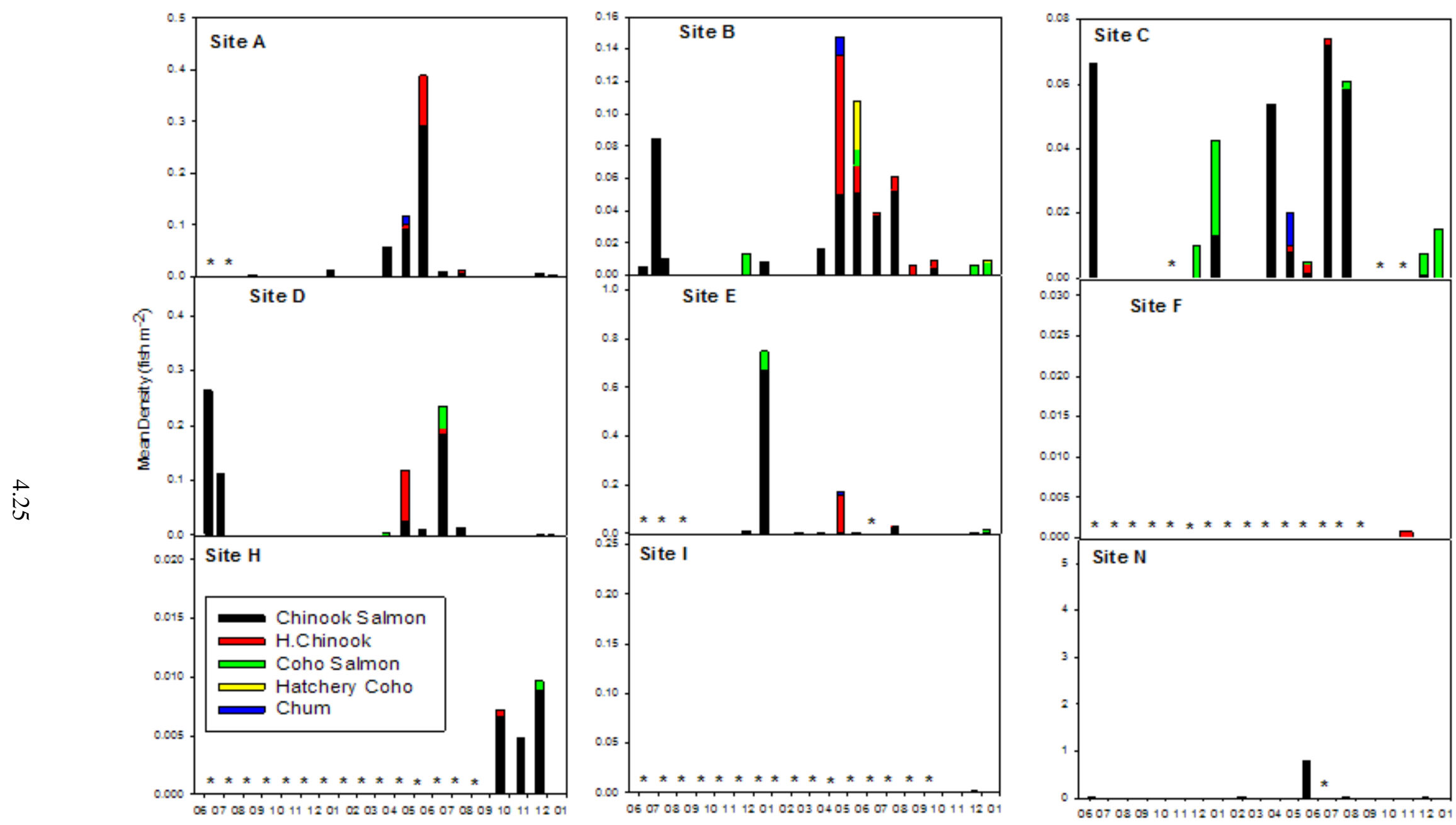

Month (June 2007 - December 2008)

Figure 4.14. Temporal Distribution of the Mean Density $\left(\mathrm{fish} / \mathrm{m}^{2}\right.$ ) of Salmonids Encountered Throughout the 2007-2008 Sampling Period. The asterisk symbol $(*)$ indicates that sampling did not occur at a particular site on the corresponding date. 


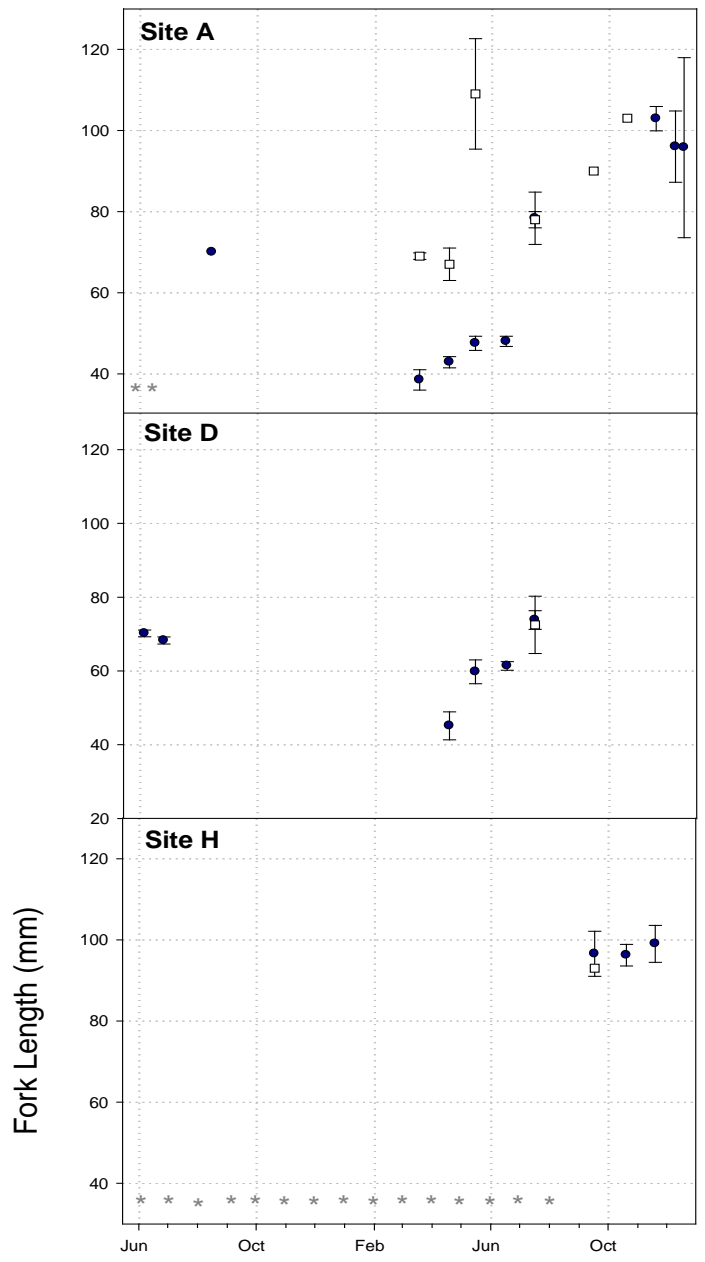

- Unmarked Chinook Salmon Hatchery Chinook Salmon
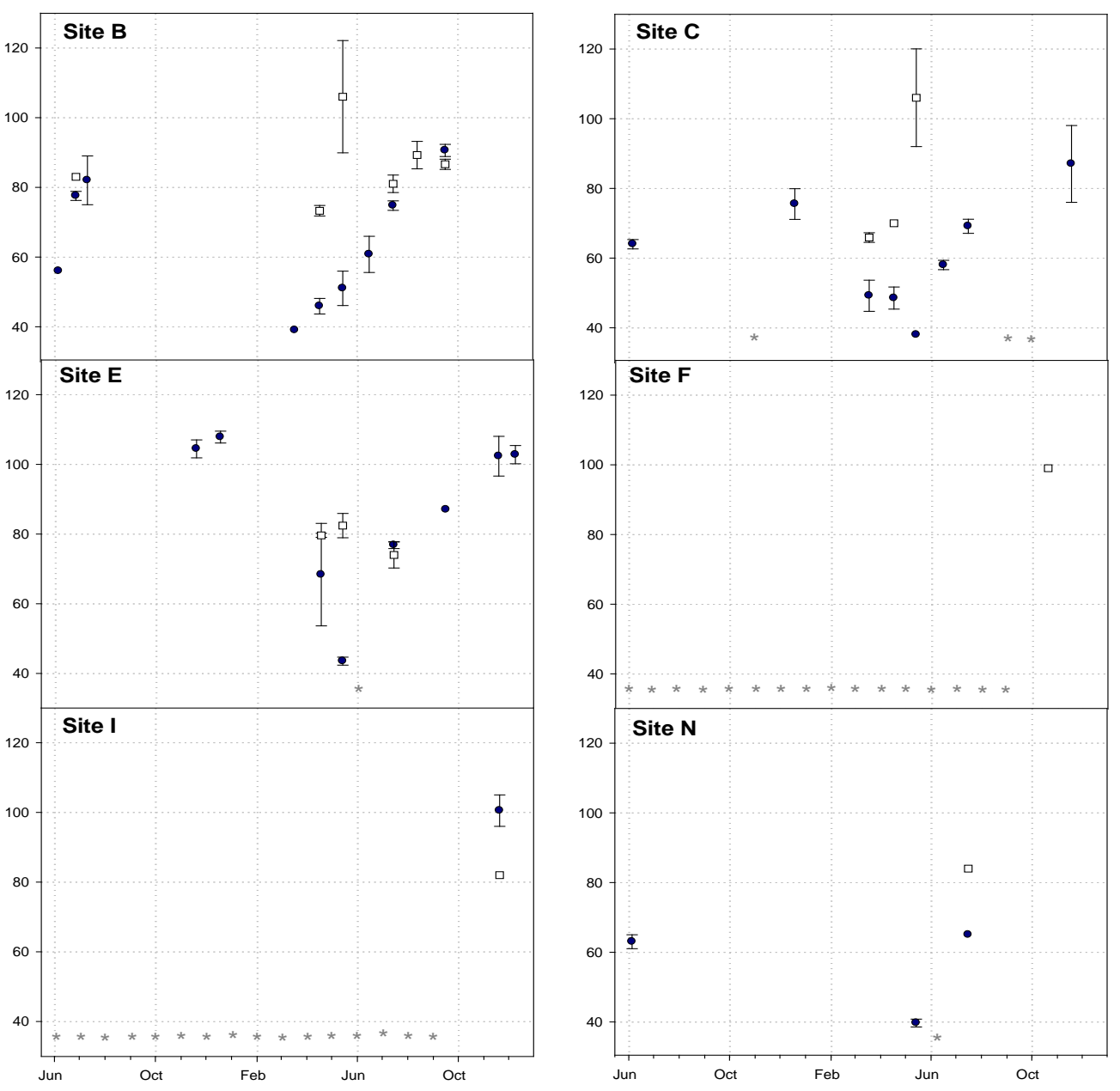

Month (June 2007 - December 2008)

Figure 4.15. Mean Fork Length for Unmarked and Marked Chinook at the TFM Sampling Sites from June 2007 Through December 2008. Error bars are equal to one standard error. The asterisk symbol $\left({ }^{*}\right)$ indicates that sampling did not occur at a particular site on the corresponding date. 


\subsubsection{Ancillary Data}

To document temporal changes in water condition, attributes such as water temperature, dissolved oxygen, and water depth were measured at each site. Each sampling location was documented by recording GPS positions at the water's edge. Visual changes throughout the season were documented with photo points (see Appendix D).

\subsubsection{Water Attributes}

Some in situ water metrics recorded during each beach seine event demonstrate seasonal patterns, while other metrics are indicative of differences between the sites. For example, water temperature was warmest during late summer and coldest during winter months (Figure 4.16). At most sites, dissolved oxygen (DO) generally oscillated between $7-13 \mathrm{mg} / \mathrm{L}$. The August 2008 reduction in DO noted at nearly all sites was associated with warmer water temperatures (Figure 4.17). Despite similar spatial and temporal trends in water temperature, DO levels at Site $\mathrm{N}$ were lower compared to those recorded at other locations; typical ranges spanned 1.8-8.4 $\mathrm{mg} / \mathrm{L}$. The only exception to these low-ranging values occurred during the May 2008 when the DO was $12.8 \mathrm{mg} / \mathrm{L}$. Regardless of the low DO values, Site N does yield water temperatures that are comparatively lower than other sites.

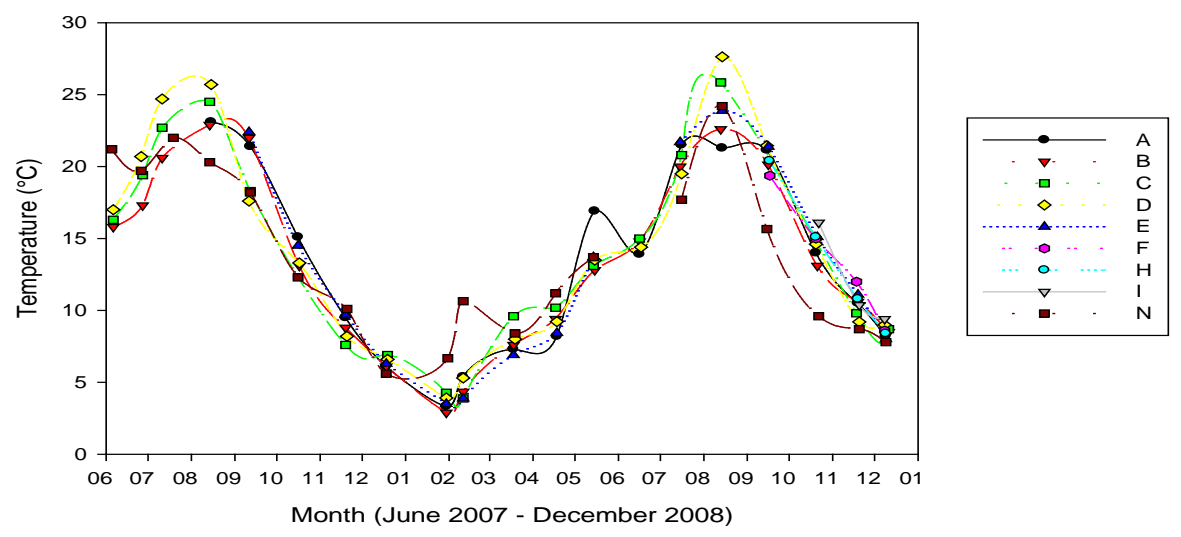

Figure 4.16. Water Temperature Measured During Beach Seining Efforts

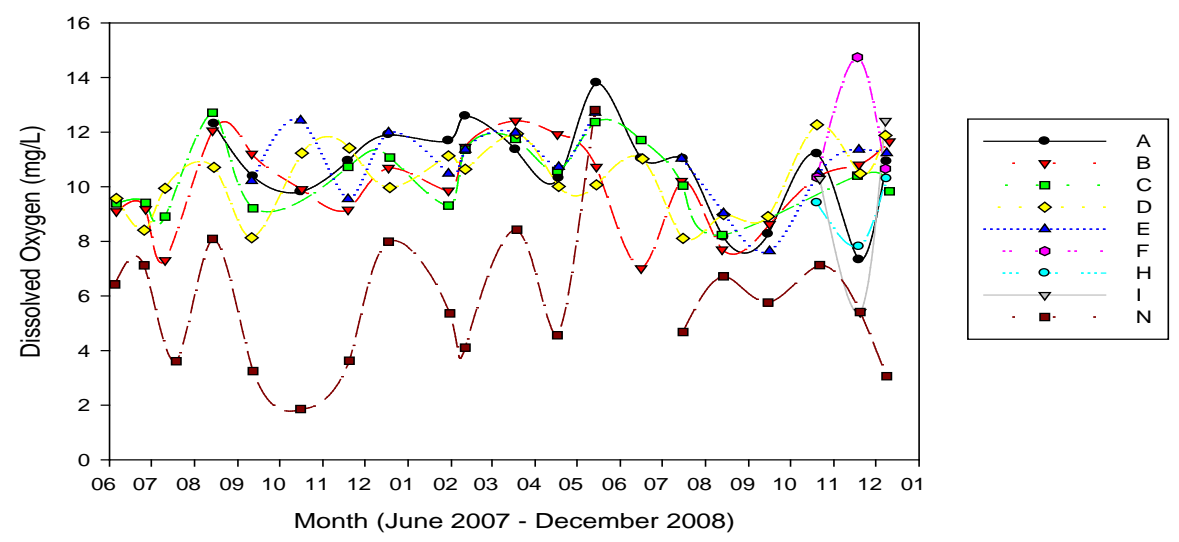

Figure 4.17. Dissolved Oxygen Measured During Beach Seining Efforts 


\subsubsection{Water Depth}

The data loggers provided continuous water surface elevation measurements at selected sites throughout an extended time period. Noting the maximum water depth during each sampling effort provides a means to track depth across all sites through time. Mean maximum water depth (m) was greatest at Sites B and E. The shallowest beach seine hauls occurred at Sites D and C, which had a mean maximum depth of less than $1 \mathrm{~m}$. Water depth recorded during beach seine hauls changed the least at Site N (Figure 4.18).
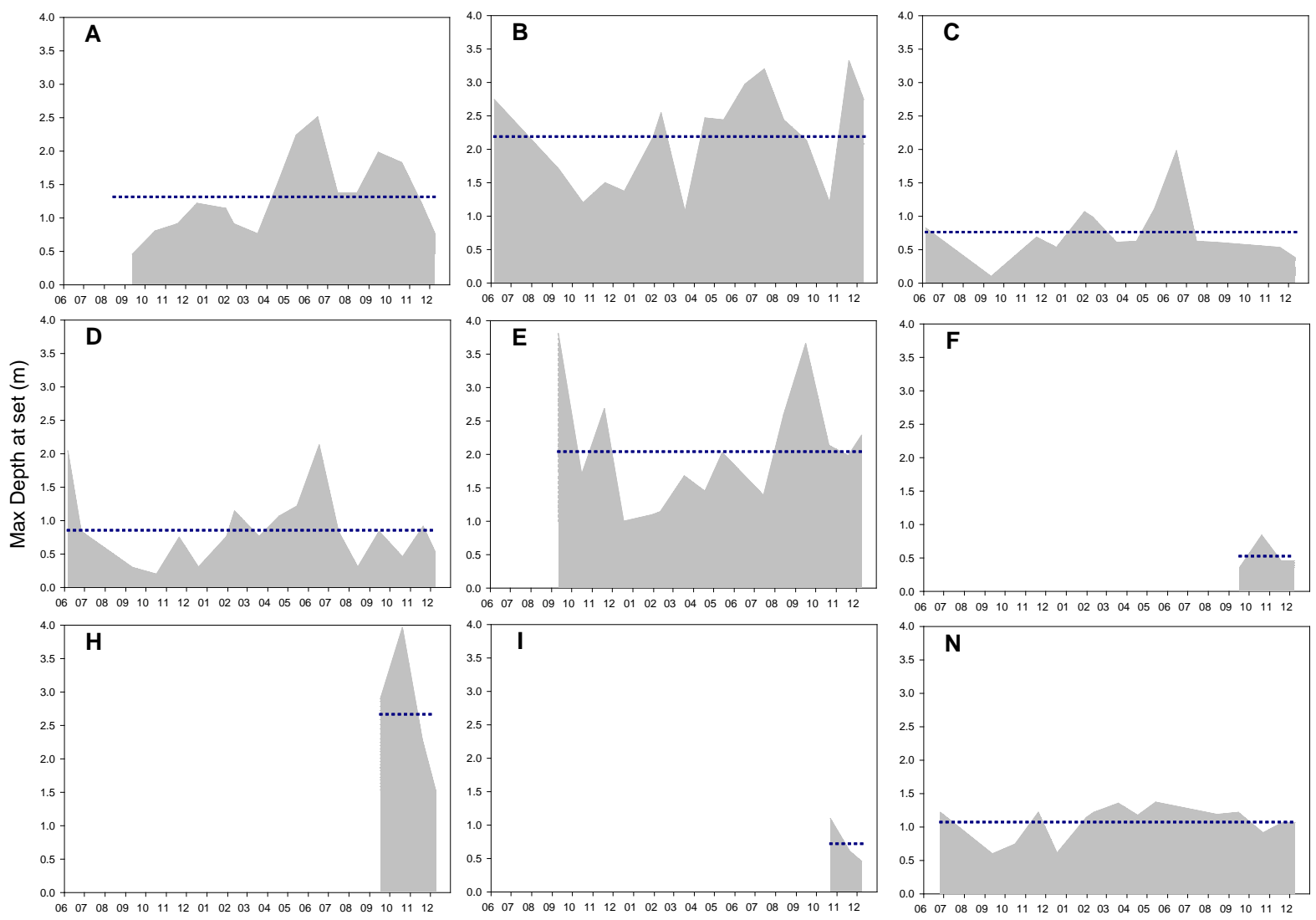

Month (June 2007 - December 2008)

Figure 4.18. Maximum Depth During Beach Seine Sets at Each Site. Incomplete area (i.e., Site F: June 07-September 09) indicates that sampling did not occur during the missing time interval. The dashed horizontal line indicates the mean depth (m) at a site throughout the entire sampling period.

\subsubsection{Variation in Sampling}

The spatial locations of the beach seine hauls provide a means of visually demonstrating the shift in sampling location caused by changing water elevation. As water levels recede between late summer and early fall, the sampling location occurs further down the beach slope towards the channel. During peak flow events in May and June, the beach slope at most sites was covered by water, and seining occurred at high elevations. Figures 4.19 and 4.20 summarize the temporal and spatial extent of sampling during 2008. The 2007 data were summarized by Sobocinski et al. (2008). 


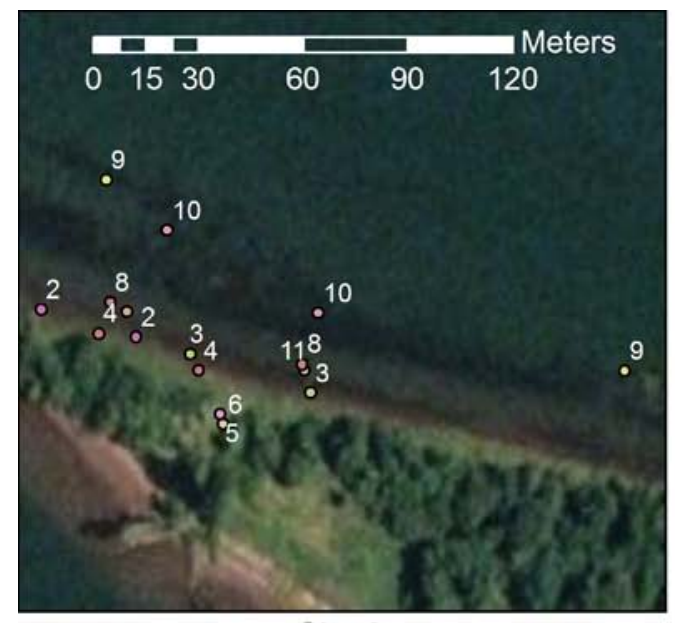

Site A

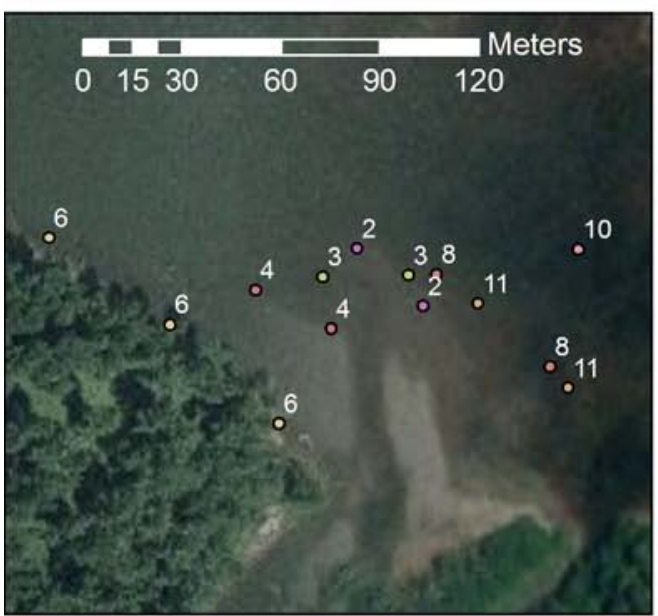

Site C

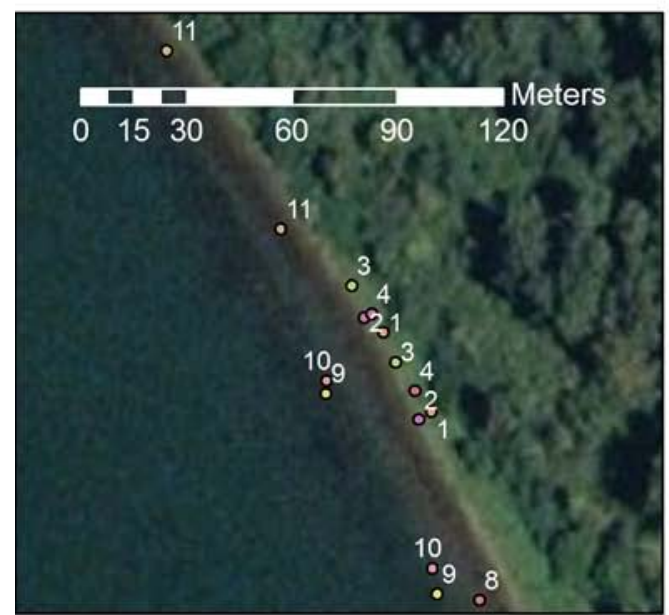

Site $\mathbf{E}$

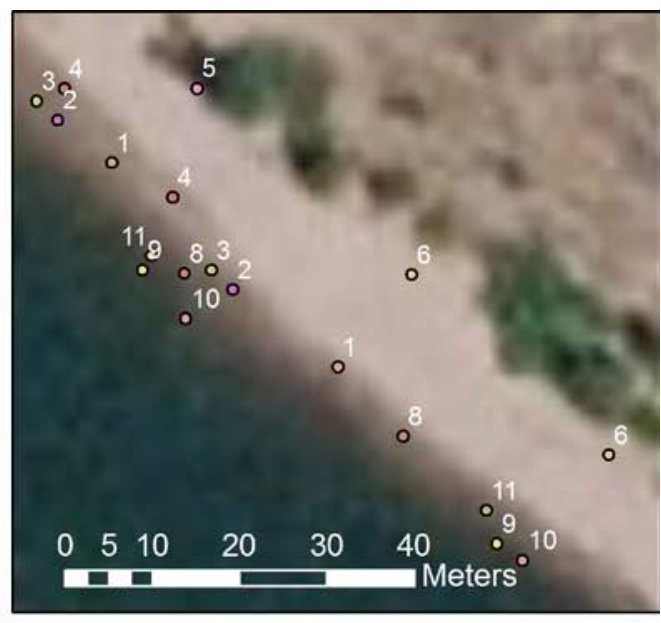

Site B

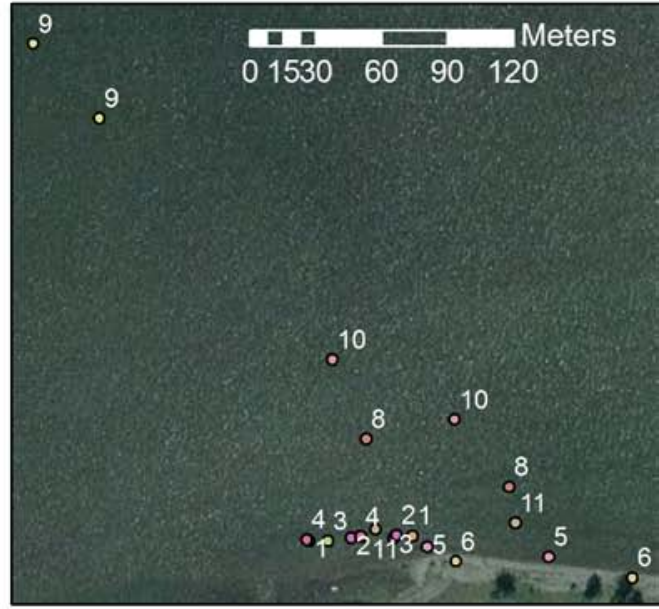

Site D

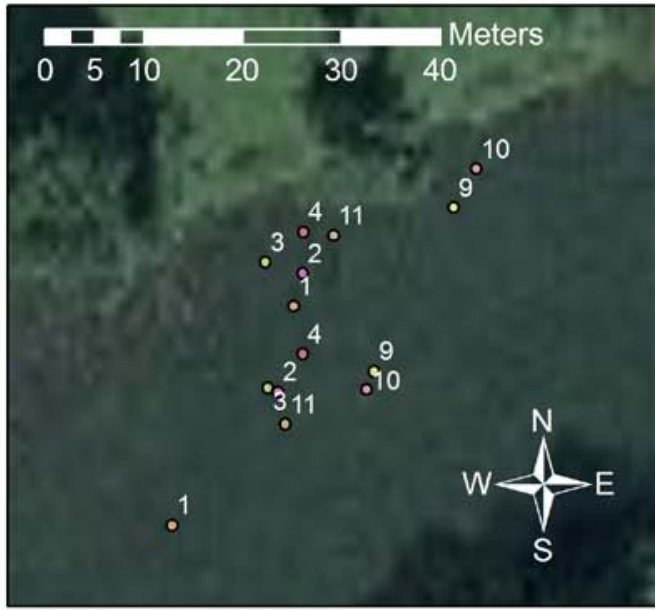

Site $\mathbf{N}$

Figure 4.19. GPS Locations of Beach Seine Hauls at the Base Sites During Year Two Sampling Efforts (2008). For 2007 GPS locations see Sobocinski et al. (2008). The numbers correspond to the sample month. 


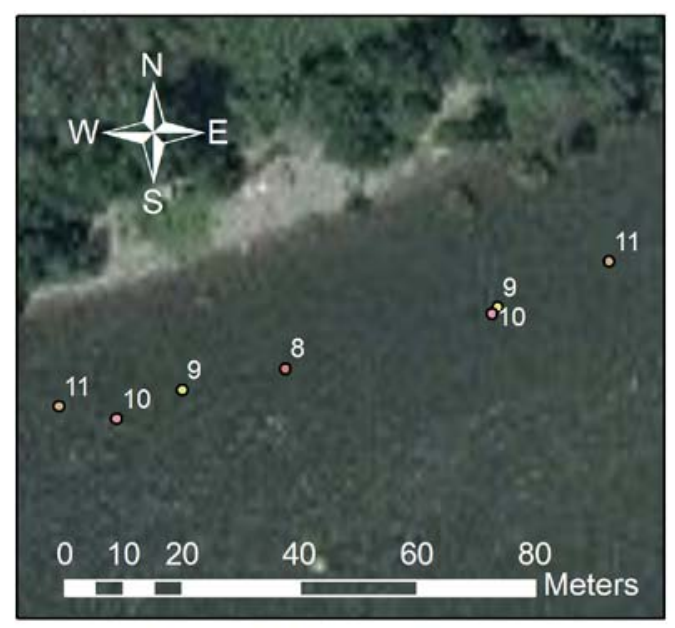

Site H - McGuire Island

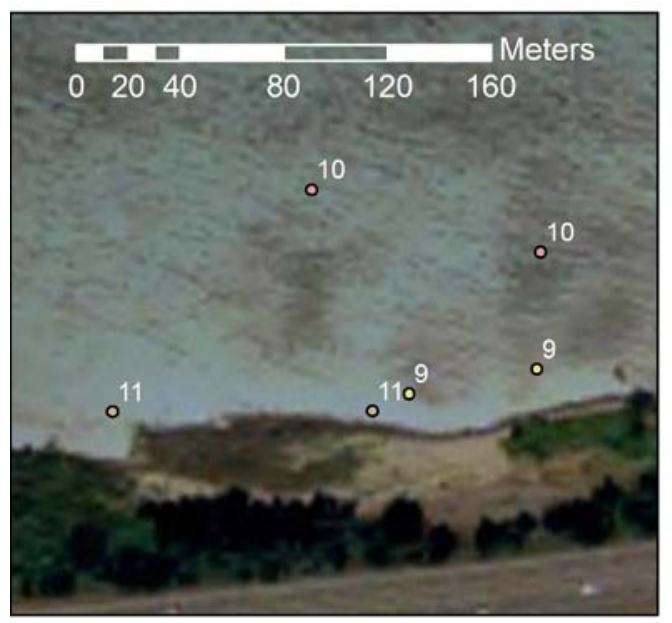

Site $\mathbf{F}$

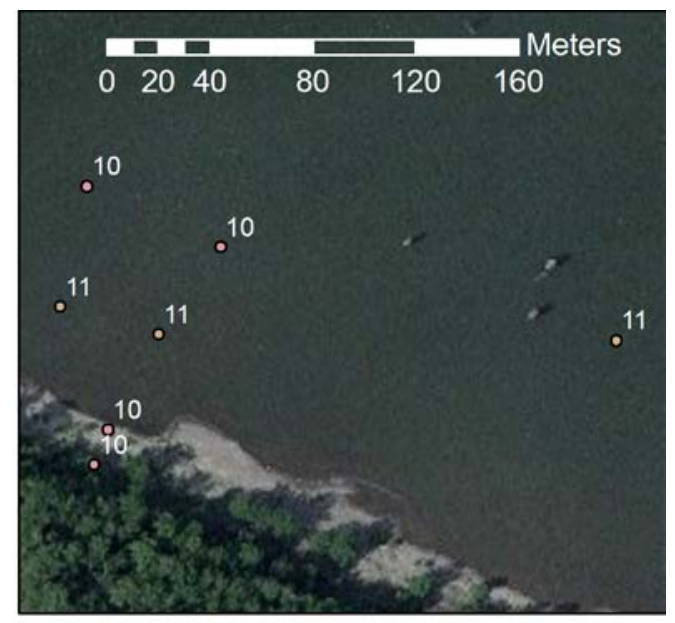

Site I - Ackerman Island

Figure 4.20. GPS Locations of Beach Seine Hauls at the Three New Sites Sampled During 2008. The numbers correspond to the sample month.

\subsubsection{Genetics}

A total of 497 Chinook salmon were screened for microsatellite DNA variation. Data for 71 samples were excluded from our analysis because we were not able to genotype those individuals for at least 7 of the 13 microsatellite loci. Most $(n=66)$ of the problem samples were collected between September 17 and December 19, 2008, and were likely preserved using denatured ethanol, rather than $100 \%$ ethanol. The denatured ethanol may have contained inhibitory compounds that interfered with the PCR process (Moran and Baker 2002) or the denaturants may have degraded the DNA. Genetic stock identification analysis was therefore conducted using data for the remaining 426 samples. Stock composition estimates from the analysis of 277 unmarked juvenile Chinook salmon are presented in Table 4.6. These samples may include both naturally produced and unmarked hatchery fish (see Section 2.2.2). Most of the fish sampled were from the upper Columbia River summer/fall stock group (approximately 52\%) and may include individuals from the upper Columbia River, mid Columbia River, Columbia Gorge, and sources below Bonneville Dam (see Sections 2.2.2 and 2.2.3). Substantial proportions were also estimated for the West Cascade Tributary (16\%) and Spring Creek (15\%) fall run stock groups. Smaller percentages were 
estimated for fall run populations in the Snake (8\%) and Deschutes (3\%) rivers and for spring Chinook salmon from the Willamette River (6\%) and West Cascade Tributary (<1\%) stock groups.

Table 4.6. Estimated Percentage Genetic Stock Group Composition and 95\% Confidence Intervals of 277 Unmarked Juvenile Chinook Salmon Sampled in the Study Area from March 18 Through September 172008

\begin{tabular}{lccc}
\hline \multicolumn{1}{c}{ Genetic Stock Group } & Estimated Contribution (\%) & \multicolumn{2}{c}{$95 \%$ Confidence Interval } \\
\hline Upper Columbia River Summer/Fall & 51.7 & 41.7 & 56.9 \\
\hline West Cascade Tributary Fall & 16.1 & 10.5 & 21.9 \\
Spring Creek Group Tule Fall & 14.6 & 9.6 & 18.9 \\
Snake River Fall & 7.9 & 4.3 & 14.6 \\
Willamette River Spring & 6.3 & 1.8 & 8.1 \\
Deschutes River Fall & 2.8 & 0.4 & 7.6 \\
West Cascade Tributary Spring & 0.6 & 0.0 & 5.4 \\
Mid and Upper Columbia River Spring & 0.0 & 0.0 & 0.0 \\
Snake River Spring & 0.0 & 0.0 & 0.0 \\
Rogue River & 0.0 & 0.0 & 0.0 \\
\hline
\end{tabular}

Results of mixture analysis conducted on 149 marked juvenile Chinook salmon are presented in Table 4.7. Individuals in these samples were marked with an adipose fin clip, CWT, or both marks and are presumed to be hatchery fish. The Spring Creek group fall stock contributed approximately $75 \%$ of the marked fish sample, likely a result of releases from Spring Creek National Fish Hatchery. Approximately $17 \%$ of the marked samples were estimated to be from upper Columbia River summer/fall stock and may include fish from both upper and lower river hatchery releases (see list of hatchery releases of marked fish in Table 2.1 and text in Section 2.2.2). Small percentages were estimated for fall Chinook salmon from the Snake River (4\%) and West Cascade Tributary (3\%) groups. We estimated that the mid and upper Columbia River spring run stock group was present in the sample of marked fish $(<1 \%)$ but not in the unmarked sample. Spring run fish from the Snake River and fish of Rogue River ancestry were absent from both the marked and unmarked samples.

Individual fish probability assignments were summed by collection date for the unmarked and marked Chinook salmon (Figures 4.21 and 4.22). Both unmarked and marked sample sets showed a shift from predominately Spring Creek group fall fish in the earliest samples to a more diverse composition of stocks throughout the summer. Samples of unmarked Chinook salmon collected in May, June, and July were primarily comprised of fish from the upper Columbia River summer/fall, West Cascade Tributary fall, and Snake River fall stock groups. The few samples analyzed in August and September were nearly all from the upper Columbia River summer/fall stock group. Unmarked fish at each of Sites A through E were from a diversity of stock groups (Figure 4.23). Samples at Sites A, C, and E contained individuals assigned with high probability values $(>0.90)$ to the Snake River fall run stock group (Table 4.8). 
Table 4.7. Estimated Percentage Genetic Stock Group Composition and 95\% Confidence Intervals of 149 Marked Juvenile Chinook Salmon Sampled in the Study Area from March 18 Through September 17, 2008. Fish were marked with adipose fin clips, CWTs, or both.

\begin{tabular}{lccc}
\hline \multicolumn{1}{c}{ Genetic Stock Group } & Estimated Contribution & \multicolumn{2}{c}{ 95\% Confidence Interval } \\
\hline Spring Creek Group Tule Fall & 74.6 & 61.3 & 76.3 \\
\hline Upper Columbia River Summer/Fall & 16.9 & 11.2 & 21.3 \\
Snake River Fall & 3.5 & 0.0 & 8.7 \\
\hline West Cascade Tributary Fall & 2.5 & 0.9 & 12.1 \\
Willamette River Spring & 1.4 & 0.0 & 2.7 \\
Deschutes River Fall & 0.4 & 0.0 & 4.7 \\
Mid and Upper Columbia River Spring & 0.7 & 0.0 & 2.0 \\
West Cascade Tributary Spring & 0.0 & 0.0 & 3.4 \\
Snake River Spring & 0.0 & 0.0 & 0.0 \\
Rogue River & 0.0 & 0.0 & 0.0 \\
\hline
\end{tabular}

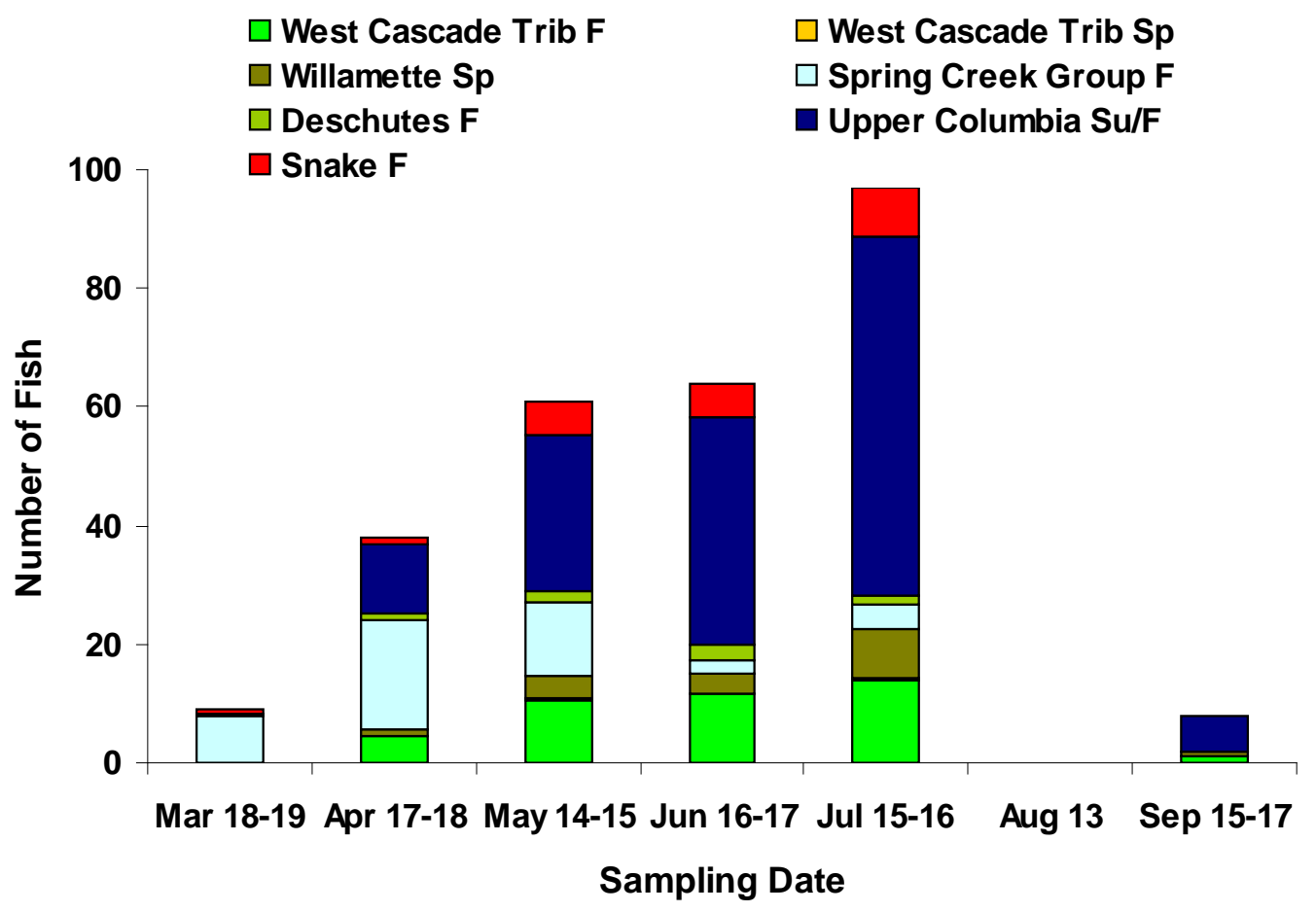

Figure 4.21. Sums of Fractional Genetic Assignments of Individual Unmarked Chinook Salmon by Collection Date. Fractions for the mid and upper Columbia spring, Snake spring, and Rogue stock totaled $\leq 1.0$ and are not shown. $\mathrm{F}=$ fall run, $\mathrm{Su}=$ summer run, $\mathrm{Sp}=$ spring run. 


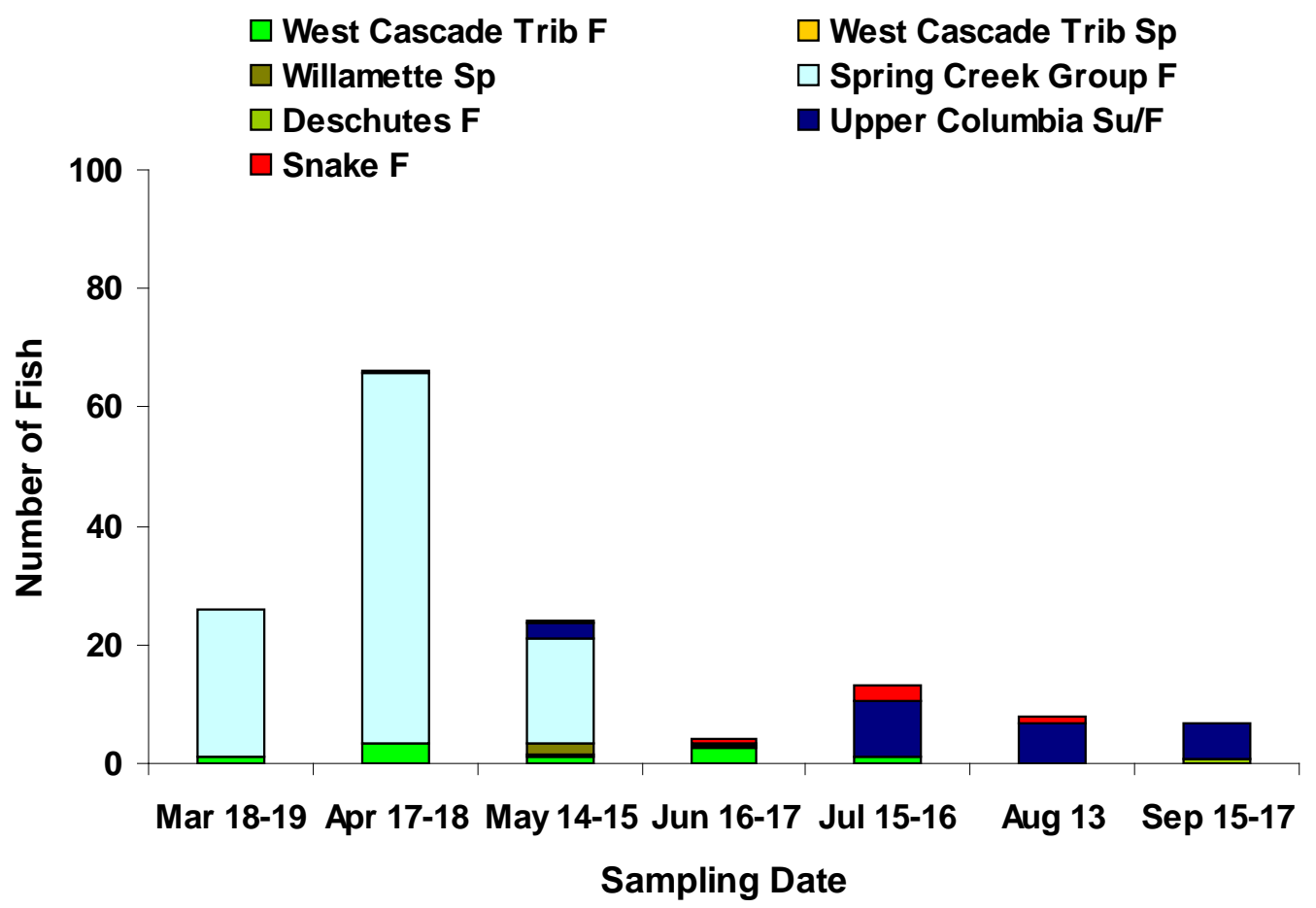

Figure 4.22. Sums of Fractional Genetic Assignments of Individual Marked Chinook Salmon by Collection Date. Fractions for the mid and upper Columbia spring, Snake spring, and Rogue stock totaled $\leq 1.0$ and are not shown. $\mathrm{F}=$ fall run, $\mathrm{Su}=$ summer run, $\mathrm{Sp}=$ spring run.

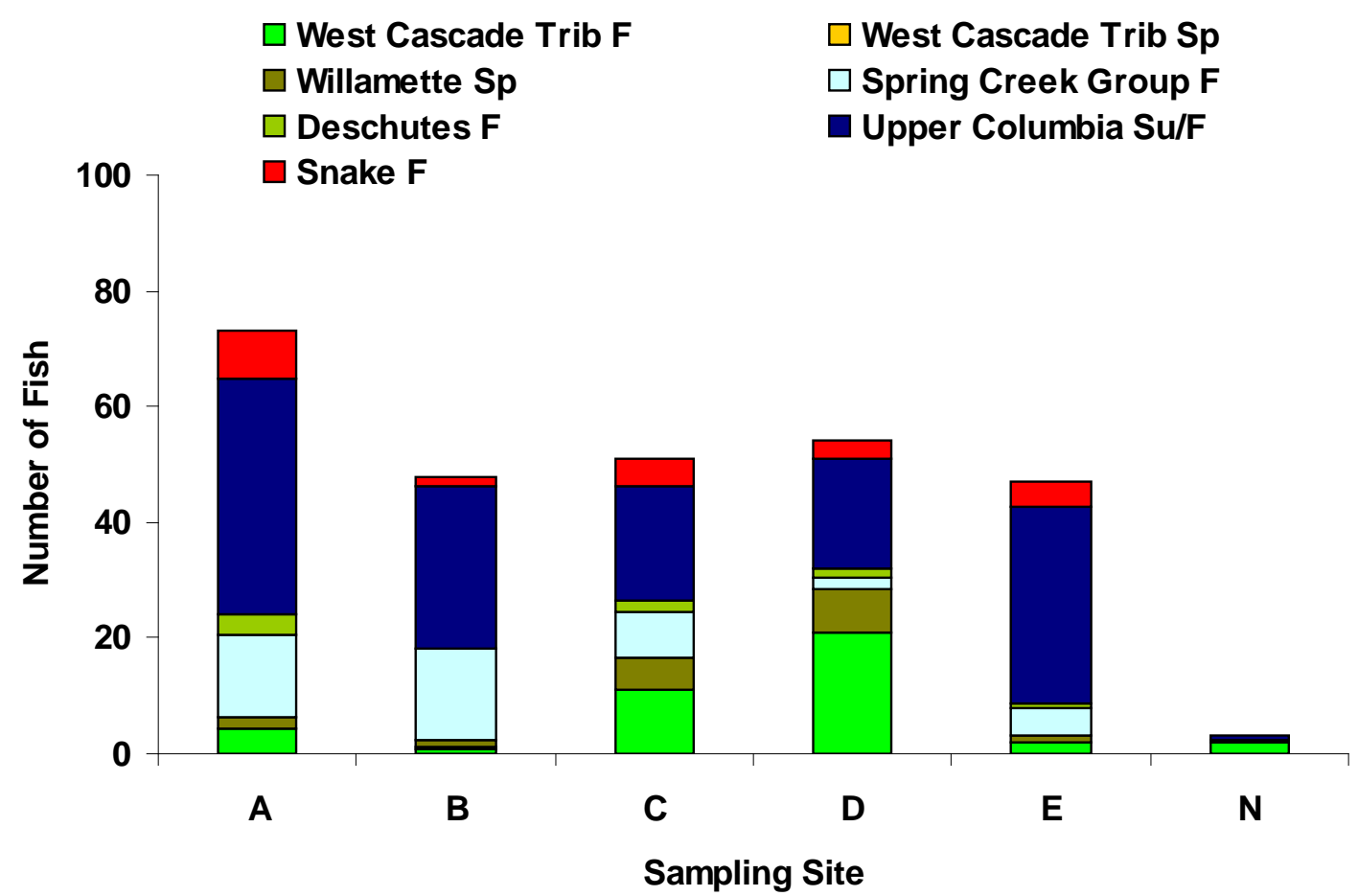

Figure 4.23. Sums of Fractional Genetic Assignments of Individual Unmarked Chinook Salmon by Sampling Site. Fractions for the mid and upper Columbia spring, Snake spring, and Rogue stock totaled $\leq 1.0$ and are not shown. $\mathrm{F}=$ fall run, $\mathrm{Su}=$ summer run, $\mathrm{Sp}=$ spring run. 
Table 4.8. Estimated Origin of Individual Chinook Salmon Assigned to the Snake River Fall and Mid and Upper Columbia Spring Stock Groups. Only individuals with probabilities (relative to membership in another stock group) of $>0.90$ are shown.

\begin{tabular}{cccccc}
\hline Date & Site & Length & Adipose clip & Genetic Stock Group & Probability \\
\hline 3/18/2008 & C & 37 & No & Snake Fall & 0.90 \\
5/14/2008 & C & 134 & Yes & Mid and Upper Columbia Spring & 1.00 \\
5/14/2008 & E & 46 & No & Snake Fall & 0.94 \\
5/15/2008 & A & 62 & No & Snake Fall & 1.00 \\
$7 / 15 / 2008$ & E & 72 & No & Snake Fall & 0.98 \\
$7 / 16 / 2008$ & C & 66 & No & Snake Fall & 0.99 \\
\hline
\end{tabular}

Chinook salmon from the Spring Creek Group Fall stock were predominate among the marked fish at all sites, although Site B also included a substantial proportion of upper Columbia River summer/fall fish (Figure 4.24). A single marked yearling-sized fish from the mid and upper Columbia River spring run group was present at Site C (Table 4.8).

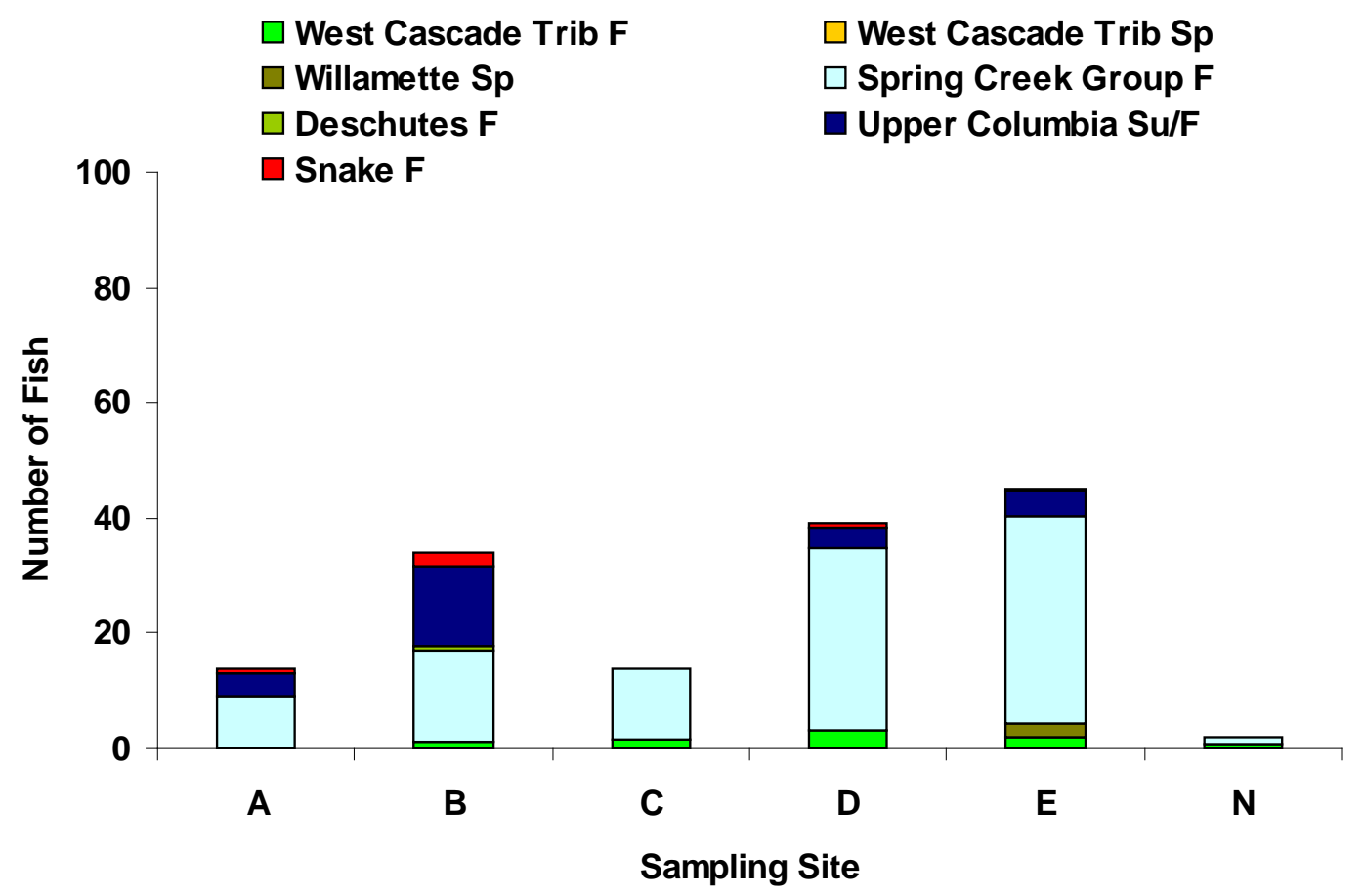

Figure 4.24. Sums of Fractional Genetic Assignments of Individual Marked Chinook Salmon by Sampling Site. Fractions for the mid and upper Columbia spring, Snake spring, and Rogue stock totaled $\leq 1.0$ and are not shown. $\mathrm{F}=$ fall run, $\mathrm{Su}=$ summer run, $\mathrm{Sp}=$ spring run. 


\subsubsection{Diets}

Gut content samples for all chum salmon analyzed contained no prey items. In general, Chinook salmon had larger proportions of empty stomachs than did coho salmon. The greatest proportions of empty stomachs occurred primarily in April (Table 4.9).

Chinook salmon included in the 2008 diet analysis were generally of comparable size among sites, ranging from 50-118-mm FL at Site A, 58-100-mm FL at Site B, 51-134-mm FL at Site C, 54-94-mm FL at Site D, and 54-117-mm FL at Site E, 82-109-mm FL at Site H, and 82-105-mm FL at Site I (Figure 4.25). Where comparisons could be made among months, statistically significant differences in fork lengths were identified at all sites except $\mathrm{H}$ (Figure 4.26). When all fork lengths were analyzed collectively, the interaction between month and site was found to be significant (two-way ANOVA, p < 0.0001).

The mean ranked fork length of coho salmon (105.91 $\pm 38.53 \mathrm{~mm}$ SD) included in the 2008 diet was significantly larger than that of Chinook salmon $(77.44 \pm 14.62 \mathrm{~mm} ; \mathrm{p}=0.0034)$. The mean ranked fork length of coho salmon from which gut contents were sampled at Site D during June differed significantly from those of fish sampled at Sites A, D, and E during May $(\mathrm{p}<0.0001)$. No significant differences were identified among mean ranked fork lengths for coho salmon at Sites A, D, and E (Figure 4.27).

Regardless of sampling month or site of capture, the diets of Chinook salmon were generally dominated by aquatic Diptera (largely Chironomidae and Ceratopogonidae; Table 4.10). Mysids and amphipods were encountered sporadically, at times composing appreciable proportions of the diet $(0.00-$ 0.50). Crustaceans (Copepoda and Cladocera) made up important components of the diet primarily during June at Sites A and B (0.39 and 0.25, respectively) and May at Site D (0.30), and July at Site N (0.54). Fish were found in the diet of Chinook salmon only during July at Site A, June and July at Site C, and April at Site D. Non-dipteran aquatic insects - trichopterans, hemipterans, and ephemeropteranscomprised no more than $20 \%$ of Chinook salmon diets during any one sampling month. Minor taxagrouped into the "other" category—were found in gut content samples during most months, composing large proportions of the diet primarily during later months (Figure 4.28). 


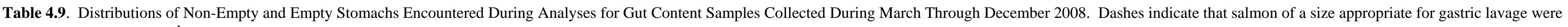
not encountered.

\begin{tabular}{|c|c|c|c|c|c|c|c|c|c|c|c|c|c|c|c|c|c|c|c|c|c|c|c|c|c|c|c|c|c|c|c|c|c|c|c|c|c|c|c|c|c|}
\hline \multirow[b]{3}{*}{ Site } & \multirow[b]{3}{*}{ Species } & \multicolumn{4}{|c|}{ Mar. } & \multicolumn{4}{|c|}{ Apr. } & \multicolumn{4}{|c|}{ May } & \multicolumn{4}{|c|}{ June } & \multicolumn{4}{|c|}{ July } & \multicolumn{4}{|c|}{ Aug. } & \multicolumn{4}{|c|}{ Sept. } & \multicolumn{4}{|c|}{ Oct. } & \multicolumn{4}{|c|}{ Nov. } & \multicolumn{4}{|c|}{ Dec. } \\
\hline & & & & & & & & En & ipty & & $\begin{array}{l}\text { on- } \\
\text { ptty }\end{array}$ & & ipty & & $\begin{array}{l}\text { on- } \\
\text { ppty }\end{array}$ & & ipty & & $\begin{array}{l}\text { on- } \\
\text { pty }\end{array}$ & & & & & & npty & & & & & & poty & & & & & & & & $\begin{array}{l}\text { on- } \\
\text { npty }\end{array}$ & & apty \\
\hline & & $\mathrm{n}$ & $\%$ & $\mathrm{n}$ & $\%$ & $\mathrm{n}$ & $\%$ & $\mathrm{n}$ & $\%$ & $\mathrm{n}$ & $\%$ & $\mathrm{n}$ & $\%$ & $\mathrm{n}$ & $\%$ & $\mathrm{n}$ & $\%$ & $\mathrm{n}$ & $\%$ & $\mathrm{n}$ & $\%$ & $\mathrm{n}$ & $\%$ & $\mathrm{n}$ & $\%$ & $\mathrm{n}$ & $\%$ & $\mathrm{n}$ & $\%$ & $\mathrm{n}$ & $\%$ & $\mathrm{n}$ & $\%$ & $\mathrm{n}$ & $\%$ & $\mathrm{n}$ & $\%$ & $\mathrm{n}$ & $\%$ & $\mathrm{n}$ & \% \\
\hline & Chinook & 4 & 100 & 0 & 0 & 1 & 25 & 3 & 75 & 6 & 75 & 2 & 25 & 13 & 87 & 2 & 13 & 7 & 100 & 0 & 0 & 0 & 0 & 1 & 100 & 1 & 100 & 0 & 0 & 1 & 100 & 0 & 0 & 5 & 100 & 0 & 0 & 4 & 100 & 0 & c \\
\hline A & Chum & - & - & - & - & 0 & 0 & 1 & 100 & - & - & - & - & - & - & - & - & - & - & - & - & - & - & - & - & - & - & - & - & - & - & - & - & - & - & - & - & - & - & - & . \\
\hline & Coho & - & - & - & - & 1 & 100 & 0 & 0 & 3 & 100 & 0 & 0 & - & - & - & - & - & - & - & - & - & - & - & - & - & - & - & - & - & - & - & - & - & - & - & - & - & - & - & . \\
\hline & Chinook & - & - & - & - & 9 & 47.4 & 10 & 52.6 & 1 & 33 & 2 & 67 & 1 & 50 & 1 & 50 & 17 & 89 & 2 & 11 & 5 & 100 & 0 & 0 & 14 & 100 & 0 & 0 & - & - & - & - & - & - & - & - & - & - & - & . \\
\hline B & Chum & - & - & - & - & 0 & 0 & 3 & 100 & - & - & - & - & - & - & - & - & - & - & - & - & - & - & - & - & - & - & - & - & - & - & - & - & - & - & - & - & - & - & - & . \\
\hline & Coho & - & - & - & - & - & - & - & - & 1 & 100 & 0 & 0 & - & - & - & - & - & - & - & - & - & - & - & - & - & - & - & - & - & - & - & - & - & - & - & - & - & - & - & . \\
\hline & Chinook & 10 & 91 & 1 & 9 & 1 & 25 & 3 & 75 & 4 & 100 & 0 & 0 & 15 & 100 & 0 & 0 & 13 & 100 & 0 & 0 & - & - & - & - & - & - & - & - & - & - & - & - & 2 & 100 & 0 & 0 & - & - & - & 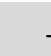 \\
\hline C & Chum & - & - & - & - & 0 & 0 & 4 & 100 & - & - & - & - & - & - & - & - & - & - & - & - & - & - & - & - & - & - & - & - & - & - & - & - & - & - & - & - & - & - & - & 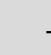 \\
\hline & Coho & - & - & - & - & - & - & - & - & 1 & 100 & 0 & 0 & - & - & - & - & - & - & - & - & - & - & - & - & - & - & - & - & - & - & - & - & - & - & - & - & - & - & - & . \\
\hline & Chinook & 8 & 73 & 3 & 27 & 12 & 100 & 0 & 0 & 3 & 100 & 0 & 0 & 19 & 95 & 1 & 5 & 20 & 100 & 0 & 0 & - & - & - & - & - & - & - & - & - & - & - & - & - & - & - & - & - & - & - & 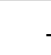 \\
\hline D & Chum & - & - & - & - & - & - & - & - & - & - & - & - & - & - & - & - & - & - & - & - & - & - & - & - & - & - & - & - & - & - & - & - & - & - & - & - & - & - & - & 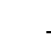 \\
\hline & Coho & - & - & - & - & - & - & - & - & 3 & 100 & 0 & 0 & 7 & 88 & 1 & 13 & - & - & - & - & - & - & - & - & - & - & - & - & - & - & - & - & - & - & - & - & - & - & - & . \\
\hline & Chinook & - & - & - & - & 19 & 100 & 0 & 0 & 9 & 90 & 1 & 10 & - & - & - & - & 16 & 94 & 1 & 6 & - & - & - & - & 1 & 100 & 0 & 0 & - & - & - & - & 3 & 100 & 0 & 0 & 12 & 100 & 0 & c \\
\hline E & Chum & - & - & - & - & - & - & - & - & - & - & - & - & - & - & - & - & - & - & - & - & - & - & - & - & - & - & - & - & - & - & - & - & - & - & - & - & - & - & - & . \\
\hline & Coho & - & - & - & - & - & - & - & - & 9 & 100 & 0 & 0 & - & - & - & - & - & - & - & - & - & - & - & - & - & - & - & - & - & - & - & - & - & - & - & - & - & - & - & . \\
\hline & Chinook & - & - & - & - & - & - & - & - & - & - & - & - & - & - & - & - & - & - & - & - & - & - & - & - & - & - & - & - & 0 & 0 & 1 & 100 & - & - & - & - & - & - & - & . \\
\hline $\mathrm{F}$ & Chum & - & - & - & - & - & - & - & - & - & - & - & - & - & - & - & - & - & - & - & - & - & - & - & - & - & - & - & - & - & - & - & - & - & - & - & $\begin{array}{lll}- & \\
-1\end{array}$ & - & - & - & . \\
\hline & Coho & - & - & - & - & - & - & - & - & - & - & - & - & - & - & - & - & - & - & - & - & - & - & - & - & - & - & - & - & - & - & - & - & - & - & - & - & - & - & - & . \\
\hline & Chinook & - & - & - & - & - & - & - & - & - & - & - & - & - & - & - & - & - & - & - & - & - & - & - & - & 1 & 50 & 1 & 50 & 4 & 100 & 0 & 0 & 5 & 83 & 1 & 17 & - & - & - & 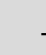 \\
\hline $\mathrm{H}$ & Chum & - & - & - & - & - & - & - & - & - & - & - & - & - & - & - & - & - & - & - & - & - & - & - & - & - & - & $\begin{array}{ll}- & \text { r }\end{array}$ & - & - & - & - & - & - & - & - & - & - & - & - & . \\
\hline & Coho & - & - & - & - & - & - & - & - & - & - & - & - & - & - & - & - & - & - & - & - & - & - & - & - & - & - & - & - & - & - & - & - & - & - & - & - & - & - & - & . \\
\hline & Chinook & - & - & - & - & - & - & - & - & - & - & - & - & - & - & - & - & - & - & - & - & - & - & - & - & - & - & - & - & - & - & - & - & 3 & 100 & 0 & 0 & - & - & - & 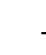 \\
\hline I & Chum & - & - & - & - & - & - & - & - & - & - & - & - & - & - & - & - & - & - & - & - & - & - & - & - & - & - & - & - & - & - & - & - & - & - & - & - & - & - & - & . \\
\hline & Coho & - & - & - & - & - & - & - & - & - & - & - & - & - & - & - & - & - & - & - & - & - & - & - & - & - & - & - & - & - & - & - & - & - & - & - & - & - & - & - & 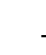 \\
\hline & Chinook & - & - & - & - & - & - & - & - & 0 & 0 & 1 & 100 & - & - & - & - & 1 & 50 & 1 & 50 & - & - & - & - & - & - & - & - & - & - & - & - & - & - & - & - & - & - & - & 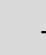 \\
\hline $\mathrm{N}$ & Chum & - & - & $\begin{array}{lll}- & -\end{array}$ & - & - & - & - & - & - & - & - & - & - & - & - & - & - & - & - & - & - & - & - & - & - & - & - & - & - & - & - & - & - & - & - & - & - & - & - & . \\
\hline & Coho & - & - & - & - & - & - & - & - & - & - & - & - & - & - & - & - & - & - & - & - & - & - & - & - & - & - & - & - & - & - & - & - & - & - & - & - & - & - & - & . \\
\hline & Chinook & 22 & 85 & 4 & 15 & 42 & 72 & 16 & 28 & 23 & 79 & 6 & 21 & 48 & 92 & 4 & 8 & 74 & 95 & 4 & 5 & 5 & 83 & 1 & 17 & 17 & 94 & 1 & 6 & 5 & 83 & 1 & 17 & 18 & 95 & 1 & 5 & 16 & 100 & 0 & ( \\
\hline Total & Chum & - & - & - & - & 0 & 0 & 8 & 100 & - & - & - & - & - & - & - & - & 0 & - & - & - & - & - & - & - & - & - & - & - & - & - & - & - & - & - & - & - & - & - & - & \\
\hline & Coho & - & - & - & - & 1 & 100 & 0 & 0 & 17 & 100 & 0 & 0 & 7 & 88 & 1 & 13 & 0 & - & - & - & - & - & - & - & - & - & - & - & - & - & - & - & - & - & - & - & - & - & - & 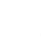 \\
\hline
\end{tabular}



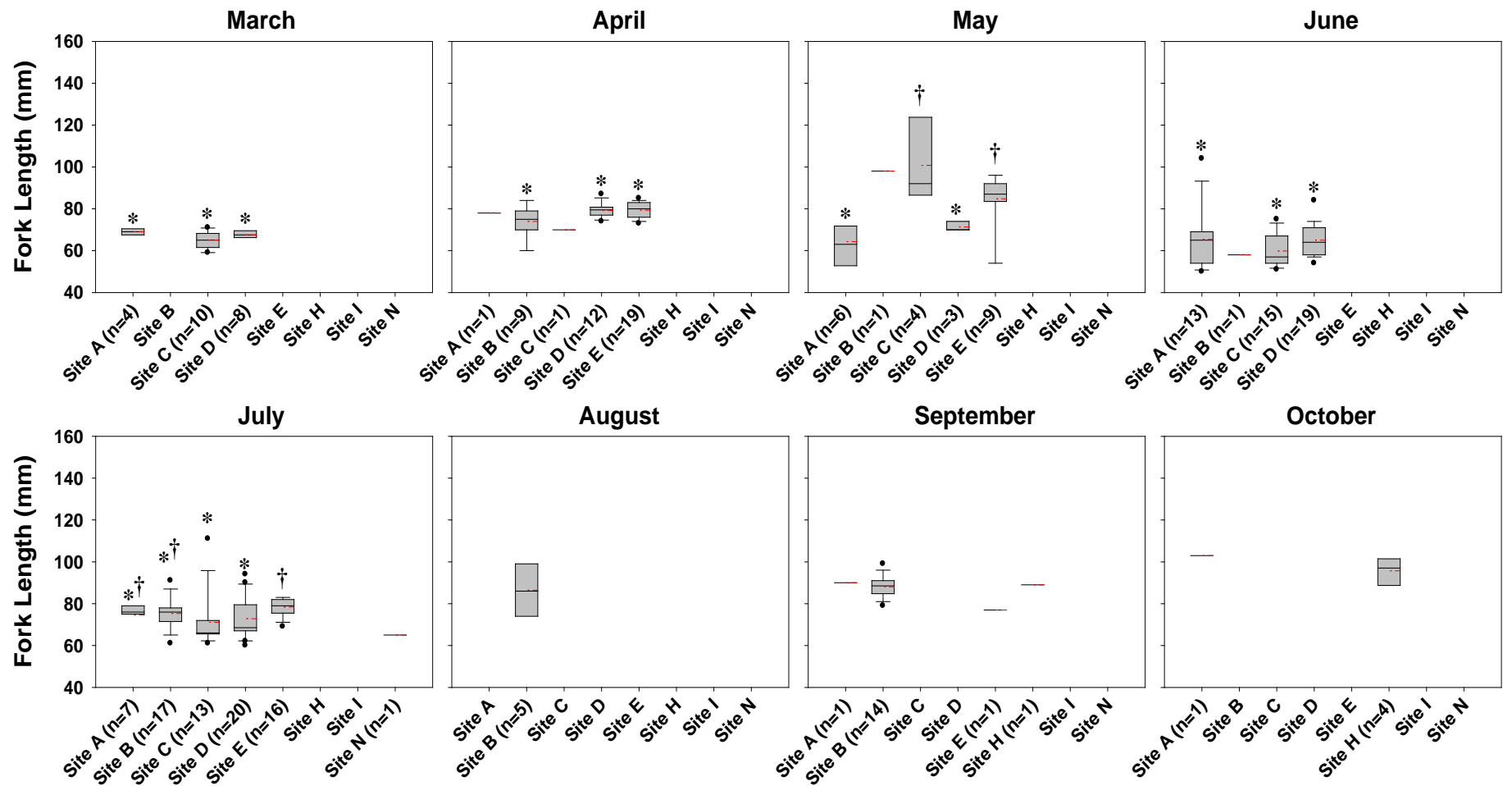

September

October

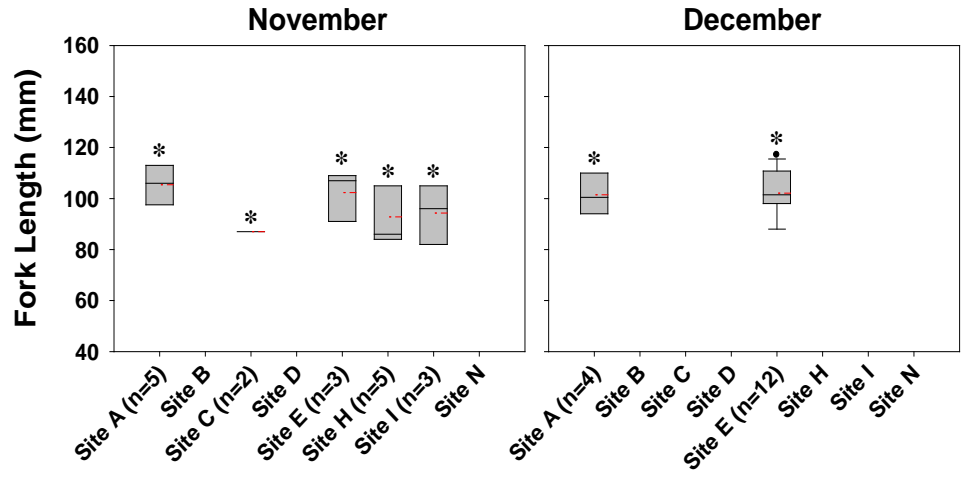

Figure 4.25. Spatial Comparison of Fork Lengths for Chinook Salmon from Which Gut Contents Were Sampled During 2008. The data are for fish with non-empty stomachs only. The box whiskers are the 90th and 10th percentiles. The solid black lines within boxes denote median FL values and the dashed red lines denote mean FL values. The solid black dots denote sample outliers. Within a site, the different symbols indicate significantly different $(\alpha=0.05)$ mean ranked FL values among sampling months. 

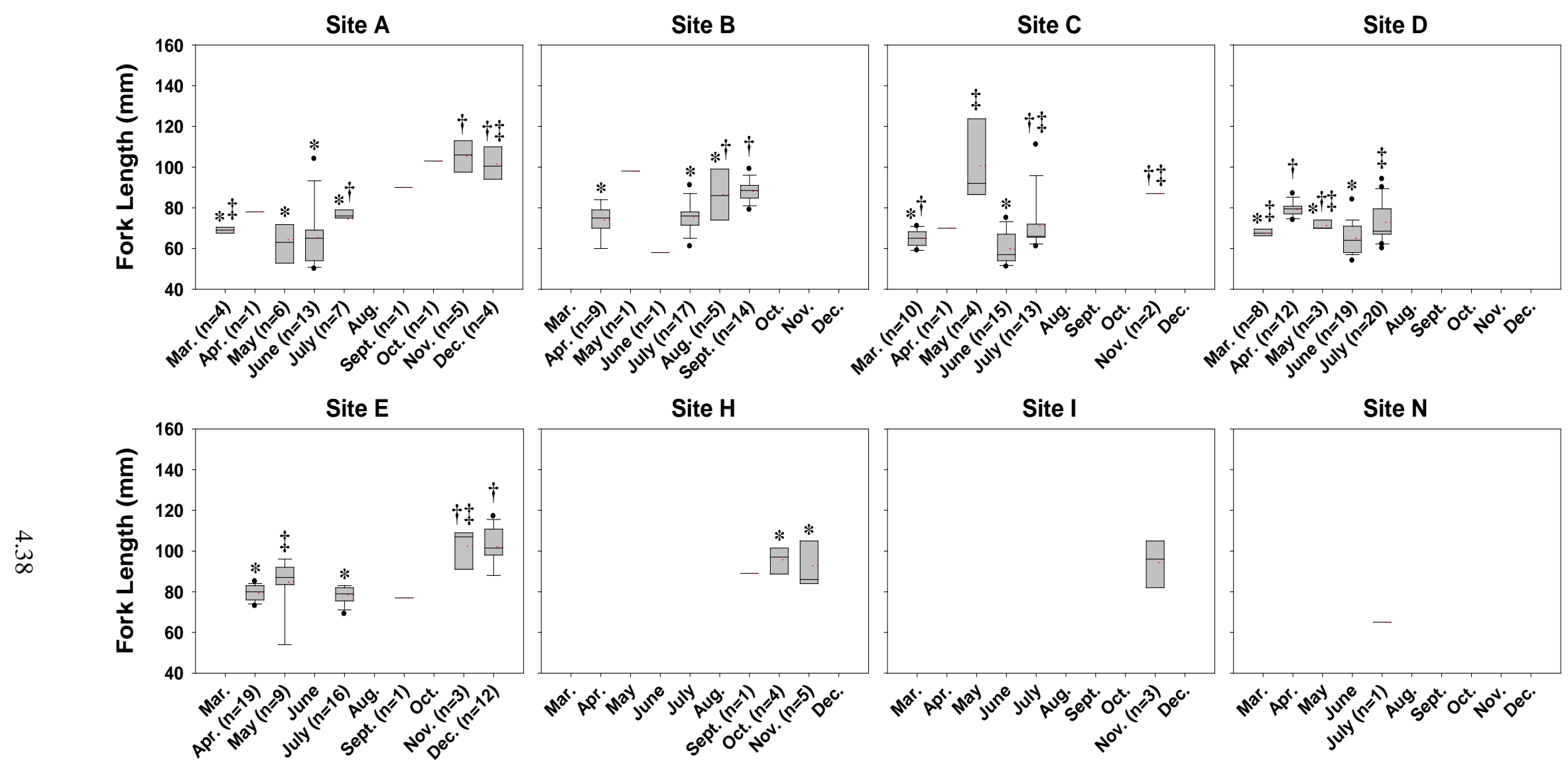

Figure 4.26. Temporal Comparison of Fork Lengths for Chinook Salmon from Which Gut Contents Were Sampled During 2008. The data are for fish with non-empty stomachs only. The box whiskers are the 90th and 10th percentiles. The solid black lines within boxes denote median FL values and the dashed red lines denote mean FL values. The solid black dots denote sample outliers. Within a site, the different letters indicate significantly different $(\alpha=0.05)$ mean ranked FL values among sites. 


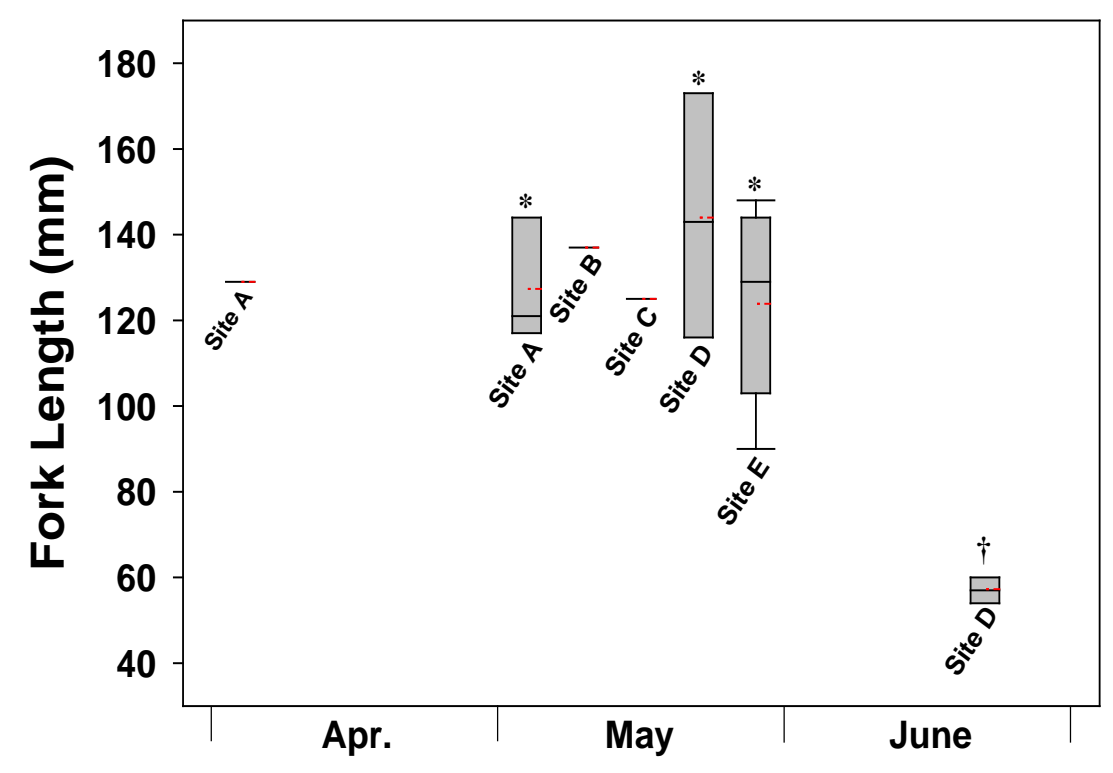

Figure 4.27. Spatial and Temporal Comparison of Fork Lengths for Coho Salmon from Which Gut Contents Were Sampled During 2008. The data are for fish with non-empty stomachs only. The box whiskers are the 90th and 10th percentiles. The solid black lines within boxes denote median FL values and the dashed red lines denote mean FL values. The solid black dots denote sample outliers. The different symbols indicate significantly different $(\alpha=0.05)$ mean ranked FL values among site by sampling month combinations.

Like Chinook salmon diets, the diets of coho salmon were generally dominated by aquatic dipterans. With the exception of a single fish sampled at Site A during April and Site D during May, coho salmon consumed few malacostracans (amphipods and mysids) or fish. Cladocerans, on average, comprised approximately $20 \%$ of the diet of fish sampled during May at Site E, but were otherwise poorly represented. Non-dipteran aquatic insects at times comprised large proportions of coho salmon diets, particularly during April at Site A, where these taxa accounted for approximately 50\% of prey items encountered. Taxa grouped into the "other" category contributed little to the average diet of coho salmon (Figure 4.29). 
Table 4.10. List of Taxa Encountered in the Gut Contents of Chinook and Coho Salmon Sampled in 2008

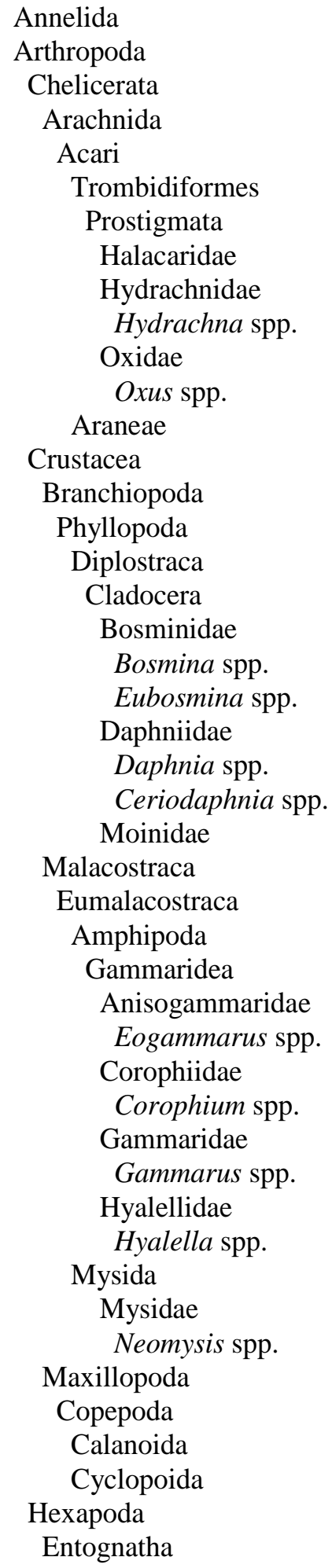

Annelida

Arthropoda

Chelicerata

Arachnida

Acari

Trombidiformes

Prostigmata

Halacaridae

Hydrachnidae

Hydrachna spp.

Oxidae

Oxus spp.

Araneae

Crustacea

Branchiopoda

Phyllopoda

Diplostraca

Cladocera

Bosminidae

Bosmina spp.

Eubosmina spp.

Daphniidae

Daphnia spp.

Ceriodaphnia spp.

Moinidae

Malacostraca

Eumalacostraca

Amphipoda

Gammaridea

Anisogammaridae

Eogammarus spp.

Corophiidae

Corophium spp.

Gammaridae

Gammarus spp.

Hyalellidae

Hyalella spp.

Mysida

Mysidae

Neomysis spp.

Maxillopoda

Copepoda

Calanoida

Cyclopoida

Hexapoda

Entognatha

\author{
Collembola \\ Entomobryomorpha \\ Entomobryidae \\ Insecta \\ Pterygota \\ Coleoptera \\ Adephaga \\ Haliplidae \\ Carabidae
}

Diptera

Brachycera

Dolichopodidae

Ephydridae

Muscidae

Phoridae

Syrphidae

Nematocera

Ceratopogonidae

Chaoboridae

Chaoborus spp.

Chironomidae

Dixidae

Simuliidae

Simulium spp.

Tipulidae

Ephemeroptera

Furcatergalia

Tricorythidae

Pisciforma

Acanthametropodidae

Siphlonuridae

Hemiptera

Auchenorrhyncha

Cicadellidae

Heteroptera

Corixidae

Glaenocorisa spp.

Hebridae

Lipogomphus spp.

Macroveliidae

Mesoveliidae

Mesovelia spp.

Saldidae

Veliidae

Sternorrhyncha

Aphididae
Hymenoptera

Apocrita

Braconidae

Diapriidae

Eulophidae

Ichneumonidae

Formicidae

Ponera spp.

Trichogrammatidae

Hydrophylita aquivolans

Lepidoptera

Pyralidae

Crambus spp.

Odonata

Anisoptera

Zygoptera

Coenagrionidae

Argia spp.

Chromagrion conditum

Plecoptera

Euholognatha

Nemouridae

Systellognatha

Perlodidae

Psocoptera

Thysanoptera

Trichoptera

Hydropsychidae

Hydroptilidae

Arctopsyche spp.

Myriapoda

Chordata

Vertebrata

Actinopterygii

Neopterygii

Salmoniformes

Salmonidae

Oncorhynchus keta

Mollusca

Bivalvia

Pholadomyoida

Nematomorpha

Gordioidea

Chordodidae

Tardigrada 

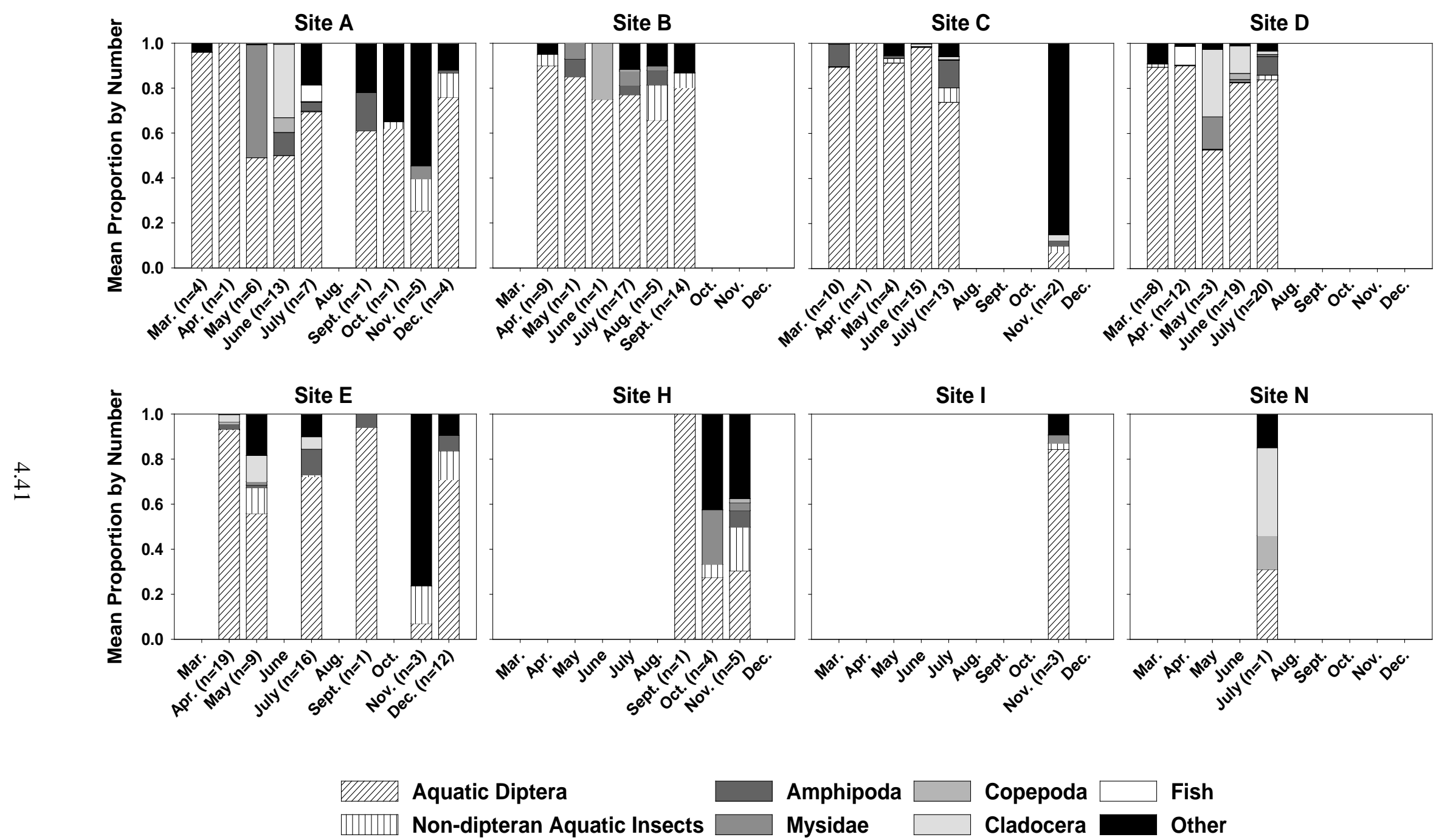

Figure 4.28. Distribution of Major Prey Categories Found in the Gut Contents of Chinook Salmon During 2008. Prey taxa were grouped based on taxanomic relationships and putative food quality values. See Table 4.10 for specific taxa within legend categories. "Other" includes Annelida, Arachnida, Collembola, Gordioidea, Mollusca, Myriapoda, Tardigrada, or terrestrial insects. The single Chinook salmon stomach sampled at Site F was empty. 
Site A
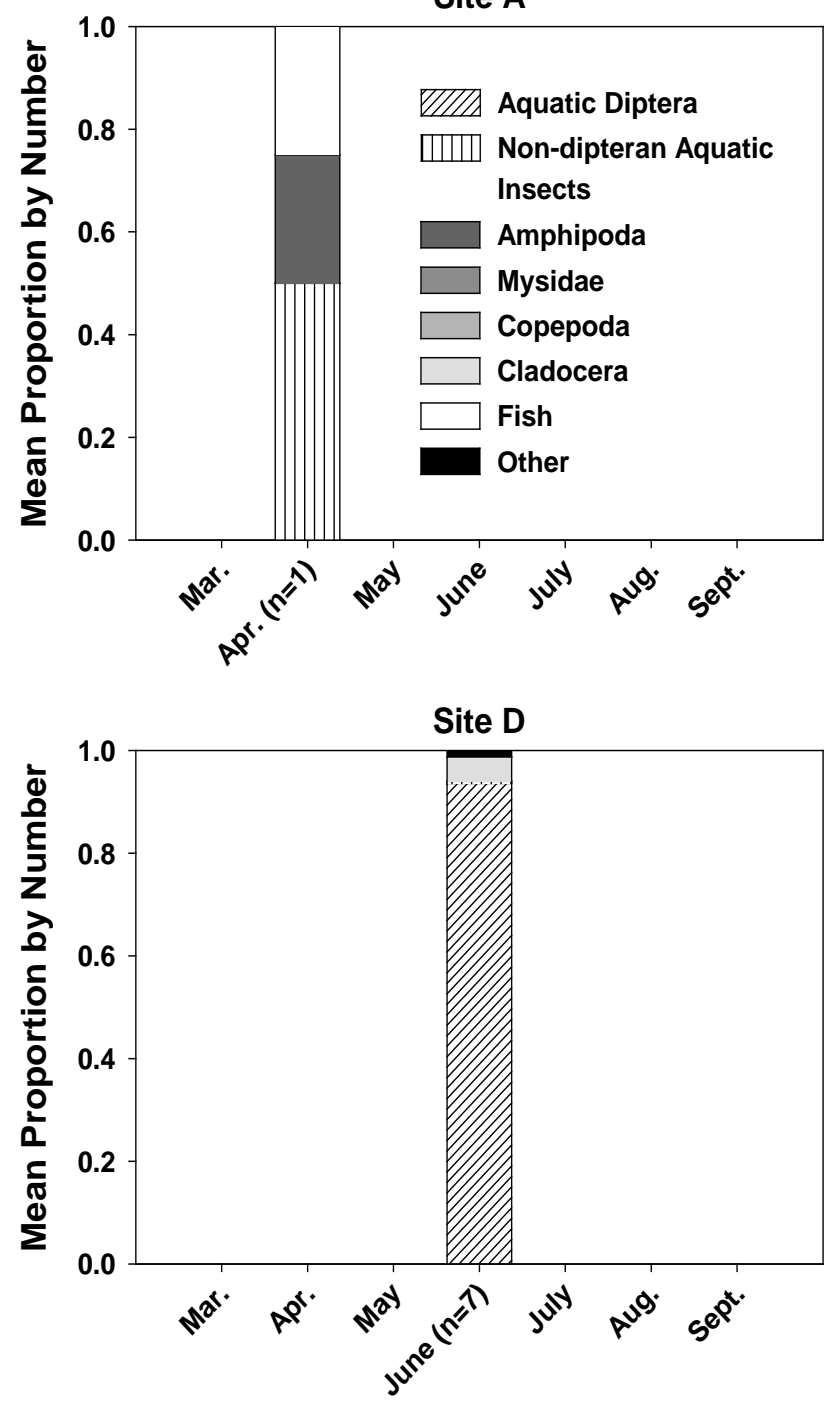

Site C

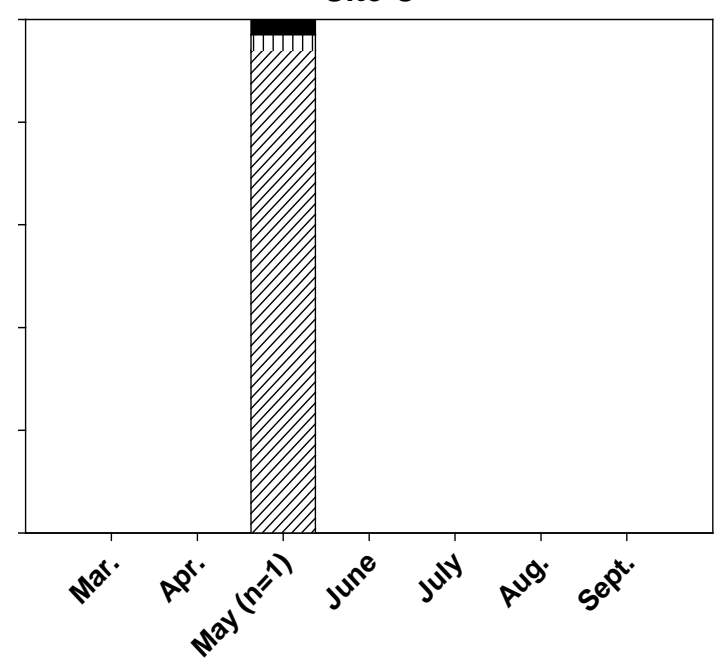

Site $\mathbf{E}$

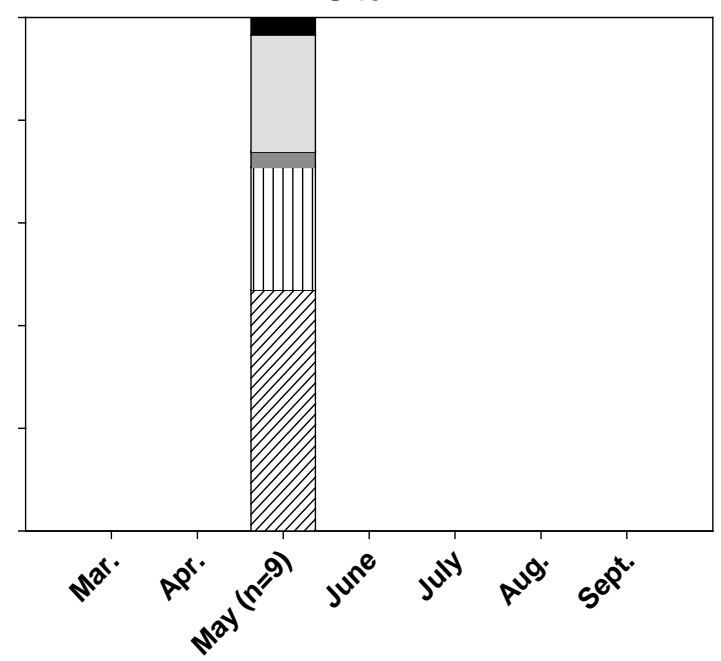

Figure 4.29. Distribution of Major Prey Categories Found in the Gut Contents of Coho Salmon During 2008. Prey taxa were grouped based on taxanomic relationships and putative food quality values. See Table 4.10 for specific taxa within legend categories. “Other” includes: Annelida, Arachnida, Collembola, Gordioidea, Mollusca, Myriapoda, Tardigrada, or terrestrial insects.

\subsubsection{Acoustic Telemetry}

Acoustic telemetry data were analyzed to estimate run timing, residence times, and migration pathways for acoustic-tagged fish in the TFM study area. A total of 981 juvenile salmonids (approximately $7 \%$ of the total number of marked fish) were detected at the acoustic nodes in the TFM study area (Table 4.11). Of this total, the majority were yearling spring Chinook salmon (500) and subyearling fall Chinook salmon (415). Sixty-six steelhead tagged with acoustic transmitters were detected at the TFM nodes. Of the 981 detected fish, 93\% were released in the Columbia River; the 
remaining 7\% were released in the Snake River at Lower Granite Dam. Fish released at the Arlington location had the highest number of detections in the TFM study area.

The majority of fish detections occurred at the Reed Island node (Table 4.11). The Flag Island node yielded the fewest detections. These detection patterns are similar to those observed during our 2007 study (Sobocinski et al. 2008). Of 981 fish, about 22\% of the acoustic-tagged fish were detected on more than one of the four nodes in the study area (Table 4.12).

Table 4.11. Numbers of Unique Acoustic-Tagged Fish Detected at the TFM Nodes by Species and Release Location

\begin{tabular}{lcccc}
\hline \multicolumn{1}{c}{ Release Location } & Spring Chinook & Steelhead & Fall Chinook & Total \\
\hline Lower Granite & 72 & 0 & 0 & 72 \\
\hline Arlington & 84 & 53 & 103 & 240 \\
\hline John Day Dam Tailwater & 31 & 13 & 51 & 95 \\
\hline The Dalles Dam Tailwater & 0 & 0 & 121 & 121 \\
\hline B2 Corner Collector & 95 & 0 & 80 & 175 \\
\hline Bonneville Dam Tailwater & 91 & 0 & 60 & 151 \\
\hline Skamania & 127 & 0 & 0 & 127 \\
\hline Total Unique Detections & 500 & 66 & 415 & 981 \\
\hline
\end{tabular}

Table 4.12. Numbers of Acoustic-Tagged Fish Detected by Sample Location (TFM Node) and Species. The total is greater than the total in Table 4.11 because some fish were detected on more than one TFM node. The ratio of the total detections to total unique detections approximates the proportion of fish detected on multiple nodes.

\begin{tabular}{lcccc}
\hline \multicolumn{1}{c}{ Sample Location (Node) } & Spring Chinook & Steelhead & Fall Chinook & Total \\
\hline 1. Reed Island (Site A) & 359 & 38 & 356 & 753 \\
2. Flag Island & 1 & 0 & 10 & 11 \\
3. Gap (between Gary and Flag islands) & 127 & 28 & 52 & 207 \\
4. Gary Island (Site E) & 138 & 27 & 56 & 221 \\
Total Detections & 625 & 93 & 474 & 1,192 \\
\hline Multiple Node Ratio & 1.25 & 1.41 & 1.14 & 1.22 \\
\hline
\end{tabular}

\subsubsection{Run Timing}

Run timing was represented by the total number of valid detections of tagged fish per day for all four nodes combined (Figure 4.30). During 2008, there were distinct peaks in abundance for yearling (AprilMay) and subyearling (June-July) Chinook salmon that correspond to seasonal migration timing. The largest peak occurred during May 21, 2008, when 100 different acoustic-tagged fish were detected. The 
near-zero detection rates during early June reflect the hiatus in tagging and release of test fish between the spring and summer periods. This run timing curve is typical for the Columbia River near Bonneville Dam (Figure 2.4).

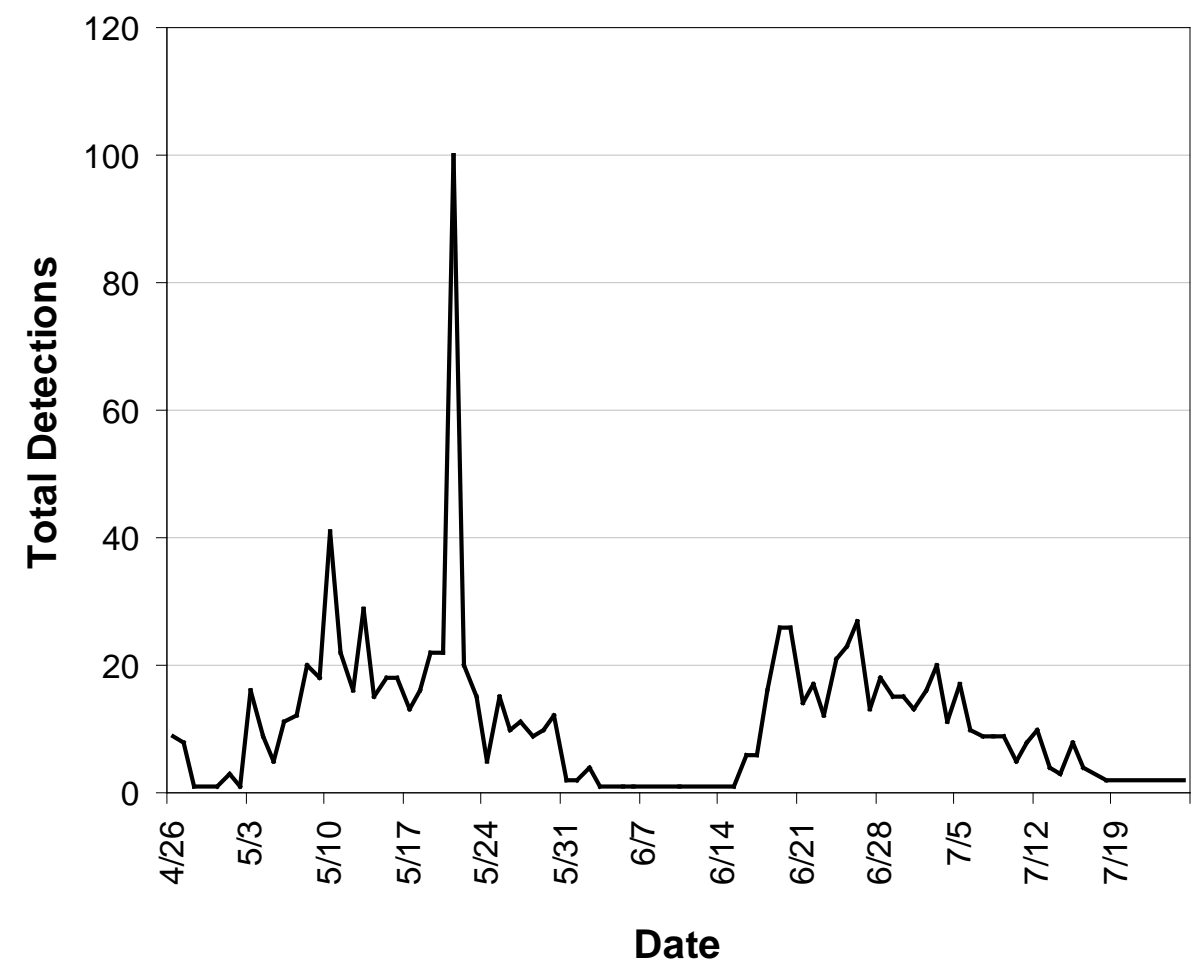

Figure 4.30. Run Timing Based on Mean Detection Time of Unique Juvenile Salmon Acoustic Telemetry System-Tagged Fish (Chinook and Steelhead) for All Locations Combined (Reed Island, Flag Island, Gary/Reed Gap, and Gary Island)

\subsubsection{Residence Times}

Residence time, as estimated by the mean duration between first and last valid detections at a given node, was longer for subyearling fall Chinook salmon than for yearlings (Figure 4.31). The longest mean residence time (10 hours) was for a subyearling detected at the Gary Island node. Steelhead had the shortest residence times of the three species of tagged fish in the study area. 


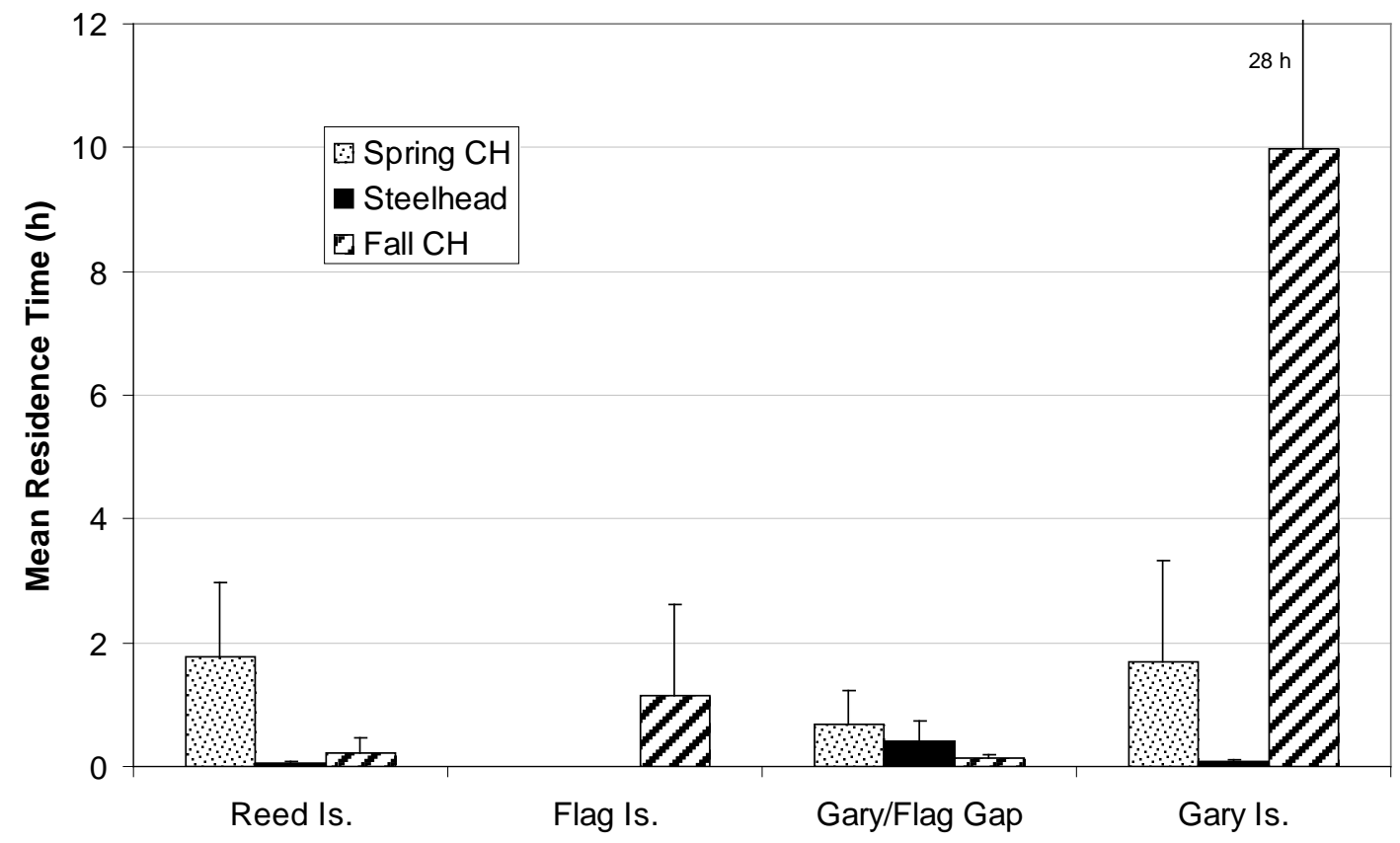

Figure 4.31. Residence Time (h) as Determined by Mean Duration Between First and Last Valid Detections at a Given Sample Site. Confidence intervals (95\%) are presented. Sample sizes are presented in Table 4.11.

\subsubsection{Migration Pathways}

Migration pathways were represented by detection histories. Based on when and where fish were detected, the majority of the acoustic-tagged fish in the study area used the main river channel exclusively (93\%; 13,063 of 14,044 fish; Table 4.13). Conversely, 7\% of the acoustic-tagged fish migrating from upriver release sites were present in side-channel habitats in the study area. Of these, an appreciable number of fish passed behind Reed Island in proximity to Site A. The migration pathway through the islands near the Sandy River delta was downstream, as indicated by sequential movements from the Gap node to the Gary Island node (Figure 3.3). Few acoustic-tagged fish appeared to use the potential migration pathway along the Oregon shore behind Chatham Island. Three fish crossed over from Reed Island to the delta islands. In fact, two of these three fish were yearling spring Chinook salmon that moved from Reed Island across the main channel and then upstream from Gary Island to the Gap to the Flag nodes. 
Table 4.13. Migration Pathways for Yearling Spring Chinook Salmon and Steelhead and Subyearling Fall Chinook Salmon. Pathways are summarized by main versus side channel (upper Reed and Lady Island arrays), around Reed Island (node 1), and through the delta islands (nodes 2, 3, and 4); see Figure 3.3.

\begin{tabular}{clcccc}
\hline & & Spring Chinook & Steelhead & Fall Chinook & Total \\
\hline A & Main Channel Only & 5,454 & 2,031 & 5,578 & 13,063 \\
& Side Channels Too & 500 & 66 & 415 & 981 \\
& Subtotal & 5,954 & 2,097 & 5,993 & 14,044 \\
B & Behind Reed & 284 & 30 & 242 & 556 \\
& Main by Reed & 73 & 8 & 113 & 194 \\
& Subtotal & 357 & 38 & 355 & 750 \\
C1 & Main to Delta & 122 & 26 & 56 & 204 \\
& Delta Only & 21 & 2 & 4 & 27 \\
& Subtotal & 143 & 28 & 60 & 231 \\
C2 & Delta to Secondary & 97 & 14 & 48 & 159 \\
& Downstream in Delta & 36 & 14 & 7 & 57 \\
& Upstream in Delta & 1 & 0 & 2 & 3 \\
& Flag Only & 0 & 0 & 2 & 2 \\
& Gap Only & 1 & 0 & 0 & 1 \\
& Gary Only & 8 & 0 & 1 & 9 \\
& Subtotal & 143 & 28 & 60 & 231 \\
Crossovers Reed to Delta & 3 & 0 & 0 & 3 \\
\hline & Grand Total & 503 & 66 & 415 & 984 \\
\hline
\end{tabular}

\subsection{Statistical Analysis}

Statistical results are included for a baseline BACI analysis, the relationship between juvenile salmon density and environmental variables, a fish community analysis, and monitoring program design.

\subsubsection{Baseline BACl Analysis}

Tukey's test of additivity was used to assess whether the salmon density over time was responding on the additive or log scale. Results of the test (Table 4.14) indicate that salmon density within habitats is closer to the log rather than the arithmetic scale, as anticipated. Therefore, trends in density over time are best represented by the log scale. The exception to these results stems from the pairing of Sites $\mathrm{N}$ and $\mathrm{C}$, which do not track on the arithmetic or log scale. 
Table 4.14. Results of Tukey's Test of Additivity. The test examined whether salmon density at replicate sites tracked through time on the arithmetic or log scale. Small $P$-values indicate rejection of the null hypothesis of tracking.

\begin{tabular}{lcc}
\hline \multicolumn{1}{c}{ Grouping } & $\begin{array}{c}\text { Tukey's Test p Value } \\
\text { (arithmetic scale) }\end{array}$ & $\begin{array}{c}\text { Tukey's Test p Value } \\
\text { (logarithmic scale) }\end{array}$ \\
\hline Sites A and E & $* * 0.016$ & 0.230 \\
Sites B and H & 0.948 & 0.949 \\
Sites C and N & $* * *<0.00001$ & $* * * 0.001$ \\
Sites D, F, and G & NA & NA \\
\hline$* *=$ Significant at $\alpha=0.05 ; * * *=$ Significant at $\alpha=0.01 ; \mathrm{NA}=$ not applicable & \\
\hline
\end{tabular}

\subsubsection{Juvenile Salmon and Environmental Variables}

Variables that explained salmon density were not persistent across months. For example, the Vancouver U.S. Geological Survey (USGS) gage height and Bonneville outflow were significantly correlated with salmon density during the December 2008 sample period, but were not found to be significant during any other sampling event (Table 4.15). Water temperature and Bonneville spill were significantly correlated with salmon density during April 2008 but not at other times. This preliminary analysis did not find any environmental covariates or set of covariates that adequately explained differences in salmon density between sites.

Table 4.15. Univariate Juvenile Salmon and Environmental Variables. Analysis was performed on the four sampling periods that yielded the highest densities of salmonids.

\begin{tabular}{|c|c|c|c|c|c|c|c|c|}
\hline \multirow[b]{2}{*}{ Variable } & \multicolumn{2}{|c|}{ December 2007} & \multicolumn{2}{|c|}{ December 2008} & \multicolumn{2}{|c|}{ April 2008} & \multicolumn{2}{|c|}{ July 2008} \\
\hline & p-Value & $\begin{array}{l}\text { Adj. R- } \\
\text { Squared }\end{array}$ & p-Value & $\begin{array}{l}\text { Adj. R- } \\
\text { Squared }\end{array}$ & p-Value & $\begin{array}{l}\text { Adj. R- } \\
\text { Squared }\end{array}$ & P-Value & $\begin{array}{l}\text { Adj. R- } \\
\text { Squared }\end{array}$ \\
\hline Temperature & 0.8702 & -0.2406 & 0.5122 & -0.07 & **0.0209 & 0.7169 & 0.5161 & -0.1096 \\
\hline Dissolved Oxygen & 0.3237 & 0.0503 & 0.6342 & -0.1038 & 0.1283 & 0.3472 & 0.3204 & 0.0538 \\
\hline Salinity & S0.1 & S0.1 & S0.1 & S0.1 & S0.1 & S0.1 & S0.1 & S0.1 \\
\hline Velocity & ND & ND & 0.4042 & -0.0273 & 0.602 & -0.1575 & 0.3438 & 0.0605 \\
\hline USGS Gage Height & 0.3832 & -0.0078 & **.0102 & 0.5816 & 0.3119 & 0.0632 & 0.969 & -0.2495 \\
\hline Bonneville Outflow & 0.6124 & -0.1625 & **.0366 & 0.4135 & 0.1385 & 0.3254 & 0.6497 & -0.1792 \\
\hline Bonneville Spill & Sp1.2 & Sp1.2 & Sp1.2 & Sp1.2 & $* 0.0871$ & 0.4498 & 0.4955 & -0.0963 \\
\hline Depth & 0.7348 & -0.2101 & 0.1928 & 0.1185 & 0.2398 & 0.1531 & 0.5082 & -0.1233 \\
\hline Mean Beach Slope & 0.6615 & -0.184 & 0.8176 & -0.1555 & 0.1617 & 0.2794 & 0.4557 & -0.0682 \\
\hline $\begin{array}{l}\text { Dominant Grain } \\
\text { Size }\end{array}$ & 0.5048 & ------ & 0.1461 & ------ & 0.3951 & ------ & 0.449 & ------ \\
\hline $\begin{array}{l}*=\text { Significant at } \alpha= \\
\text { S0.1 = salinity } 0.1 \mathrm{fc} \\
\text { ND = no data; Sp1.2 }\end{array}$ & $\begin{array}{l}10 ; * *= \\
\text { ll sites } \\
\text { spill } 1.2\end{array}$ & nificant a & $\begin{array}{l}=0.05 \\
\text { pling per }\end{array}$ & & & & & \\
\hline
\end{tabular}




\subsubsection{Community Analysis}

The only covariate found to be significant was DO (Table 4.16). No covariates were found to be significant for December 2007 and December 2008. The first two principal components (PC1 and PC2) explain 81\% of the variance for December 2007 (Figure 4.32). PC1 distinguishes salmon from non-salmon, while PC2 distinguishes native from non-native species. For December 2008, PC1 and PC2 account for $98 \%$ of the variance (Figure 4.32). Native species density is the predominant component of PC1, and non-native species density is the predominant component of PC2.

Table 4.16. Environmental Covariates Analyzed with Salmon Density for Time Periods in Which Density was Highest. Significant p-values appear in bold.

\begin{tabular}{lcccc}
\hline \multicolumn{1}{c}{ Covariate } & December 2007 & December 2008 & April 2008 & July 2008 \\
\hline Temperature & 0.267 & 0.528 & 0.285 & 0.172 \\
Dissolved Oxygen & 0.508 & 0.119 & $\mathbf{0 . 0 0 2}$ & $\mathbf{0 . 0 6 2}$ \\
Salinity & S0.1 & S0.1 & 0.296 & S0.1 \\
Velocity & ND & 0.605 & 0.412 & 0.804 \\
USGS Gage Height & 0.817 & 0.434 & 0.034 & 0.217 \\
Bonneville outflow & 0.318 & 0.318 & 0.807 & 0.875 \\
Bonneville spill & Sp1.2 & Sp1.2 & 0.681 & 0.829 \\
Depth & 0.766 & 0.698 & 0.662 & 0.884 \\
Mean Slope & 0.931 & 0.606 & 0.591 & 0.743 \\
\hline
\end{tabular}

S0.1 = Salinity 0.1 for all sites

$\mathrm{ND}=$ No data

Sp1.2 = Spill 1.2 throughout sampling period
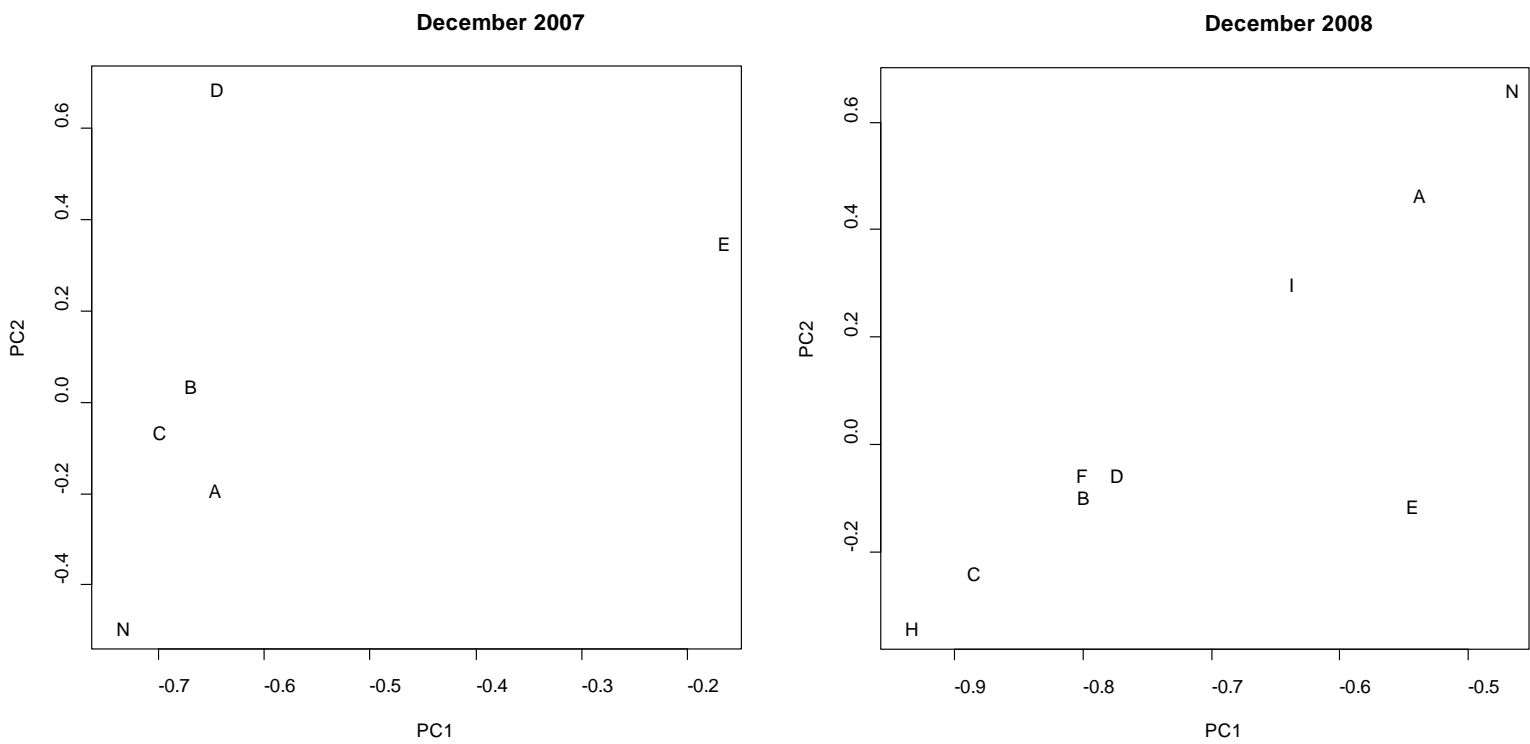

Figure 4.32. Principal Components for December 2007 and 2008 
Both dissolved oxygen and USGS gage height were determined to be significant covariates for April 2008. PC1 and PC2 explain over $96 \%$ of the variation. PC1 distinguishes salmon from non-salmon, while PC2 distinguishes native from non-native species (Figure 4.33). During July 2008, DO was found to be a significant covariate. PC1 and PC2 account for over 99.9\% of the variance. Native species density is by far the largest component of PC1, and PC2 distinguishes salmon from non-native species. The analysis indicates that community composition towards greater native and salmon composition was related to higher DO concentrations. The result is similar to the finding for April 2008. In addition, gage height was inversely related to salmon and native species composition.
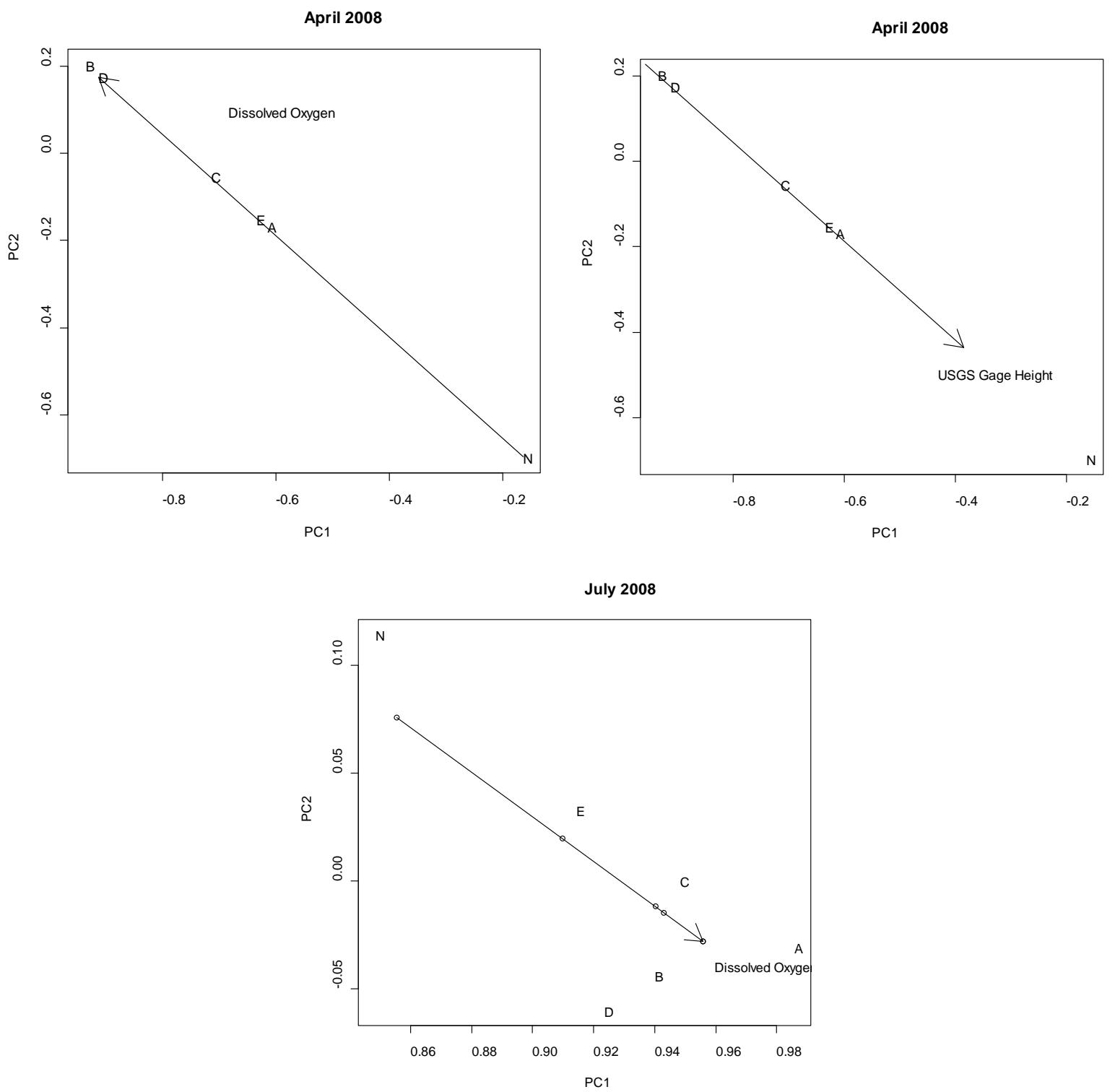

Figure 4.33. Principal Components for April 2008 and July 2008 


\subsubsection{Monitoring Program Design}

Optimal allocation of monitoring effort to sampling site and within-site sampling effort will depend on the relative magnitude of the between- and within-site variance components. With two net sets per site visit, the variance in salmon density was partitioned to between-site and within-site variance components (Table 4.17). The analysis indicates the within-site variability among replicate net sets is twice as large as the between-site variability (i.e., coefficient of variation [CV] of 1.514 vs. 0.731 ). Within-site standard deviation between samples is $150 \%$ larger than the mean salmon density. Hence, precise site characterization is very difficult and can obscure between-site differences. Effective monitoring may necessitate greater within-site sampling effort, other more consistent techniques, or greater efforts aimed at sampling over larger spatial scales as opposed to an intensive site-scale focus.

Table 4.17. Summary of the Mean Salmonid Density per Survey Period Along with the Within-Site Measurement Error and Spatial (i.e., between-site) Variance on a Monthly Basis. These variance components are also expressed in terms of a coefficient of variation (i.e., $\mathrm{CV}=\sigma / \bar{x})$ used in expressing sampling precision.

\begin{tabular}{lccccc}
\hline \multicolumn{1}{c}{ Month } & $\begin{array}{c}\text { Measurement } \\
\text { Error }\end{array}$ & $\begin{array}{c}\text { Spatial } \\
\text { Variance }\end{array}$ & Mean & $\begin{array}{c}\text { CV Measurement } \\
\text { Error }\end{array}$ & CV Spatial \\
\hline December 2007 & 0.1874 & 0 & 0.1355 & 3.194 & 0 \\
March 2008 & 0.0009 & 0.00022 & 0.0220 & 1.376 & 0.665 \\
April 2008 & 0.0078 & 0.00093 & 0.0950 & 0.924 & 0.319 \\
\hline May 2008 & 0.1114 & 0.0478 & 0.2200 & 1.516 & 0.993 \\
\hline June 2008 & 0.0024 & 0.009 & 0.0889 & 0.549 & 1.065 \\
\hline July 2008 & 0.00084 & 0.0000539 & 0.0350 & 0.835 & 0.211 \\
\hline September 2008 & 0.000018 & 0.0000046 & 0.0025 & 1.666 & 0.857 \\
\hline October 2008 & 0.000003 & 0.0000012 & 0.0008 & 2.259 & 1.405 \\
\hline December 2008 & 0.000046 & 0.0000306 & 0.0052 & 1.310 & 1.067 \\
\hline Mean & 0.0345 & 0.00645 & 0.0672 & 1.514 & 0.731 \\
\hline
\end{tabular}




\subsection{Discussion}

\subsection{Fish and Habitat}

Chinook salmon were the most abundant salmonid and occurred within various habitat types throughout the study period from June 2007 through December 2008. Unlike other salmonids encountered during our study, the seasonal distribution of Chinook salmon was not relegated to a single time period. We noted three distinct peaks in Chinook salmon density. The first two occurred during spring and summer and correspond to the outmigration periods. The third peak occurred during the winter months, which may indicate a life history strategy that includes overwintering in tidal freshwater of the lower Columbia River.

Most of Chinook salmon found within the shallow tidal freshwater habitats in our study area were likely subyearling migrants. Some Chinook salmon of a size to be classified as yearling fish began to appear in our catches during May. However, we did not measure the age of fish encountered in our study area and, therefore, are unable to definitively classify age groups of Chinook salmon. The predominance of smaller subyearling Chinook salmon within shallow habitats is consistent with observations linking size of migrating salmon to occupancy within particular habitats. Dawley et al. (1986) found that yearling smolts with migration distances that exceeded a few kilometers generally used deeper main-channel areas for migration pathways. Our analysis of migratory pathways of large ( $>95-\mathrm{mm}$ FL) Chinook salmon indicate few (approximately 7\%) of the acoustic-tagged salmon used the shallow off-channel habitats in our study area. The few yearling-sized fish encountered in our study area may be reflective of differences in life history requirements by larger migrating salmon. However, the absence of larger size classes of most taxa encountered during our study may be indicative of the sampling efficiency of our seine, but also the accessibility of habitats to smaller sized fish in shallow water areas.

Fish access to shallow off-channel habitats is linked to the dynamic relationship between bathymetry and river discharge. Accessibility issues were most notable during periods of low flow. For example, while Chatham Island maintains a deep channel on the southwest side of the island, accessibility to and from the island was constrained by the low bathymetric relief. Additionally, beach habitats characterized by expansive flats (Sites $\mathrm{C}$ and $\mathrm{D}$ ) often became inaccessible by boat; at times Site C dewatered completely. During periods of low flow, the data loggers indicated the amplitude of water elevation fluctuation was greatest at Site A compared with Sites B and C. This may be partially explained by the degree of hydraulic connectivity between Site A and the mainstem of the river. Furthermore, the bathymetry associated with the shallow water habitats near Sites B and C is more complex and contains an expansive array of micro-topographies that may dilute the signal of changes in water elevation. We also noted that the degree of habitat connectivity may be linked to habitat quality. At Site N, dissolved oxygen values were markedly lower compared with other sites. This is likely explained by the lack of surface water connectivity between the blocked channel and the historic Sandy River delta.

The link between bathymetry and water elevation is also an important consideration for vegetation in the types of habitats encountered within shallow tidal freshwater areas of the LCRE. The large percentage of obligate vegetation species found at Sites A, B, C, E, and N indicates the level of water inundation at these sites is sufficient to support wetland communities. Many of the obligate species noted at our sites are representative of stable, native tidal freshwater wetlands (e.g., creeping spikerush, slough sedge, rice cutgrass, and wapato) found throughout the lower Columbia River (Christy and Putera 1994). 
Growth of wetland plants at our sites appeared to be limited by several factors, including inundation, elevation, substrate condition, and interactions with other plant species. We noted an inter-annual variation in coverage of submerged aquatic vegetation at Site C, where high coverage during 2007 was followed by low coverage during 2008. This variation may be linked to high river discharge throughout the spring and early summer 2008 that may have inhibited the amount of light necessary for plants to establish. In addition to being constrained by too much water, the growth and establishment of vegetation may be limited where steeply sloping beach faces prevent adequate inundation (Sites $\mathrm{F}$ and $\mathrm{H}$ ). Because soil moisture content is an important factor for the survival of emergent vegetation, it is not surprising that substrates composed of larger grain size fractions appeared to limit vegetation growth and were often associated with large expanses of bare ground at our study sites. Further, coarse substrates appeared to limit the coverage of reed canary grass at our sites; however, high coverage of saplings at elevations typically occupied by this invasive plant may also be preventing the establishment of this invasive wetland plant.

\subsection{Fish Community}

While our primary goal was to investigate salmon ecology within shallow, tidal freshwater habitats, reviewing the entire species composition provides a holistic understanding of the fish community structure at our sampling sites. Overall abundance of salmon was much less than native non-salmon taxa and exotic groups. This is likely explained by the low number of taxa within the salmon group compared to the native and non-native groups. Introductions of exotic fishes can impose adverse impacts on native species, commonly through interspecific competition (McIntosh et al. 1994, Marchetti 1999, Hasegawa and Maekawa 2006), direct predation (Townsend and Crowl 1991, Marsh and Douglas 1997), or alteration of physical habitat (Byers et al 2006). Throughout the 2007-2008 sampling period, approximately $46 \%$ of the fish taxa encountered were non-native. Two introduced species, banded killifish and bluegill, comprised 22\% of the total combined catch. Because this research was not designed to assess interactions between native and introduced fishes, and despite the prevalence of some exotics in our catches, we can only speculate upon the impacts of non-native fishes on juvenile salmon at our sites.

The diets of the two most abundant introduced species in our catches, banded killifish and bluegill, overlap substantially with those of Chinook and coho salmon, particularly in the size ranges we collected. Banded killifish approximately 31-41 mm in total length have been found to consume aquatic insect larvae, crustaceans, and terrestrial insects; banded killifish greater than $64 \mathrm{~mm}$ in length consume similar prey items in addition to larger insects and small mollusks. Bluegills maintain a relatively constant diet throughout their lives, consisting primarily of aquatic insects (Wydoski and Whitney 2003). The results of the diet analysis presented in this study showed that, at our sites, juvenile Chinook and coho salmon consumed small invertebrates, primarily aquatic dipterans and terrestrial insects. The species composition of our catches, the length distributions of salmon and abundant introduced taxa, results of our diet analysis on Chinook and coho salmon and the putative diets of non-native fishes, and the consistent spatial and temporal overlap in occurrence of the dominant exotic species and salmon suggest interspecific resource competition between introduced fishes and native salmon may occur at our sites. While our data indicate potential competition, the strength and outcome of these interactions will likely depend upon factors including prey and space availability, fish density, niche plasticity, strength of intraspecific competition, species-specific forage capabilities, and the residence time of juvenile salmon in tidal freshwater habitats. 
Based on the size distributions of exotic species in our catches, it appears unlikely that direct predation by non-native fishes plays a large role in structuring yearling and subyearling salmon populations at our sites. The two most prevalent exotics, banded killifish and bluegill, typically do not consume other fishes. Although bluegill have been shown to consume larval fish (Kim and DeVries 2001), to our knowledge, no studies have reported larger salmon in the gut contents of the bluegill. The sizes of most Chinook and coho salmon in our samples likely preclude consumption by small, gapelimited exotics. Introduced fish known to be piscivorous as adults, including smallmouth bass, largemouth bass, yellow perch, and brown bullhead, occurred rarely in our catches, and were likely encountered at life stages during which invertebrates contribute more to their diets than fish prey (Wydoski and Whitney 2003).

Although our data indicate predatory exotic species encountered at the TFM sites comprised sizeclasses that may not impose predation risks to juvenile salmon, several additional factors must be considered. Gear biases may have led to under representation of very small salmon, able to be consumed by the larger predators we encountered, or larger exotic predators, capable of consuming larger salmon. In addition, our sampling was conducted during the day, and therefore, diel horizontal movement or crepuscular feeding habits of larger predators were not necessarily accounted for in our sampling regime. To appropriately evaluate predator-prey interaction between introduced and native fishes in tidal freshwater areas of the Columbia River, sampling techniques should consider predator movements and ontogenetic feeding variability.

Like competition and direct predation, alteration of physical habitat by exotic fishes can have deleterious impacts on native species (Zambrano et al. 2006). For example, by uprooting or consuming aquatic macrophytes, the common carp can limit access to refuge or alter local hydrology leading to shifts in useable/favorable habitat. Additionally, bottom-associated exotics, such as the common carp, can limit the foraging capabilities of other fishes by re-suspending fine sediments during feeding (Wydoski and Whitney 2003). In our samples, “ecosystem engineers” (Byers et al 2006) like carp were encountered rarely. The degree to which introduced species are impacting salmon through alteration of physical habitat is unknown; however, the low densities of species such as carp encountered at our sampling sites suggests this interaction may be minimal.

Although assessing specific consequences of fish introductions is beyond the scope of this research, the presence of certain non-salmon species in our samples indicates potential for negative impacts on salmon populations. In addition to those discussed above, other direct and indirect consequences of species introductions including the alteration of food web dynamics (Eby et al. 2006) and the introduction of novel parasites (e.g., Vincent and Font 2003) may act to limit salmon growth and survival at our sites.

\subsection{Diets}

A quantitative understanding of the feeding ecology of fishes is essential to elucidating factors that may constrain or promote growth and survival in specific areas. Knowledge of mechanisms regulating the acquisition of energy and nutrients through diet can help characterize the suitability of specific habitats for fish. Although our data provide only an instantaneous description of recently consumed prey items, these results identify generalized juvenile Pacific salmon foraging patterns across discrete habitat types, leading to future research examining more directed ecological questions. 
Ontogenetic diet shifts are common in most fish species (Werner and Hall 1976; Buijse and Houthuijzen 1992). We identified several statistically significant differences in fork length among sampling months. In general, temporal shifts in diet exhibited similar patterns regardless of the mean length of fish sampled, indicating little effect of length on diet composition. Although mean ranked fork lengths both among species and, during certain sampling months, among sites were statistically different, diet composition was generally similar. During months when stomachs from both Chinook and coho salmon were sampled, aquatic dipterans were the principal diet component. At most sites where Chinook gut contents were collected, the diet typically was dominated by aquatic dipterans during early months with a shift toward greater proportions of other taxa in later periods. Thus, statistically significant differences in fish length were not reflected by marked differences in diet composition, spatially, temporally, or among species.

During most months at sites where Chinook or coho salmon stomach contents were sampled, aquatic dipterans comprised large proportions of the diets of both species. The dietary importance of aquatic dipterans identified in this study is consistent with other studies conducted in areas of the LCRE. Lott (2004) found the diets of juvenile Chinook salmon were dominated by chironomids. Similarly, Bottom et al. (2008) reported adult dipterans were commonly the most important prey taxon in the diets of subyearling Chinook salmon. Viewed in terms of foraging efficiency, the pervasiveness of aquatic dipterans in the diets of young salmon at our sites is logical, because members of this order account for most of the macroinvertebrates in freshwater environments (Bode 1990).

In later months, prey items included in the "other" category-composed primarily of terrestrial insects-became important constituents of the diet. This shift toward larger proportions of non-dipteran prey may indicate opportunistic exploitation of an easily accessible pool of drifting invertebrates. Assuming that the densities of aquatic dipterans, such as chironomids, decrease as environmental conditions change in later months (e.g., Lott 2004), this hypothesis conforms to optimal foraging theory (Werner and Hall 1974; Gerking 1994); fish consuming larger proportions of drifting invertebrates will likely expend less energy than when actively pursuing benthic or emerging prey.

Malacostracans occasionally comprised small proportions of the gut contents of Chinook salmon. While an analysis of gape limitation is beyond the scope of our data, the small size of fish included in this study may have largely precluded encountering large-bodied amphipods and mysids in gut contents. Like Chinook, coho salmon consumed few malacostracans, with one exception; during May at Site D, amphipods and mysids comprised approximately $40 \%$ of the diet. The mean fork length of fish from which gut contents were examined during this period was $144 \mathrm{~mm}$. Presumably, these larger salmon were less constrained by gape width, and therefore better able to handle and ingest larger invertebrates.

Although our analyses were constrained by lack of temporal representation and small sample sizes, this synthesis has identified general foraging patterns of juvenile Pacific salmon at our sampling sites. Future work, including characterization of prey availability and a determination of the relative importance of prey items by weight, will help shed light on more explicit questions related to feeding ecology and resource use of yearling and subyearling salmon in shallow, tidally influenced freshwater habitats in the vicinity of the Sandy River delta. 


\subsection{Genetics}

Genetic analysis of Chinook salmon juveniles collected in 2008 revealed distinct differences in the stock compositions of fish that were unmarked and marked (by adipose fin clip, CWT, or both). Whereas the major proportion of the unmarked sample was fish from the upper Columbia River summer/fall stock (51\%), the Spring Creek group tule fall stock was predominate in the marked fish (75\%). In addition, while only two stock groups were estimated to contribute greater than $5 \%$ to the marked population, five genetic groups including Snake River fall run were present at that level in the unmarked population.

It is likely that all of the marked fish we sampled were hatchery fish. While small numbers of naturally produced salmon are sometimes caught and tagged or marked for research purposes, more than 31 million marked subyearling hatchery Chinook salmon were released in locations upstream of our study site in 2008 (Table 2.1). In addition, more than 7 million unmarked subyearlings were released. These releases included fish from all of the major stock groups, with more than $70 \%$ of the unmarked fish belonging to the upper Columbia River fall stock released in areas between McNarry and Priest Rapids dams. We therefore conclude that while our analysis of unmarked fish provides insight into the habitat use of naturally produced Chinook salmon, the samples likely include some hatchery fish as well.

The large proportion of the upper Columbia River summer/fall stock in our unmarked samples may be comprised of fish from sources down-river from the historic range of the stock. One potential source is a population of upper Columbia River fall natural spawners $35 \mathrm{rkm}$ upstream from our study area at Ives Island (Myers et al. 2006). In recent years, from 1200 to 1900 Chinook salmon are estimated to have spawned at Ives Island (Tomaro et al. 2007; Van der Naald et al. 2006). A second potential lower river source of upper Columbia River fall fish in our unmarked samples is from hatcheries. In late June and in July 2008, approximately 2.0 million unmarked upper Columbia River fall Chinook salmon were released into the Klickitat River (Table 2.1). In addition, 2.0 million upper Columbia River fall Chinook salmon were released from the Little White Salmon National Fish Hatchery into the Little White Salmon River and 3.6 million were released into Tanner Creek from the Bonneville Hatchery, near Bonneville Dam. Although the releases from the Little White Salmon and Bonneville hatcheries were 100\% marked with adipose fin clips, some fish may have inadvertently remained unmarked or been inadequately marked for

detection in the field. In addition to these lower river sources, populations further upriver, including those within the area of the upper Columbia River summer and fall ESU, may have contributed fish to our samples (see Tables 2.1 and 2.2). Additional genetic data, or perhaps information provided by environmental markers such as from otolith analyses, are needed to estimate the proportions of upper Columbia River summer/fall fish in our study area that are of natural and hatchery origin as well as the fractions that are from lower and upper river locations.

The second year of our study included sampling in the spring, a period not sampled in 2007. As a result, we were able to document a seasonal shift in stocks from mostly Spring Creek group fall fish to a more diverse mixture of populations in the summer. A seasonal transition in stock proportions has also been detected in lower estuary beach seine habitats (Roegner et al. 2004). However, in contrast to lower estuarine nearshore areas, which are mostly occupied by West Cascade Tributary fall run fish throughout the summer, the predominate genetic stock in Sandy River delta habitats is the upper Columbia River summer/fall stock group.

It is noteworthy that the habitats we sampled in the Sandy River delta area during the first two years of our study are occupied by juvenile Chinook salmon from multiple distinct genetic lineages. Previous 
research has documented contrasting life-history features among these Columbia River basin genetic groups, including differences in age at sea entry, patterns of ocean migration, age at maturation, and adult run and spawn timing (e.g., Waples et al. 2004, Myers et al. 2006). Because similar information about estuarine habitat usage is much less complete, one of the goals of our study is to collect genetic data that can be combined with those from other surveys and develop such a baseline.

\subsection{Acoustic Telemetry}

The overall objective of 2007-2008 acoustic telemetry research at the Sandy River delta was to assess the feasibility of applying acoustic telemetry technology for action effectiveness research in side-channel, tidal freshwater habitats of the LCRE. Given the potential Sandy River delta rechannelization of the old river channel, we collected pre-construction, baseline data to quantify temporal distributions, residence times, and migration pathways in the general vicinity of the restoration site. We used existing state-ofthe-art acoustic telemetry technology, taking advantage of the thousands of acoustic-tagged fish migrating downstream through the study area that were released at sites upstream near Bonneville Dam and beyond as part of studies by the USACE. In cooperation and coordination with the USACE and PNNL, this secondary use of fish tagged and released upstream for other studies is cost-effective and should be considered where appropriate in the LCRE.

The study demonstrated the feasibility of detecting fish tagged with the smallest available acoustic transmitters ( $0.45 \mathrm{~g}$ in air) in relatively deep (>3 m) side-channel habitats of the LCRE. During 2007, detecting tagged fish in shallow water $(<3 \mathrm{~m})$ was problematic, because fluctuating water surface elevations affected the ability to receive acoustic transmissions. Furthermore, detection capability is problematic in shallow water $(<5 \mathrm{~m})$, because transmitted signals can be distorted when they are received by a hydrophone after traveling multiple paths to the hydrophone. Accordingly, during 2008 we deployed receivers only in the relatively deep areas behind Gary and Reed islands. We were able to detect tagged fish migrating downstream in these side-channel pathways.

Although the bulk of the tagged fish population migrated down the main channel of the LCRE, some fish used side-channel routes in the vicinity of the Sandy River delta. This is consistent with findings downstream of Puget Island where tagged fish were detected in side-channel routes in Cathlamet and Grays bays (McComas et al. 2009). Access to side-channel habitats is likely important for rearing and refuge opportunities for juvenile salmon (Bottom et al. 2008). The off-channel distribution may also reflect density-dependent allocation of available space given the large numbers of juvenile salmon entering the LCRE each year. The migration characteristics we observed, however, are not representative of the juvenile salmon population as a whole in the LCRE because of limitations caused by transmitter size.

The size of the transmitter limited the group of fish that could be reliably tagged to those greater than 95-mm FL. While salmon of this size may be representative of one life history strategy, the majority of juvenile salmon encountered during our study period were made up of smaller size classes (overall mean $\mathrm{FL}=65 \mathrm{~mm}$ ). The size distribution for Chinook salmon encountered via beach seine efforts at our study sites ranged from 33 to $158 \mathrm{~mm}$. To gain an appreciable understanding of salmon ecology in shallow tidal freshwater habitats, using acoustic telemetry, the tag size will need to be drastically reduced to accommodate smaller fish. 
Tag effects are a concern with any methodology where an object is surgically implanted in an animal. While the tagged fish in this study seemed to be actively migrating, we do not know how the implanted tag may have affected fish behavior. Hockersmith et al. (2008), researching tag effects studies for the same types of transmitters and species of fish we studied, reported that travel times in most reaches investigated were not significantly different between fish tagged with Juvenile Salmon Acoustic Telemetry System transmitters and fish tagged with PIT tags. Furthermore, laboratory experiments by Hockersmith et al. (2008) showed low mortalities (<4.5\%) of yearling Chinook salmon for both tag types. For subyearling Chinook salmon, mortality among sub-yearling control and PIT-tag treatments ranged up to $7.7 \%$, while integrated and non-integrated treatments had slightly higher rates (up to $8.3 \%$ and $7.9 \%$, respectively). Tag effects must be accounted for during action effectiveness research using acoustic telemetry.

Acoustic telemetry has the potential to provide useful data about temporal distributions, residence times, and migration pathways to assess the effectiveness of restoration actions in the LCRE. However, the current technology remains limited by transmitter size (tagged fish must be $>95 \mathrm{~mm}$ ), receiving capability in shallow water $(<3 \mathrm{~m})$, and transmitter life. Besides downsizing the existing acoustic tags, the size limitation could be addressed by developing a "pinger" tag that transmits an uncoded acoustic signal instead of the coded pulse currently used to obtain a unique identifier. Because the pinger signal would not be unique, new statistical approaches similar to those used in analysis of batch mark data in fisheries would be necessary. To overcome the limitations of shallow water, we recommend comparing the performance of the omni-directional hydrophone we used to the performance of a directional (e.g., 30 deg) hydrophone to support development of design guidelines for the optimum acoustic transmitter/receiving system for shallow water. Moreover, the transmitters we used lasted for 45-60 days. A long-life tag would be useful for over-wintering studies in LCRE tidal freshwater.

Radio-frequency transmitters are another option worth considering for shallow water. Receiving antennas could be placed on shore with fewer logistical constraints than would be the case with underwater acoustic receivers. As tagging technologies evolve and improve, they should be considered for application to action-effectiveness research in the LCRE. Objectives could include mark-recapture for juvenile salmon residence time, abundance and distribution relative to pile structures, and alternatives assessment and field tests of acoustic telemetry methods for survival estimation at restoration sites.

\subsection{Sampling Considerations}

Beach seines are used to sample fish communities in a variety of ecosystems (e.g., lotic, lentic, marine) and are best suited for shallow water habitats (Hayes et al. 1996). The overall size of the seine and the corresponding deployment technique is largely dependent on project needs. Based on the collective technical experience of the TFM team, we found it necessary to modify our sampling approach during 2008. Our current net design and deployment technique stems from a modification of the protocols designed for sampling fish in Puget Sound (Miller et al. 1990). The haul lines used to set the net perpendicular to shore provide an advantage over setting the net in a semicircle, because we are able to effectively sample a larger area and achieve greater consistency in size of the area swept between sets. However, this approach of setting the net farther from shore is not without its disadvantages. At some sites, retrieving the seine was industrious when river discharge was high. Under these circumstances, we set the net closer to the shore and documented the change in area swept by the seine. 
Our current sampling approach is effective for researching nearshore fish communities in a variety of shallow tidal freshwater water habitats within the LCRE. The exception to this includes Site N, a seasonally ponded channel that is too narrow to accommodate effectively setting two non-overlapping hauls with our large seine. Because Site $\mathrm{N}$ is critical to one of our study objectives aimed at evaluating the implications of ecosystem restoration on the ecology of juvenile salmon, we found it important to minimize confounding before-after comparisons, and therefore, we use the smaller (30-m) seine at this site. After site restoration, it will be important to continue the use of the smaller seine even if channel reconnection facilitates using the larger seine.

Monthly sampling allows us to examine the seasonal variation in the community structure of fishes in shallow tidal freshwater water habitats. For example, we noted the abundance of native fishes demonstrated seasonal trends with distinct peaks occurring in late summer and winter months. At the TFM sites, salmon abundance was strongly correlated to the spring outmigration period, yet we also noted peaks during summer and the winter months. Monthly sampling provides better temporal resolution compared to less frequent approaches. However, a thorough investigation of the diversity of salmon within shallow water habitats may necessitate a sampling regime that occurs more frequently. Because the migration of juvenile salmon occurs as a continuum of strategies that may be linked to a multitude of metrics (e.g., migration timing, genetic stock, size class, density), an increase in sampling frequency may increase the resolution of knowledge as it pertains to the diversity and early life history of salmon in the LCRE.

The results of the 2008-2010 field study will be integrated into a tidal-freshwater monitoring design. The findings will be used to help determine where, when, and how much monitoring is necessary to track the status and trends in salmon use over time on the tidal-freshwater segment of the Columbia River. The TFM data are providing a means by which to assess the allocation of sampling effort within and between sites. Various component estimates will be used to optimally allocate such sampling efforts. The result should be a well-focused and statistically valid monitoring program suitable for salmon populations and for making inferences to the tidal-freshwater environment efficiently and precisely.

The planned 2009 fish blitz effort aimed at investigating stock-specific distribution of salmon within the tidal-freshwater habitat will also be used to outline site-selection processes for a regional monitoring program. The sampling approach will produce reach-specific site lists as well as information pertaining to sites that are incapable of being sampled according to existing techniques. Reconnaissance surveys will provide this information as well as criteria to stratify the sampling frame by habitat types. The blitz sampling, in turn, will be used to compare fish abundance and density between shoreline habitat types. It is anticipated that this information will be used to identify key habitats used by juvenile salmon and provide a means to focus monitoring efforts on important habitat types.

\subsection{Rechannelization Restoration}

Site-specific understanding of the Sandy River delta gained from baseline monitoring under the TFM project is applicable to a discussion of the efficacy of the proposed reconnection of the old Sandy River to the Columbia River. The primary outlet of the Sandy River was plugged with an earthen dam in the 1930s. The confluence of the Sandy River was redirected to a distributary channel and has remained approximately $3 \mathrm{~km}$ downstream of the historic mouth of the Sandy River for the past 60 years. Removal of the dam will be aimed at reestablishing the connectivity of the Sandy River channel to its historic 
confluence (Harkenrider 2006). The remnant channel was seasonally ponded during periods of low flow, but connectivity between the Sandy River and the historic delta was achieved during high-flow conditions.

The low degree of connectivity between the Sandy River and the historic confluence likely constrains the functional integrity of this floodplain-deltaic ecosystem. Episodic wetting and drying phases within floodplain areas can impact the dynamics of microbial activities in sediments which in turn influence the flux of carbon, nitrogen, and phosphorous (Thoms 2003; Baldwin and Mitchell 2000). We noted the low degree of surface water connectivity was correlated with low DO within the remnant channel, yet the absence of elevated water temperatures indicated the remnant channel maintains some degree of hyporheic connection with the Sandy River. Vegetation surveys near the remnant channel indicate a large proportion of obligate wetland species. Compared with other sites closer to the Columbia River, the remnant channel was also noted to have the greatest amount of submerged aquatic vegetation. This may be explained by the low degree of hydraulic flushing, which, when coupled with riparian interactions in abandoned channels, can lead to the accumulation of detritus and a high degree of soil organic content (Schwarz et al. 1996).

Despite the seasonal fluctuations in water elevation at the remnant channel, this location (Site N) as well as our sampling location at the historic mouth of the Sandy River (Site C) yielded the highest mean densities of fish (native non-salmon taxa and exotic species) relative to other sampling locations. We have also encountered salmon in the remnant channel during our study. These fish likely enter the remnant channel via overland flow from the Sandy River or from the downstream end of the channel at the former mouth of the Sandy River. Removal of the earthen barrier would likely increase fish accessibility to the remnant channel as well as habitats within the historic Sandy River delta. While sediment deposition at river confluences is a common geomorphic feature (Benda et al. 2004), the lack of hydrologic connectivity at the former mouth of the Sandy River is likely linked to the substantive flats that become exposed, bare ground during low-flow periods.

Changes in the flow regime, coupled with riparian plantings as part of other restoration efforts in the delta, will likely increase water quality, sediment export, and nutrient flux within the Sandy River delta. Confluences offer a source of heterogeneity in mainstem rivers by influencing morphological features and aquatic habitats. This heterogeneity may elicit favorable biological responses through an increase in species richness (Benda et al. 2004). Large river deltas with distributary channels are not common features in the present tidal freshwater landscape of the Columbia River. The link between deltaic features and juvenile salmon ecology has been investigated in tidally dominated systems (Beamer et al. 2005), but to our knowledge the role of functioning deltaic habitats in the tidal freshwater portion of the Columbia River has yet to be fully explored. Although most fish migrating long distances in the Columbia River basin use the main river channel (Dawley et al. 1986), our data (genetic and acoustic telemetry) indicate that juvenile salmon originating from upstream populations such as the Snake River are encountered within the shallow water habitats of our study area. Reconnecting the old Sandy River channel to the Columbia River will likely increase the opportunity and capacity of habitats for aquatic biota, including juvenile salmon. 



\subsection{Conclusions and Recommendations}

The results from the June 2007 through December 2008 study period lead to the following conclusions about the habitats and ecology of juvenile salmon in tidal freshwater of the LCRE as sampled monthly with beach seines and other equipment at nine sites in the vicinity of the Sandy River delta (rkm 192-208):

1. Habitat characteristics at the nine monthly sampling sites are diverse. Substrate spans from sandy to silty. Topography ranges from gradually sloping, low-relief areas to steeply graded beaches. Some sites have a moderate or high percent cover of emergent vegetation dominated by $E$. palustris, while Salix spp. are wide spread.

2. Juvenile Chinook and/or coho salmon are present at all types of tidal freshwater habitats sampled at one time or another. And they are present during all months of the year at one location or another. The fish community we sampled in shallow tidal freshwater is dominated by four species - threespine stickleback, peamouth chub, Northern pikeminnow, and banded killifish.

3. Unmarked juvenile Chinook salmon are mostly from the upper Columbia River summer/fall stock group, which may include individuals from the upper Columbia River, mid Columbia River, Columbia Gorge, and sources below Bonneville Dam. The West Cascade Tributary, Spring Creek, Snake River, and Deschutes River fall run stock groups are also present in the study area. Marked juvenile Chinook salmon are mostly from the Spring Creek group with some from the Snake River and West Cascade Tributary groups.

4. Regardless of sampling month or site of capture, the diets of juvenile Chinook salmon are generally dominated by aquatic insects (Diptera, mostly Chironomidae and Ceratopogonidae).

5. It is feasible to use acoustic telemetry to detect juvenile salmon tagged with the smallest available acoustic transmitters ( $0.45 \mathrm{~g}$ in air) in relatively deep ( $>3 \mathrm{~m})$ side-channel habitats of the LCRE. Although most of the tagged fish population ( $>95 \mathrm{~mm}$ FL) migrates downstream in the main river channel, about $10 \%$ of the tagged fish use side channel routes in tidal freshwater.

6. The TFM project's baseline data on fish densities will be applicable to the evaluation of the potential rechannelization of the Sandy River delta and design of a juvenile salmon monitoring program for beach habitats within tidal freshwater segment of the lower Columbia River and estuary (rkm 56-234).

Future TFM research will evaluate our cumulative datasets in the context of providing an understanding of the relationship between the ecological role of shallow tidal freshwater habitats and juvenile salmon life histories. Recommended objectives for the Year 3 study (May 2009 through April 2010) are as follows:

1. Describe migration characteristics of juvenile salmon in tidal freshwater in the context of their habitats and fish communities by completing the following activities:

a. Characterize the fish community and juvenile salmon migration, including species composition, length-frequency distribution, average weights, density $\left(\# / \mathrm{m}^{2}\right)$, and temporal and spatial distributions in the vicinity of the Sandy River delta and other tidal freshwater 
habitats within the lower Columbia River, and apply the density data to contribute to the design a juvenile salmon monitoring program for the entire tidal freshwater segment (rkm 56-234).

b. Determine the genetic stock of origin for juvenile Chinook salmon captured at beach seine sampling sites.

c. Characterize vegetation composition and percent cover, conventional water quality, water surface elevation, substrate composition, bathymetry, and beach slope at sites within tidal freshwater.

d. Assess statistical relationships between salmon abundance and habitat characteristics, including ancillary variables such as temperature and river stage.

2. Assess the ecological importance of tidal freshwater habitats to juvenile salmon in the vicinity of the Sandy River delta by completing the following activities:

a. Assess juvenile salmon diet, including the composition and weight of stomach contents.

b. Ascertain the species composition and abundance of available prey from terrestrial, planktonic, and benthic sources.

c. Model the bioenergetics of juvenile salmon in shallow tidal freshwater to evaluate differences in growth among species, seasons, and habitat types.

d. Assess the condition of juvenile salmon using Fulton's Condition Factor.

e. Perform a pilot acoustic telemetry study to estimate residence times through mark-recapture of juvenile Chinook salmon during winter 2009/2010.

During the period June 2007 through December 2008, the TFM project made substantial progress addressing the questions: In what types of habitats within the tidal freshwater area of the Columbia River are juvenile salmon found, when are they present, and under what environmental conditions? What is the ecological contribution of shallow ( $0-5 \mathrm{~m})$ tidal freshwater habitats to the recovery of ESA-listed salmon in the Columbia basin? A comprehensive report answering these questions will be released after research scheduled for January 2009 to April 2010 has been completed. 


\subsection{References}

Adams, NS, DW Rondorf, SD Evans, JE Kelley, and RW Perry. 1998. Effects of surgically and gastrically implanted radio transmitters on swimming performance and predator avoidance of juvenile Chinook salmon (Oncorhynchus tshawytscha). Can J. Fish. Aquat. Sci. 55:781-787.

Baldwin, DS and AM Mitchell. 2000. The Effects of Drying and Re-Flooding on the Sediment and Soil Nutrient Dynamics of Lowland River-Floodplain Systems: A Synthesis. Regulated Rivers: Research \& Management 16: 457-467.

Beamer, E, A McBride, C Greene, R Henderson, G Hood, K Wolf, K Larsen, C Rice, K Fresh. 2005. Delta and Nearshore Restoration for the Recovery of Wild Skagit River Chinook Salmon: Linking Estuary Restoration to Wild Chinook Salmon Populations. Skagit River System Cooperative, La Conner, Washington.

Benda, L, NL Poff, D Miller, T Dunne, G Reeves, G Pess, and M Pollock. 2004. The Network Dynamics Hypothesis: How Channel Networks Structure Riverine Habitats. BioScience 54(5): 413-426.

Bisson, PA, CC Coutant, D Goodman, R Gramling, D Lettenmaier, J Lichatowich, E Loudenslager, W Liss, L McDonald, D Philipp, and B Riddell. 2000. The Columbia River Estuary and the Columbia River Basin Fish and Wildlife Program. ISAB 2000-5, Independent Scientific Advisory Board report to the Northwest Power and Conservation Council, Portland, Oregon.

Bode, RW. 1990. “Chironomidae.” In Freshwater Macroinvertebrates of Northeastern North America. Eds. Peckarsky, BL, PA Fraissinet, MA Penton, and DJ Conklin, Jr. Cornell University Press, Ithaca, New York.

Bottom, D, K Jones, T Cornwell, A Gray, and C Simenstad. 2005a. Patterns of Chinook Salmon Migration and Residency in the Salmon River Estuary (Oregon). Estuarine Coastal and Shelf Science 64:79-93.

Bottom, DL, CA Simenstad, J Burke, AM Baptista, DA Jay, KK Jones, E Casillas, and M Schiewe. 2005b. Salmon at river's end: the role of the estuary in the decline and recover of Columbia River salmon. NOAA Technical Memorandum NMFS-NWFSC-68, U.S. Department of Commerce. 246 p.

Bottom, DL, G Anderson, A Baptista, J Burke, M Burla, M Bhuthimethee, L Campbell, E Casillas, S Hinton, K Jacobson, D Jay, R McNatt, P Moran, GC Roegner, CA Simenstad, V Stamatiou, D Teel, and JE Zamon. 2008. Salmon Life Histories, Habitat, and Food Webs in the Columbia River Estuary: An Overview of Research Results, 2002-2006. Report of Research, 2002-2006, U.S. Army Corps of Engineers, Portland District, Northwest Division, Portland, Oregon, and Bonneville Power Administration, Environment, Fish, and Wildlife Division, Portland, Oregon.

Buijse, AD and RP Houthuijzen. 1992. Piscivory, growth and size-selective mortality of age 0 pikeperch (Stizostedion lucioperca). Canadian Journal of Fisheries and Aquatic Sciences 49:894-902. 
Byers, JE, K Cuddington, CG Jones, TS Talley, A Hastings, JG Lambrinos, JA Crooks, and WG Wilson. 2006. Using ecosystem engineers to restore ecological systems. Trends in Ecology and Evolution 21:493-500.

Carl, LM and MC Healey. 1984. Differences in Enzyme Frequency and Body Morphology among Three Juvenile Life History Types of Chinook Salmon (Oncorhynchus tshawytscha) in the Nanaimo River, British Columbia. Can J. Fish. Aquat. Sci 41:1070-1077.

Christy, JA and JA Putera. 1993. Lower Columbia River Natural Area Inventory 1992. Prepared for the Nature Conservancy, Washington Field Office, Seattle, Washington. 89 pp.

DART 2009a. DART River Environment Graphics and Text. Data Courtesy of U.S. Army Corps of Engineers, NWD and Grant County PUD. Available at: http://www.cbr.washington.edu/dart/river.html. (Accessed on March 2, 2009)

DART 2009b. DART Smolt Index Metadata and Glossary. Available at: http://www.cbr.washington.edu/dart/help/pass_def.html. (Accessed on March 30, 2009)

Dawley, EM, RD Ledgerwood, TH Blahm, CW Sims, JT Durkin, RA Kirn, AE Rankis, GE Monan, and FJ Ossiander. 1986. Migrational Characteristics, Biological Observations, and Relative Survival of Juvenile Salmonids Entering the Columbia River Estuary, 1966-1983. DACW57-85-F-0623, Report to Bonneville Power Administration. 256 p.

Eby, LA, WJ Roach, LB Crowder, and JA Stanford. 2006. Effects of stocking-up freshwater food webs. Trends in Ecology and Evolution 21:576-584.

Environmental Science Research Institute (ESRI). 2008. Creating TIN surface data from vector data. Available online: http://webhelp.esri.com/arcgisdesktop/9.3 (Accessed on 2/20/2009)

Environmental Science Research Institute (ESRI). 2009. Using Kriging in 3D Analyst. Available online: http://webhelp.esri.com/arcgisdesktop/9.3 (Accessed on 2/20/2009)

Fresh, KL, E Casillas, L Johnson, and D Bottom. 2005. Role of the Estuary in the Recovery of Columbia River Basin Salmon and Steelhead: An Evaluation of Limiting Factors. NOAA Technical Memorandum NMFS-NWFSC-69, U.S. Department of Commerce, Seattle, WA. 105 pp.

Gerking, SD. 1994. Feeding Ecology of Fish. Academic Press, San Diego. 416 pp.

Harkenrider, DT. 2006. Sandy River Delta Small Dam Removal Proposal. United States Forest Service. File Code: 2620/1950. Hood River, OR.

Hasegawa, K and K Maekawa. 2006. The effects of introduced salmonids on two native stream-dwelling salmonids through interspecific competition. Journal of Fish Biology 68:1123-1132.

Hayes, DB, CP Ferreri, and WW Taylor. 1996. Active Fish Capture Methods. In Fisheries Techniques. Eds. BR Murphy and DW Willis, American Fisheries Society, Bethesda, Maryland. p. 27 
Hockersmith EE, RS Brown, and TL Liedtke. 2008. Comparative Performance of Acoustic-tagged and PIT-tagged Juvenile Salmonids. PNNL-16604, final report submitted to the U.S. Army Corps of Engineers, Portland District by National Marine Fisheries Service, Pasco, Washington, Pacific Northwest National Laboratory, Richland, Washington, and the U.S. Geological Survey, Cook, Washington.

Hoffarth, P. 2008. District 4 Fish Management Annual Report 2008. Available from Washington Department of Fish and Wildlife, 600 Capital Way N., Olympia, WA 98501.

Independent Scientific Review Panel (ISRP). 2006. Final Review of Proposals Submitted for Fiscal Years 2007-2009. ISRP 2006-6, Northwest Power and Conservation Council, Portland, Oregon.

Johnson, G, H Diefenderfer, B Ebberts, C Tortorici, T Yerxa, J Leary, and J Skalski. 2008.

Kalinowski, ST, KR Manlove, and ML Taper. 2007. ONCOR: A Computer Program for Genetic Stock Identification. Department of Ecology, Montana State University, Bozeman, Montana. Available at http://www.montana.edu/kalinowski/kalinowski_software.htm

Kim, GW and DR DeVries. 2001. Adult fish predation on freshwater limnetic fish larvae: a mesocosm experiment. Transactions of the American Fisheries Society 130:189-203.

Kukulka, T and D Jay. 2003. Impacts of Columbia River discharge on salmonid habitat: 1. A nonstationary fluvial tidal model. Journal of Geophysical Research 108:9-1 to 9-20.

Kunz, L.M. 1994. Preliminary Classification of Native, Low Elevation, Freshwater Wetland Vegetation in Western Washington. Washington Department of Natural Resources, Olympia, WA. 120pp.

Lott, MA. 2004. Habitat-specific feeding ecology of ocean-type juvenile Chinook salmon in the lower Columbia River estuary. M.S. Thesis, University of Washington, Seattle, Washington. 110 pp.

Lower Columbia River Estuary Partnership (LCREP) and Lower Columbia Fish Recovery Board (LCFRB). 2004a. Lower Columbia Salmon and Steelhead Recovery and Subbasin Plan. Volume I and II. Report prepared for the Northwest Power and Conservation Council, May 28, 2004. Available at http://www.nwcouncil.org/fw/subbasinplanning/lowerColumbia/plan/.

Manel, S, O Gaggiotti, and RS Waples. 2005. Assignment methods: matching biological questions with appropriate techniques. Trends in Ecology and Evolution 20:136-142.

Marchetti, MP. 1999. An experimental study of competition between the native Sacramento perch (Archoplites interruptus) and Introduced bluegill (Lepomis macrochirus). Biological Invasions 1:55-65.

Marsh, PC and ME Douglas. 1997. Predation by introduced fishes on endangered humpback chub and other native species in the Little Colorado River, Arizona. Transactions of the American Fisheries Society 126:343-346.

Marshall, A. 1998. Genetic analysis of mainstem Columbia River, below Bonneville Dam, Chinook spawners. Memo. to K. Harlan, 9 Feb. 1998 (Available from WDFW, 600 Capitol Way N., Olympia,WA 98501.) 
Marshall, A. R., C. Smith, R. Brix, W. Dammers, J. Hymer, and L. LaVoy. 1995. Genetic diversity units and major ancestral lineages for Chinook salmon in Washington. In C. Busack and J. B. Shaklee (editors), Genetic diversity units and major ancestral lineages of salmonid fishes in Washington. p 111173. Wash. Dep. Fish Wildl. Tech. Rep. RAD 95 02. (Available from Washington Department of Fish and Wildlife, 600 Capital Way N., Olympia WA 98501-1091.)

McComas, RL, GA McMichael, JA Vucelick, L Gilbreath, JP Everett, SG Smith, TJ Carlson, G Matthews, and JW Ferguson. 2009. A Study to Estimate Salmonid Survival Through the Columbia River Estuary Using Acoustic Tags, 2007. Draft report submitted to the U.S. Army Corps of Engineers, Portland District by National Marine Fisheries Service, Seattle, Washington, and Pacific Northwest National Laboratory, Richland, Washington.

McComas, RL, GA McMichael, JA Vucelick, L Gilbreath, JP Everett, SG Smith, T Carlson, G Matthews, and JW Ferguson. 2008. A Study to Estimate Salmonid Survival through the Columbia River Estuary using Acoustic Tags, 2006. National Marine Fisheries Service, Seattle, Washington. Available at: ttps://www.nwp.usace.army.mil/ pm/e/afep_estuary.asp

McIntosh, AR, TA Crowl, and CR Townsend. 1994. Size-related impacts of introduced brown trout of the distribution of native common river galaxias. New Zealand Journal of Marine and Freshwater Research 28:135-144.

Meehan, WR and RA Miller. 1978. Stomach flushing: Effectiveness and influence on survival and condition of juvenile salmonids. Journal of the Fisheries Research Board of Canada 35:1359-1363.

Merritt, RW and KW Cummins. 1996. An Introduction to the Aquatic Insects of North America. Third ed., Kendall/Hunt Publishing Co., Dubuque, Iowa. 862 p.

Miller, B, D Gunderson, P Dinnel, R Donnelly, and D Armstrong. 1990. Recommended Guidelines for Sampling Soft-Bottom Demersal Fishes by Beach Seine and Trawl in Puget Sound. In Recommended Protocols for Measuring Selected Environmental Variables in Puget Sound. Ed. Puget Sound Water Quality Action Team, U.S. Environmental Protection Agency; Region 10, Seattle, Washington.

Miller, BA and S. Sadro. 2003. Residence time and seasonal movements of juvenile Coho salmon in the ecotone and lower estuary of Winchester Creek, South Slough, Oregon. Transactions of the American Fisheries Society 132:546-559.

Milner, G. B., D. J. Teel, F. M. Utter, and G. A. Winans. 1985. A genetic method of stock identification in mixed populations of Pacific salmon, Oncorhynchus spp. Marine Fisheries Review 47:1-8.

Moran, P and J Baker. 2002. Polymerase Chain Reaction Inhibition in Historical Fish Scale Mounting Cards. Transactions of the American Fisheries Society 131:109-119.

Myers, J. M., R. G. Kope, G. J. Bryant, D. Teel, L. J. Lierheimer, T. C. Wainwright, W. S. Grant, F. W. Waknitz, K. Neely, S. T. Lindley, and R. S. Waples. 1998. Status review of Chinook salmon from Washington, Idaho, Oregon, and California. U.S. Dept. Commer., NOAA Tech. Memo. NMFS-NWFSC-35, 443 p. 
Myers, JM, C Busack, D Rawding, AR Marshall, DJ Teel, DM Van Doornik, and MT Maher. 2006. Historical population structure of Pacific salmonids in the Willamette River and lower Columbia River basins. NOAA Technical Memo, NMFS-NWFSC-73, U.S. Department of Commerce, Seattle, Washington. $311 \mathrm{p}$.

Narum, SR, JJ Stephenson, and MR Campbell. 2007. Genetic Variation and Structure of Chinook Salmon Life History Types in the Snake River. Transactions of the American Fisheries Society 136:1253-1262.

National Oceanic and Atmospheric Administration (NOAA 2009). Satellite and Information Service. Available at: http://www.ncdc.noaa.gov/oa/ncdc.html. (Accessed in March 2009).

NOAA Fisheries. 2008. Biological Opinion - Consultation on Remand for Operation of the Federal Columbia River Power System, 11 Bureau of Reclamation Projects in the Columbia Basin and ESA Section 10(a)(1)(A) Permit for Juvenile Fish Transportation Program. National Marine Fisheries Service (NOAA Fisheries), Northwest Region, Seattle, Washington.

Peven, C, T Hillman, M Miller, M Tonseth, T Miller, K Truscott, and A Murdoch. 2008. Monitoring and Evaluation of the Chelan County PUD Hatchery Programs 2007 Annual Report. Available from Chelan County PUD, 327 N. Wenatchee Ave, Wenatchee, WA.

Puget Sound Water Quality Authority. 1986. Recommended Protocols for Measuring Conventional Sediment Variables in Puget Sound. U.S. Environmental Protection Agency Region 10. Seattle, WA.

Research Monitoring and Evaluation for the Federal Columbia River Estuary Program. PNNL-17300, report prepared for the Bonneville Power Administration by Pacific Northwest National Laboratory, Richland, Washington.

Roegner, GC, DL Bottom, AM Baptista, J Burke, SA Hinton, DA Jay, CA Simenstad, E Casillas, and KK Jones. 2004. Estuarine Habitat and Juvenile Salmon: Current and Historical Linkages in the Lower Columbia River and Estuary, 2002. Report of Research by Fish Ecology Division, Northwest Fisheries Science Center, National Marine Fisheries Service, National Oceanic and Atmospheric Administration prepared for the U.S. Army Corps of Engineers, Portland District, Contract W66QKZ20374382, vi, 62 p.

Sandercock, FK 1991. Life History of Coho Salmon (Oncorhynchus kisutch). In Pacific Salmon Life Histories. Eds. C Groot and L Margolis, University of British Columbia Press, Vancouver, BC. pp. 397-445.

SAS Institute. 2005. SAS/STAT User’s Manual, release 9.0 edition. SAS Institute Inc., Cary, North Carolina.

Schwarz, WL, GP Malanson, and FH Weirich. 1996. Effect of landscape position on the sediment chemistry of abandoned-channel wetlands. 1996. Landscape Ecology 11(1): 27-38

Seeb, LW, A Antonovich, MA Banks, TD Beacham, MR Bellinger, SM Blankenship, MR Campbell, N A Decovich, JC Garza, CM Guthrie III, TA Lundrigan, P Moran, SR Narum, JJ Stephenson, KT Supernault, DJ Teel, WD Templin, JK Wenburg, SF Young, and CT Smith. 2007. Development of a Standardized DNA Database for Chinook Salmon. Fisheries 32:540-552. 
Sobocinski, K, G Johnson, N Sather, A Storch, T Jones, C Mallette, E Dawley, J Skalski, D Teel, P Moran. 2008. Ecology of Juvenile Salmonids in Shallow Tidal Freshwater Habitats in the Vicinity of the Sandy River Delta, lower Columbia River, 2007. PNNL-17395, final report submitted to the Bonneville Power Administration by Pacific Northwest National Laboratory, National Marine Fisheries Service, Oregon Department of Fish and Wildlife, and University of Washington, Richland, Washington.

Teel, DJ, C Baker, DR Kuligowski, TA Friesen, and B Shields. 2009. Genetic Stock Composition of Subyearling Chinook Salmon in Seasonal Floodplain Wetlands of the Lower Willamette River.

Transactions of the American Fisheries Society 138:211-217.

Thom RM, R Zeigler, and AB Borde. 2002. Floristic Development Patterns in a Restored Elk River Estuarine March, Grays Harbor, Washington. Restoration Ecology 10(3): 487-496.

Thoms, MC. 2003. Floodplain-river ecosystems: lateral connections and the implications of human interference. Geomorphology 56: 335-349.

Tomaro, LM, W Van der Naald, RR Brooks, TA Jones and T A Friesen. 2007. Evaluation of fall Chinook and chum salmon spawning below Bonneville Dam. 2005-2006 Annual Report, BPA Report DOE/BP000029512-1, Bonneville Power Administration, Portland, Oregon.

Townsend, CR and TA Crowl. 1991. Fragmented population structure in a native New Zealand fish: an effect of introduced brown trout? Oikos 61:347-354.

U.S. Army Corps of Engineers (USACE), Bureau of Reclamation and Bonneville Power Administration. 2005. 2005-2007 Implementation Plan for the Federal Columbia River Power System Endangered Species Act Updated Proposed Action. Portland, Oregon. Available at http://www.salmonrecovery.gov/implementation.

Van der Naald, W, C Duff, TA Friesen, RR Brooks, and L M Tomaro. 2006. Evaluation of fall Chinook and chum salmon spawning below Bonneville, The Dalles, John Day, and McNary Dams. 2004-2005 Annual Report, BPA Report DOE/BP-00004028-5, Bonneville Power Administration, Portland, Oregon.

Van der Naald, W.D., B. Spellman, and R. Clark. 2001. 1998-1999 Evaluation of fall Chinook and chum spawning below Bonneville, The Dalles, John Day, and McNary dams. Report DOE/BP-15007-1. U.S. Dept. Energy, Bonneville Power Administration, Portland OR.(Available from BPA, P.O. Box 3621, Portland OR 97208.)

Vincent, VG and WF Font. 2003. Host specificity and population structure of two exotic helminthes Camallanus cotti (Nematoda) and Bothriocephalus acheilognathi (Cestoda), parasitizing exotic fishes in Waianu Stream, O’Ahu Hawaii. Journal of Parisitology 89:540 - 544.

Waknitz, F.W., G.M. Mathews, T. Wainwright, and G.A. Winans. 1995. Status review for Mid-Columbia River summer chinook salmon. NOAA Tech. Mem. NMFS-NWFSC-22, 80 p. (Available from Natl. Mar. Fish. Serv., Northwest Fisheries Science Center, Coastal Zone and Estuarine Studies Division, 2725 Montlake Blvd. E., Seattle, WA 98112-2097.)

Waples, RS, DJ Teel, JM Myers, and AR Marshall. 2004. Life-history divergence in Chinook salmon: Historic contingency and parallel evolution. Evolution 58:386-403. 
Werner, EE and DJ Hall. 1974. Optimal foraging and the size selection of prey by the bluegill sunfish (Lepomis macrochirus). Ecology 55:1042-1052.

Werner, EE and DJ Hall. 1976. Niche shifts in sunfishes: experimental evidence and significance. Science 191:404-406.

Wydoski, RS and RR Whitney. 2003. Inland Fishes of Washington, second edition. University of Washington Press, Seattle, Washington.

Zambrana, L, E Martinez-Meyer, N Menezes, and AT Peterson. 2006. Invasive potential of common carp (Cyprinus carpio) and Nile tilapia (Oreochromis niloticus) in American freshwater systems. Canadian Journal of Fisheries and Aquatic Sciences 63:1903-1910. 

Appendix A

Relationships to Other Programs and Projects 



\section{Appendix A}

\section{Relationships to Other Programs and Projects}

Since the original proposal for the tidal freshwater monitoring (TFM) project was submitted in January 2006, Pacific Northwest National Laboratory (PNNL) has collaborated with other estuary researchers at three important events. At the invitation of the National Marine Fisheries Service (NMFS), we attended the workshop on the project on historic and current food web linkages, jointly undertaken by NMFS, the University of Washington (UW), Oregon State University (OSU), and the Oregon Health and Sciences University (OHSU). Also, we coordinated the Columbia River Estuary Research Conference in Astoria in April 2006 and April 2008. We completely support substantive integration with applicable projects. The relationship of our study to relevant projects in the lower Columbia River estuary (LCRE) is summarized in Table A.1. Some of the more important inter-project relationships for the study are described in more detail following the table.

Table A.1. Study Relationship to LCRE Projects

\begin{tabular}{|c|c|c|c|c|c|}
\hline Project Title & Number & Funding & Sponsor & Description & Relationship \\
\hline $\begin{array}{l}\text { Acoustic } \\
\text { Tracking for } \\
\text { Estimating } \\
\text { Ocean Survival }\end{array}$ & $\begin{array}{c}\text { BPA } \\
\text { 2003-114- } \\
00\end{array}$ & BPA & Kintama & $\begin{array}{l}\text { Acoustic } \\
\text { telemetry } \\
\text { evaluation of } \\
\text { juvenile salmon } \\
\text { migration } \\
\text { patterns }\end{array}$ & $\begin{array}{l}\text { We will inform these researchers, } \\
\text { who are using a different acoustic } \\
\text { telemetry system than we propose. } \\
\text { The two approaches are } \\
\text { complementary, designed to answer } \\
\text { different questions in different } \\
\text { environments. }\end{array}$ \\
\hline $\begin{array}{l}\text { Alternative } \\
\text { Smolt } \\
\text { Transportation } \\
\text { Methods }\end{array}$ & $\begin{array}{c}\text { Corps } \\
\text { TPE-W- } \\
06-02\end{array}$ & USACE & $\begin{array}{c}\text { PNNL } \\
\text { and } \\
\text { NOAA } \\
\text { Fisheries }\end{array}$ & $\begin{array}{l}\text { Acoustic } \\
\text { telemetry } \\
\text { evaluation of } \\
\text { barged fish } \\
\text { released at } \\
\text { different } \\
\text { locations in the } \\
\text { LCRE }\end{array}$ & $\begin{array}{l}\text { We will use tagged fish from this } \\
\text { study. }\end{array}$ \\
\hline $\begin{array}{l}\text { Collaborative } \\
\text { Systemwide } \\
\text { Monitoring and } \\
\text { Evaluation } \\
\text { Project } \\
\text { (CSMEP) }\end{array}$ & $\begin{array}{c}\text { BPA } \\
\text { 2003-036- } \\
00\end{array}$ & BPA & CBFWA & $\begin{array}{l}\text { Columbia basin- } \\
\text { wide } \\
\text { coordination of } \\
\text { M\&E }\end{array}$ & $\begin{array}{l}\text { We will inform CSMEP of our } \\
\text { efforts. }\end{array}$ \\
\hline $\begin{array}{l}\text { Crims Island } \\
\text { Monitoring }\end{array}$ & Unk. & USACE & USGS & $\begin{array}{l}\text { Action } \\
\text { effectiveness } \\
\text { monitoring at the } \\
\text { Crims Island } \\
\text { restoration } \\
\text { project (RM 55) }\end{array}$ & $\begin{array}{l}\text { We will integrate our results with } \\
\text { those from Crims Island. }\end{array}$ \\
\hline
\end{tabular}


Table A.1. (cont'd)

\begin{tabular}{|c|c|c|c|c|c|}
\hline Project Title & Number & Funding & Sponsor & Description & Relationship \\
\hline $\begin{array}{l}\text { Cumulative } \\
\text { Ecosystem } \\
\text { Effects of } \\
\text { Habitat } \\
\text { Restoration }\end{array}$ & $\begin{array}{c}\text { Corps } \\
\text { EST-P-04- } \\
04\end{array}$ & USACE & $\begin{array}{l}\text { PNNL } \\
\text { and } \\
\text { NOAA } \\
\text { Fisheries }\end{array}$ & $\begin{array}{l}\text { Development of } \\
\text { innovative } \\
\text { ecological } \\
\text { methods through } \\
\text { focused field } \\
\text { studies }\end{array}$ & $\begin{array}{l}\text { We will inform this study of our } \\
\text { telemetry monitoring protocols for } \\
\text { action effectiveness research and vice } \\
\text { versa. }\end{array}$ \\
\hline $\begin{array}{l}\text { Current and } \\
\text { Historic } \\
\text { Biophysical } \\
\text { Linkages in the } \\
\text { Estuary }\end{array}$ & $\begin{array}{c}\text { BPA } \\
\text { 2003-010- } \\
\text { 00, Corps } \\
\text { EST-P-02- } \\
02\end{array}$ & $\begin{array}{l}\text { BPA } \\
\text { and } \\
\text { USACE }\end{array}$ & $\begin{array}{l}\text { NOAA } \\
\text { Fisheries }\end{array}$ & $\begin{array}{l}\text { Fundamental } \\
\text { research } \\
\text { regarding } \\
\text { juvenile salmon } \\
\text { in RM 0-46 }\end{array}$ & $\begin{array}{l}\text { We will integrate our results with } \\
\text { these. On July 10, 2006, Mr. } \\
\text { Johnson and Dr. Casillas, project } \\
\text { leader for the NMFS consortium, } \\
\text { specifically agreed to collaborate and } \\
\text { exchange data between their } \\
\text { respective research efforts. }\end{array}$ \\
\hline $\begin{array}{l}\text { Ecosystem } \\
\text { Monitoring - } \\
\text { Habitat and } \\
\text { Water Quality }\end{array}$ & $\begin{array}{c}\text { BPA } \\
\text { 2003-007- } \\
00\end{array}$ & BPA & LCREP & $\begin{array}{l}\text { Status monitoring } \\
\text { at selected sites } \\
\text { in the LCRE } \\
\text { (e.g., habitat } \\
\text { monitoring at } \\
\text { RM } 70 \text { and } 95 \text { in } \\
2005 \text {, but no fish } \\
\text { sampling except } \\
\text { for purpose of a } \\
\text { toxics objective }\end{array}$ & $\begin{array}{l}\text { We will coordinate and integrate our } \\
\text { study with this one; we will share } \\
\text { some sampling sites so that habitat } \\
\text { characteristics will be measured }\end{array}$ \\
\hline $\begin{array}{l}\text { Estuary/Ocean } \\
\text { RME Subgroup }\end{array}$ & $\begin{array}{c}\text { BPA } \\
\text { 2002-077- } \\
00\end{array}$ & BPA & PNNL & $\begin{array}{l}\text { Facilitate the } \\
\text { Estuary/Ocean } \\
\text { Subgroup for } \\
\text { federal RME and } \\
\text { help develop the } \\
\text { Estuary RME } \\
\text { Plan }\end{array}$ & $\begin{array}{l}\text { We will provide monitoring data to } \\
\text { help design sampling for the Estuary } \\
\text { RME Plan and we will implement } \\
\text { applicable elements of the Estuary } \\
\text { RME Plan when it is revised in } 2006 \text {. }\end{array}$ \\
\hline $\begin{array}{l}\text { Juvenile } \\
\text { Salmon } \\
\text { Stranding from } \\
\text { Ship Traffic }\end{array}$ & Unknown & USACE & PNNL & $\begin{array}{l}\text { Beach seining for } \\
\text { a before/after } \\
\text { channel } \\
\text { deepening study } \\
\text { of stranding at } \\
\text { sites at RM 51, } \\
62,97\end{array}$ & $\begin{array}{l}\text { We will integrate our results with } \\
\text { these and may use fish-sampling data } \\
\text { for comparison. }\end{array}$ \\
\hline $\begin{array}{l}\text { Juvenile } \\
\text { Salmon } \\
\text { Survival in the } \\
\text { Estuary }\end{array}$ & $\begin{array}{l}\text { USACE } \\
\text { EST-P-02- } \\
\quad 01\end{array}$ & USACE & $\begin{array}{l}\text { NOAA } \\
\text { Fisheries } \\
\text { and } \\
\text { PNNL }\end{array}$ & $\begin{array}{l}\text { Acoustic } \\
\text { telemetry study } \\
\text { of reach survival } \\
\text { between BON } \\
\text { and the mouth of } \\
\text { yearling and } \\
\text { subyearling } \\
\text { salmonids }\end{array}$ & $\begin{array}{l}\text { We will sample tagged fish from this } \\
\text { study. }\end{array}$ \\
\hline
\end{tabular}


Table A.1. (cont'd)

\begin{tabular}{|c|c|c|c|c|c|}
\hline Project Title & Number & Funding & Sponsor & Description & Relationship \\
\hline $\begin{array}{l}\text { LCRE Habitat } \\
\text { Mapping }\end{array}$ & $\begin{array}{l}\text { BPA } \\
2002-012- \\
00\end{array}$ & $\begin{array}{l}\text { BPA } \\
\text { and } \\
\text { USACE }\end{array}$ & LCREP & $\begin{array}{l}\text { Remote-sensing } \\
\text { mapping project, } \\
\text { Landsat } 7 \text { TM for } \\
\text { the entire LCRE } \\
\text { and Compact } \\
\text { Airborne } \\
\text { Spectrographic } \\
\text { Imager (CASI) } \\
\text { imagery at } \sim \text { RM } \\
7,25,64 \text { and } 95\end{array}$ & $\begin{array}{l}\text { We will consult maps from this } \\
\text { project. }\end{array}$ \\
\hline $\begin{array}{l}\text { LCRE Habitat } \\
\text { Restoration }\end{array}$ & $\begin{array}{l}\text { BPA } \\
2003-011- \\
00\end{array}$ & BPA & LCREP & $\begin{array}{l}\text { On-the-ground } \\
\text { projects passing a } \\
\text { technical vetting }\end{array}$ & $\begin{array}{l}\text { We will inform this project of our } \\
\text { findings. }\end{array}$ \\
\hline $\begin{array}{l}\text { Pacific } \\
\text { Northwest } \\
\text { Aquatic } \\
\text { Monitoring } \\
\text { Partnership }\end{array}$ & $\begin{array}{l}\text { BPA } \\
2004-002- \\
00\end{array}$ & BPA & USGS & $\begin{array}{l}\text { Coordination of } \\
\text { the regional } \\
\text { RME process; } \\
\text { includes PNAMP } \\
\text { estuary } \\
\text { workgroup }\end{array}$ & $\begin{array}{l}\text { We will inform this effort of our } \\
\text { work. }\end{array}$ \\
\hline $\begin{array}{l}\text { Pilot } \\
\text { Monitoring in } \\
\text { Wenatchee and } \\
\text { Grande Ronde } \\
\text { Basins }\end{array}$ & $\begin{array}{l}\text { 2003-017- } \\
00\end{array}$ & BPA & NOAA & $\begin{array}{l}\text { Pilot RME } \\
\text { monitoring } \\
\text { projects in } \\
\text { tributary habitats }\end{array}$ & $\begin{array}{l}\text { We will consult with these } \\
\text { researchers regarding RME. }\end{array}$ \\
\hline $\begin{array}{l}\text { Sandy River } \\
\text { Delta Habitat } \\
\text { Restoration }\end{array}$ & $\begin{array}{c}\text { BPA } \\
1999-025- \\
00\end{array}$ & $\begin{array}{l}\text { BPA } \\
\text { and } \\
\text { USACE }\end{array}$ & USFWS & $\begin{array}{l}\text { On-the-ground } \\
\text { restoration at the } \\
\text { proposed study } \\
\text { site }\end{array}$ & $\begin{array}{l}\text { We will coordinate, integrate, and } \\
\text { inform this key project about our } \\
\text { work. }\end{array}$ \\
\hline $\begin{array}{l}\text { Technical Basis } \\
\text { for } \\
\text { Prioritization of } \\
\text { Habitat } \\
\text { Restoration } \\
\text { Projects in the } \\
\text { LCRE }\end{array}$ & $\begin{array}{l}\text { Part of } \\
\text { BPA } \\
\text { 2003-011- } \\
00\end{array}$ & $\begin{array}{l}\text { BPA } \\
\text { and } \\
\text { State of } \\
\text { Oregon }\end{array}$ & LCREP & $\begin{array}{l}\text { Research to } \\
\text { develop a } \\
\text { technical basis } \\
\text { for restoration } \\
\text { project selection }\end{array}$ & $\begin{array}{l}\text { We will inform this effort of our } \\
\text { work, which will be useful in their } \\
\text { prioritization process. }\end{array}$ \\
\hline \multicolumn{4}{|c|}{$\begin{array}{l}\text { BPA = Bonneville Power Administration } \\
\text { LCRE = lower Columbia River and estuary } \\
\text { LCREP = Lower Columbia River and Estuary } \\
\text { Program } \\
\text { NMFS = National Marine Fisheries Service } \\
\text { NOAA = National Oceanic and Atmospheric } \\
\text { Administration } \\
\text { PNAMP = Pacific Northwest Aquatic Monitoring } \\
\text { Partnership }\end{array}$} & \multicolumn{2}{|c|}{$\begin{array}{l}\text { PNNL = Pacific Northwest National Laborato } \\
\text { RM = river mile } \\
\text { RME = research, monitoring, and evaluation } \\
\text { TM = Thematic Mapper } \\
\text { USACE = U.S. Army Corps of Engineers } \\
\text { USFWS = U.S. Fish and Wildlife Service } \\
\text { USGS = U.S. Geological Survey }\end{array}$} \\
\hline
\end{tabular}


The study will have a working relationship with the Estuary/Ocean RME Subgroup project (BPA Project 2002-077-00) and the Plan for Research, Monitoring, and Evaluation of Salmon in the Columbia River Estuary. Data from this study will inform the sampling designs for the LCRE status monitoring program and action effectiveness research. The RME Plan will provide the framework for a monitoring program under which the study will fall. Such a formal, organized, and integrated monitoring program does not exist at this time.

The study in the vicinity of the Sandy River delta is strongly related to Estuary Partnership's LCRE Ecosystem Monitoring project (BPA Project 2003-064-00, Table 1). This project includes a large-scale effort to develop a new hydrogeomorphic-based habitat classification system and apply it to map aquatic habitats in the entire LCRE. As the habitat classification scheme is coupled with habitat and water quality data within this project, the array of potential habitats in the tidal freshwater area will be quantified and mapped. The Ecosystem Monitoring project will provide the context for the landscape containing the Sandy River delta study area. In turn, the study will provide useful data about fish presence and/or absence at various habitat complexes in the vicinity of the Sandy River delta. Overall, the Estuary Partnership's LCRE Ecosystem Monitoring project may fill the current void of a formal, organized monitoring program for the LCRE. The study would be an integral part of this program.

The Sandy River Delta Habitat Restoration project (BPA Project 1999-025-00) will use the fish and ancillary data collected as part of the study. We will share our data and coordinate our efforts with theirs. Note, however, that at this time we are not proposing to formally perform action effectiveness research on the blockage removal because of the uncertainty regarding implementation of the action. Information from the ongoing restoration project, however, will be useful to our study, especially when used in conjunction with information from the LCRE Ecosystem Monitoring project. The tie-in with the Sandy River restoration effort is limited at this time, because restoration to date has concerned re-vegetation. If and when the tidal reconnection project happens, we will coordinate with the appropriate parties.

The relationship between our study and the USACE estuary survival project (EST-P-02-01, Table 1) is important. During 2000-2005, the USACE funded National Aeronautics and Atmospheric Administration (NOAA) Fisheries and PNNL to develop a miniaturized acoustic tag and acquisition hardware. This acoustic telemetry technology is called the Juvenile Salmon Acoustic Telemetry System (JSATS). The USACE-funded research continued in fiscal year 2008, because improving survival rates for subyearling salmon passing through the federal hydrosystem is a high priority (NOAA 2004). The large USACE effort involves focused research at mainstem hydropower dams and project, reach, and system-wide survival estimates on a species-specific basis. To estimate survival rates, juvenile salmon will be marked with acoustic tags, released in the Snake River and other locations, and detected at downstream hydrophones arrays, such as at the mouth of the Columbia River. For example, plans for USACE studies in 2008 call for tagging over 15,000 juvenile salmonids. Because most of these fish will be migrating through the Sandy River and vicinity, there is an important opportunity to perform feasibility work on acoustic telemetry monitoring protocols in shallow tidal freshwater. As an Action Agency, the USACE has agreed to consider collaborating on applying its acoustic telemetry technology to the proposed study. Specifically, the USACE would allow us to listen for fish tagged for their purposes.

Another related effort using acoustic telemetry technology is the project called Acoustic Tracking for Estimating Ocean Survival (BPA Project 2003-014-00, Table 1). This project is using equipment manufactured by Vemco to study yearling salmon migration patterns along the continental shelf in the Northeast Pacific Ocean. By necessity, the Vemco tags have long battery lives and are therefore 
relatively large. The JSATS acoustic telemetry technology was designed to provide a way to estimate survival rates in subyearling Chinook salmon (at this time, the minimum size fish tagged is $90 \mathrm{~mm}$ long). Thus, the two technologies are complementary-designed to answer different questions in different environments.

The TFM study involves status and trends monitoring and uncertainties research (Objective 1) and testing action effectiveness monitoring protocols (Objective 2). It will be integrated with other relevant LCRE research in the sense of tributary habitat "pilot" monitoring studies described by NOAA Fisheries and the Action Agencies (2003) in their draft Research, Monitoring, and Evaluation Plan for the NOAA Fisheries 2000 Federal Columbia River Power System Biological Opinion (NOAA 2004). According to the NOAA plan, a pilot monitoring project would involve coordination and integration of existing and new monitoring efforts for status/trends and action effectiveness in a selected sub-basin. A monitoring project can also include testing monitoring protocols and sharing data (Jordan 2005). Pilot monitoring projects are underway in the John Day (Oregon), Salmon (Idaho), and Wenatchee (Washington) river basins (e.g., BPA Project 2003-017-00, Table 1). In a joint review, the Independent Scientific Advisory Board (ISAB) and the Independent Scientific Review Panel (ISRP) supported the tributary pilot studies (ISAB and ISRP 2004). Furthermore, the concept of a pilot monitoring study for the estuary was proposed in the Estuary/Plume RME Plan (Johnson et al. 2004) and supported by the ISRP in its review of the plan (ISRP 2004, p. 10). However, the study we plan for 2007-2009 is not the same as the pilot study concept described in the Estuary/Plume RME Plan. Thus, it is worthwhile to note some similarities and differences between the approach for tributary pilot monitoring studies espoused in the Estuary/Plume RME Plan for the LCRE and the study proposed here for the tidal freshwater region of the Columbia River in 2007-2009 (Table A.2).

Table A.2. Comparison of Tributary Pilot Studies to the TFM Study

\begin{tabular}{lcc}
\hline \multicolumn{1}{c}{ Factor } & $\begin{array}{c}\text { Tributary Pilot Monitoring Studies } \\
\text { Scale }\end{array}$ & $\begin{array}{c}\text { Tidal Freshwater Monitoring Study } \\
\text { (2007-2009) }\end{array}$ \\
\hline $\begin{array}{l}\text { Relative Scope of Work } \\
\text { Status Monitoring }\end{array}$ & Large \\
reach to sites & Sites within one reach \\
Action Effectiveness Research & Yes & Small \\
Uncertainties Research & Yes & Yes \\
$\begin{array}{l}\text { Coordination and Integration } \\
\text { Among Projects in the Study } \\
\text { Area }\end{array}$ & Yes & Yes \\
& Yes & Yes \\
Management Implications & $\begin{array}{c}\text { Fundamental data about the results } \\
\text { of the Fish \& Wildlife Program } \\
\text { (FWP) and Updated Proposed } \\
\text { actions (UPA ) for salmon }\end{array}$ & Yes \\
\hline
\end{tabular}




\section{A.1 References}

Independent Scientific Advisory Board and Independent Scientific Review Panel. 2004. Draft Research, Monitoring \& Evaluation Plan for the NOAA-Fisheries 2000 Federal Columbia River Power System Biological Opinion. Portland, Oregon.

Johnson, G, H Diefenderfer, T Berquam, B Ebberts, C Tortorici, and J Wilcox. 2004. Plan for Research, Monitoring, and Evaluation of Salmon in the Columbia River Estuary. PNNL-14632, Final draft prepared by Pacific Northwest National Laboratory, Richland, Washington, for the Bonneville Power Administration.

National Oceanic and Atmospheric Administration (NOAA). 2004. Biological Opinion of the Operation of the Federal Columbia River Power System. National Marine Fisheries Service, Northwest Region, Seattle, Washington. 
Appendix B

Contour Maps of Beach Seine Sites 



\section{Appendix B}

\section{Contour Maps of Beach Seine Sites}

At Site F, the elevations were collected using the same methods described in Section 3.2.2 with the addition of two transects that crossed the grid at approximately 45 degrees. The point spacing on these two additional transects was $2 \mathrm{~m}$. We used these additional transects to perform an error analysis of our methods for producing contours. After the surface was created, an intersect point tool (Beyer 2004) was used to extract elevation data from the surface. The tool uses point data from the additional transects to locate a corresponding location in the surface. The extracted data and the original point data were compared using difference squared values. Summary statistics calculated the difference squared values to get an average difference between the original elevation data and the generated surface (Table B.1).

Table B.1. Summary Stats for Site F Statistics Contour Generation Methods

\begin{tabular}{lcccc}
\hline & Kriging & TIN & Spline & IDW \\
\hline Count & 73 & 73 & 73 & 73 \\
Minimum & 0 & 0 & 0 & 0 \\
Maximum & 0.184 & 0.499 & 5.957 & 0.615 \\
Sum & 1.007 & 2.111 & 39.514 & 4.39 \\
Mean & 0.013795 & 0.028918 & 0.541288 & 0.060137 \\
Standard Deviation & 0.034357 & 0.090123 & 1.17915 & 0.123542 \\
\hline
\end{tabular}

TIN $=$ Triangulated irregular network

IDW = inverse distance weighting

The following figures are a result of the elevation data collection effort and the above described analysis used for mapping contours. 


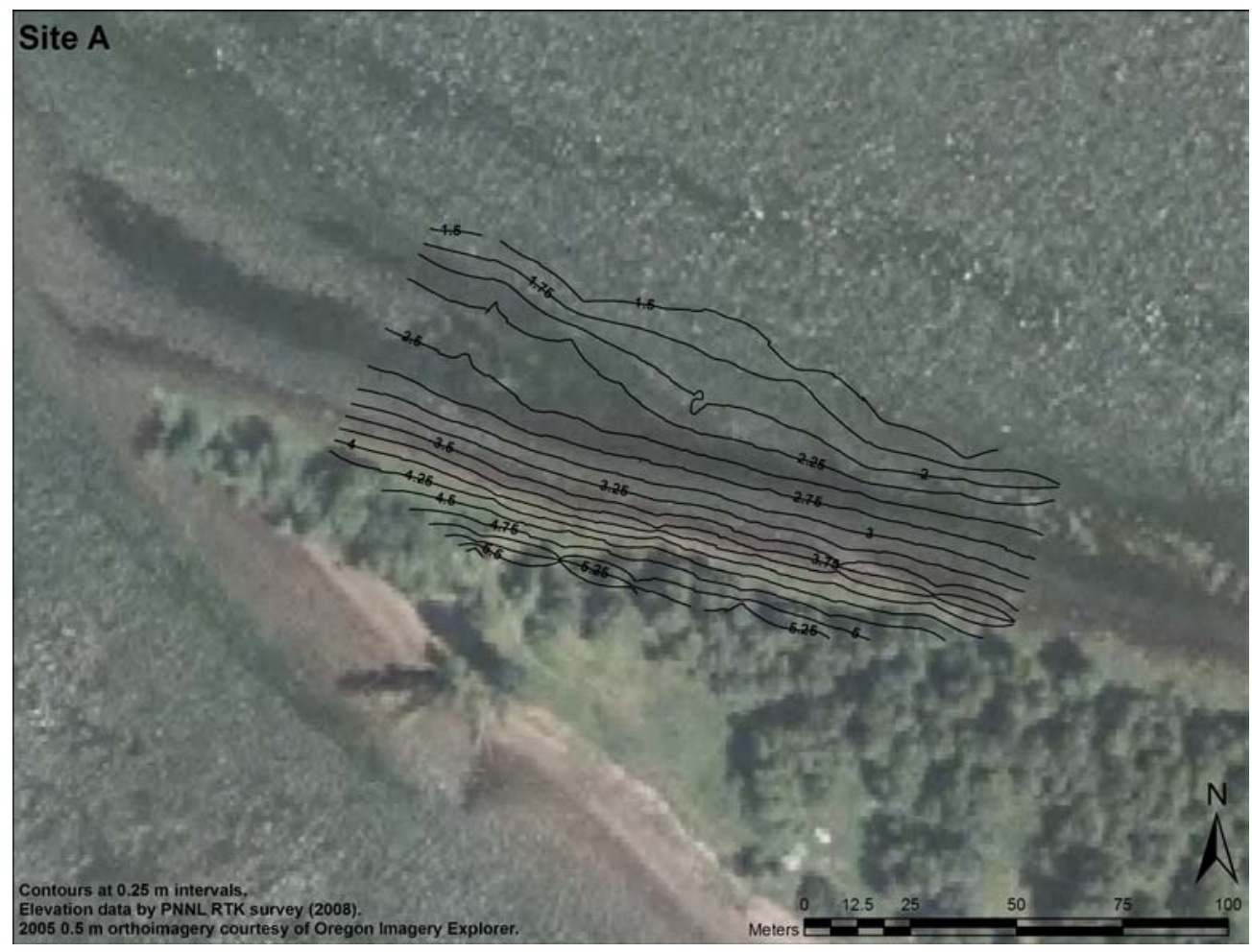

Figure B.1. Bathymetric Contours of the Beach Slope at Site A, Reed Island

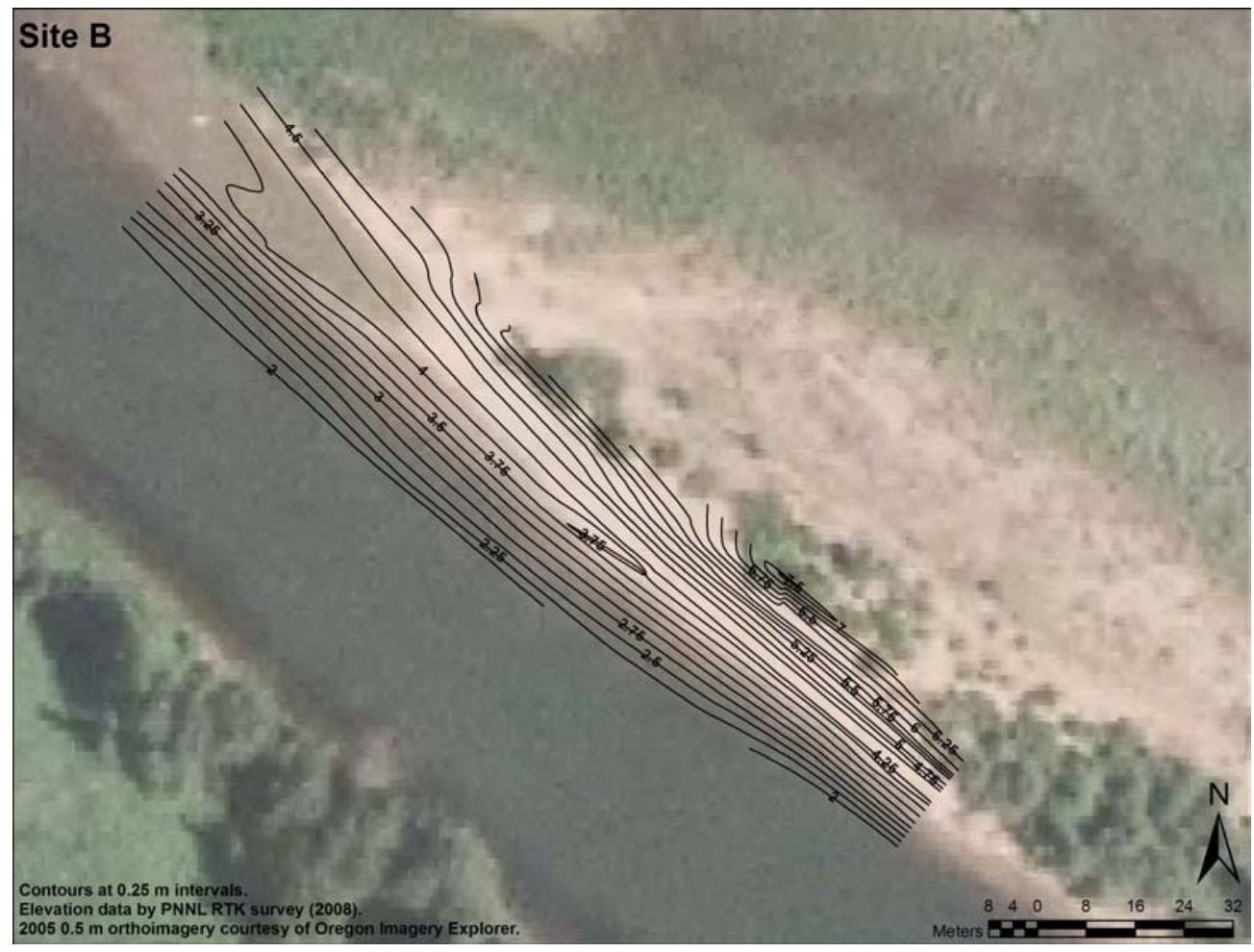

Figure B.2. Bathymetric Contours of the Beach Slope at Site B, Chatham Island 


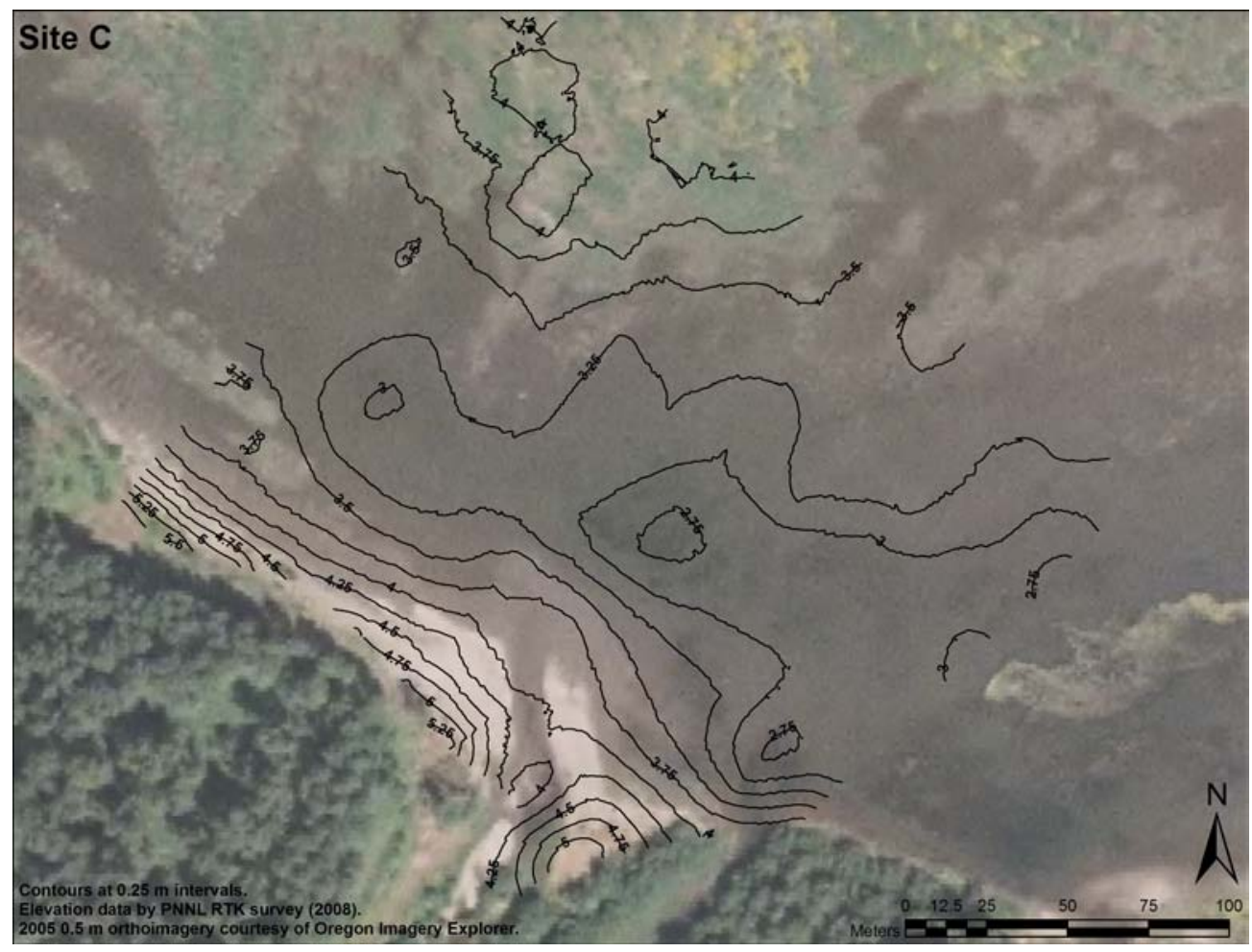

Figure B.3. Bathymetric Contours of the Beach Slope at Site C, the Historic Mouth of the Sandy River

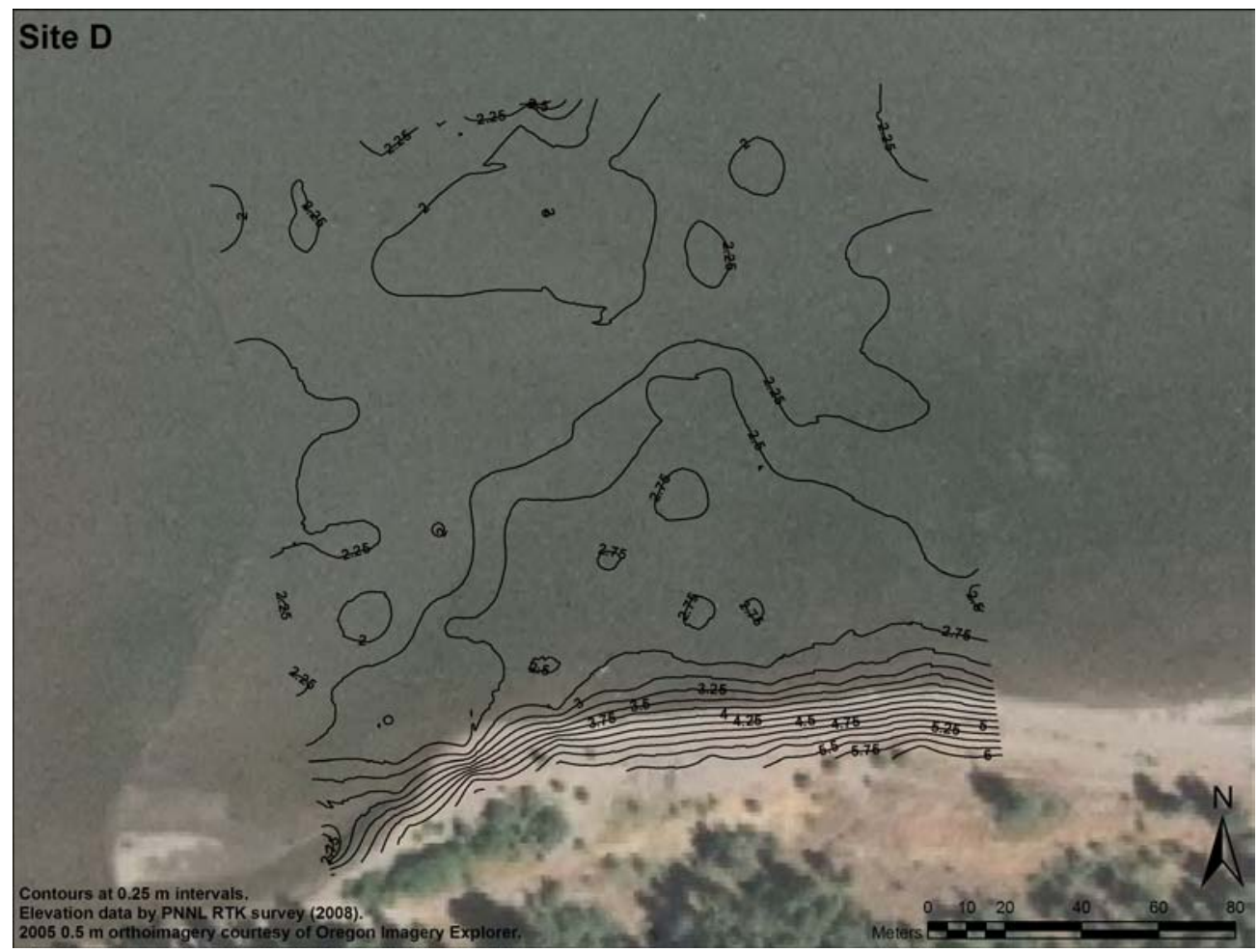

Figure B.4. Bathymetric Contours of the Beach Slope at Site D Adjacent to the Sandy River Confluence 


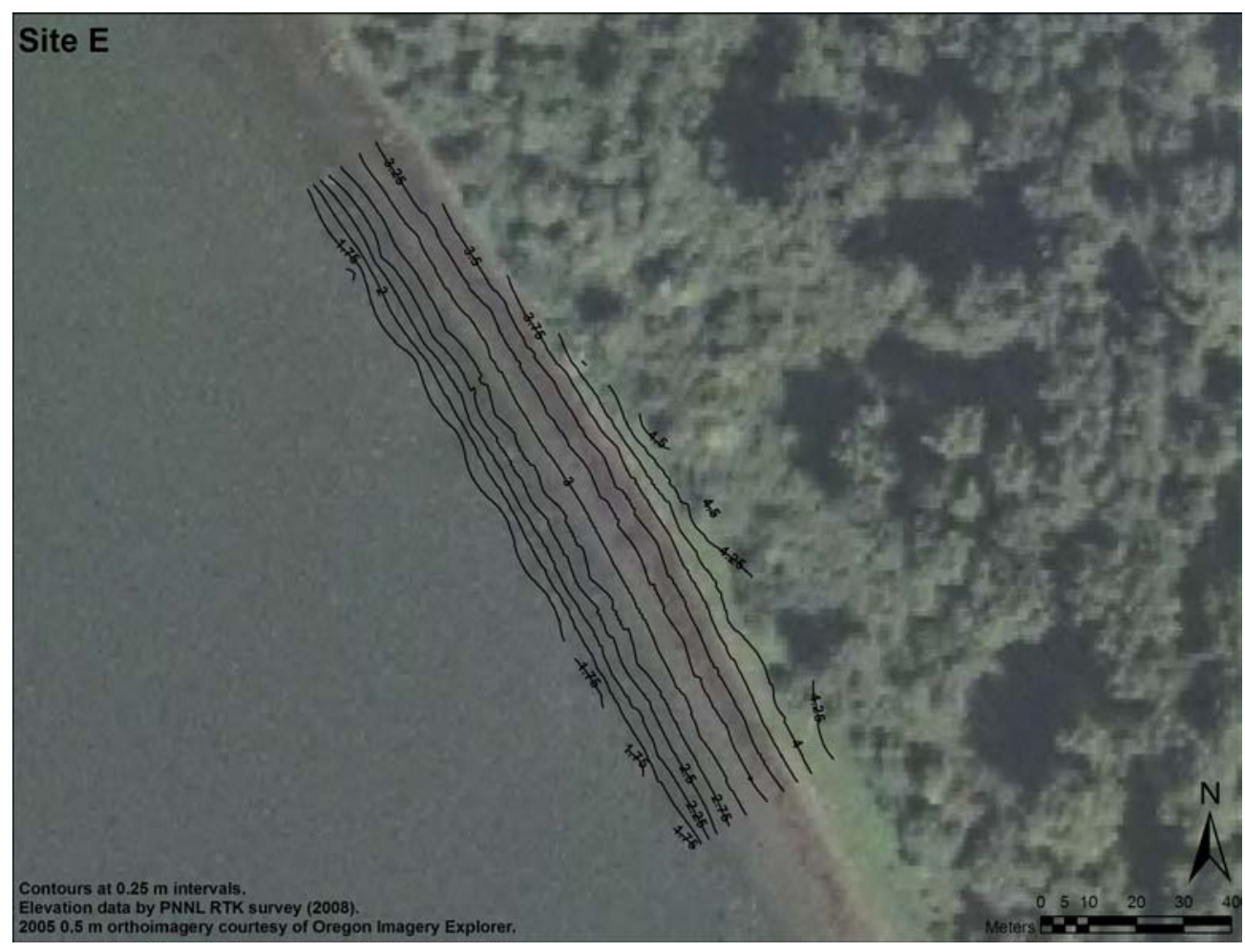

Figure B.5. Bathymetric Contours of the Beach Slope at Site E, Gary Island

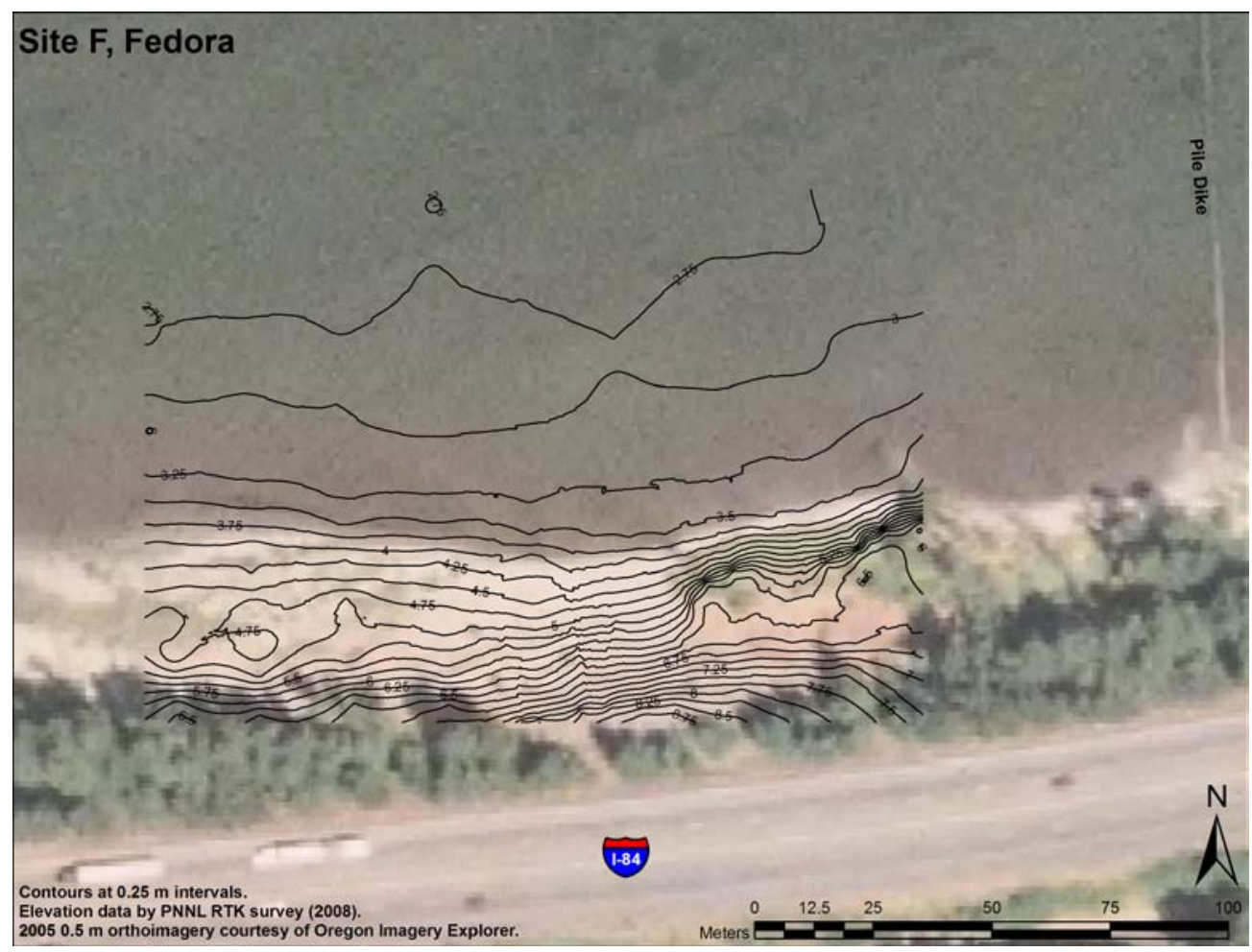

Figure B.6. Bathymetric Contours of the Beach Slope at Site F Adjacent to Highway 84 Upstream of Chatham Island 


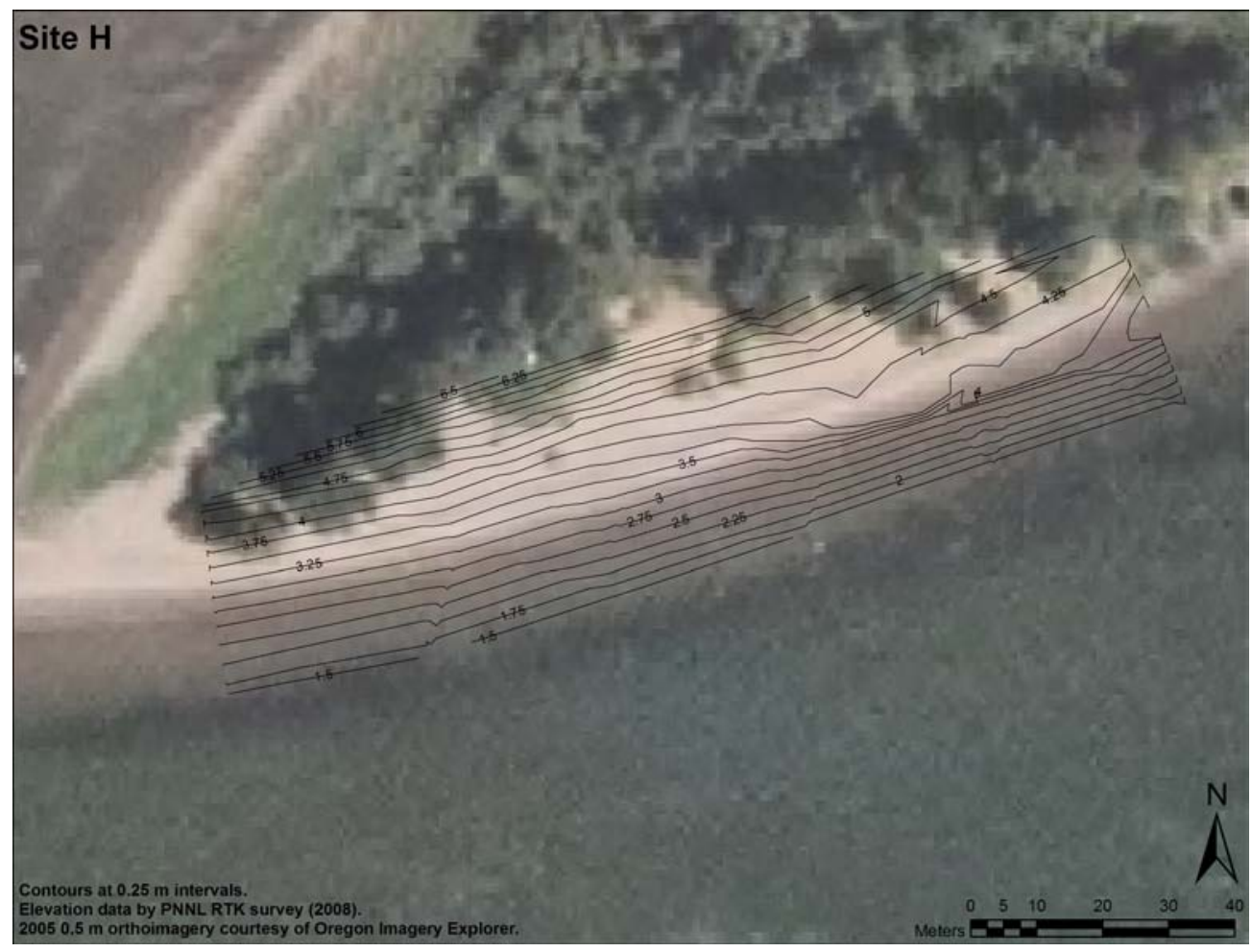

Figure B.7. Bathymetric Contours of the Beach Slope at Site H, McGuire Island

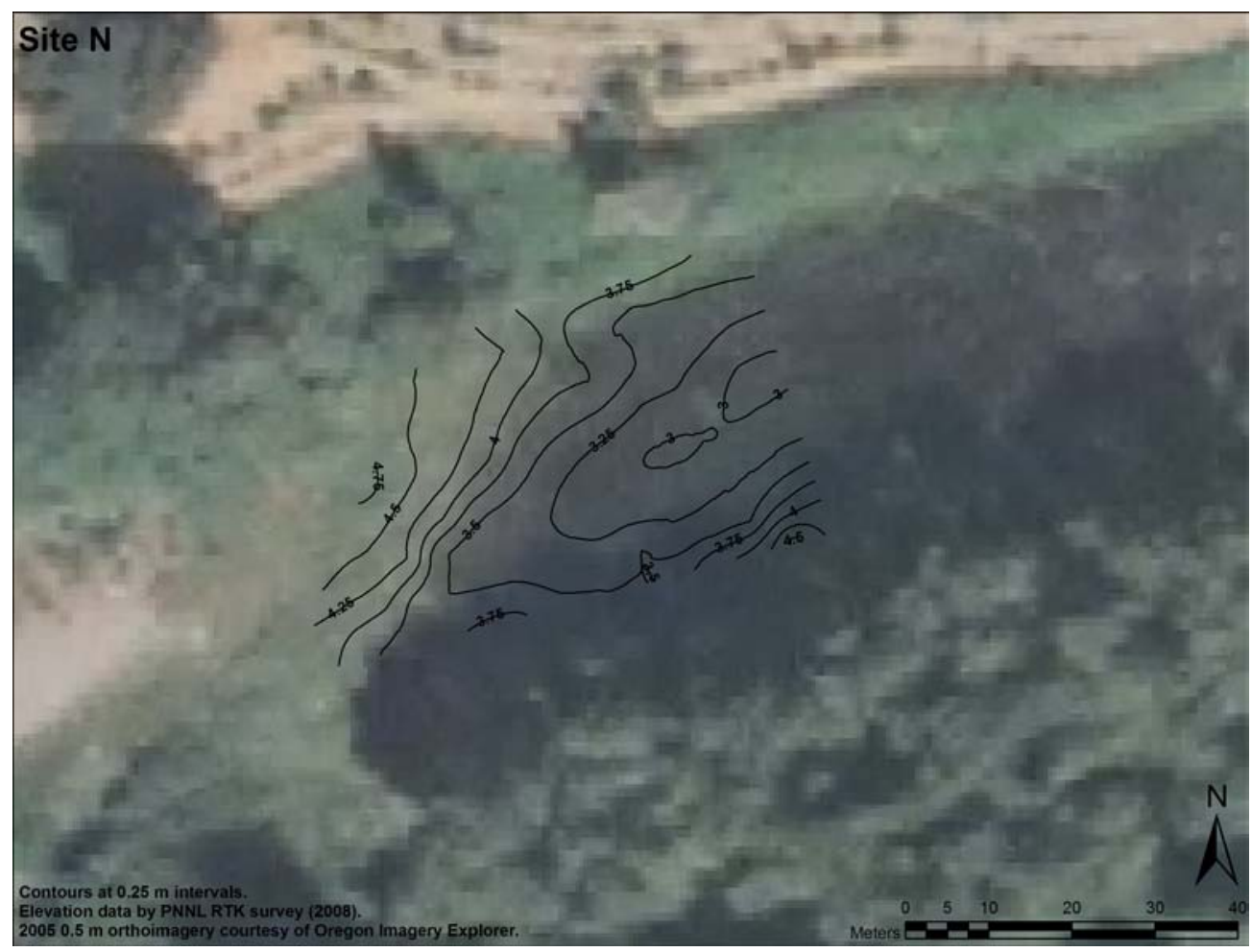

Figure B.8. Bathymetric Contours of the Beach Slope at Site N, the Blocked Channel in the Sandy River Delta 


\section{B.1 References}

Beyer, HL. 2004. Hawth's Analysis Tools for ArcGIS. Available at http://www.spatialecology.com/htools. 
Appendix C

\section{Statistical Synopsis}





\title{
Statistical Considerations for the Tidal Water \\ Monitoring Study, 2008-2009
}

\author{
Prepared for: \\ Gary Johnson \\ Nikki Sather \\ Battelle Pacific Northwest National Lab \\ 620 SW Fifth Avenue, Suite 810 \\ Portland, Oregon 97204 \\ Prepared by: \\ John R. Skalski \\ Columbia Basin Research \\ School of Aquatic and Fishery Sciences \\ University of Washington \\ 1325 Fourth Avenue, Suite 1820 \\ Seattle, Washington 98101
}

15 October 2008 



\section{C.1 Introduction}

The Tidal Freshwater Monitoring Study's goals are to determine the types of shallow water habitats that the yearling and subyearling salmonids are using, at what times of the year, and under what environmental conditions to understand the ecological importance of these habitats to the recovery of upper Columbia River spring Chinook salmon and steelhead and Snake River fall Chinook salmon. This study in tidal freshwater of the lower Columbia River in the vicinity of the Sandy River delta has five general objectives.

1. Status and Trends - Monitor the status and trends of the fish communities in shallow water habitats.

2. Uncertainty Research - Address the critical uncertainty of usage of these habitats by subyearling Chinook salmon.

3. Action Effectiveness - Evaluate the statistical suitability of baseline data collected for an evaluation of the effectiveness of a restoration project at the Sandy River delta to reconnect the old river channel to the Columbia River.

4. Acoustic Telemetry - Monitor acoustic-tagged fish in the vicinity of the Sandy River delta to assess the potential of this technology as a tool for monitoring action effectiveness.

5. Monitoring Program Design -- Apply the fish catch data collected in this study to a preliminary design for a potential full-scale juvenile salmonid monitoring program in shallow tidal freshwater environments of the Columbia River.

In 2008, emphasis is on increasing the number of sites sampled to provide greater replication and increase the diversity of fish habitats surveyed in the freshwater intertidal environment. This synopsis describes the sampling scheme and intended statistical analyses of the data.

\section{C.2 Sampling Scheme}

\section{C.2.1 Site Locations}

\section{C.2.1.1 Fixed Locations}

Nine fixed-location sampling sites will be monitored in 2008 (Fig. 1). The sites are described as follows:

- Site A: North shore of Reed Island in the Washington State side of the Columbia River

- Site B: Beach side of Chatham Island, upshore of Sandy River Delta on the Oregon State side of the Columbia River

- Site C: Near the mouth of the old channel at Sandy River Delta on the Oregon State side of the Columbia River

- Site D: Near the mouth of the current channel at Sandy River Delta on the Oregon State side of the Columbia River 
- Site E: West shore of Gary Island on the Oregon state side of the Columbia River

- Site F: Oregon State side of main channel upstream of Sandy River Delta

- Site G: Mainstem side of Lady Island

- Site H: Side channel on McGuire Island downstream of Sandy River Delta

- Site N: At the current blockage in the old channel of the Sandy River Delta

Six of the sites (i.e., A, B, C, D, E, N) were also sampled in 2007. Three new sites (i.e., F, G, H) were added to the study to increase habitat diversity and replication. Three sites are within the main channel with sandy substrata (D, F, and G), two sites are in side channels with sandy substrata (B and H), two sites are in side channels with muddy substrata (A and E), and two sites are associated with the Sandy River Delta (C and N).

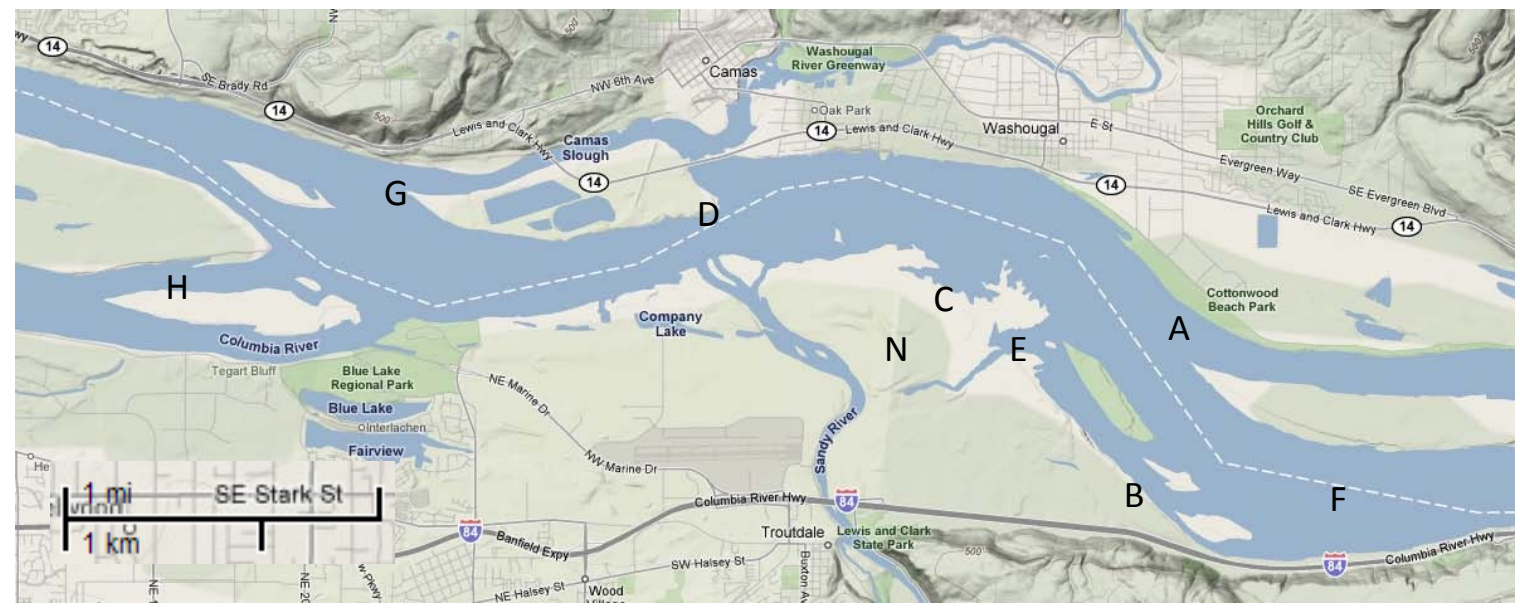

Figure C.1. Location of the Nine Fixed Monitoring Sites

\section{C.2.1.2 Blitz Sites}

Twice, during early and late winter 2008-2009, the nine fixed sites and eight additional "blitz" sites will be sampled. These two spatial blitzes will be used to provide a "snapshot" of the spatial variation in fish abundance and composition. The eight new sites will be sampled in river reach(s) not represented by the fixed location sites. Reach F downstream of the confluence of the Columbia and Willamette rivers will be sampled as part of the blitz. Reach $\mathrm{H}$ may also be sampled, depending on discussions at a team meeting in late October 2008.

A pool of approximately 20 or more logistically feasibly and environmentally diverse sites will be identified. A random sample of 8 of the 20 sites will be independently selected during each blitz for canvassing. 


\section{C.2.2 Sampling Within a Site}

\section{C.2.2.1 Fish Sampling}

Once each month, the fixed monitoring sites will be sampled in random order over a two-day consecutive period. At each site, two replicate seine samples will be collected from the designated sampling station. All fish collected will be identified to species (or genus if species identification not possible) and, for a subset, length recorded. The second seine set will be performed upstream of the first set at least 30 minutes after the first to allow the fish population to reestablish itself so independent index data on fish densities can be collected. The response variable measured will be average fish density by species based on areas swept by the two replicate beach seines (i.e., $\# / \mathrm{m}^{2}$ ).

Through August 2008, just the six original fixed location sites will be sampled monthly. Beginning September 2008, all nine fixed location sites will be sampled monthly. The same fish sampling protocols will be used at both fixed location and blitz sites.

\section{C.2.2.2 Ancillary Data and Habitat Characterization}

At both the fixed and blitz sites, ancillary environmental variables will be measured during fish sampling. Ancillary data will include water temperature, water surface position, river stage, river flow, water velocity, dissolved oxygen, substrate, and turbidity.

Also at each fixed site, habitat will be characterized once during summer by measuring, including vegetation composition and cover, beach slope, substrate composition, and bathymetry. These environmental covariates will be used to describe differences in fish abundance and community structure.

\section{C.3 Data Analysis}

\section{C.3.1 Status and Trends Monitoring}

Descriptive analyses will be performed on the fish density and species composition data collected at both the fixed location and blitz sites. Information on seasonal species composition and density will be assembled and presented in tabular and graphical form. Fish relative abundance will be summarized, both by species (i.e., yearling Chinook salmon, coho salmon, etc.) as well as grouped by family (e.g., salmonids) and functional groups (e.g., cold-water vs. warm-water species, predators, etc.). For salmonids, hatchery vs. assumed wild (i.e., adipose fin clipped or not) counts over the seasons will be examined. Species composition and density trends will be compared and contrasted across sites and habitats (e.g., main channel vs. backwater, sandy vs. mud substrate). Data from the entire study will be presented (June 2007 through December 2008).

\section{C.3.2 Uncertainty Research}

Currently when and where salmonids use the freshwater intertidal environment of the lower Columbia River is unknown. An important objective of this study is therefore to understand the temporal and spatial use of this habitat. Both univariate and multivariate analyses of the fish sampling data will be 
performed to better understand fish-habitat associations. This information will be valuable in both understanding the biology of the system and how best to direct restoration efforts for salmonid recovery.

\section{C.3.2.1 Univariate Juvenile Salmon and Habitat Associations}

Multiple regression analysis will be used to assess relationships between observed salmonid densities and environmental/habitat variables measured at both the fixed and blitz sites. The purpose of the analysis is to identify those factors that could be used in stratifying sites in a regional monitoring program.

\section{C.3.2.2 Multivariate Fish Community and Habitat Associations}

Using the expanded spatial sampling of the blitz sites (i.e., total of $9+8=17$ sites), associations between fish community and habitat characterizations will be examined. Principal component analysis (PCA) will be used to identify the two principal components that most describe the variability in the fish community traits between sites. Bivariate principal component (PC) plots will be used to characterize the range in site variability for the fish (Figure C3.1).

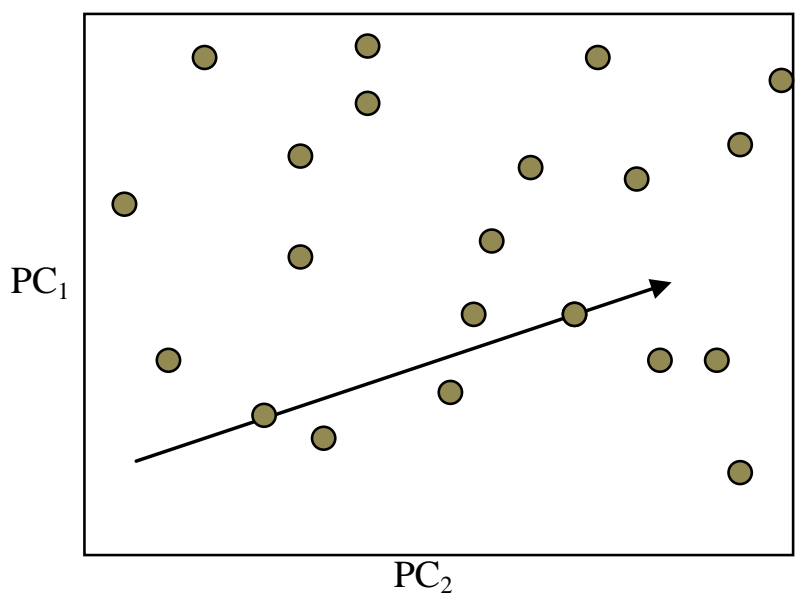

Figure C.2. Bivariate Principal Component Plots with Salmonid Fish Density Regressed Against Principal Components ( $\rightarrow$, arrow, show direction of increased fish density). 
Analysis of distance (ANODIS) (Skalski et al. Unpublished) will be used to regress the habitat principal components against salmonid density based on PC1 and PC2 being orthogonal (i.e., independent). The result will be a bivariate regression line that can be superimposed on the bivariate PC plots. The ANODIS table will be of the form:

\begin{tabular}{lllll}
\hline \multicolumn{1}{c}{ Source } & DF & \multicolumn{1}{c}{ SS } & MS & $F$ \\
\hline Total $_{\text {Cor }}$ & $2(n-1)$ & $\sum_{i=1}^{n}\left[\left(x_{i}-\bar{x}\right)^{2}+\left(y_{i}-\bar{y}\right)^{2}\right]$ & & \\
Regression & 2 & SSR $=\sum_{i=1}^{n}\left[\left(\bar{x}_{i}-\left(\alpha_{1}+\beta_{1} d_{i}\right)\right)^{2}+\left(\bar{y}_{i}-\left(\alpha_{2}+\beta_{2} d_{i}\right)\right)^{2}\right]$ & MSR $=\frac{\text { SSR }}{2}$ & $F_{2}=\frac{\text { MST }}{\text { MSE }}$ \\
Error & $2(n-2)$ & SSE $=\sum\left[\left(x_{i}-\left(\alpha_{1}+\beta_{1} d_{i}\right)\right)^{2}+\left(y_{i}-\left(\alpha_{2}+\beta_{2} d_{i}\right)\right)^{2}\right]$ & MSE $=\frac{\text { SSE }}{2(n-2)}$ & \\
\hline
\end{tabular}

where

$x_{i}=\mathrm{PC}_{1}$ for the $i$ th site $(i=1, \ldots, n)$;

$y_{i}=\mathrm{PC}_{2}$ for the $i$ th site $(i=1, \ldots, n)$;

$d_{i}=$ fish density for the $i$ th site $(i=1, \ldots, n)$.

\section{C.3.3 Action Effectiveness - BACI Analysis}

Should rechannelization occur during the course of this study, a BACI analysis (Skalski and McKenzie 1982) could be performed to assess the effects of that activity on local fish populations. The expectation of the mitigation action is to decrease non-native warm-water species (e.g., killifish, largemouth bass, and bluegill) densities and increase the density of salmonids and other native resident fishes. Therefore, separate analyses should be performed to assess both expected losses and gains in fish density.

For the fixed location sites, monthly and annual time trends in salmonid density will be depicted. In the BACI analysis of restoration effects, it will be important to know on what mathematical scale (e.g., arithmetic, log, etc.) are location and seasonal effects additive. Besides graphical analysis, a two-way ANOVA test for location-by-season interactions will be used to test for additivity.

It is recommended that only seasonal data be used to help minimize the potential effects of autocorrelation on the repeated measures through time. Using the log of the impact-control ratios should also minimize any perceived autocorrelations.

For purposes of illustration, consider the scenario of 4 seasonal surveys, 2 years before and 2 years after the restoration action at the old Sandy River Delta channel. At each survey occasion, the two impact-control ratios of sites (i.e., C/D and N/B) are measured. The result will be 32 estimates of impact/control ratios which will be analyzed using a normal error, log-link, generalized linear model (GLM). The anticipated degree-of-freedom table for the analysis is illustrated in Table C3.1. 
Table C.1. Illustration of a Degree-of-Freedom Table for a BACI Analysis Assuming Four Seasons, Two Years per Monitoring Phase, and Two Impact/Control Pairs

\begin{tabular}{|c|c|c|}
\hline Source & $\mathrm{DF}$ & $F$-test \\
\hline Total $_{\text {Cor }}$ & 31 & \\
\hline Season & 3 & \\
\hline Site pair & 1 & \\
\hline Phase & 1 & $\mathrm{~F}_{1,10}$ \\
\hline Site pair $\times$ phase & 1 & \\
\hline Season $\times$ phase & 3 & \\
\hline Season $\times$ pair & 3 & \\
\hline Season $\times$ pair $\times$ phase & 9 & \\
\hline Error & 10 & \\
\hline
\end{tabular}

The F-test for the main effect of the monitoring phase tests the overall effect of the mitigation action. However, the site-pair-by-phase interaction may likely occur because the fish response to the rechannelization at the potential impacted sites (i.e., $\mathrm{C}$ and $\mathrm{N}$ ) is anticipated to be different. Other interactions may also occur requiring more detailed interpretation of the data. Data plots and Tukey's test of additivity (Box et al. 1978:222-223) will be used to assure the impact assessment data are analyzed on the correct scale.

Given the 2007-2008 baseline data set of fish density, a pre-operational assessment of the Control:Impact ratio tracking is appropriate. Analysis of the pre-operational data will be performed to determine whether the fish densities at the control and potentially impacted sites track and on what scale. Often, the time trends are parallel on the log-scale because regional effects on abundance are multiplicative. Graphical inspection and Tukey's tests of additivity will be performed to determine whether pre-operational data are meeting the requirements of the BACI design.

\section{C.3.4 Acoustic-Telemetry}

Acoustic-tag arrays upstream and downstream of Sandy River Delta (Fig. 3.1) will be used to estimate average residence time in that reach. For fish known to have traversed the reach (i.e., detected both upstream and downstream), average residence time will be computed as the arithmetic average

$$
\bar{t}=\frac{\sum_{i=1}^{n} t_{i}}{n}
$$

where

$t_{i}=$ time between upstream and downstream detections,

$n=$ number of fish detected, 
with associated standard errors

$$
\mathrm{SE}(\bar{t})=\sqrt{\frac{\sum_{i=1}^{n}\left(t_{i}-\bar{t}\right)^{2}}{n(n-1)}} .
$$

Mean travel times will be computed for different fish stocks (i.e., yearling, subyearling Chinook salmon) and over different periods of the outmigration. If the rechannelization of the old channel is performed during this monitoring program, mean residence time will be compared between pre- and postmitigation periods.

There will also be four single acoustic receivers located between the arrays to monitor fish activity. One of the receiver nodes is located at the old mouth of the Sandy River. This receiver node will be used to estimate an index of fish usage of the old channel environment. The index of usage will be calculated as the fraction

$$
I=\frac{x}{m}
$$

where

$m=$ number of unique tagged fish detected at one or both of the acoustic arrays,

$x=$ number of the $m$ fish that are detected at the channel node.

Because the expected value of $x$ is a function of both the probability of old Sandy River mouth usage and detection, the value $I$ is only an index of proportional use. It will be important for the detection probability and location of the channel node to be constant over the course of the study in order to properly interpret trends in the value of $I$. The standard error for $I$ is based on the binomial sampling where

$$
\mathrm{SE}(I)=\sqrt{\frac{I(1-I)}{m}}
$$

Again, in the case where rechannelization occurs during the course of the study, $I$ can be compared between pre- and post-mitigation periods.

The three hydrophones along the Oregon shoreline (Fig. 3.1) will also be used jointly to calculate an activity index within the vicinity of the Sandy River Delta. The linear contrast

$$
c_{i}=1 t_{3 i}-2 t_{2 i}+1 t_{1 i}
$$

where

$t_{1 i}=$ arrival time of the $i$ th fish to the first node $(i=1, \ldots, n)$;

$t_{2 i}=$ arrival time of the $i$ th fish to the middle node $(i=1, \ldots, n)$;

$t_{3 i}=$ arrival time of the $i$ th fish to the third (i.e., most downstream) node $(i=1, \ldots, n)$; 
will be approximately zero if the ith fish directly swims downstream through the array of three nodes. If, on the other hand, fish quickly travel past the two upstream nodes and then linger at or below the middle node before exiting the array, the contrast will increase in positive value.

\section{C.3.5 Monitoring Program Design}

This section shows how the fish data collected for the Tidal Freshwater Monitoring Study can be used to calculate sample sizes for a full-scale status and trends monitoring program for juvenile salmonids in shallow, tidal freshwater of the lower Columbia River.

\section{C.3.5.1 Variance Component Estimation}

Considering the replicate beach seines within a site as repeated measures of the same local response (i.e., measurement or sampling error), the data within a survey period can be used to estimate spatial variability $\left(\sigma_{s}^{2}\right)$ and average measurement error $\left[\right.$ i.e., $\left.\overline{\operatorname{Var}\left(\hat{x}_{i} \mid x_{i}\right)}\right]$ by habitat type. For example, consider $k$ replicate sites within a habitat and $n$ replicate samples per site, then a one-way ANOVA can be used to estimate the variance components as follows:

\begin{tabular}{ccccc}
\hline Source & DF & SS & MS & E(MS) \\
\hline Total $_{\text {Cor }}$ & $n k-1$ & SSTOT $_{\text {Cor }}$ & & \\
Between sites & $k-1$ & SST & MST & $\overline{\operatorname{Var}\left(\hat{x}_{i} \mid x_{i}\right)}+n \sigma_{S}^{2}$ \\
Within sites & $n k-k$ & SSE & MSE & $\overline{\operatorname{Var}\left(\hat{x}_{i} \mid x_{i}\right)}$ \\
\hline
\end{tabular}

From the one-way ANOVA table above, average measurement error is estimated by MSE and spatial variance $\left(\sigma_{S}^{2}\right)$ by the expression

$$
\hat{\sigma}_{S}^{2}=\frac{\mathrm{MST}-\mathrm{MSE}}{n}
$$

where $k=$ number of sites and $n=$ number of replicate samples per locations (e.g., 2).

In many biological systems, particularly for fish density data, the variance increases as the mean abundance increases. In such cases, the variance tends to follow the negative binomial rule where

$$
\sigma_{S}^{2}=\mu+\frac{\mu^{2}}{c}
$$


where $\mu=$ mean density and $c$, negative binomial coefficient. In other cases where the data are lognormally distributed,

$$
\sigma_{S}^{2}=c \mu^{2}
$$

in other words, the coefficient of variation $(\sigma / \mu)$ is constant. Repeated sampling across the seasons and habitats will be used to determine the best characterization for $\sigma_{S}^{2}$ for subsequent sample size calculations. Similar mean-variance relationships often hold for measurement error as well. Based on the most appropriate variance-to-mean relationship, data will be pooled across sampling events to obtain more precise estimates of the variance components for subsequent sample size calculations.

\section{C.3.5.2 Estimates of Correlation}

The degree of temporal correlation between sites over time will be important in any monitoring program that uses a paired design. This correlation within a habitat category can be estimated using the intra-class correlation coefficient estimated (Zar 1999:404-407) from, again, a one-way ANOVA. Consider the case of $k$ sites sampled over 4 years, the one-way ANOVA can then be constructed as follows:

\begin{tabular}{ccccc}
\hline Source & DF & SS & MS & E(MS) \\
\hline Total $_{\text {Cor }}$ & $4 k-1$ & & & \\
Years & 3 & SST & MST & $\sigma^{2}+\sigma_{T}^{2}$ \\
Error & $4 k-4$ & SSE & MSE & $\sigma^{2}$ \\
\hline
\end{tabular}

Then the intra-class correlation $\left(\rho_{I}\right)$ is estimated by the variance components where

$$
\hat{\rho}_{I}=\frac{\hat{\sigma}_{T}^{2}}{\hat{\sigma}^{2}+\hat{\sigma}_{T}^{2}}
$$

Following the analysis of previous Section 3.2, the estimate $\hat{\sigma}^{2}$ in Eq. (4) can be partitioned into natural variation $\left(\sigma_{S}^{2}\right)$ and average measurement error $\left(\overline{\operatorname{Var}\left(\hat{x}_{i} \mid x_{i}\right)}\right)$, leading to a more accurate estimate of the actual temporal correlation 


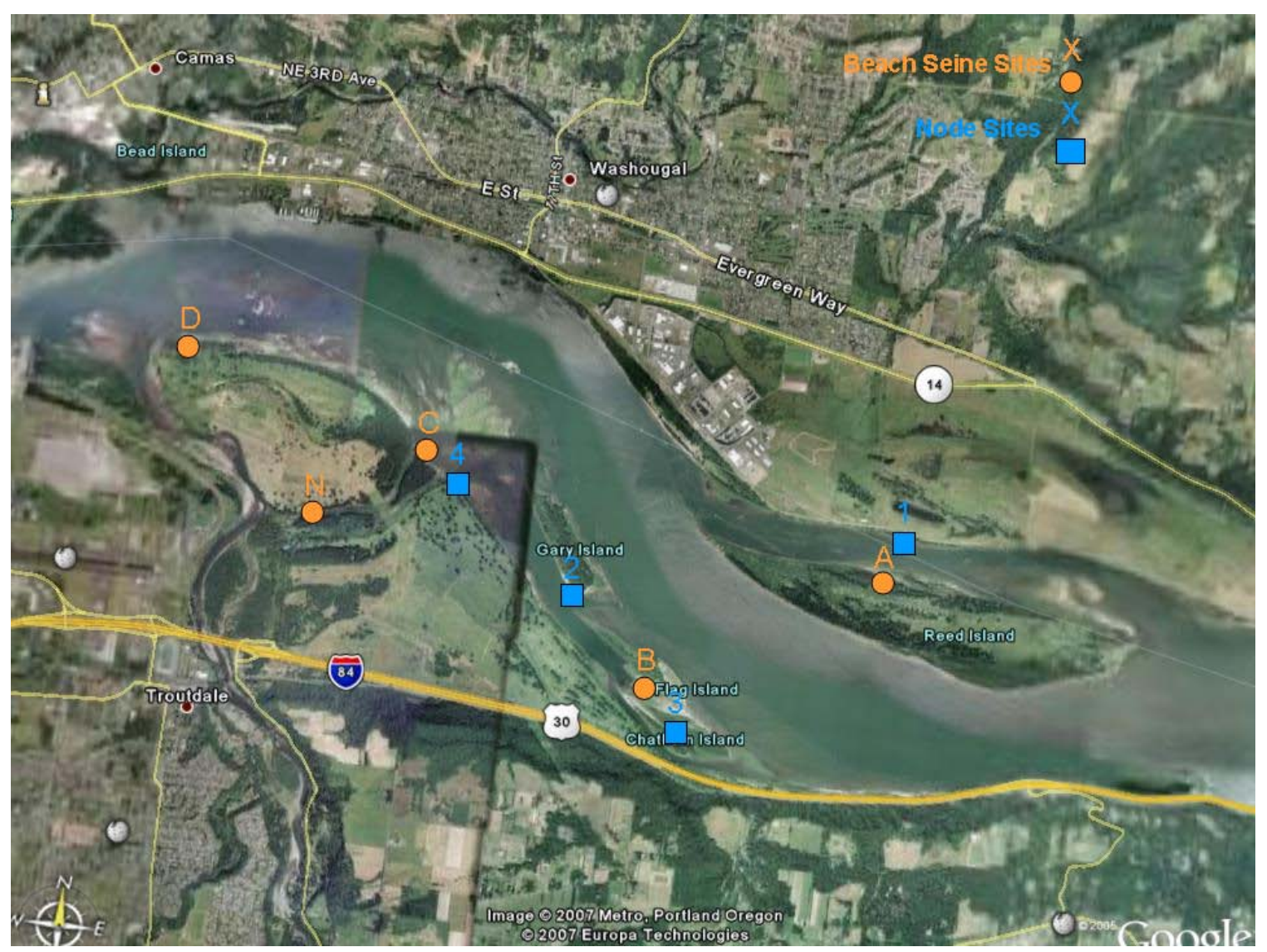

Figure C.3. Photograph of Sandy River Delta and Associated Acoustic-tag Detection Nodes and Arrays

$$
\hat{\rho}_{2}=\frac{\hat{\sigma}_{T}^{2}}{\hat{\sigma}_{S}^{2}+\hat{\sigma}_{T}^{2}}
$$

Patterns in the correlations between different habitats and response variables will be examined. In paired-plot designs, those responses with the highest correlation will tend to have the smallest overall error variance and have a better opportunity to detect change over time. Hence, contrast (8) will provide an additional index of usage of the old channel mouth. Rechannelized activities might be expected to increase fish usage of the old channel, thereby increasing the activity index. For fish detected at the three nodes, the average activity index will be calculated as follows:

$$
\bar{c}=\frac{\sum_{i=1}^{m}\left(t_{3 i}-2 t_{2 i}+t_{1 i}\right)}{m}=\frac{\sum_{i=1}^{m} c_{i}}{m}
$$


with associated standard error:

$$
\mathrm{SE}(\bar{c})=\sqrt{\frac{\sum_{i=1}^{m}\left(c_{i}-\bar{c}\right)^{2}}{m(m-1)}}
$$

where $m=$ number of fish detected at all three nodes.

\section{C.4 Literature Cited}

Box, G.E.P., Hunter, W.G., and Hunter, J.S. 1978. Statistics for experimenters. Wiley \& Sons, New York, New York, USA.

Skalski, J.R., and McKenzie, D.H. 1982. A design for aquatic monitoring programs. Journal of Environmental Management 14: 237-251.

Skalski, J.R., Millspaugh, J.J., Cooper, C., and Coats, D.A. Unpublished. A statistical test and sample size calculations for differences in ecological community composition based on analysis of distance (ANODIS). University of Washington, Seattle, WA.

Zar, J.H. 1999. Biostatistical analysis. Prentice-Hall, Inc., Upper Saddle River, New Jersey, USA. 

Appendix D

Photo Points 



\section{Appendix D}

\section{Photo Points}

To document seasonal changes, we established a photo point station at each of the sampling sites. During each sampling event, one or more photos were taken from the station. Attempts were made to achieve a visual perspective that was similar between sampling trips; however, variability often introduced a level of error into the photos such that the spatial depiction captured in the photographs was not identical. This variability also resulted in the inability to stitch some photos together for particular sites and months. Photos for various sites and months are shown in relation to one another on the following pages. 


\section{D.1 Site A - 2008}
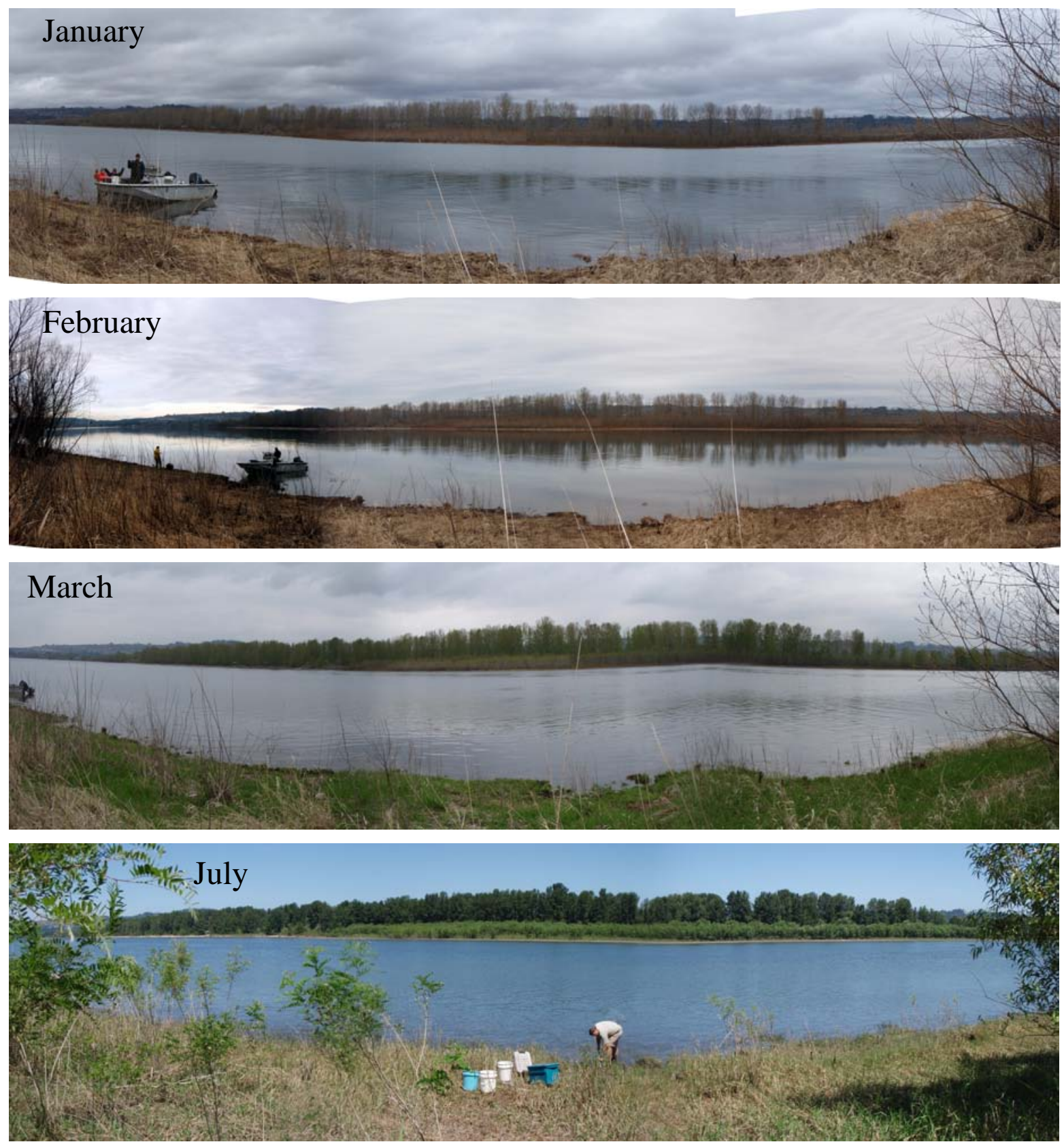

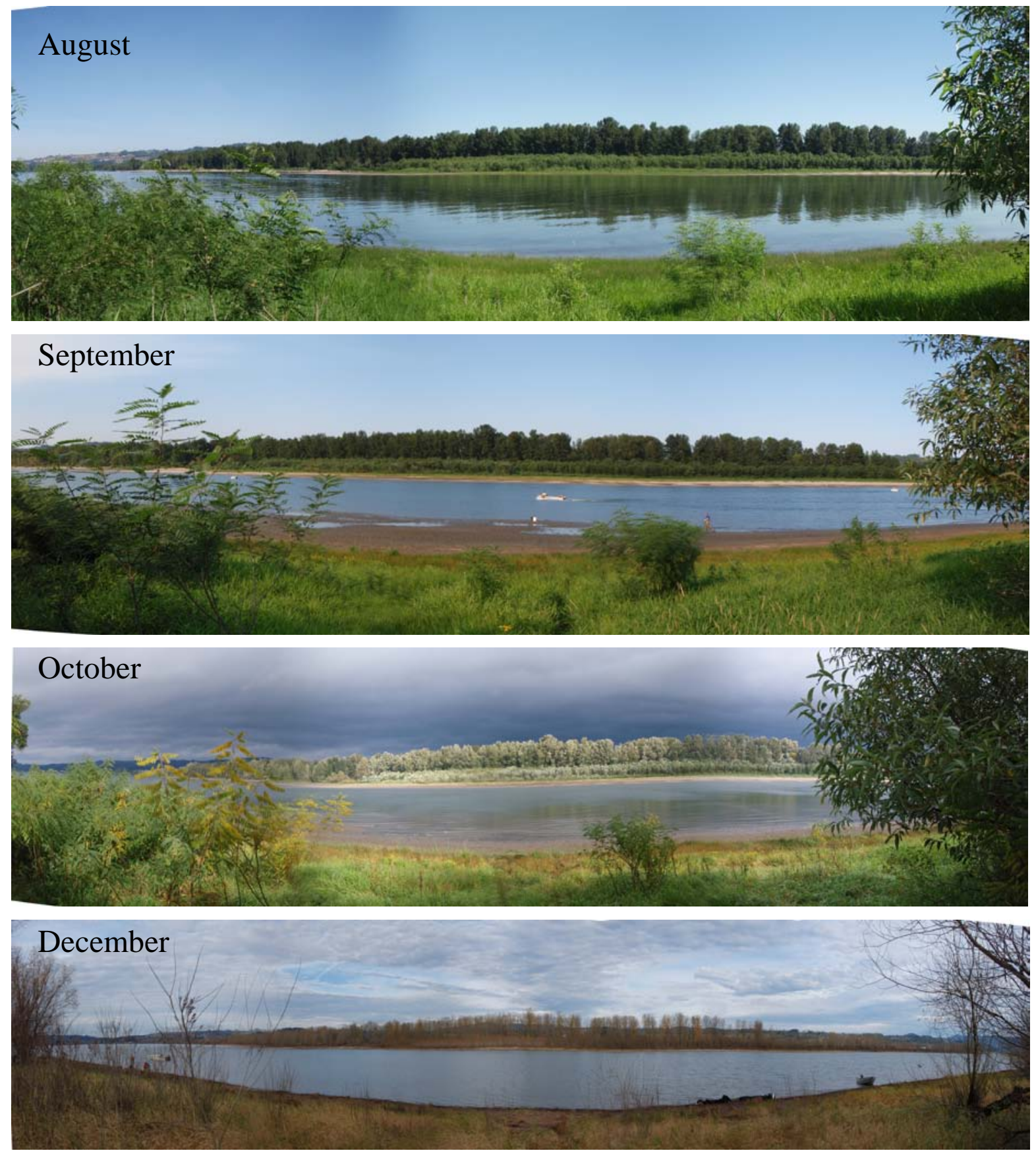


\section{D.2 Site B - 2008}
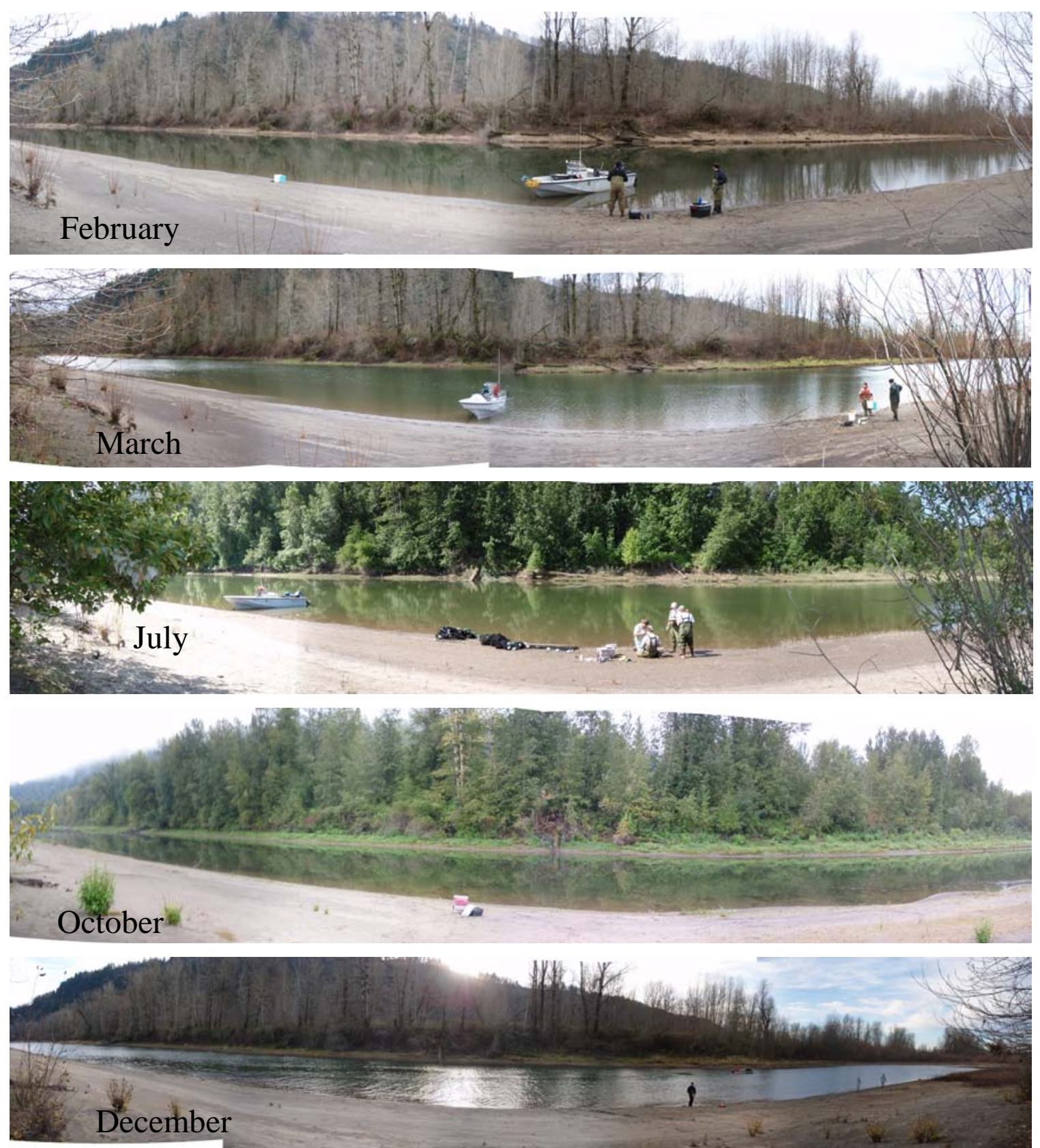


\section{D.3 Site C - 2008}

January

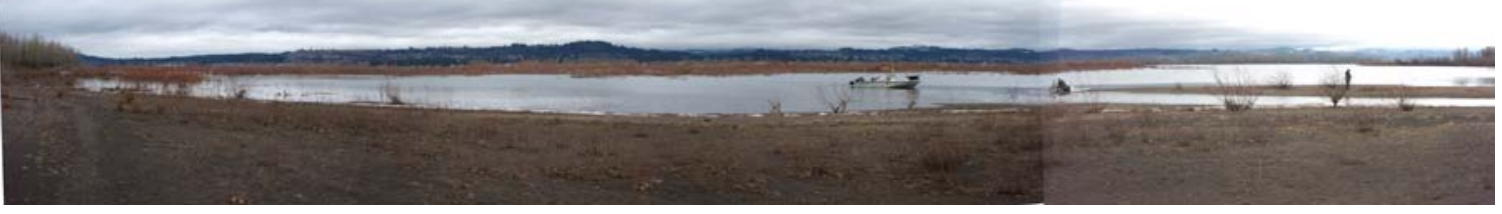

February
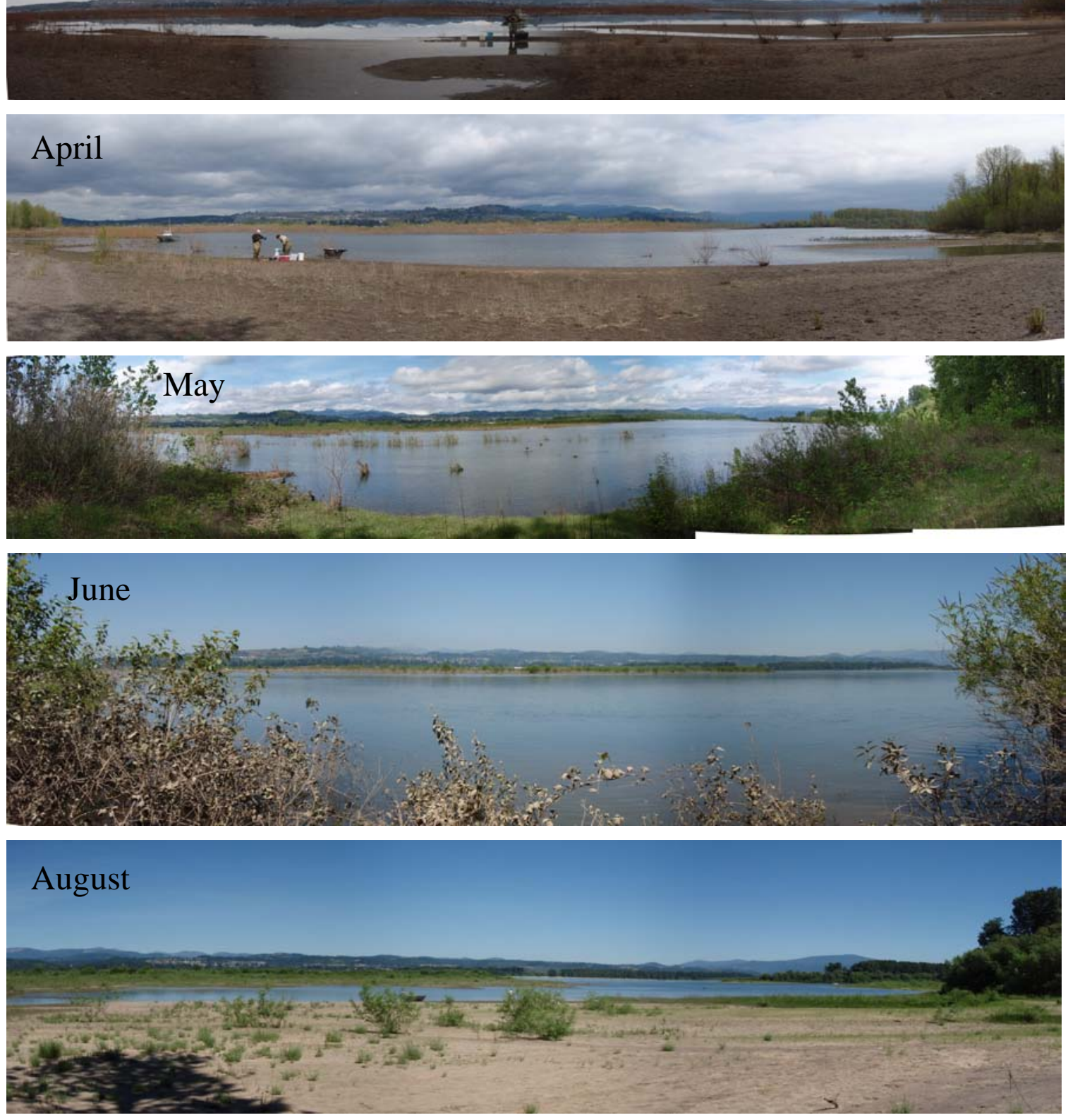

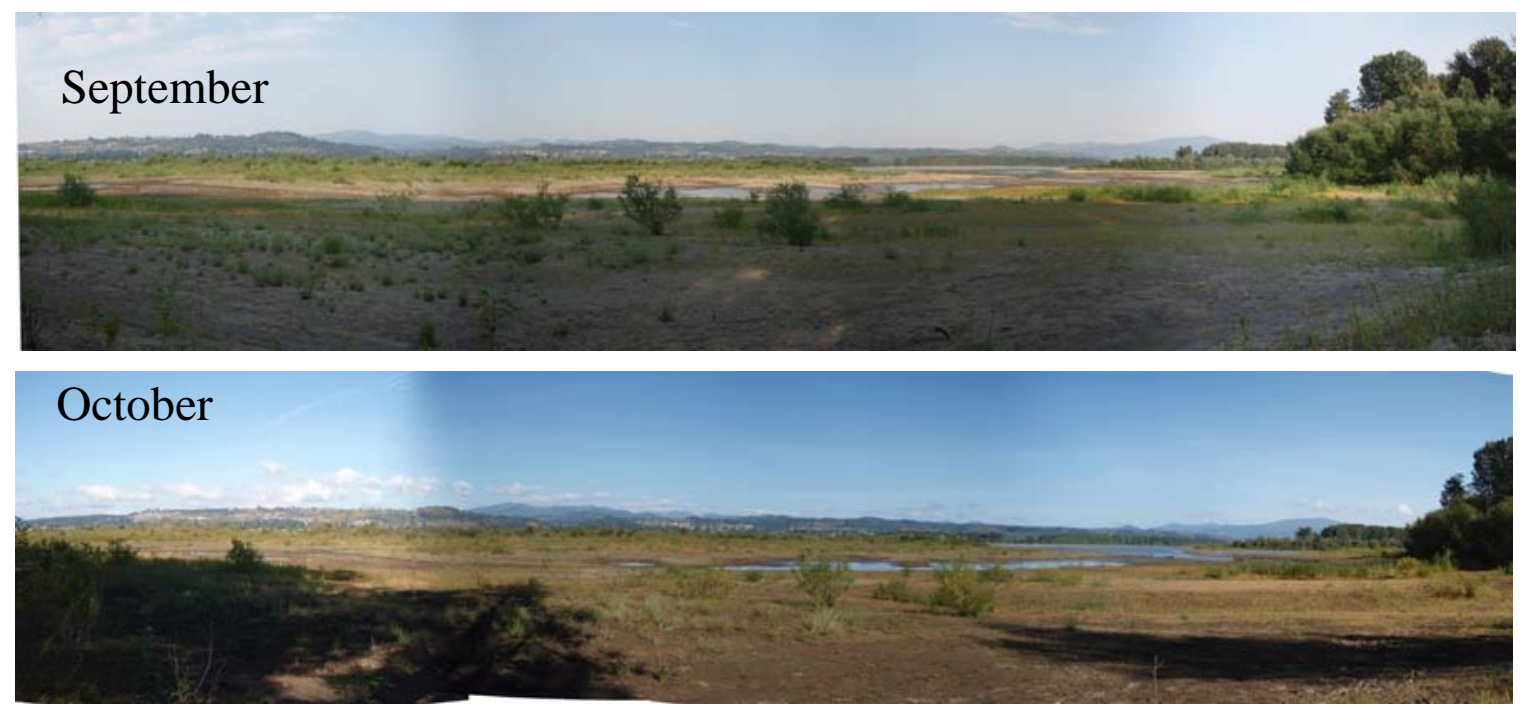

November

December 

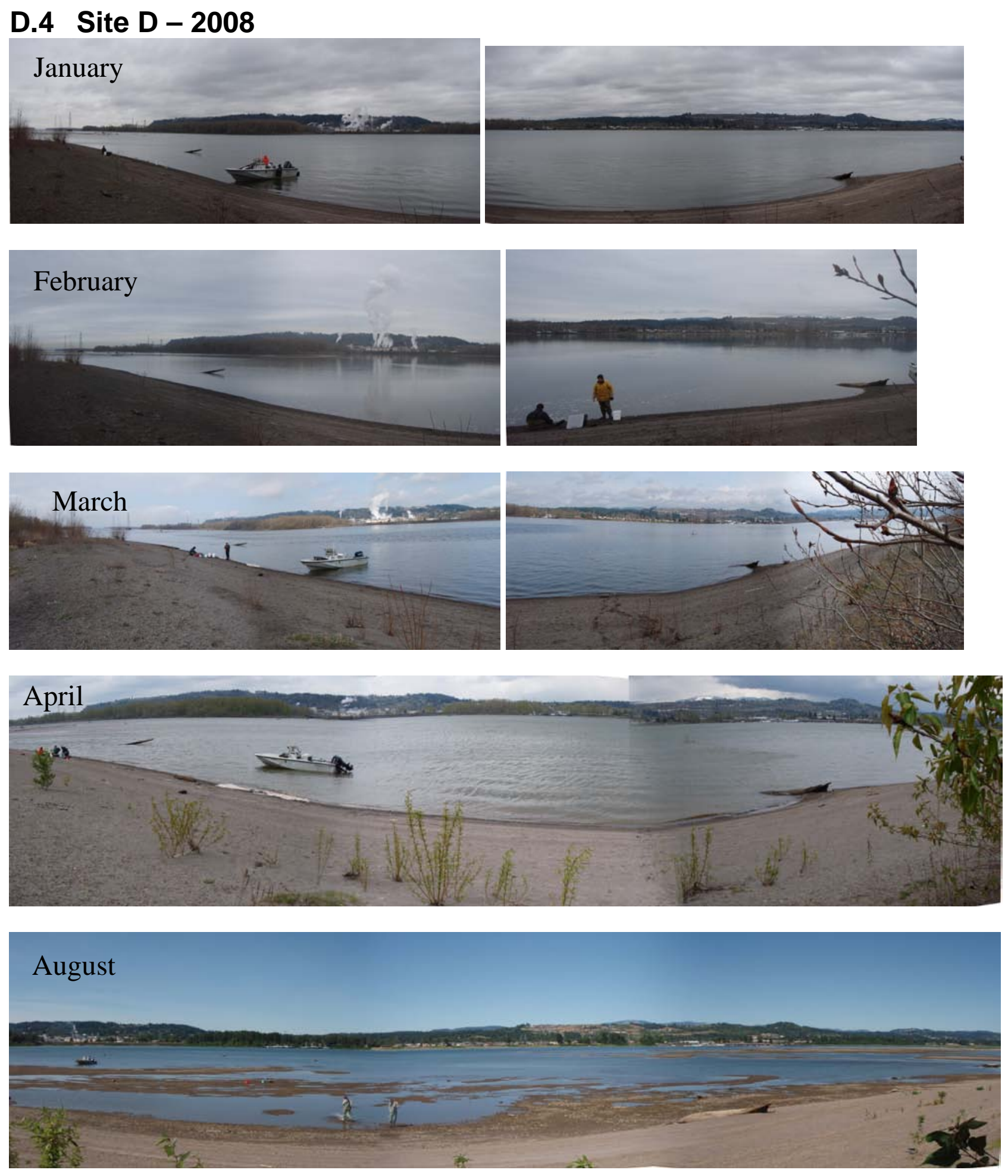

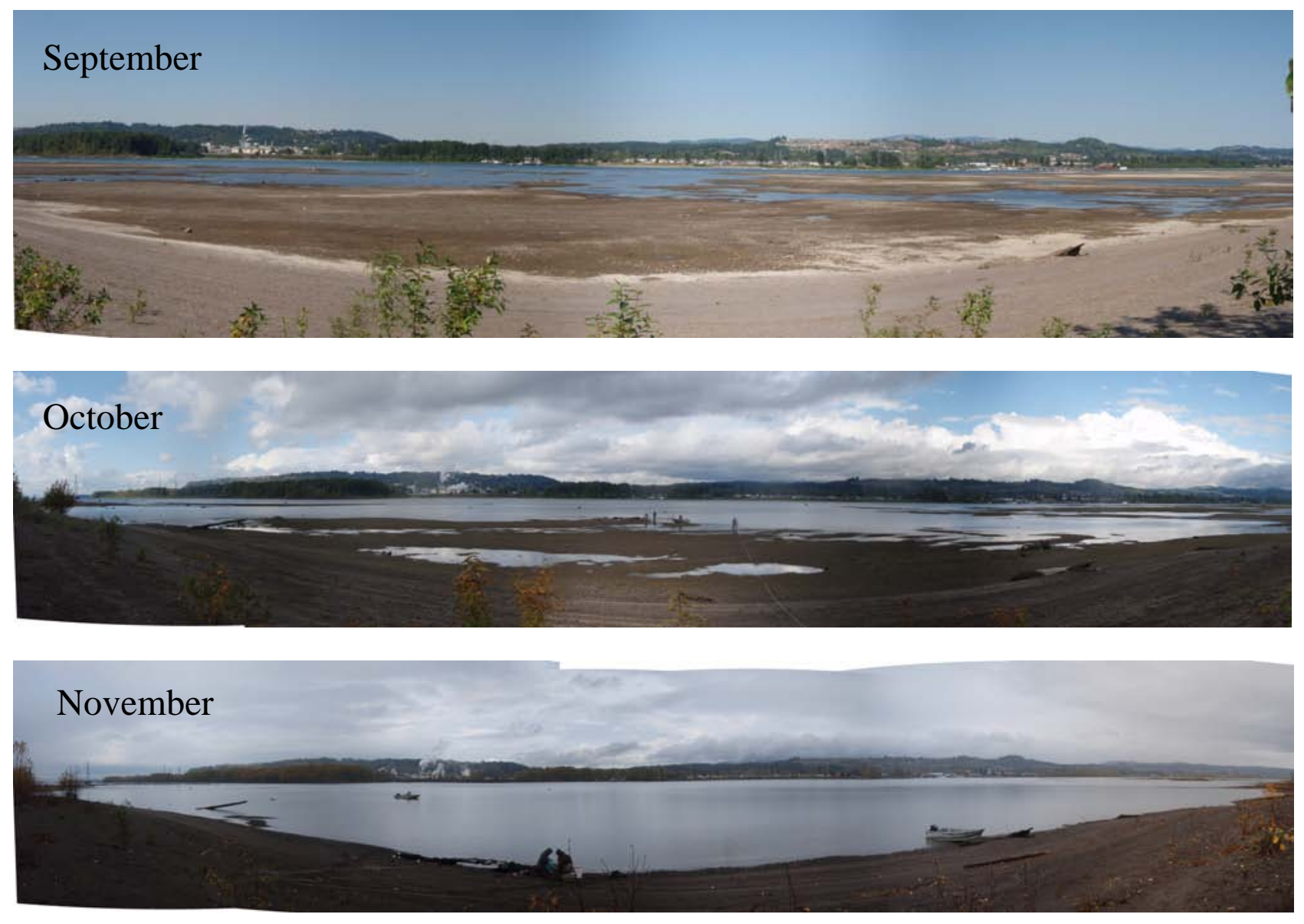

\section{December}

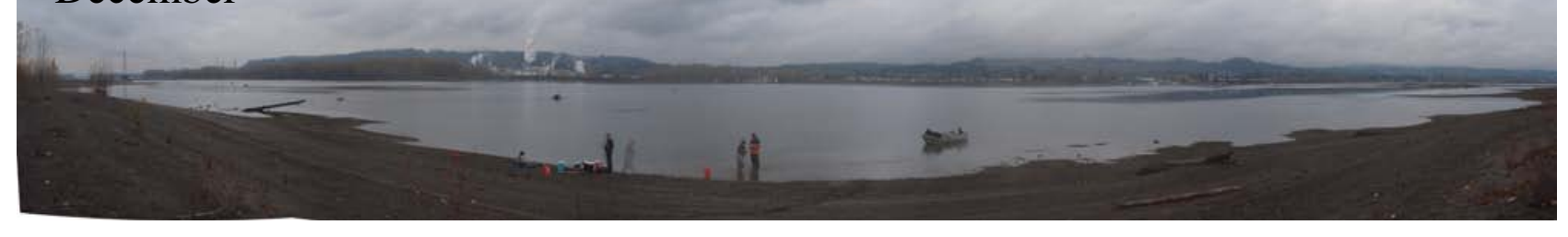




\section{D.5 Site E - 2008}
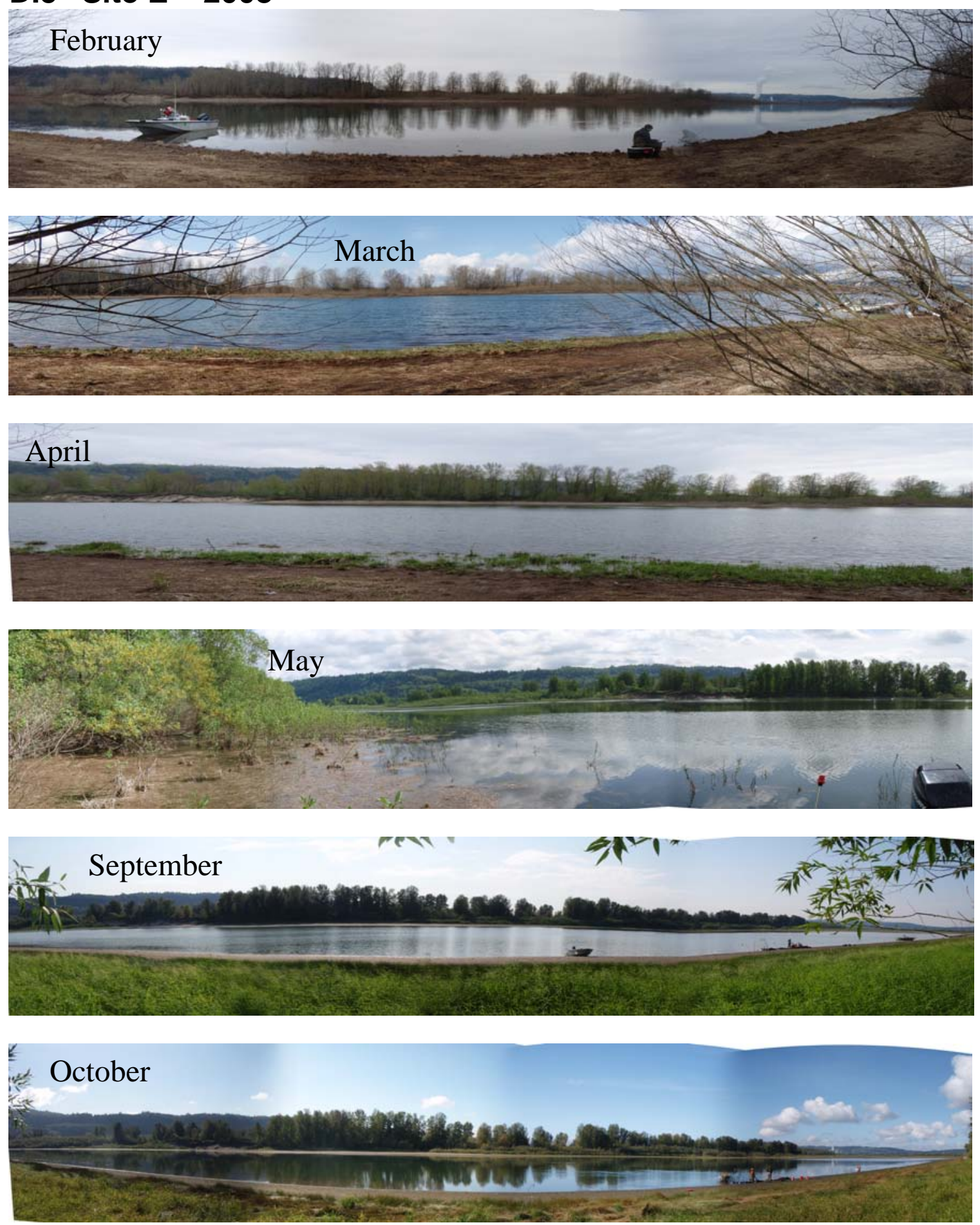

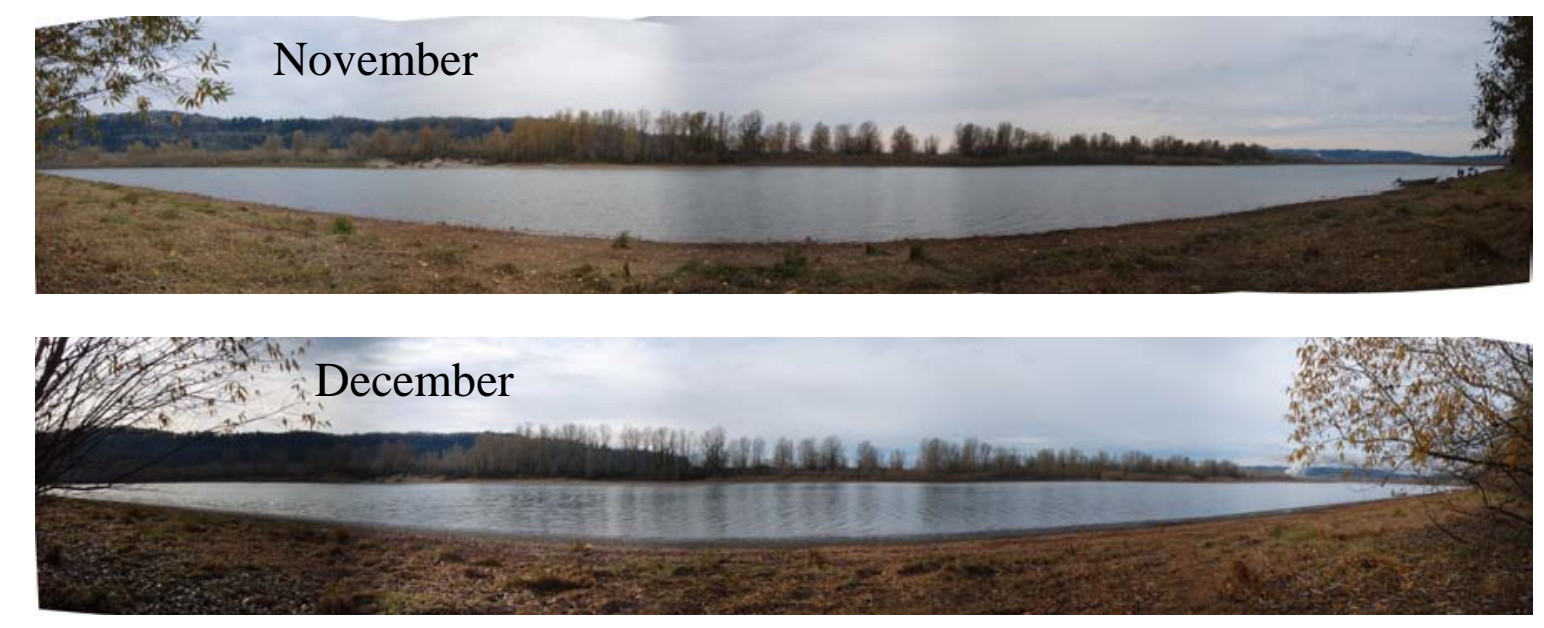

D.10 


\section{Appendix E}

Estimated of Spawner Abundances in the Upper Columbia River 



\section{Appendix E}

\section{Estimates of Spawner Abundances in the Upper Columbia River}

The following data describe spawner abundance of the Upper Columbia River Summer and Fall Run ESU from the Wenatchee, Methow, Okanagon, Similkameen, and Yakima Rivers as well as mainstem spawners in the Hanford Reach of the Columbia.

Table E.1. Spawning escapment estimates for summer and fall Chinook salmon in the mid and upper Columbia River in 2007. Estimates for summer Chinook salmon are from Miller et al. 2008 and fall Chinook salmon are from Hoffarth 2008.

\begin{tabular}{cccc}
\hline Region & Stock Group & River & Spawners \\
\hline \multirow{3}{*}{ Upper Columbia } & & Okanogan & 2,862 \\
& Upper Columbia & Similkameen & 1,555 \\
& River Summer & Methow & 1,364 \\
& & Wenatchee & 4,590 \\
\multirow{2}{*}{ Mid Columbia } & \multirow{2}{*}{ Upriver Bright Fall } & Hanford Reach & 47,095 \\
& & Yakima & 1,268 \\
\hline
\end{tabular}

\section{E.1 References:}

Hoffarth, P. 2008. District 4 Fish Management Annual Report 2008. Available from Washington Department of Fish and Wildlife, 600 Capital Way N., Olympia, WA 98501. 



\section{Appendix F}

Ives Island Fall Chinook Salmon 



\section{Appendix F}

\section{Ives Island Fall Chinook salmon}

The population of Chinook salmon at Ives Island, approximately $35 \mathrm{rkm}$ upstream of our study location, is a potential source of juveniles occupying our study sties. A previous study concluded that Ives Island Chinook salmon were genetically similar to summer and fall run populations in the upper Columbia River (Marshall 1998). We used estimates of spawner abundances to estimate the number of fry produced at Ives Island from 2001 through 2007 (Table F.1)

Table F.1. Estimates of the Numbers of Fall Chinook Salmon Spawners, Females, Eggs, Fry and Juveniles From Ives Island Reach

\begin{tabular}{|c|c|c|c|c|c|c|c|}
\hline $\begin{array}{c}\text { Outmigration } \\
\text { Year }\end{array}$ & $\begin{array}{c}\text { Spawning } \\
\text { Year }\end{array}$ & $\begin{array}{c}\text { URB } \\
\text { Spawners }^{(a)}\end{array}$ & $\begin{array}{c}\text { URB } \\
\text { Females }^{(a)}\end{array}$ & $\begin{array}{l}\text { Estimated } \\
\text { No. of } \\
\text { Eggs }^{(b)}\end{array}$ & $\begin{array}{l}\text { Estimated No. of } \\
\text { fry migrants (c) }\end{array}$ & $\begin{array}{c}\text { Juveniles } \\
\text { sampled }\end{array}$ & $\begin{array}{l}\text { Proportion of } \\
\text { juveniles } \\
\text { sampled to no. } \\
\text { of female } \\
\text { spawners }\end{array}$ \\
\hline 2007 & 2006 & 1,200 & 600 & $1,800,000$ & 900,000 & 4,946 & 8.2 \\
\hline 2006 & 2005 & 1,275 & 635 & $1,905,000$ & 952,500 & 3,115 & 4.9 \\
\hline 2005 & 2004 & 1,733 & 865 & $2,595,000$ & $1,297,500$ & 28,800 & 33.3 \\
\hline 2004 & 2003 & 1,600 & 800 & $2,400,000$ & $1,200,000$ & 18,000 & 22.5 \\
\hline 2003 & 2002 & 1,900 & 950 & $2,850,000$ & $1,425,000$ & 7,000 & 7.4 \\
\hline 2002 & 2001 & 750 & 375 & $1,125,000$ & 562,500 & 1,300 & 3.5 \\
\hline 2001 & 2000 & 725 & 365 & $1,095,000$ & 547,500 & -- (d) & -- (d) \\
\hline 2000 & 1999 & 898 & 449 & $1,347,000$ & 673,500 & 9,000 & 20.0 \\
\hline 1999 & 1998 & 554 & 277 & 831,000 & 415,500 & 5,886 & 21.2 \\
\hline \multicolumn{8}{|c|}{$\begin{array}{l}\text { (a) Number of Upriver Bright spawners and females were obtained from several published sources which can be } \\
\text { found in the reference section following this table. } \\
\text { (b) Estimates were derived by assuming 3,000 eggs per female. } \\
\text { (c) Estimates were derived by assuming and egg to fry survival rate equal to } 50 \% \text {. } \\
\text { (d) No data. }\end{array}$} \\
\hline
\end{tabular}




\section{F.1 References}

Tomaro, LM, W Van der Naald, RR Brooks, TA Jones and T A Friesen. 2007. Evaluation of fall Chinook and chum salmon spawning below Bonneville Dam. 2005-2006 Annual Report, BPA Report DOE/BP000029512-1, Bonneville Power Administration, Portland, Oregon.

Van der Naald, W, C Duff, TA Friesen, RR Brooks, and L M Tomaro. 2006._Evaluation of fall Chinook and chum salmon spawning below Bonneville, The Dalles, John Day, and McNary Dams. 2004-2005

Annual Report, BPA Report DOE/BP-00004028-5, Bonneville Power Administration, Portland, Oregon.

Van der Naald, W., C Duff, and RR Brooks. 2005. Evaluation of fall Chinook and chum salmon spawning below Bonneville, The Dalles, John Day, and McNary Dams. 2003-2004 Annual Report, BPA Report DOE/BP-00004028-4, Bonneville Power Administration, Portland, Oregon.

Van der Naald, W, R Clark, RR Brooks, and C Duff. 2004. Evaluation of fall Chinook and chum salmon spawning below Bonneville, The Dalles, John Day, and McNary Dams. 2002-2003 Annual Report, BPA Report DOE/BP-00004028-3, Bonneville Power Administration, Portland, Oregon.

Van der Naald, W, R Clark, and B Spellman. 2003. Evaluation of fall Chinook and chum salmon spawning below Bonneville, The Dalles, John Day, and McNary Dams. 2001-2002 Annual Report, BPA Report DOE/BP-00004028-2, Bonneville Power Administration, Portland, Oregon.

Van der Naald, W, R Clark, and B Spellman. 2002. Evaluation of fall Chinook and chum salmon spawning below Bonneville, The Dalles, John Day, and McNary Dams. 2000-2001 Annual Report, BPA Report DOE/BP-00004028-1, Bonneville Power Administration, Portland, Oregon.

Van der Naald, W, B Spellman, and R Clark, Evaluation of Fall Chinook and Chum Salmon Spawning below Bonneville, The Dalles, John Day and McNary Dams, 1999-2000 Annual Report, Project No. 199900301 (et al.), 45 electronic pages, (BPA Report DOE/BP-15007-2) 
PNNL 18450

\section{Distribution}

No. of

Copies

2 Tracey Yerxa

Bonneville Power Administration

PO Box 3621

Portland, Oregon 97208 Code

1 Blaine Ebberts

US Army Corps of Engineers

PO Box 2946

Portland, Oregon 97208 Code

1 Dan Bottom

National Marine Fisheries Service 2031 SE Marine Science Dr.

Newport, Oregon 97365 Code

2 David Teel

National Marine Fisheries Service 7305 E. Beach Dr.

Port Orchard, WA 98366

1 John Skalski

University of Washington

1325 Fourth Ave. Suite 1820

Seattle, Washington 98101 Code

1 Earl Dawley

651 Grand Ave

Astoria, Oregon 97103 Code
No. of

Copies

5 Oregon Department of Fish \& Wildlife Clackamas, Oregon ZIP Code Christine Mallette

5 Local Distribution

Pacific Northwest National Laboratory Gary Johnson Nikki Sather

Portland

Amy Borde

Sequim

Heida Diefenderfer

Shon Zimmerman

(PDF)

(PDF) 


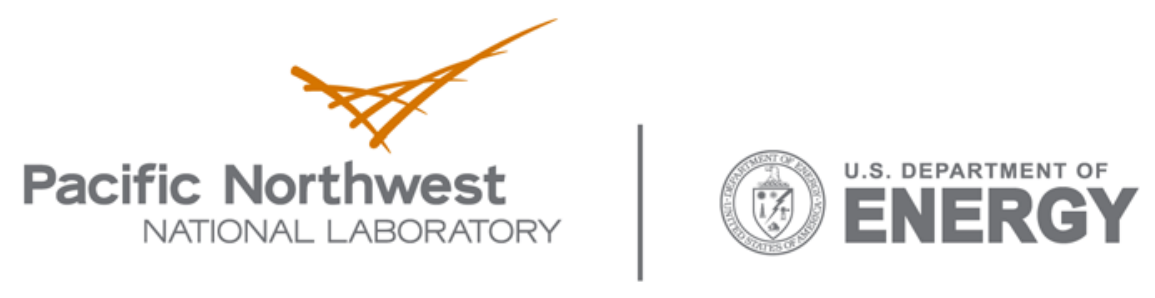

902 Battelle Boulevard

P.O. Box 999

Richland, WA 99352

1-888-375-PNNL (7665)

www.pnl.gov 